\title{
Charakterisierung eines neuen ATP-binding-cassette Transporters aus der ABCA-Subfamilie
}

\author{
Dissertation \\ zur Erlangung des Doktorgrades \\ der Mathematisch-Naturwissenschaftlichen Fakultäten \\ der Georg-August-Universität zu Göttingen
}

vorgelegt von

Frauke Petry

aus Dresden

Göttingen 2004 
D7

Referent:

Professor Dr. A. Zeeck

Korreferent:

Professor Dr. H. Laatsch

Tag der mündlichen Prüfung: $\quad 30.06 .2004$ 
Die vorliegende Arbeit wurde in der Zeit von Oktober 2000 bis Mai 2004 in der Abteilung Toxikologie des Zentrums Pharmakologie und Toxikologie der Georg-August-Universität Göttingen angefertigt.

Teile dieser Arbeit wurden veröffentlicht:

F. Petry, A. Kotthaus, K.I. Hirsch-ERnst, Cloning of human and rat ABCA5/Abca5 and detection of a human splice variant, Biochem. Biophys. Res. Commun. 300 (2003) 343-350.

Mein besonderer Dank gilt Frau Priv.-Doz. Dr. K.I. Hirsch-Ernst und Herrn Prof. Dr. G.F. Kahl für die interessante Themenstellung, ihr stetes Interesse am Fortgang dieser Arbeit und für ihre großzügige Förderung. Herrn Prof. Dr. A. Zeeck danke ich herzlich für sein Interesse an diesem Projekt und die Vertretung gegenüber der Fakultät für Chemie. Ebenso bedanke ich mich bei Herrn Prof. Dr. H. Laatsch für die freundliche Übernahme des Koreferates. Der Studienstiftung des Deutschen Volkes danke ich für die Gewährung eines Promotionsstipendiums. 
Der Fortgang der wissenschaftlichen Entwicklung ist eine ständige Flucht vor dem Staunen.

nach Albert Einstein (1879-1955) 


\section{Inhaltsverzeichnis}

ABKÜRZUNGEN

1

EINLEITUNG

$1.1 \quad$ Die Superfamilie der ABC-Proteine

Subfamilien E (OABP) und F (GCN20)

2.1.6.1 Kulturmedien für kompetente E.coli Bakterien 17

2.1.6.2 Medien für die Zellkultur 18

2.1.6.2.1 Eukaryotische Zellinien 18

2.1.6.2.2 Primäre Rattenhepatozyten 19

2.1.7 Tiere und Biologisches Material 20

$\begin{array}{lll}\text { 2.1.7.1 Versuchstiere } 20 & 20\end{array}$ 
2.1.7.2 Bakterien 20

2.1.7.3 Vektoren 20

2.1.7.4 Eukaryotische Zellinien 20

2.1.7.5 Antikörper 21

2.1.7.6 Oligonukleotide 21

2.1.7.7 Gensonden 24

2.1.7.8 RNA-Proben 24

2.1.7.9 Molekulargewichtstandards 25

$2.2 \quad$ Methoden 25

2.2.1 Vorbehandlung und Sterilisation 25

2.2.2 Präparation von Nukleinsäuren 25

2.2.2.1 Minipräparation von Plasmid-DNA 25

2.2.2.2 Herstellung von Glycerinkryokulturen 26

2.2.2.3 Endotoxin-freie Maxipräparation von Plasmid-DNA 26

2.2.2.4 Isolierung von Gesamt-RNA 26

2.2.2.5 Konzentrationsbestimmung von Nukleinsäuren 28

2.2.3 Enzymatische Modifikationen von Nukleinsäuren 28

2.2.3.1 Restriktionsspaltung von Plasmid-DNA 28

2.2.3.2 Herstellung von blunt-end DNA-Fragmenten 28

2.2.3.3 Dephosphorylierung von Vektor-DNA 29

2.2.3.4 Digoxygenin-Markierung von cRNA-Sonden 29

2.2.3.5 Dot-Blot-Analyse der cRNA-Sonden 30

2.2.3.6 Radioaktive Markierung von Oligonukleotiden 31

2.2.4 Isolierung von DNA-Fragmenten aus Agarosegelen 31

2.2.4.1 QIAquick Gel Extraction Kit 32

2.2.4.2 Low-Melting-Methode 32

2.2.4.2 DNA-Präzipitation 32

2.2.5 Klonierung von DNA-Fragmenten 32

2.2.5.1 TOPO-Ligation 3

2.2.5.2 Ligation mit T4-DNA-Ligase 33

2.2.5.3 Herstellung elektrokompetenter E.coli Zellen 33

2.2.5.4 Transformation durch Elektroporation 33

2.2.6 PCR-Techniken 34

2.2.6.1 Reverse Transcription-PCR (RT-PCR) 34

2.2.6.2 5'-RACE-PCR 36

2.2.6.3 Two-step RT-PCR 37

2.2.6.4 Real-Time quantitative PCR (RTQ-PCR) I 38

2.2.6.5 Kolonie-PCR 42

2.2.7 Sequenzanalyse 43

2.2.8 Agarose-Gelelektrophorese 43 
2.2.8.1 DNA-Gelelektrophorese 43

2.2.8.2 Denaturierende RNA-Gelelektrophorese 44

2.2.9 Transfer von Nukleinsäuren $\quad 45$

2.2.9.1 RNA-Transfer auf Nylon-Membranen $\quad 45$

2.2.10 Radioaktive Hybridisierung von RNA an Northern Blots 46

2.2.10.1 Hybridisierung mit ${ }^{32}$ Phosphor-markierten Sonden 46

2.2.11 Nicht-radioaktive Hybridisierung - In situ Hybridisierung 47

2.2.11.1 Herstellung von Paraffinschnitten 47

2.2.11.2 Vorbehandlung und Hybridisierung 48

2.2.11.3 Waschschritte und Antikörper-Inkubation 48

2.2.11.4 Waschschritte und Antikörper-Inkubation 50

2.2.11.5 Fotografische Auswertung 50

2.2.12 Zellkultur 50

2.2.12.1 Kultur eukaryotischer Zellinien 50

2.2.12.2 Kultur primärer Rattenhepatozyten 51

2.2.12.3 Abbruch der Kultivierung 52

2.2.13 Transfektion von Zellinien mit Expressionsplasmiden 53

2.2.14 Proteinbiochemische Methoden 53

2.2.14.1 Subfraktionierung von Zellen 53

2.2.14.2 Homogenisation von Zellen 53

2.2.14.3 Fraktionierung der Zellhomogenate 53

2.2.14.4 Isolierung von Gesamt-Proteinextrakten 55

2.2.14.5 Proteinbestimmung 56

2.2.14.6 Auftrennung von Proteinen durch SDS-Polyacrylamid-Gelelektrophorese 56

2.2.14.7 Herstellung von vertikalen SDS-Polyacrylamid-Minigelen 57

2.2.14.8 Probenvorbereitung 58

2.2.14.9 Elektrophorese 58

2.2.14.10 Nachweis von Proteinen im Western-Blot 59

$\begin{array}{lll}3 & \text { ERGEBNISSE } & 62\end{array}$

$\begin{array}{lll}3.1 & \text { Vorarbeiten } & 62\end{array}$

3.2 Charakterisierung eines neuen humanen $A B C A-G e n s \quad 62$

3.2.1 Isolierung des humanen ABCA5-Gens 62

3.2.2 Genomische Struktur von $A B C A 5 \quad 67$

3.2.3 Identifizierung einer ABCA5-Splicevariante ABCA5 V20+16 68

3.2.4 Isolierung des orthologen Abca5-Gens der Ratte 69

3.2.5 Genomische Struktur des Abca5-Gens der Ratte 73

3.2.6 Identifizierung einer rAbca5-Splicevariante rAbca5 V+16 74

3.2.7 Untersuchungen zur Membran-Topologie 75

3.2.7.1 Membransegmente in ABCA5 und ABCA5 V20+16 75 
3.2.7.2 Membransegmente in rAbca5 und rAbca5 V+16

Untersuchungen zur mRNA-Gewebeverteilung von $h A B C A 5$ und rAbca5

Expression des humanen ABCA5-Gens

3.5.3 Einfluß eines synthetischen LXR-Agonisten

$$
\text { auf die rAbca5-mRNA Expression }
$$

Das ABCA5-Gen ist Bestandteil eines ABCA-Genclusters 
Einfluß der Kulturbedingungen auf die rAbca5-mRNA-Expression in Kulturen primärer Hepatozyten der Ratte

Einfluß von LXR-Liganden auf die rAbca5-mRNA-Expression in Kulturen primärer Hepatozyten der Ratte

4.7.1 Induktion der rAbca5-mRNA-Expression mit 22-R-Hydroxycholesterol Induktion der rAbca5-mRNA mit 22-R-Hydroxycholesterol und 9-cis-Retinsäure 


\section{Abkürzungen}

Abb.

Abbildung

$A B C$

ATP-binding-cassette

BCIP

5-Brom-4-Chlor-3-Indolyl-Phosphat

bp

Basenpaare

$\mathrm{Bq}$

Becquerel

BSA

Rinderserumalbumin

bzw.

beziehungsweise

${ }^{\circ} \mathrm{C}$

Grad Celsius

ca.

circa

cDNA

komplementäre DNA

CIAP

Calf Intestine Alkaline Phosphatase

d-

Desoxy-

dd-

Didesoxy

DAB

3,3'-Diaminobenzidin

dATP

Desoxyadenosintriphosphat

dest.

Destiliert

DIG

Digoxygenin-

DEPC

Diethylpyrocarbonat

DMEM

Dulbeccos Modified Eagle Medium

DMF

Dimethylformamid

DMSO

Dimethylsulfoxid

DNA

Desoxyribonukleinsäure

DNAse

Desoxyribonuklease

dNTPs

Desoxynukleotidtriphosphate

DTT

Dithiothreitol

ECL

enhanced chemiluminescence

E.coli

Escherichia coli

EDTA

Ethylendiamintetraessigsäure

et al.

et alteri

$\mathrm{EtOH}$

Ethanol

FAM

6-Carboxyfluorescin

FKS

Fetales Kälberserum

$\mathrm{xg}$

Erdbeschleunigung $\left(9.81 \mathrm{~m} / \mathrm{s}^{2}\right)$

GAPDH

Glycerinaldehyd-3-phosphat-Dehydrogenase

GTC

Guanidiniumthiocyanat

HRP

Horseradish peroxidase (Meerrettich Peroxidase)

I.E.

Internationale Einheit

IPTG

Isopropyl- $\beta$-thiogalaktopyranosid 
$\mathrm{kb}$

LB

LSB

M

MD

MGB

MOPS

mRNA

MS

NBR

NBT

nt

OD

$\mathrm{p}$

PBS

PBS

PCR

$\mathrm{pH}$

PVDF

RACE

RE

RNA

RNase

rpm

RPMI

RT

SDS

SSC

Taq

TBE

TE

TEMED

TES

Tris

Tween 20

U

u.a.

ü.N.

UTR

$\mathrm{v} / \mathrm{v}$
Kilobasenpaare

Luria-Bertani Medium

Lämmli Sample Buffer

Molarität

Membrandomäne

minor groove binder

3-[N-Morpholino]-Propansulfonsäure

messenger Ribonukleinsäure

Membransegment

Nukleotidbindungsregion

Nitrotetrazoliumblau

Nukleotide

optische Dichte

Signifikanzniveau

Phosphatgepufferte Salzlösung

Phosphatpuffer mit Tween

polymerase chain reaction

$\mathrm{pH}$-Wert

Polyvinyliden-Difluorid

rapid amplification of cDNA ends

Restriktionsendonukleasen

Ribonukleinsäure

Ribonuklease

rounds per minute

Roswell Park Memorial Institute Medium 1640

Raumtemperatur

Natriumdodecylsulfat

standard saline citrate buffer (Standard Natrium Citrat Puffer)

Thermophilus aquaticus

Tris-Borat-EDTA-Puffer

Tris-EDTA-Puffer

$\mathrm{N}, \mathrm{N}, \mathrm{N}$ ',N'-Tetramethylethylendiamin

Tris-EDTA-Saccharose-Puffer

Tris-hydroxymethyl-aminomethan

Polyoxyethylensorbitan-Monolaureat

unit (Einheit der Enzymaktivität)

unter anderem

über Nacht

untranslatierte Region

Volumen pro Volumen 
$w / v$

X-Gal

z.B.
Gewicht pro Volumen

5-Brom-4-Chlor-3-Indolyl- $\beta$-Galaktosid

zum Beispiel

\section{Code der Nukleinsäuren}

$\begin{array}{cl}\text { A } & \text { Adenin } \\ C & \text { Cytosin } \\ G & \text { Guanin } \\ T & \text { Thymin } \\ U & \text { Uracil }\end{array}$

\section{Code der Aminosäuren}

$\begin{array}{lllll}\text { A (Ala) } & \text { Alanin } & \text { M } & \text { (Met) } & \text { Methionin } \\ \text { C (Cys) } & \text { Cystein } & \text { N } & \text { (Asp) } & \text { Asparagin } \\ \text { D (Asp) } & \text { Asparaginsäure } & \text { P } & \text { (Pro) } & \text { Prolin } \\ \text { E (Glu) } & \text { Glutaminsäure } & \text { Q } & \text { (Glu) } & \text { Glutamin } \\ \text { F (Phe) } & \text { Phenylalanin } & \text { R } & \text { (Arg) } & \text { Arginin } \\ \text { G (Gly) } & \text { Glycin } & \text { S } & \text { (Ser) } & \text { Serin } \\ \text { H (His) } & \text { Histidin } & \text { T } & \text { (Thr) } & \text { Threonin } \\ \text { I (lle) } & \text { Isoleucin } & \text { V } & \text { (Val) } & \text { Valin } \\ \text { K (Lys) } & \text { Lysin } & \text { W } & \text { (Trp) } & \text { Tryptophan } \\ \text { L (Leu) } & \text { Leucin } & \text { Y } & \text { (Tyr) } & \text { Tyrosin }\end{array}$




\section{$1 \quad$ Einleitung}

Der Transport von Molekülen durch Membranen stellt eine essentielle Funktion aller lebenden Organismen dar. Im Lauf der Evolution entstand eine Vielzahl von spezifischen Transportproteinen, die sich nach ihrer Abhängigkeit von einem Energielieferanten in aktive und passive Transporter klassifizieren lassen. Letztere ermöglichen eine erleichterte Diffusion von Substraten (z.B. Ionen) durch membranständige Poren (Kanäle) als Reaktion auf einen chemischen, elektrophysiologischen oder mechanischen Stimulus entlang eines Konzentrationsgradienten. Aktive Transportproteine hingegen vermitteln eine energieabhängige Substratbewegung entgegen einem Konzentrationsgradienten.

Membranpumpen wie die ABC-Transporter gehören zu den primär aktiven Transportproteinen und koppeln die freiwerdende Energie aus der exergonisch verlaufenden ATPHydrolyse $(-30.5 \mathrm{~kJ} / \mathrm{mol})$ mit der endergonischen Translokation diverser Substrate durch Membranen.

\subsection{Die Superfamilie der ABC-Proteine}

Die Superfamilie der ATP-binding-cassette (ABC)-Proteine ist eine der größten Proteinfamilien mit Vertretern in allen bekannten Organismen von Bakterien bis zu Säugetieren und besteht überwiegend aus Membranproteinen, die als aktive Transporter (s.o.) eine Vielzahl chemisch diverser Substrate, darunter Kohlenhydrate, Aminosäuren, Peptide, Proteine, Steroide, Metallionen und ein breites Spektrum hydrophober Verbindungen bzw. ihrer Metabolite durch zelluläre Membranen transportieren. Einige ABCProteine fungieren als lonenkanäle (CFTR bzw. ABCC7), ATP-sensitive Kanalmodulatoren (SUR1/2) oder als RNAse $L$ Inhibitor ohne Transportaktivität (OABP bzw. ABCE1). Mutationen in $A B C$-Genen sind an der Ausbildung verschiedener genetisch bedingter Dysfunktionen beteiligt, darunter Mukoviszidose (CFTR), Degenerationen der Retina (ABCA4), Defekte des Transports von Cholesterol, Gallensäuren und pflanzlichen Sterolen ( $A B C A 1, A B C B 4, A B C B 11, A B C G 5$ und $A B C G 8)$, neuronale Störungen ( $A B C D 1$ und $A B C D 2)$, anämische Zustände $(A B C B 7)$ und veränderte Medikamenten-Suszeptibilität ( $A B C B 1$ bzw. Pgp und $A B C C 1, A B C C 2, A B C C 4$ und $A B C C 5$ bzw. MRP1/2/4/5).

Die Charakterisierung eukaryotischer Genome führte zur vollständigen Identifizierung aller $A B C$-Gene in den Genomen der Bierhefe Saccharomyces cerevisiae (31), der Fruchtfliege Drosophila (56) und des Nematoden Caenorhabditis elegans (56). Aktuell sind 49 humane ABC-Proteine bekannt, die auf Basis der Homologie ihrer Aminosäuresequenz und der Organisation der Proteindomänen in 7 Subfamilien (A-G) unterteilt sind. 


\section{$1.2 \quad$ Struktur und Topologie der ABC-Proteine}

ABC-Transporter sind aus zwei verschiedenen Domänen aufgebaut, den hydrophoben Membrandomänen (MD) und den hydrophilen Nukleotidbindungsregionen (NBR), den ATPBindungskassetten (WALKER et al. 1982, HIGGINS et al. 1986). Diese 100-150 Aminosäuren lange zytoplasmatische Proteinregion enthält mehrere Sequenzmotive, die in allen $A B C$ Genen konserviert sind. Die sogenannten Walker A und Walker B Motive sind jeweils 6-8 Aminosäuren lang und durch 90-120 Aminosäuren voneinander getrennt. Die Signatursequenz LSGGQ (auch C-Motiv genannt) befindet sich ca. 25 Aminosäuren strangaufwärts der Walker $B$ Sequenz und ist in der ersten NBR der $A B C$-Gene ebenfalls stark konserviert (HYDE et al. 1990). Während die ATP-Bindungskassetten mittels ATP-Hydrolyse die Funktion eines Transportmotors übernehmen, stellen die Membrandomänen das Transportvehikel dar. Die Sequenzen der Membrandomänen besitzen einen geringeren Konservierungsgrad als die ATP-Bindungskassetten und damit die Voraussetzung für eine individuelle Substratbindung. Eine Membrandomäne besteht aus 6-11 hydrophoben Segmenten, die durch Ausbildung $\alpha$-helikaler Strukturen die Membran durchspannen.

Ein funktionell aktives ABC-Protein benötigt 2 Nukleotidbindungsregionen und 2 Membrandomänen, die in verschiedenen Anordnungen vorkommen können (DASSA et al. 2001). Eukaryotische ABC-Gene werden als Volltransporter mit je 2 NBR- und 2 MD-Einheiten in einem Polypeptidmolekül (MD-NBR-MD-NBR oder NBR-MD-NBR-MD) oder als Halbtransporter (MD-NBR oder NBR-MD) exprimiert, wobei letztere zur Erlangung ihrer Funktionalität Homo- oder Heterodimere bilden müssen. In bakteriellen Transportern wird dieses Ziel z.B. durch Vereinigung von vier separat exprimierten essentiellen Proteindomänen erreicht.

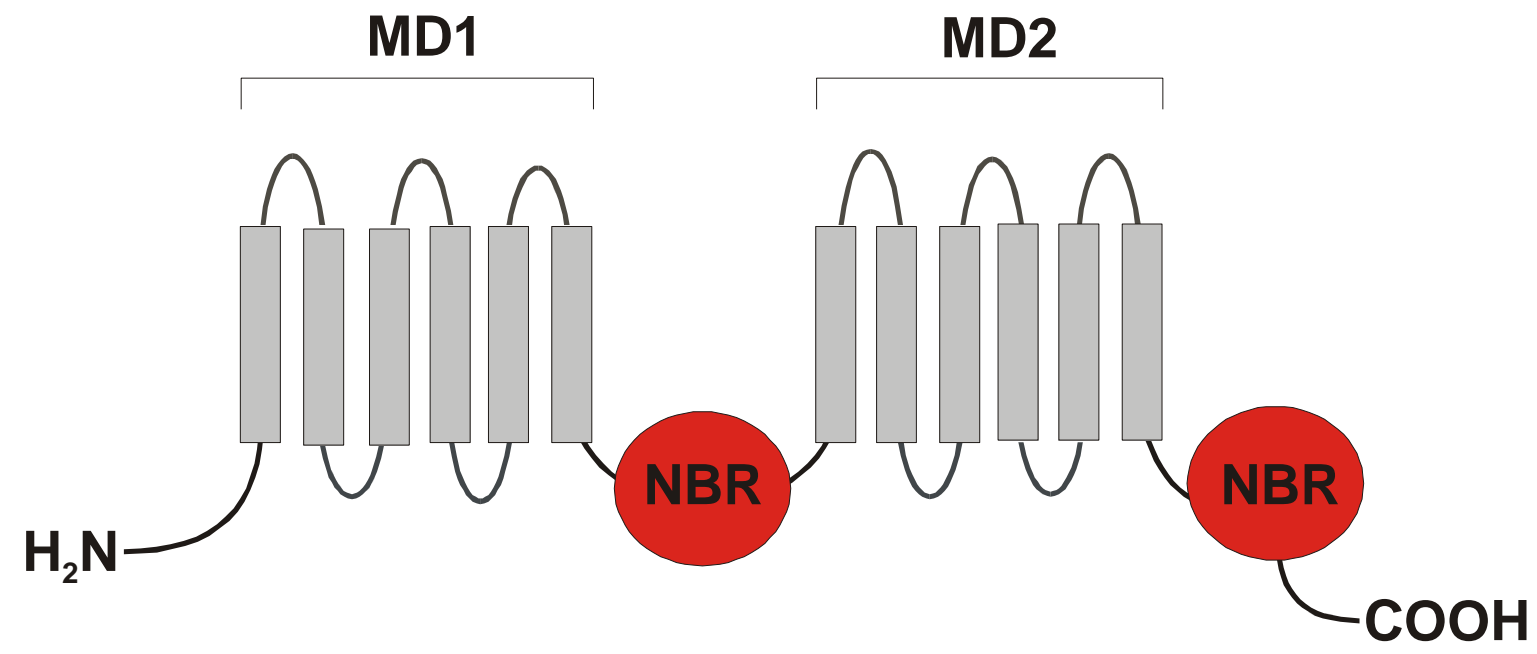

Abb. 1.1 Schematische Darstellung eines typischen ABC-Volltransporters. Die putative, zweidimensionale Topologie verdeutlicht den Aufbau des Proteins aus je zwei in der Membran verankerten Membrandomänen (MD) und zwei intrazellulär lokalisierten, hydrophilen Nukleotidbindungsregionen. 
Die zumeist unidirektionalen ABC-Transporter erfüllen je nach Organismus spezialisierte Aufgaben. In Bakterien vermitteln sie sowohl den Import lebenswichtiger Verbindungen, die die Membran nicht mittels Diffusion überwinden können (Kohlenhydrate, Vitamine, Metallionen) als auch den Efflux diverser Substrate (z.B. Antibiotika). In Eukaryoten sind ABC-Transporter nach bisherigem Erkenntnisstand ausschließlich am Efflux von meist hydrophoben Molekülen aus dem Zytoplasma in den Extrazellulärraum oder in intrazelluläre Kompartimente (Endoplasmatisches Retikulum, Mitochondrien, Peroxisomen) beteiligt.

\subsection{Humane ABC-Proteine - Die 7 Subfamilien}

Neben den bisher charakterisierten 49 humanen $A B C$-Genen wurden mindestens $19 \mathrm{ABC}$ Pseudogene und weitere mögliche $A B C$-Genfragmente im menschlichen Genom identifiziert (DEAN 2002). Vergleicht man die humane $A B C$-Gensuperfamilie mit den $A B C$-Genen anderer Eukaryoten (z.B. Drosophila), so scheint es in der Evolution aufgrund von Selektionseinflüssen unterschiedliche Auffächerungen von $A B C$-Genen und damit ein weiteres Indiz für das hohe Spezialisierungsniveau der ABC-Transporter zu geben.

Im folgenden werden die einzelnen ABC-Subfamilien in umgekehrter Reihenfolge (ABCGABCA) vorgestellt.

\subsubsection{Die ABCG-Subfamilie (White Subfamilie)}

Die ABCG-Subfamilie besteht aus fünf Halbtransportern und einem weiteren, bisher nur in der Maus identifizierten Vertreter, Abcg3. Alle ABCG-Gene weisen eine reverse Domänenstruktur der Form NBR-MD auf. Das humane ABCG1 zeigt eine dominante Expression in Makrophagen und ist über einen nuclear receptor protein regulierten (LXR $\alpha)$ Mechanismus am Cholesterol-Efflux beteiligt (VENKATESWARAN et al. 2000). Ein kürzlich identifiziertes zweites ABCG1-Transkript zeigt eine ähnliche Regulierbarkeit und könnte als Dimerpartner in Frage kommen (KENNEDY et al. 2001). Ebenfalls über LXR $\alpha$ reguliert sind die in Leber, Dünn- und Dickdarm exprimierten Halbtransporter ABCG5 und ABCG8 an der Kontrolle der Aufrechterhaltung des Gleichgewichts zwischen aufgenommenen pflanzlichen Sterolen bzw. Cholesterol beteiligt. Defekte in den beiden benachbarten Genloki auf Chromosom 2p21 verursachen eine Störung der intestinalen Aufnahme pflanzlicher Sterole (Sitosterolämie), die meistens mit einer Hypercholesterinämie einhergeht. Eine dauerhafte erhöhte Aufnahme und Akkumulation pflanzlicher Sterole und Cholesterol führen zu sklerotischen Lipidablagerungen und infolge dessen zu einem erheblichen Risiko, an Durchblutungsstörungen, insbesondere der Koronargefäße zu erkranken (LEE et al. 2001). Zum Substratspektrum des vermehrt in Plazenta, Brustgewebe und daraus entstandenen Tumoren exprimierten ABCG2-Proteins gehören diverse zytostatisch wirksame Medikamente wie Mitoxantron und diverse Anthracycline, die eine Beteiligung von ABCG2 an der 
Ausprägung einer multidrug resistance nahelegen (DOYLE et al. 1998). Neuere ABCG2Transportsubstrate umfassen Sulfatkonjugate von Steroiden und Chlorophyll-Metaboliten (JONKER et al. 2002, SUZUKI et al. 2003). Für ABCG4 ist bisher keine Funktion bekannt.

\subsubsection{Subfamilien E (OABP) und F (GCN20)}

Die ABC-Proteine dieser Subfamilien besitzen aufgrund fehlender Membrandomäne keine eigene Transportaktivität, sondern fungieren als Regulationsenzyme bei der Proteinsynthese. ABCF1 (GCN50) interagiert mit dem eukaryotischen Initiationsfaktor 2 (elF2) am Ribosom (TYZACK et al. 2000). ABCE1 hat eine inhibierende Wirkung innerhalb des 2-5A/RNase-L-Signalwegs und beeinflußt die antiviralen bzw. antiproliferativen Effekte der zellulären Interferonantwort. (BISBAL et al. 1995).

\subsubsection{Subfamilie D (ALD)}

Diese Subfamilie ist nach einer erblichen X-chromosomalen neurodegenerativen Störung, der Adrenoleukodystrophie, benannt, die aufgrund behinderter peroxisomaler $\beta$-Oxidation zur Ablagerung langkettiger gesättigter Fettsäuren in der weißen Gehirnsubstanz, aber auch in anderen Geweben führen kann. Assoziiert mit diesem peroxisomalen Defekt ist das ALDProtein (ABCD1), ein an der zytosolischen Peroxisomenmembran lokalisierter Halbtransporter, der vermutlich in den Import oder Katabolismus langkettiger Fettsäuren eingreift (DODD et al. 1997). Auch ABCD2-4 sind in den Peroxisomen lokalisiert und werden mit verwandten peroxisomalen Störungen in Verbindung gebracht. Mittels two-hybrid-Untersuchungen konnten Interaktionen zwischen drei peroxisomalen ABCD-Proteinen (ABCD1-3 bzw. ALDP, ALDR, PMP70) untereinander und mit einem an der Peroxisomenbiosynthese beteiligten Protein PEX19p beobachtet werden, so daß eine Homo- und Heterodimerbildung zwischen den verschiedenen ABCD-Proteinen möglich erscheint (LIU et al. 1999, GLÖCKNER et al. 2000).

\subsubsection{Subfamilie C (CFTR/MRP)}

Die ABCC-Subfamilie besteht aus 12 Volltransportergenen und einem mit 325 Aminosäuren ungewöhnlich kurzen Gen $A B C C 13$ (YABUUCHI et al. 2002). Sie fungieren als Vermittler im Transport diverser Anionsubstrate, als lonenkanalmodulatoren und sind an der Sekretion verschiedener, im Rahmen der Biotransformation gebildeten, Xenobiotika-Konjugate beteiligt.

Das bekannteste Protein dieser Subfamilie CFTR (Cystic Fibrosis Transmembrane Conductance Regulator, $\mathrm{ABCC} 7$ ) leitet seinen Namen von der mit ihm assoziierten genetischen Störung, der Zystischen Fibrose (Mukoviszidose), ab, die in ihren vielen Ausprägungen gestörter exokriner Funktionen in verschiedenen Organen (u.a. Pankreas, Bronchien, 
Schweißdrüsen, Darm) zu den häufigsten Erbkrankheiten zählt (QUINTON 1999). Das voll funktionstüchtige CFTR weist eine charakteristische MD-NBR-R-MD-NBR Topologie auf und bildet in zahlreichen Geweben einen cAMP-aktivierten Chloridionenkanal. Konservierte Serin-Substituenten in der regulatorischen R-Domäne wurden bereits 1992 von PICCIOTTO et al. als kritische Phosphorylierungsstellen postuliert. Seitdem wurde vielfach gezeigt, daß die selektive Phosphorylierung der R-Domäne durch die cAMP-abhängige Proteinkinase A (PKA) die Voraussetzung für die Öffnung der Kanalporen schafft (XIE et al. 2002).

ABCC8 (SUR1) und ABCC9 (SUR2) sind Sulfonylharnstoffrezeptoren an ATP-abhängigen Kaliumionenkanälen im Pankreas (SUR1, INAGAKI 1995), in Herz und Skelettmuskel (SUR2 Isoformen A und B, INAGAKI 1996) und regulieren über die Öffnung spannungsabhängiger Calciumkanäle die Insulinsekretion.

Von den verbleibenden $A B C C$-Proteinen wird vor allem $A B C C 1$, und in einem geringeren Maß auch $A B C C 2$ und 3 mit dem klinischen Phänomen der multidrug resistance assoziert, das auf der intrinsischen oder erworbenen Fähigkeit der Zelle beruht, durch ATP-abhängigen Efflux hydrophober Zytostatika und ihrer Konjugate (Glutathione, Glukuronide, Sulfate) einer Anreicherung wirksamer Medikamentenkonzentrationen entgegenzuwirken. ABCC2 (MRP2) komplementiert den auch durch ABCB4 (MDR3) und ABCB11 (BSEP) vermittelten Transport organischer Anionkonjugate (z.B. Bilirubindiglukuronid) durch die kanalikuläre Hepatozytenmembran in den biliären Kreislauf. Ein genetisch bedingter Ausfall von MRP2 wird mit dem Dubin-Johnson-Syndrom in Verbindung gebracht, das sich durch das Auftreten einer konjugierten Hyperbilirubinämie mit pigmentösen Ablagerungen in Hepatozyten auszeichnet. Möglicherweise kann diese Störung durch eine überlappende Substratspezifität alternativer MRP-Transporter in der Leber (MRP1 oder MRP3) kompensiert werden.

Die Peptide für $A B C C 4, A B C C 5, A B C C 11$ und $A B C C 12$ bestehen aus maximal 1437 Aminosäuren und sind damit etwas kleiner als die übrigen Proteine der Subgruppe (bis 1581 Aminosäuren für SUR1). Ihnen fehlt das strukturelle Merkmal der zusätzlichen N-terminalen Membrandomäne (MD0), für die bisher keine relevante Funktion beschrieben wurde. Die in diversen Geweben exprimierten Anionentransporter ABCC4 und 5 vermitteln den Efflux zyklischer Nukleotide und Nukleoside sowie auf diesen Strukturen basierender antiviraler Medikamente und können damit zur Resistenzentwicklung der exprimierenden Gewebe beitragen (SCHUETZ et al. 1999, WIJNHOLDS et al. 2000). Für ABCC11 und 12 wurden eine Vielzahl alternativer mRNA-Transkripte detektiert, deren Relevanz für die physiologische Funktion der beiden Proteine noch nicht geklärt ist (YABUUCHI et al. 2001). Die Überexpression von $A B C C 11$ in einer humanen, gegen Nukleosid-Analoga resistenten T-Zell Leukämiezellinie deutet auf eine mit $\mathrm{ABCC} 4$ und 5 überlappende Substratspezifität hin (TURRIZIANI et al. 2002). 


\subsubsection{Subfamilie B (MDR/TAP)}

Diese Subfamilie enthält als einzige in Säugetieren sowohl Halbtransporter- (ABCB2 und 3, 6-10) als auch Volltransportergene (ABCB1, ABCB4, ABCB5 und ABCB11), darunter auch den ersten charakterisierten humanen ABC-Transporter MDR1 (ABCB1, CHEN et al. 1986). Am Beispiel dieses multisubstratspezifischen $A B C$-Proteins wurde die Grundlage einer durch Xenobiotikaefflux vermittelten multidrug resistance aufgeklärt und die Bedeutung dieses Phänomens als universelle Überlebensstrategie von Zellsystemen erkannt. MDR1 wird basal in gesunden exkretorischen Geweben der Leber, des Dünndarms, der Niere, an der BlutHirnschranke sowie in hämatopoetischen Stammzellen exprimiert und vermittelt vermutlich die Elimination potentiell toxischer Fremdstoffe bzw. endogener Verbindungen aus dem Zytoplasma. So wurde z.B. berichtet, daß funktionsrelevante Mutationen des MDR1-Gens zur Durchlässigkeit der Blut-Hirn-Schranke für bestimmte MDR1-Substrate führen können (SCHINKEL et al. 1994, 1997, MEALEY et al. 2001). Diese Studien zeigen jedoch auch, daß ein MDR1-Defekt außer einer erhöhten Sensitivität gegenüber einer Reihe von Xenobiotika keinen störenden Einfluß auf eine normale Entwicklung hat.

Im Gegensatz dazu sind ABCB4 (MDR3) und ABCB11 (BSEP, bile salt export pump) für die physiologische Leberfunktion unentbehrlich. Trotz einer hohen Sequenzhomologie im Vergleich zu MDR1 (75\% bzw. 50\%), gibt es keinen Hinweis auf eine mdr-Aktivität dieser beiden Proteine. ABCB4 und 11 vermitteln zusammen mit ABCC2 $(\rightarrow 1.2 .4)$ den Efflux von Phospholipiden bzw. Gallensalzen durch die kanalikuläre Hepatozytenmembran. Mutationen in den Genen dieser Transporter resultieren in der Entwicklung zweier Formen der Progressiven Familiären Intrahepatischen Cholestase (PFIC3 und PFIC2), einer Erbkrankheit, die zu zirrhotischen Leberveränderungen führen kann (SMIT et al. 1993, STRAUTNIEKS et al. 1998). ABCB2 und ABCB3 (TAP1 und TAP2) konstituieren ein Heterodimer an der Membran des Endoplasmatischen Retikulums. Sie transportieren degradierte Peptide ins ER-Lumen zur Präsentation durch Glykoproteine des major histocompatibility complex (MHC) an der Zelloberfläche (SPIES et al. 1990) und sind damit inhärenter Bestandteil der zellulären Immunantwort. Genetisch bedingte Mutationen auf den Genloki von TAP1 und TAP2 können Immundefizienzen zur Folge haben (DE LA SALLE et al. 1999, 1994).

Das am nächsten den TAP-Proteinen verwandte Gen ist $A B C B 9$, ein in den Lysosomen lokalisiertes Protein, dessen Funktion ebenso wie die von ABCB8 und ABCB10 bisher nicht aufgeklärt wurde. Die verbleibenden vier ABCB-Halbtransporter (ABCB6, 7, 8 und 10) sind in den Mitochondrien lokalisiert und an der Aufrechterhaltung der Eisenhomöostase bzw. am Transport von Eisen/Schwefel-Proteinvorstufen ins Zytosol beteiligt. ABCB6 (UMAT, ubiquitously expressed mammalian transporter) und $A B C B 7$ werden als funktionelle Entsprechungen des Atm1p-Transporters in S. cerevisiae diskutiert (MITSUHASHI et al. 2000). Bei Mutationen auf dem Genlokus für $A B C B 7$ kommt es zur Ausbildung cerebraler Ataxien und anämischer Störungen, die mit Eisenablagerungen in den Mitochondrien der Erythroblasten einhergehen (ALLIKMETS et al. 1999, BEKRI et al. 2000). 


\subsection{Charakterisierung der ABCA-Subfamilie}

Die ausschließlich aus Volltransportergenen bestehende ABCA-Subfamilie des Menschen wurde auf Basis der Intron-Exon-Organisation und einer phylogenetischen Analyse in zwei ABCA-Subgruppen unterteilt (BROCCARDO et al. 1999). Die erste Subgruppe umfaßte zu Beginn dieses Projekts vier, für vollständige Leserahmen kodierende cDNA-Sequenzen ( $A B C A 1, A B C A 3, A B C A 4$, und $A B C A 7)$ und Genfragmente drei weiterer ABCA-Vertreter ( $A B C A 2, A B C A 11$ und $A B C A 13)$, von denen sich $A B C A 11$ als Pseudogen herausstellte. Die

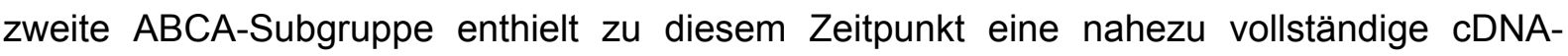
Sequenz für ein Gen auf Chromosom 17 (KIAA0822, später ABCA8, NAGASE et al. 1998). Der Fortschritt des Humangenomprojekts erlaubte außerdem auf Basis von Homologierecherchen mit den bekannten ABCA-Vertretern die Vorhersage weiterer vier Gene auf Chromosom 17, die im weiteren Verlauf zusammen mit $A B C A 8$ als Bestandteile eines neuen ABCA-Genclusters identifiziert wurden (DEAN et al. 2001, ARNOULD et al. 2001, ANNILO et al. 2003). Die ABCA-Subfamilie ist die einzige ohne strukturelle Entsprechung in den Genomen von Drosophila und $S$. cerevisiae und konnte bisher nur in multizellulären Organismen gefunden werden. Evolutionsgenetische Untersuchungen lassen den Ursprung der ABCA-Gene in Halbtransportern vermuten, die nach der Trennung der Entwicklungsstränge von Wirbeltieren, Insekten und Würmern durch Duplikation zu Volltransportergenen wurden (ANJARD et al. 2002).

\subsubsection{Stand der aktuellen ABCA-Forschung}

Zum aktuellen Zeitpunkt enthält die ABCA-Subfamilie 12 vollständig charakterisierte Gene. Für einige Vertreter wird eine Rolle in der Lipidhomöostase verschiedener Zellsysteme diskutiert, die bisher aber nur für ABCA1 nachgewiesen werden konnte (ORAM et al. 2001).

\subsubsection{ABCA1}

Das bereits 1994 von LUCIANI et al. identifizierte ABCA1-Gen weist eine ubiquitäre Expression in der Zytoplasmamembran humaner Zellen auf und ist ein kritischer Faktor der komplexen Lipidexportmaschine der Zelle, ohne selbst ein direkter Cholesterintransporter zu sein. Bindungsstudien in ABCA1-überexprimierenden Zellen konnten zeigen, daß ABCA1 an freies Apolipoprotein A-I (apo-Al als Kernprotein des Cholesterin-transportierenden highdensity-lipoprotein [HDL] Partikels) bindet und als direkte Folge ein gesteigerter zellulärer Phospholipidefflux (Phosphatidylcholin und -serin) und Cholesterinexport zu beobachten sind (WANG et al. 2000). Daher wird eine Flippase-Funktion für ABCA1 postuliert, die durch den Transport von Phopholipiden vom inneren zum äußeren Membranblatt und damit zum auf der Zelloberfläche gebundenen lipiddefizienten Apo-AI-Partikel dessen anschließende Beladung mit Cholesterol vermittelt (DEAN et al. 2001). Desweiteren wird eine Rolle von ABCA1 bei der Makrophagen-gestützten Vernichtung von apoptotischem Zellmaterial diskutiert (HAMON et al. 2000, 2002). 
Die Charakterisierung endogener Oxysterole als Liganden der nuclear- hormone-Rezeptoren ( $L X R, F X R, R X R$ ) eröffnete neue Einblicke in die Regulation des Lipidstoffwechsels. Diese Rezeptoren binden zur Regulation des Zielgens als Hetereodimere ( $L X R / R X R$ bzw. FXR/RXR) an charakteristische DNA-Sequenzen (response elements) im Promotor und aktivieren über diesen Mechanismus auch ABCA1 (REPA et al. 2000, VENKATESWARAN et al. 2000). Die Entdeckung zahlreicher Bindungsstellen für Lipidmetabolismus-assoziierte Transkriptionsfaktoren in der ABCA1-Promotorregion bestätigte die Hypothese einer zentralen Rolle dieses ABCA-Proteins in der zellulären Lipidhomöostase und ermöglicht neue experimentelle Strategien zur Therapie von Lipidstoffwechselerkrankungen (PULLINGER et al. 2000, SANTAMARINA-FOJO et al. 2001).

Im Fall einer mutationsbedingten Inaktivierung des ABCA1-Gens treten die als TangierKrankheit oder familiäre HDL-Defizienz bekannten rezessiven Störungen der Lipidhomöostase auf. Bei den betroffenen Personen wird einerseits ein ungewöhnlich niedriger HDLPlasmaspiegel, andererseits eine verstärkte Ablagerung von Cholesterinestern in Makrophagen und Gefäßen diagnostiziert (SCHMITZ et al. 2001). Kürzlich konnte am Abca1defizienten Mausmodell auch eine Entwicklungsstörung in Sertoli- und Leydigzellen beobachtet werden, die vermutlich auf einen Abca-1 bedingten Defekt des Lipidtransports im Testis zurückzuführen ist (SELVA et al. 2004).

\subsubsection{ABCA4}

Neue Analysemethoden wie die quantitative RT-PCR ermöglichen die Bestimmung der mRNA-Expression von Genen bis zu wenigen Kopien pro Zelle. Dennoch läßt sich die Spezialisierung von ABC-Proteinen auch an ihrer dominanten Expression in individuellen Geweben verdeutlichen. Der ABCA4-Transporter wird ausschließlich in den Membranen der äußeren Stäbchensegmente der Netzhaut (Retina) exprimiert und fungiert analog zu ABCA1 vermutlich als Flippase für einen protonierten Schiff-Basen-Komplex aus all-transRetinylaldehyd und Phosphatidylethanolamin (N-Retinyliden-Phosphoethanolamin) im Rahmen des Transports von Vitamin A- und Phospholipid-Derivaten ins Zytoplasma der Photorezeptorzellen (AZARIAN et al. 1997, WENG et al. 1999). Mutationen des ABCA4-Gens resultieren in diversen Augenfunktionsstörungen, die entweder bereits in früher Kindheit (Retinitis pigmentosa, Stargardt Krankheit) oder aber als Ergebnis von Umweltfaktoren und einer $A B C A 4$-assoziierten genetischen Prädisposition im späteren Lebensalter auftreten können (AMD, age-related macular degeneration, ALLIKMETS et al. 1997). Der genaue Mechanismus dieser retinalen Degenerationserscheinungen ist bisher nicht vollständig aufgeklärt, wird aber mit einer im Abca4-defizienten Mausmodell detektierten abnormalen Akkumulation von Retinoiden im hinteren Pigmentepithel der Netzhaut in Verbindung gebracht (MATA et al. 2001). 


\subsubsection{Weitere ABCA-Transporter}

Auf Basis der bekannten Daten zur subzellulären Lokalisation von ABC-Transportern wurde lange postuliert, daß Volltransporter in der Plasmamembran verankert sind, Halbtransporter dagegen an intrazellulären Organellmembranen wirken. Für das funktionell aktive Heterodimer ABCG5/ABCG8 konnte jedoch eine Lokalisation in der apikalen Membran an der Zelloberfläche gezeigt werden (GRAF et al. 2003).

Das erste Beispiel eines intrazellulären Volltransporters ist das zweitgrößte ABC-Protein ABCA2 (2436 Aminosäuren), das in lysosomalen und endosomalen Vesikeln neuraler Zellen des Gehirns, des Zentralnervensystems und des Rückenmarks (VULEVIC ET AL. 2001) lokalisiert ist. Aufgrund der Präsenz einer Signatursequenz für Lipocalin in einer regulatorischen Region im Zentrum von ABCA2 wird eine Funktion des Proteins im Lipidoder Steroidtransport vermutet. Lipocaline bilden eine Proteinfamilie, die am Transport diverser Retinoide, Steroide, Cholesterin und anderer Lipide beteiligt sind (FLOWER 1996). Bis zur Charakterisierung endogener ABCA2-Substrate bleibt die genaue Rolle dieses Transporters jedoch unklar.

Auch ABCA3 scheint ein intrazellulär in der Lunge wirksames Protein zu sein. Lokalisiert in Vesikelmembranen alveolarer Typ II Zellen, könnte es am Aufbau der tensidhaltigen Lamellarkörperchen mitwirken. Nach Exozytose der Lamellarkörperchen in den Alveolarraum sorgt ihr Inhalt aus oberflächenaktiven Verbindungen (Phospholipide und Proteine) durch Herabsetzung der Oberflächenspannung für die Aufrechterhaltung des Gas-Flüssigkeitsgleichgewichts in der Lunge (YAMANO et al. 2001) und verhindert das Kollabieren des Organs. Diese Hypothese wird durch neue Erkenntnisse über bei Neugeborenen auftretende pulmonale Tensiddefizienzen gestützt, die sich in der Bildung annormaler Lamellarkörperchen äußern und meist mit Mutationen des ABCA3-Gens einhergehen (SHULENIN et al. 2004).

Aufgrund der Verwandtschaft zu ABCA1 werden alle $A B C A-G e n e$ in Bezug auf ihre Relevanz in der zellulären Lipidhomöostase untersucht. Für das vor allem in den myelolymphatischen Geweben des Immunsystems exprimierte $A B C A 7$ wurde kürzlich eine ABCA1-komplementierende oder kompensierende Rolle im apo-A1-gekoppelten Cholesterintransport vorgeschlagen (ABE-DOHMAE et al. 2004).

Für den Lokus des ABCA12-Gens auf Chromosom 2q35 wurden kürzlich mehrere Mutationen assoziiert, die eine schwere Verhornungsstörung der Epidermis (Lamelläre Ichtyose Typ 2) hervorrufen (ANNILO et al. 2002, LEFĖVRE et al. 2003). Dies könnte in Analogie zu den diskutierten Beispielen einen weiteren Hinweis für die Relevanz von ABCATransportern in der Aufrechterhaltung des Lipidmetabolismus diverser Zellsysteme (hier Keratinozyten) darstellen. 
Das verbleibende Mitglied der ersten ABCA-Subgruppe ist zugleich das größte bekannte $A B C-P r o t e i n . ~ D a s ~ A B C A 13-G e n$ erstreckt sich auf Chromosom 7p11-q11 über $450 \mathrm{~kb}$ und kodiert für ein Polypeptid der Länge 5058 Aminosäuren. Trotz seiner immensen Länge besitzt dieses Protein die typische ABCA-Topologie eines vorwärts gerichteten Volltransporters. Es besitzt das zusätzliche N-terminale Membransegment, gefolgt von einer hydrophilen Schleife (PRADES et al. 2002), die hier 3500 Aminosäuren beinhaltet (ABCA1: 596 Aminosäuren) und ein zentrales hydrophobes Segment HH1 (highly hydrophobic), dem eine Bedeutung in der Regulation der Transporter zugeschrieben wird. ABCA13 zeigt auf Ebene der Aminosäuresequenz die größte Sequenzähnlichkeit zu ABCA1 (31\%) und ABCA4 (30\%). Kürzlich wurde ein murines Abca13-Gen identifiziert, das mit 2143 Aminosäuren eine zu anderen ABCA-Genen vergleichbare Länge aufweist (BARROS 2003).

\subsubsection{Der ABCA-Gencluster auf Chromosom 17}

Die fünf Vertreter dieses Clusters ( $A B C A 5, A B C A 6, A B C A 8, A B C A 9$ und $A B C A 10)$ bilden die zweite ABCA-Subgruppe und führen mit ca. 1600 Aminosäuren zu wesentlich kürzeren Polypeptiden als die übrigen ABCA-Proteine. Sie besitzen einen kürzeren N-Terminus mit einer kleineren hydrophilen Schleife und ein möglicherweise degeneriertes hydrophobes Segment im Anschluß an die erste ATP-Bindungskassette. Das Signaturmotiv der zweiten ATP-Bindungskassette ist in allen fünf Vertretern degeneriert. In ABCA8 fehlt zusätzlich in der ersten ATP-Bindungskassette ein Bereich der Länge 36 Aminosäuren zwischen dem Walker A und dem Walker B Motiv, der die Signatursequenz beinhaltet. Die Sequenzhomologie zwischen einzelnen Vertretern beträgt bis zu $71 \%$ ( $A B C A 8$ und $A B C A 9$ ) und deutet auf Duplikationsereignisse während der Entstehung dieses Clusters hin (ANJARD et al. 2002). Die Expressionsmuster dieser Gene variieren zwischen den einzelnen Vertretern. Für $A B C A 6, A B C A 9$ und $A B C A 10$ wurde während der Differenzierung von Makrophagen eine Cholesterin-Responsivität beobachtet, die bisher jedoch nicht mit speziellen Funktionen in Verbindung gebracht werden konnte (KAMINSKI et al. 2001, PIEHLER et al. 2002, WENZEL et al. 2003). Transportversuche mit ABCA8 in Xenopus laevis Oozyten ergaben ein Substratspektrum ähnlich dem des ABCC2-Transporters (u.a. Estradiol- $\beta$ glukuronid, Taurocholat, Leukotrien $C 4$ und Ochratoxin-A) und lassen eine Vielfalt physiologischer Substrate für die neuen ABCA-Transporter vermuten (TSURUOKA et al. 2002).

Das interessanteste Gen des Genclusters ist $A B C A 5$. Es weist eine vergleichbare geringe Homologie (40-42\%) zu den übrigen $A B C A-C l u s t e r g e n e n$ auf und wurde in genomischen

Studien anderer Organismen (Maus, japanischer Kugelfisch, Anophelesmücke) als evolutionär ältestes Gen dieser Subgruppe bestätigt (ANNILO et al 2003, THE ANOPHELES GenOME SEQUENCING CONSORTIUm, Genbank XM_311531). Auch die vergleichbar geringe Ähnlichkeit zu ABCA1 und ABCA4 (23\% bzw. 24\%) legt eine von anderen ABCA-Vertretern abweichende Funktion für ABCA5 nahe. 


\subsection{Ziele der vorliegenden Arbeit}

Im Rahmen eines Genscreenings nach bisher unbekannten $A B C$-Genen in humanem Testisgewebe wurde ein Fragment eines neuen $A B C A-G e n s$ identifiziert, das später als das $A B C A 5-G e n$ des neuen $A B C A-C l u s t e r s$ auf Chromosom 17 identifiziert wurde.

Die vorliegenden Untersuchungen sollten die Existenz eines funktionell aktiven, neuen $A B C A-G e n s$ bestätigen und eine umfassende Charakterisierung dieses Gens zum Ziel haben. Dazu gehörte die Erschließung der gesamten kodierenden Sequenz und angrenzender untranslatierter Bereiche, Analysen der mRNA-Expression in verschiedenen Zellsystemen unter dem Einfluß geeigneter Effektoren, und, wenn möglich, Studien zur zellspezifischen mRNA-Expression. Außerdem sollte das resultierende ABCA5-Protein biochemisch hinsichtlich seiner subzellulären Verteilung untersucht werden. Der bekannt hohe Konservierungsgrad zwischen homologen $A B C$-Genen verschiedener Säugetierspezies, insbesondere zwischen Mensch und Ratte, legte die Existenz eines orthologen Abca5-Gens der Ratte nahe. Es sollte versucht werden, diese Hypothese zu bestätigen und parallel $\mathrm{zu}$ den Arbeiten am humanen ABCA5-Gen eine Charakterisierung des entsprechenden Gens der Ratte vorzunehmen. Insgesamt ergaben sich daraus folgende Aufgabenstellungen:

1. Auswahl eines geeigneten Zellsystems zur experimentellen Erschließung der vollständig kodierenden cDNA des neuen $A B C A-G e n s$.

2. Erfassung des vollständigen ABCA-Gens mittels einer 5'/3'-RACE-PCR Strategie mit nachfolgender Klonierung der Genfragmente und Sequenzanalyse.

3. Untersuchungen zur Verteilung der mRNA-Expression in verschiedenen Geweben und Zellkulturmodellen.

4. Untersuchung des Einflusses möglicher Expressionsmodulatoren auf die mRNAExpression in geeigneten Zellkulturmodellen.

5. Untersuchungen zur subzellulären Verteilung des Transporters durch Klonierung der gesamten kodierenden cDNA-Sequenz in Expressionsvektoren zur Expression als Fusionsprotein in geeigneten Zellsystemen.

6. Parallele Charakterisierung eines putativen orthologen Rattentransporters Abca5. 


\section{$2 \quad$ Material und Methoden}

\section{$2.1 \quad$ Material}

\subsubsection{Reagenzien und Enzyme}

Alle im folgenden nicht gesondert aufgeführten Reagenzien wurden im höchstmöglichen Reinheitsgrad bzw. als für die Zellkultur und Molekularbiologie geeignet von den Firmen Applichem (Darmstadt), Fluka (Buchs, CH), Merck (Darmstadt), Roche Diagnostics (Mannheim), Sigma (Deisenhofen) und Serva (Heidelberg) bezogen.

Acrylamid 4K $\left(29: 1,30 \%\right.$ in $\left.\mathrm{H}_{2} \mathrm{O}\right)$

Agar

Agarose

Agarose LM

Ampicillin

Aquamount

$\beta$-Agarase

BSA, Fraktion V

Calf Intestine Alkaline Phosphatase (CIAP)

Chloroform

Complete Protease Inhibitor

Diethylpyrocarbonat (DEPC)

Dextransulfat

DTT

DNAse I

dNTPs

Entwickler G153

Ethidiumbromid

Fetales Kälberserum (FKS)

Ficoll (MW 400 000)

Folin-Ciocalteus-Phenolreagenz

Formaldehyd

Formamid

Fugene 6

Guanidiniumthiocyanat (97\%)

Heparin (Liquemin N 25 000)

IPTG
Applichem, Darmstadt

Applichem

Genaxis, Spechbach

Genaxis

Applichem

BDH/Promochem, Wesel

MBI Fermentas

Paesel und Lorei, Frankfurt

MBI Fermentas $\mathrm{GmbH}$, St. Leon-Rot

Merck

Roche

Sigma

Sigma

Applichem

MBI Fermentas

MBI Fermentas

Agfa-Gevaert AG, Mortsel, Belgien

Serva

Biochrom KG, Berlin

Sigma

Merck

Merck

Merck

Roche Diagnostics, Mannheim

Fluka, Buchs (Schweiz)

Hoffmann-La Roche, Grenzach-Wyhlen

Applichem 
Hefeextrakt

Heringssperma-DNA

High Fidelity Polymerase

Hydrocortisonhemisuccinat

Kanamycin

Klenow Fragment $(5 \mathrm{u} / \mu \mathrm{l})$

Kollagenase CLS II (172 I.E./mg)

Lachssperma-DNA

Expand Long Template System

$\beta$-Mercaptoethanol

Magermilchpulver Fremareform

MEM Non-essential Amino Acid Solution

Mikrospin-Säulen G-25, S-300

MOPS

$\mathrm{N}, \mathrm{N}, \mathrm{N}$ ',N'-Tetramethylethylenendiamin

Penicillin/Streptomycin, A2213

$10000 \mathrm{E} / 10000 \mu \mathrm{g} / \mathrm{ml}$

Phenol

Poinceau S

Polyvinylpyrrolidon

$\left[\mathrm{Y}^{-}{ }^{32} \mathrm{P}\right]-\mathrm{dATP}$ (Aktivität in $222 \mathrm{TBq} / \mathrm{mmol}$ )

Proteinase K, S3004, S3020

Restriktionsenzyme

Rinderinsulin

RNAse A

RNAse Block

RPMI 1640, R6504

Schnellfixierer G354

SDS

Superscript II Reverse Transcriptase

T4-DNA-Ligase, $5 \mathrm{u} / \mu \mathrm{l}$

T3-RNA-Polymerase

T7-RNA-Polymerase

T4-Polynucleotid-Kinase

Thermoscript Reverse Transcriptase

Trinatriumcitrat
Applichem

Roche

Invitrogen, Karlsruhe

Sigma

Applichem

MBI Fermentas

Biochrom

Biomol, Plymouth Meeting (PA, CA, USA)

Roche

Merck

DE-VAU-GE Gesundkostwerk Lüneburg

Sigma, M7145

Amersham

Sigma

Serva

Biochrom

Roth, Karlsruhe

Sigma

Sigma

PerkinEImer, Wellesley (MA, USA)

DAKO, Hamburg

MBI Fermentas

New England Biolabs, Beverly (MA, USA)

Sigma

MBI Fermentas

Stratagene, La Jolla (CA, USA)

Sigma

Agfa-Gevaert

Sigma

Invitrogen

MBI Fermentas

Roche Diagnostics

Roche Diagnostics

Roche Diagnostics

Invitrogen

Merck 
Tris-Base

Trypsin/EDTA

Trypton

Tween 20

X-Gal
Merck

Biochrom

Applichem

Sigma

Applichem

\subsubsection{Kits}

BigDye Terminator Cycle

Applied Biosystems, Weiterstadt

DAKO ChemMate (DAB)

DAKO

DIG RNA-Labeling Kit

Roche

DIG Nucleic Acid Detection Kit

Roche

Endo Free Plasmid Maxi Kit

Qiagen, Hilden

Human 12-Lane MTN Blot

Clontech, Palo Alto (USA)

One-Step RT-PCR Kit

pcDNA3.1/N5-His TOPO Cloning Kit

Invitrogen

Invitrogen

pCR2.1 TOPO Cloning Kit

Invitrogen

QIAquick Gel Extraction Kit

Qiagen

5'/3' RACE PCR Kit

Roche

Super Signal West Pico Kit

TOPO-XL Cloning Kit

Pierce Biotechnology, Rockford (IL, USA)

Invitrogen

TSA $^{\text {TM }}$ Biotin Kit

PerkinElmer

Human 18S-RNA-Kit

Applied Biosystems, \#4319413E

Taqman Mastermix

Eurogentec, Liège (Belgien)

TOP 10 Electrocompetent cells

Invitrogen

\subsubsection{Verbrauchsmaterialien}

Nicht gesondert aufgeführte Verbrauchsmaterialien, wurden von den Firmen Krannich und Schütt (Göttingen), Nunc (Kamstrup, Dänemark), Greiner (Nürtingen) und Sarstedt (Nümbrecht) bezogen.

Braunülen

Elektroporationsküvetten, $2 \mathrm{~mm}$

Eppendorf UVetten 50-1000 $\mu \mathrm{l}$

Falcon-Röhrchen $15 \mathrm{ml}$

Filterkartuschen Sartolab-P-plus $(0.2 \mu \mathrm{m})$

Filterpapier: fein (2043) und grob (2668)
Braun, Melsungen

Peqlab, Erlangen

Eppendorf

BD Biosciences, Heidelberg

Sartorius

Schleicher und Schüll 
Halbmikro-Kunststoff-Küvetten 1.6 ml

Hyperfilm-ECL

Hyperfilm-MP

Kanülen

Kryoröhrchen $1.8 \mathrm{ml}$

Kulturschalen. $56.7 \mathrm{~cm}^{2}, 21.9 \mathrm{~cm}^{2}, 8.8 \mathrm{~cm}^{2}$

Kunststoffpipetten $1 \mathrm{ml}, 2 \mathrm{ml}, 10 \mathrm{ml}$

Multiwell Platten, 6 Vertiefungen à $9.6 \mathrm{~cm}^{2}$

PCR tubes $0,2 \mathrm{ml}$

Polaroid-667-Filme

PP-Rörchen: $13 \mathrm{ml}, 50 \mathrm{ml}$

Spitzen Gel Saver II

Sephadex Micro Spin Säulen G-25

Spritzenvorsatzfilter $0.2 \mu \mathrm{m}$ und $0.45 \mu \mathrm{m}$

Spritzen $1 \mathrm{ml}, 2 \mathrm{ml}, 5 \mathrm{ml}, 10 \mathrm{ml}, 50 \mathrm{ml}$

Vakuumfilter $125 \mathrm{ml}, 0.2 \mu \mathrm{m}$ und $0.45 \mu \mathrm{m}$
Sarstedt

Amersham

Amersham

Braun

Nunc

Nunc

Greiner

Nunc

Abigene, Epsom (GB)

Sigma

Sarstedt

Gerlinde Kisker, Mühlhausen

Pharmacia Biotech, Freiburg

Schleicher und Schüll

Braun

Schleicher und Schüll

\subsubsection{Geräte}

\subsubsection{Zellkultur}

Autoklav
Inkubatoren

Verikal-Autoklav: FV

Technomara, Fernwald

Steri-Cult 3033

Forma Scientific, Marietta (USA)

C200

Kühlzentrifuge

5810R mit Ausschwingrotor

Labotect, Göttingen

Mikroskop

Inverstoskop: ID 02

Perfusionspumpe

Masterflex 7013.21

Sterilbank

Biogard Hood B40-112

SterilGard III Advance

Sterilfiltration

Schlauchpumpe:

PML 1305-ND100

Tischzentrifuge

Rotanta/P

Zählkammer

Fuchs-Rosenthal: Bright Line

Tiefe: $0.2 \mathrm{~mm}, 0.0625 \mathrm{~mm}^{2}$

Eppendorf, Hamburg

Zeiss, Oberkochen

Cole-Parmer (Chicago, USA)

Baker, Sanford (MN, USA)

Labotect, Göttingen

KNF Flodos/ Sartorius

Hettich, Tuttlingen

Karl-Hecht-Assistent,

Sonderheim/Röhn

\subsubsection{Molekularbiologie}

$\begin{array}{ll}\text { Elektroporator } & \text { Gene Pulser II } \\ \text { Inkubator } & \text { Trockeninkubator MIR-153 } \\ \text { Schüttler } & \text { Vibramax } 100 \\ \text { Sequencer } & 3100 \text { Genetic Analyzer }\end{array}$

Bio-Rad

Sanyo/Krannich

Heidolph, Kehlheim

$\mathrm{ABI}$ 


$\begin{array}{lll}\text { Software } & \text { Staden Package } & \\ & \text { Chromas } & \\ & \text { ClustalW } & \\ & \text { DNA Sequencing Analysis } & \\ \text { Taqman } & 7900 \mathrm{HT} & \text { ABI, Darmstadt } \\ \text { Thermocycler } & \text { Gradient Mastercycler } & \text { Eppendorf } \\ \text { Vakuumzentrifuge } & \text { Thermoblock UNO } & \text { Biometra, Göttingen } \\ & \text { Concentrator 5301 } & \text { Eppendorf } \\ & \text { mit Membranvakuumpumpe } & \text { Vaccubrand, Wertheim }\end{array}$

\subsubsection{DNA- und RNA-Analytik}

\begin{tabular}{|c|c|c|}
\hline \multirow[t]{3}{*}{ Elektrophorese } & Horizontale Gelkammer: H5 & Gibco/BRL, Eggenstein \\
\hline & Horizon 11-14 & Biometra \\
\hline & Horizon $20-25$ & Biometra \\
\hline \multirow[t]{3}{*}{ Hybridisierung } & Glasröhrchen 15 x 3,5 cm & Biometra \\
\hline & Hybridisierungsofen Hybaid & Biometra \\
\hline & Hybridisierungsofen OV5 & Biometra \\
\hline \multirow[t]{2}{*}{ Kamera } & Polaroid DS-34 mit & Sigma \\
\hline & Abblendung und Orangefilter & \\
\hline Küvetten & Quarz-Küvetten: $1 \mathrm{ml}$ & Hellma,/Krannich \\
\hline \multirow[t]{2}{*}{ Membran } & Nylon-Membran: & Amersham \\
\hline & Hybond-N; $0.45 \mu \mathrm{m}$ & \\
\hline Netzteil & Phero-Stab 330 & Biotech-Fischer, Reiskirchen \\
\hline \multirow[t]{4}{*}[{}^{32}P]{$-N a c h w e i s:$} & Bio-Imaging-Analyzer & Fujix, Tokio \\
\hline & BAS1500 & \\
\hline & \multicolumn{2}{|c|}{ Imaging-Plates, $2040\left({ }^{32} \mathrm{P}\right.$-sensitiv), Fujix-Kassetten } \\
\hline & \multicolumn{2}{|c|}{ Auswertesoftware Bas-Reader2.9, TINA 2.0} \\
\hline Photometer & Biophotometer 6313 & Eppendorf \\
\hline Schüttler & GFL 1083 (Wasserbad) & Schütt \\
\hline Strahlendetektor & Flächendetektor $(\beta / \mathrm{Y})$ LB122 & Berthold, Pforzheim \\
\hline UV-Durchlichttisch & $\mathrm{TI} 2$ & Biometra \\
\hline UV-Crosslinker & Bio-Link & Biometra \\
\hline
\end{tabular}

\subsubsection{Protein-Analytik}

$\begin{array}{lll}\text { Elektrophorese } & \text { Horizon 11-14 } & \text { Hoefer, San Francisco (USA) } \\ & \text { Gel casting system } & \\ & \text { Mighty Small SE245 DualGel Caster } \\ & \text { Mighty Small II Vertikal-Elektrophorese-Kammer } \\ \text { Homogenisation: } & \text { Rührmotor RW12 } & \text { Janke \& Kunkel, Staufen } \\ & \text { Glas/Teflonhomogenisatoren } & \text { Braun }\end{array}$




$\begin{array}{lll}\text { Mikroskop } & \text { Fluoreszenzmikroskop DM Irbe } & \text { Leica } \\ \text { Membran } & \text { PVDF-Membran } & \text { Millipore, Eschborn } \\ \text { Immobilon-P; 0.45 } \mu \mathrm{m} & \\ \text { Transfer: } & \text { Standard Power Pack P25 } & \text { Biometra } \\ & \text { Semidry-Kammer mit } & \text { Phase, Lübeck } \\ \text { Ultraschallbad: } & \text { Glas/Graphit- und Edelstahlelektrode } \\ \text { Zentrifugen: } & \text { Sonorex RK 106 } & \text { Bandelin, Berlin } \\ & \text { L8-M Ultrazentrifuge } & \text { Beckmann, München } \\ & \text { J2-21M/E Kühlzentrifuge } & \\ & 5810 R \text { mit Ausschwingrotor } & \text { Eppendorf } \\ & \text { Rotanta/P Tischzentrifuge } & \text { Hettich, Tuttlingen } \\ & \text { Kühlzentrifuge 22R } & \text { Hettich }\end{array}$

\subsubsection{Puffer und Lösungen}

Reagenzien für Puffer und Lösungen wurden den Erfordernissen entsprechend in bidestilliertem oder deionisiertem Wasser gelöst und nach Bedarf autoklaviert oder sterilfiltriert. Die Zusammensetzung der erforderlichen Puffer wird im Zusammenhang mit der jeweils beschriebenen Methode erläutert.

\subsubsection{Kulturmedien}

\subsubsection{Kulturmedien für kompetente E.coli Bakterien}

\begin{tabular}{llll}
\hline & SOC-Medium & LB-Medium & LB-Agar-Platten \\
\hline Trypton & $2.0 \%(\mathrm{w} / \mathrm{v})$ & $1.0 \%(\mathrm{w} / \mathrm{v})$ & $1.0 \%(\mathrm{w} / \mathrm{v})$ \\
Hefeextrakt & $0.5 \%(\mathrm{w} / \mathrm{v})$ & $0.5 \%(\mathrm{w} / \mathrm{v})$ & $0.5 \%(\mathrm{w} / \mathrm{v})$ \\
$\mathrm{NaCl}$ & $0.06 \%(\mathrm{w} / \mathrm{v})$ & $1.0 \%(\mathrm{w} / \mathrm{v})$ & $1.0 \%(\mathrm{w} / \mathrm{v})$ \\
$\mathrm{KCl}$ & $2 \mathrm{mM}$ & - & - \\
$\mathrm{MgCl}_{2}$ & $10 \mathrm{mM}$ & - & - \\
$\mathrm{MgSO}_{4}$ & $10 \mathrm{mM}$ & - & - \\
$\mathrm{Glucose}$ & $20 \mathrm{mM}$ & - & - \\
Agar & & - & $1.5 \%(\mathrm{w} / \mathrm{v})$ \\
$\mathrm{pH}$ & 7.0 & 7.0 & 7.0 \\
\hline
\end{tabular}

Die Medien wurden mit bidestilliertem Wasser angesetzt und autoklaviert. Die erforderliche Glukosemenge wurde in autoklaviertem Aqua bidest. gelöst, sterilfiltriert und dem autoklavierten Medium zugesetzt. SOC-Medium wurde bei $-20^{\circ} \mathrm{C}$ aufbewahrt und vor 
Gebrauch aufgetaut. LB-Medium wurde bei $4^{\circ} \mathrm{C}$ für einige Wochen gelagert. LB-AgarMedium wurde nach dem Autoklavieren auf ca. $55^{\circ} \mathrm{C}$ gekühlt, mit dem entsprechenden Selektionsantibiotikum (Endkonzentrationen Ampicillin $0.1 \mathrm{mg} / \mathrm{ml}$, Kanamycin $0.05 \mathrm{mg} / \mathrm{ml}$ ) und nach Bedarf IPTG und X-Gal (Endkonzentrationen $80 \mathrm{mg} / \mathrm{l}$ X-Gal, $100 \mu \mathrm{M}$ IPTG) versetzt und unter semi-sterilen Bedingungen in Kulturschalen $\left(56.7 \mathrm{~cm}^{2}\right)$ gegossen. Nach dem Aushärten der Agarplatten wurden diese für einige Wochen bei $4{ }^{\circ} \mathrm{C}$ gelagert.

\begin{tabular}{l}
\hline Stammlösungen \\
\hline $50 \mathrm{mg} / \mathrm{ml}$ Ampicillin in $\mathrm{H}_{2} \mathrm{O}$ \\
$50 \mathrm{mg} / \mathrm{ml}$ Kanamycin in $\mathrm{H}_{2} \mathrm{O}$ \\
$100 \mathrm{mM}$ IPTG in $\mathrm{H}_{2} \mathrm{O}$ \\
$40 \mathrm{mg} / \mathrm{ml} \mathrm{X-Gal} \mathrm{in} \mathrm{DMF}$
\end{tabular}

Die Stammlösungen wurden sterilfiltriert und bei $-20^{\circ} \mathrm{C}$ gelagert.

\subsubsection{Medien für die Zellkultur}

\subsection{Eukaryotische Zellinien}

Medien für die Kultur eukaryotischer Zellinien (Caco-2, HepG2, HEK 293 und SER-W3) wurden als Pulver-Medien von Sigma bezogen und wie folgt mit autoklaviertem Wasser angesetzt:

DMEM Grundmedium

$\underline{\text { RPMI-Grundmedium }}$

$\underline{\text { Caco-2 Medium }}$

$\underline{\text { HepG2 Medium }}$
$13.4 \mathrm{~g} / \mathrm{l}$ DMEM-Pulver (Sigma R5648)

$3.7 \mathrm{~g} / \mathrm{N}$ Natriumhydrogenkarbonat $\mathrm{pH} 7.4$

10.4g/l RPMI 1640-Pulver (Sigma R6504)

$2.0 \mathrm{~g} / \mathrm{l}$ Natriumhydrogenkarbonat $\mathrm{pH} 7.4$

DMEM Grundmedium

$1 \%$ (v/v) MEM Non-essential Amino Acid Mix (100x) $10 \%(\mathrm{v} / \mathrm{V})$ FKS

$1 \%(v / v)$ Penicillin/Streptomycin

(100U/ml Penicillin, $100 \mu \mathrm{g} / \mathrm{ml}$ Streptomycin)

RPMI 1640 Grundmedium

$10 \%(v / v)$ FKS

$1 \%(v / v)$ Penicillin/Streptomycin 
HEK 293 Medium

SER-W3 Medium
DMEM Grundmedium

$10 \%$ (v/v) FKS

1\% (v/v) Penicillin/Streptomycin

DMEM Grundmedium

$10 \%$ (v/v) FKS

Zur Langzeitlagerung von Zellstocks in flüssigem Stickstoff wurde dem entsprechenden Kulturmedium Fetales Kälberserum (FKS) in einer Endkonzentration von 20\% und DMSO in einer Endkonzentration von $10 \%$ zugesetzt.

\subsection{Primäre Rattenhepatozyten}

Medien für die Kultur primärer Rattenhepatozyten wurde aus Einzelkomponenten wie folgt hergestellt:

MX-82 nach HofFMANN et al. (1989) diente als Grundmedium für das MX-83-Medium und als Medium für die ca. 3-stündige Anwachsperiode. Hierbei handelt es sich um eine Modifikation des DMEMs (Dulbecco's modified Eagle's medium; SMITH et al. 1960). Das Medium enthielt als Antibiotika Penicillin G $(15 \mu \mathrm{g} / \mathrm{l})$ sowie Streptomycinsulfat $(31.5 \mu \mathrm{g} / \mathrm{l})$. Die Pufferung war auf eine Kulturatmosphäre vom $10 \% \mathrm{CO}_{2}$ abgestimmt. Das zweifach konzentrierte Grundmedium wurde aus den Einzelkomponenten angesetzt, eine Stunde mit $\mathrm{CO}_{2}$ begast und anschließend durch Sartolab-P-plus Filterkartuschen $(0.2 \mu \mathrm{m})$ sterilfiltriert. MX-82 wurde für einige Wochen bei $4{ }^{\circ} \mathrm{C}$ gelagert.

MX-83 enthielt als Grundmedium MX-82 und wurde mit weiteren Vitaminen, Lipiden, Spurenelementen, Metaboliten und Transferrin (10 nM) angereichert. Die Aminosäure Arginin wurde im MX-83 Medium durch Ornithin $(67.4 \mathrm{mg} / \mathrm{ml})$ ersetzt, um das Wachstum anderer Zelltypen zu hemmen. Da der Harnstoffzyklus eine hepatozytenspezifische Stoffwechselfunktion darstellt, sind nur Hepatozyten in der Lage, Arginin durch Umsetzung von Ornithin über den Harnstoffzyklus zu synthetisieren. Zusätzlich war im MX-83-Medium in den vorliegenden Experimenten, abweichend von HOFFMANN et al. (1989) $60 \mathrm{mg} / \mathrm{ml}$ Mevalonsäure enthalten. Dem serumfreien MX-83-Medium wurde zur Aufrechterhaltung differenzierter Zellfunktionen und zur besseren Substratanheftung unter Standardbedingungen Rinderinsulin ( $1 \mu \mathrm{M}$, Stammlösung: $100 \mu \mathrm{M}$ in $0.1 \mathrm{M} \mathrm{HCl} / 0.1 \%$ BSA) und Hydrocortisonhemisuccinat $(20 \mu \mathrm{M}$, Stammlösung: $2 \mathrm{mM}$ in sterilem Aqua bidest.) zugegeben. Alle Stammlösungen wurden bei $-20^{\circ} \mathrm{C}$ aufbewahrt. MX-83 wurde direkt vor dem Gebrauch frisch angesetzt und nur wenige Tage bei $4{ }^{\circ} \mathrm{C}$ gelagert. 


\subsubsection{Tiere und Biologisches Material}

\subsubsection{Versuchstiere}

Für die Präparation primärer Rattenhepatozyten wurden männliche Wistar-Ratten (Rattus norvegicus L.) mit einem Körpergewicht von 180-240 g aus der zentralen tierexperimentellen Einrichtung der Universität Göttingen verwendet. Die Tiere wurden unter konstanten Bedingungen mit abwechselnden Hell- und Dunkelperioden von jeweils 12 Stunden gehalten und erhielten Standardfutter (Altrumin Standard, Nr. 13324, Lage, Lippe) und Wasser ad libitum.

\subsubsection{Bakterien}

Es wurde mit folgenden Escherichia coli Stämmen gearbeitet:

$\mathrm{DH} 10 \beta$

TOP10
Abt. Immungenetik, Göttingen

Invitrogen

\subsubsection{Vektoren}

Es wurden folgende Vektoren verwendet:

$\begin{array}{ll}\text { pCR }^{\circledR}-\mathrm{XL}-\mathrm{TOPO} & \text { Invitrogen } \\ \text { pCR2.1-TOPO } & \text { Invitrogen } \\ \text { pCDNA 4-TOPO TA } & \text { Invitrogen } \\ \text { pcDNA3.1/N5-His TOPO } & \text { Invitrogen } \\ \text { pEGFP-N1 } & \text { BD Biosciences }\end{array}$

\subsubsection{Eukaryotische Zellinien}

Die Zellinien wurden von der Deutschen Sammlung von Mikroorganismen und Zellkulturen $\mathrm{GmbH}(\mathrm{DSMZ})$ bezogen.

Caco-2

Humane Kolonkarzinomzellinie

Humane Nierenzellinie

Humane Hepatomzellinie
FOGH et al. (1977)

ROUSSET et al. (1986)

PINTO et al. (1983)

BACHER et al. (1992)

GRAHAM et. al. (1977)

AdEN et al. (1979)

KNOWLES et al. (1980) 


\subsubsection{Antikörper}

Es wurden folgende Antikörper verwendet:

\section{Primäre Antikörper}

Anti-Maus IgG Alkalische-Phosphatase-gekoppelt

Jackson ImmunoResearch

Anti-Kaninchen DIG/HRP-gekoppelt

DAKO

Living Colors Anti-GFP-AK (polyklonal)

BD Biosciences

Anti-V5-AK (polyklonal)

Invitrogen

\section{Sekundäre Antikörper}

Anti-Peroxidase Maus/Kaninchen

Sigma

Anti-Maus IgG Peroxidase-gekoppelt

Sigma

\subsubsection{Oligonukleotide}

Alle in dieser Arbeit verwendeten Oligonukleotide wurden entweder von der Firma IBA (Göttingen) als $100 \mu \mathrm{M}$ Stocklösung oder von Sigma/ARK (München) als Lyophylysat bezogen und mit autoklaviertem Wasser auf $100 \mu \mathrm{M}$ eingestellt. Stocks wurden bei $-20^{\circ} \mathrm{C}$ gelagert.

Die Sequenzabschnitte aller benutzten Primer und Sonden sind in 5' $\rightarrow 3^{\prime}$ - Richtung auf dem Plus-Strang dargestellt.

\subsection{Sense-Primer für die Charakterisierung der humanen ABCA5 cDNA}

\begin{tabular}{ll}
\hline Sense-Primer & 5'-Sequenz-3' \\
\hline HF1 & CAGACTGAGCGCGTCCAG \\
HF2 & GAGGTTTATTCAGAAAACATGTCC \\
HF3 & CATCCAGTCTCTCTAAGCCGAGCA \\
HF4 & TGTGAGGCTGCTCAGTACTGGTCCTC \\
HF5 & GAGGAGTTATCAGAGGGCAATG \\
HF6 & GTGGTATTCAGAAGACATACAG \\
HF7 & CTGCCTTACTTGGCCACAGTGGAAC \\
HF8 & GTGGACTCTGCCCACCTTCTG \\
HF9 & TGCCCACCTTCTGATGGGTTTGC \\
HF10 & CTTCAATCAAAGGGATACCAGCC \\
HF11 & GCTGTCATTAGGAATGCTGTTCTTG \\
HF12 & GTCTGCTTCTTCAAAATTC
\end{tabular}


HF13

HF14

A1

A2
GAGCTGATGGGTTGCCAGTGTTG

CGAACACAAGAAGATAGAGTAG

GACCA GCGTATCGATGTCGACTTTTTTTTTTTTTTTTV

GACCACGCGTATCGATGTCGAC

Tabelle 2.1 Verwendete Sense-Primer für hABCA5. A1 ist ein kommerzieller Ankerprimer aus dem 5'/3'-RACE-Kit (Roche), $V=A / C / G$.

2.1.7.6.2 Antisense-Primer für die Charakterisierung der humanen ABCA5 cDNA

\begin{tabular}{ll}
\hline Antisense-Primer & 5'-Sequenz-3' \\
\hline HR14 & CTCAATCCTATGGACAAG \\
HR13 & GCAGCATCATGCAGAAAGTGTCT \\
HR12 & CAGTCTCTCTAAGCCGAG \\
HR11 & GAGGCTGCTCAGTACTGGTCCTC \\
HR10 & GtATTGCaCAGGTCATGC \\
HR9 & GTGGACTCTGCCCACCTTCTG \\
HR8 & TGCCCACCTTCTGATGGGTTTGC \\
HR7 & CAATCAAAGGGATACCAGCCA \\
HR6 & GCTGTCATTAGGAATTGCTGTTCTTG \\
HR5 & GAGCTGATTTTCAAGCAGC \\
HR4 & GTGGCAACTAAATACATCTC \\
HR3 & CACAAGAAGATAGAGTAGTATTT \\
HR2 & GTTCGGTCTGCTTACTGGGAC \\
HR1 & GGAATGGTAACTGGAGAACCAAG \\
\hline
\end{tabular}

Tabelle 2.2 Verwendete Anti-Sense-Primer für hABCA5.

2.1.7.6.3 Sense-Primer für die Charakterisierung der Ratten Abca5 cDNA

\begin{tabular}{ll}
\hline Sense-Primer & 5'-Sequenz-3' \\
\hline RF1 & CGCTTCAGCGGAGAGAGTAAG \\
RF2 & CAGCGGAGAGAGTAAGCTGACC \\
RF3 & CTGACCTAGAAAACATGGCTAC \\
RF4 & GCTGATATTAATTAGCATGATG \\
RF5 & CATCTACCTCGTCATAGCCTTC \\
RF6 & GCTGGCTGTGTACCTTGATCAGGTCA \\
RF7 & GACATCTATGAAGGCCAG \\
RF8 & GATTGGCATATGTCCACAGTCAGA \\
RF9 & TGGCTTCAGTCAAAGGAATACCAGCC
\end{tabular}




\begin{tabular}{ll} 
RF10 & CAGAGTCGCTCTCGTCGCTG \\
RF11 & CTGCTGCAGCAGAATGACCAGC \\
RF12 & CTGCTCTAGACATTCATTC \\
RF13 & GCTGTGGTTCCCATCAAGCTCG \\
RF14 & GCATTGGAACAGTACAACATC \\
A1 & GAC CAC GCG TAT CGA TGT CGA CTTTTTTTTTTTTTTTTV \\
A2 & GAC CAC GCG TAT CGA TGT CGA C \\
\hline
\end{tabular}

Tabelle 2.3 Verwendete Sense-Primer für rAbca5. A1 ist ein kommerzieller Ankerprimer aus dem 5'/3'-RACE-Kit (Roche), $V=$ A/C/G.

2.1.7.6.4 Antisense-Primer für die Charakterisierung der Ratten Abca5 cDNA

\begin{tabular}{ll}
\hline Antisense-Primer & 5'-Sequenz-3' \\
\hline RR13 & GACGTCATGTCCTATGAACTGC \\
RR12 & CAGCTTTACAGGCCTCAATAG \\
RR11 & GCTCGCTCTGGACAGTGTG \\
RR10 & GCTGGCTGTGTACCTTGATCAGGTCA \\
RR9 & GGAGCTATCAGAGGGCAACATCAATG \\
RR8 & TGCCCACCTTCTGATGGGTTTGC \\
RR7 & GGCTTCAGTCAAAGGAATACCAGCC \\
RR6 & CTCTAGTGAGCACCATGAG \\
RR5 & CATAGTGCGGCTCTCAATGTG \\
RR4 & GAGCTGATGGGTTGCCAGTG \\
RR3 & CAAACAGCACATGTGGCGAGC \\
RR2 & GCAGGAAGACAGAGTCGTGTTC \\
RR1 & GCACTTGGAAATTCCTAAACTCC \\
\hline
\end{tabular}

Tabelle 2.4 Verwendete Anti-Sense-Primer für rAbca5.

\subsection{PCR-Primer für die Charakterisierung der Splicevarianten}

\begin{tabular}{ll}
\hline Primer & 5'-Sequenz-3' \\
\hline HSV FR1 & GTAGA GTGTGTGAAGAC \\
KRSV R1 & TCTACTGGTGAGAGCGTG \\
RSV R1 & GTGAGAGCGTGTGAAGAT \\
RSV F1 & CTGGTGAGAGCGTGTGAAG \\
\hline
\end{tabular}

Tabelle 2.5 Verwendete Sense- und Anti-Sense-Primer zur Erfassung der Splicevarianten. 


\subsection{Diverse PCR-Primer}

\begin{tabular}{lll}
\hline Primer & 5'-Sequenz-3' & Verwendung \\
\hline S1.for & TCN GGN KSN GGN AAR AGY AC & D-RT-PCR \\
S2.rev & TCN ARN GCR CTN GTN GSY TCR TC & D-RT-PCR \\
RTQ F1 & AGAAAGCAAATCAGTGCGCTCT & RTQ-PCR \\
RTQ R1 & TGCTTCAAAATTCTACTGATTC & RTQ-PCR \\
SVRTQ R1 & GTGAGAGCGTGTGAAGATTCAGA & RTQ-PCR \\
RISH F1 & TAATACGACTCACTATAGGGCTGCCCTAGACAGTCATTC & ISH-RT-PCR \\
RISH R1 & CTCTAGTGAGCACCATGAGTCCCTTTAGTGAGGGTTAAT & ISH-RT-PCR \\
\hline
\end{tabular}

Tabelle 2.6 Verschiedene Sense- und Antisense-Primer für hABCA5 und rAbca5.

$\mathrm{D}-\mathrm{RT}-\mathrm{PCR}=$ Degenerierte RT-PCR, RTQ-PCR = real time quantitative PCR, ISH-RT$\mathrm{PCR}=\mathrm{RT}-\mathrm{PCR}$ für in situ Hybridisierungs-Sonden.

\subsubsection{Gensonden}

Die nachfolgende Tabelle erläutert die Verwendung, Herkunft und Größe sämtlicher in der Arbeit benutzter Gensonden.

\begin{tabular}{|c|c|c|}
\hline Sonde & 5'-Sequenz-3' bzw. Herkunft & Verwendung \\
\hline HR8 & GCAAA CCATCAGAAGGTGGGCA & Nachweis $h A B C A 5$ im Northern Blot \\
\hline R8 & GCAAACCCATCAGAAGGTGGGCA & Nachweis $r A b c a 5$ im Northern Blot \\
\hline R13 & GCAGTTCATAGGACA TGACGTC & Nachweis rAbca5 im Northern Blot \\
\hline$\beta$-Aktin (h) & GCGCTCAGGAGGAGCAATG & Kontrollhybridisierung Northern Blot \\
\hline$\beta$-Aktin (r) & GACTTCCTGTAACCATCTATGCCGTG & Kontrollhybridisierung Northern Blot \\
\hline GAPDH (r) & CAGGATGCATTGCTGACAATCTTGA & Kontrollhybridisierung Northern Blot \\
\hline RTQ 1 & 6-FAM-TGCTGTGGTTCCCAT-MGB & Real time quantitative-PCR \\
\hline RISH 1 & 308 bp Fragment aus rAbca5 & In-situ Hybridisierung \\
\hline RISH 2 & 232 bp Fragment aus rAbca5 & In-situ Hybridisierung \\
\hline
\end{tabular}

Tabelle 2.7 Verwendete Anti-Sense-Primer für hABCA5. Die RISH1-Sonde entspricht dem Sequenzbereich Nukleotide 2241-2548, die RISH2-Sonde dem Sequenzbereich Nukleotide 2317-2548 auf der cDNA-Sequenz für rAbca5 (Genbank Accession Number AJ426052).

\subsubsection{RNA-Proben}

Zur Erschließung der Gensequenz für humanes $A B C A 5$ wurde Biopsiematerial aus humaner Leber (Universitätsklinikum Göttingen) verwendet. Gesamt-RNA aus verschiedenen Rattengeweben wurde aus frisch isolierten Organen präpariert. Der Verwendung menschlichen Materials zur Analyse war durch die Ethikkommission zugestimmt worden. 


\subsubsection{Molekulargewichtstandards}

$\begin{array}{lll}\text { DNA-Längenstandard } & 1 \mathrm{~kb} \text { Leiter } 1 \mu \mathrm{g} / \mu \mathrm{l}(0.12-12.2 \mathrm{~kb}) & \text { Invitrogen } \\ \text { SDS-Proteinmarker } & \text { SDS-6H }(29-205 \mathrm{kDa}) & \text { Sigma } \\ & \text { Low Range Marker }(6-66 \mathrm{kDa}) & \text { Sigma } \\ & \text { Color Burst Marker }(8-220 \mathrm{kDa}) & \text { Sigma }\end{array}$

\section{$2.2 \quad$ Methoden}

\subsubsection{Vorbehandlung und Sterilisation}

Alle Geräte zur RNA-Isolierung und Northern-Blot-Analyse wurden für 20 min in $50 \mathrm{mM}$ $\mathrm{NaOH}-\mathrm{Lösung}$ inkubiert, um eine eventuelle RNAse Kontamination zu eliminieren. Wasser für in situ Hybridisierungspuffer wurde mit $0.1 \%$ DEPC für mehrere Stunden inkubiert und anschließend autoklaviert. Für die in situ Hybridisierung wurden alle Puffer mit DEPCvorbehandeltem Wasser in RNAse-freien Gefäßen angesetzt.

Hitzebeständige Lösungen, sowie hitzebeständige Glas- und Kunststoffmaterialien wurden durch einen 25-minütigen Autoklaviervorgang bei $121^{\circ} \mathrm{C}$ sterilisiert. Nicht hitzestabile Lösungen wurden sterilfiltriert. Die Porenweite $(0.2 \mu \mathrm{m}$ bzw. $0.45 \mu \mathrm{m})$ der Sterilfilter richtete sich dabei nach der Konsistenz der Lösungen.

\subsubsection{Präparation von Nukleinsäuren}

\subsubsection{Minipräparation von Plasmid-DNA}

Resuspensionspuffer ( $\mathrm{pH} 8.0)$

Lysepuffer

Neutralisationspuffer $(\mathrm{pH} 5.5)$

$$
\begin{aligned}
& 50 \mathrm{mM} \text { Tris } \\
& 10 \mathrm{mM} \text { EDTA } \\
& 0.1 \% \text { RNAse A }
\end{aligned}
$$

$200 \mathrm{mM} \mathrm{NaOH}$

$1 \%$ SDS

3 M Kaliumacetat

Zur Herstellung einer Minikultur wurden $5 \mathrm{ml}$ LB-Medium mit dem entsprechenden Antibiotikum zur Selektion versetzt und anschließend mit einer frisch isolierten Kolonie von der Agarplatte inokuliert. Diese Kultur wurde ca. $8-12 \mathrm{~h}$ bei $750-900 \mathrm{rpm}$ und $37^{\circ} \mathrm{C}$ geschüttelt. Die Isolierung der auf diese Weise erhaltenen Plasmid-DNA diente analytischen Zwecken (Restriktionsverdau, Sequenzierung) und wurde in modifizierter Form der alkalischen Lyse (BIRNBOIM und DOLY, 1979) durchgeführt. Von der Minikultur wurden $2 \mathrm{ml}$ für $10 \mathrm{~min}$ bei $1780 \times \mathrm{g}$ und $4^{\circ} \mathrm{C}$ zentrifugiert. Das Pellet wurde in $100 \mu \mathrm{l}$ RNase A 
enthaltenden Resuspensionspuffer aufgenommen, 5 min mit $200 \mu$ lalkalischem Lysepuffer und anschließend für $5 \mathrm{~min}$ mit schwach saurem Neutralisationspuffer inkubiert. Das Proteinpräzipitat wurde 30 min bei $21910 \times \mathrm{g}$ und $4{ }^{\circ} \mathrm{C}$ sedimentiert. Der Überstand wurde in ein neues Reaktionsgefäß (1.5 ml Eppendorfgefäß) überführt, mit 2 Volumenanteilen absoluten Ethanols $(1 \mathrm{ml})$ versetzt und nach sorgfältigem Mischen 20 min bei $4{ }^{\circ} \mathrm{C}$ und 21910 x g zentrifugiert. Das erhaltene DNA-Pellet wurde mit $80 \%$ Ethanol gewaschen, für 5 min bei $4{ }^{\circ} \mathrm{C}$ und $21910 \times$ g zentrifugiert, in der Vakuumzentrifuge bei RT getrocknet und in 20-40 $\mu \mathrm{l}$ autoklaviertem Aqua bidest. aufgenommen.

\subsubsection{Herstellung von Glycerinkryokulturen}

Glycerinkryokulturen wurden aus den LB-ü.N.-Kulturen der Plasmidminipräparationen $(\rightarrow$ 2.2.2.1) durch Zugabe von $200 \mu \mathrm{l}$ Glycerin zu $400 \mu \mathrm{l}$ der Bakteriensuspension hergestellt. Die Stocklösungen wurden gut gemischt und unverzüglich bei $-20^{\circ} \mathrm{C}$ eingefroren. Nach $24 \mathrm{~h}$ wurden die Eppendorfgefäße zur Dauerlagerung in den $-80^{\circ} \mathrm{C}$ Tiefkühlschrank überführt.

\subsubsection{Endotoxin-freie Maxipräparation von Plasmid-DNA}

Für die Transfektion von DNA in eukaryotische Zellen wurde das Plasmid mit dem EndoFree Plasmid Maxi Kit (Qiagen) gemäß dem mitgelieferten Protokoll präpariert. Dazu wurden $100 \mathrm{ml}$ ü.N. Bakterienkultur durch Zentrifugation für $20 \mathrm{~min}$ bei $4{ }^{\circ} \mathrm{C}$ und $3220 \mathrm{xg}$ sedimentiert (5810R, Eppendorf) und mittels alkalischer Lyse aufgeschlossen. Zelltrümmer, Proteine und Salzkomplexe wurden nach der Neutralisation mittels Filtration durch die QIAfilter Maxi Cartridge abgetrennt. Einem Schritt zur Entfernung von Endotoxinen schloß sich eine Aufreinigung der DNA über eine äquilibrierte Anionen-Austauscher-Silica-Säule an. Das gereinigte DNA-Eluat wurde mit 0.7 Volumenanteilen Isopropanol versetzt und für $30 \mathrm{~min}$ bei $4{ }^{\circ} \mathrm{C}$ und $17000 \times \mathrm{g}$ (J2-21M/E Kühlzentrifuge) zentrifugiert. Nach einem Waschschritt mit $80 \%$ Ethanol, erneuter Zentrifugation für 10 min bei $4{ }^{\circ} \mathrm{C}$ und $17000 \times \mathrm{g}$ wurde das DNA-Pellet luftgetrocknet und in 80-100 $\mu$ l endotoxinfreiem TE-Puffer (Qiagen) aufgenommen. Nach photometrischer Bestimmung der DNA-Konzentration in einer 1:1000 Verdünnung mit Aqua bidest. $(\rightarrow 2.2 .2 .5)$ wurde die DNA bei $-80^{\circ} \mathrm{C}$ aufbewahrt.

\subsubsection{Isolierung von Gesamt-RNA}

Gesamtzelluläre RNA wurde mittels einer Guanidiniumthiocyanat-Phenol-ChloroformExtraktion nach einer Modifikation der ursprünglich von CHOMZCYNSKI und SACCHI (1987) veröffentlichten Methode gewonnen.

GTC-Lösung (pH 7.5):

$\begin{array}{ll}4 \mathrm{M} & \text { GTC } \\ 17 \mathrm{mM} & \text { Sarcosyl } \\ 25 \mathrm{mM} & \text { Trinatriumcitrat } \\ 0.1 \mathrm{M} & \beta \text {-Mercaptoethanol }\end{array}$


GTC, Sarcosyl (N-Dodecanoyl-N-methylglycin, Na-Salz) und Trinatriumcitrat wurden bei $50{ }^{\circ} \mathrm{C}$ gelöst und sterilfiltriert. Diese Lösung konnte bei $4{ }^{\circ} \mathrm{C}$ bis zu drei Monate gelagert werden. Vor Gebrauch wurde der Lösung $1 \%$ (v/v) $\beta$-Mercaptoethanol zugesetzt.

\subsection{Gesamt-RNA aus Zellkulturen}

Zur Isolierung von RNA wurden pro Parameter $5 \times 10^{6}$ bis $1 \times 10^{7}$ Zellen (ein bis zwei $10 \mathrm{~cm}$ Kulturschalen) eingesetzt. Die kultivierten und in flüssigem Stickstoff schockgefrorenen Zellen wurden mit einem Gummiwischer in $3 \times 1 \mathrm{ml}$ Guanidiniumthiocyanat (GTC)-Lösung von den Kulturplatten geschabt und das erhaltene Zellysat in sterile $13 \mathrm{ml}$ PolypropylenZentrifugenröhrchen überführt. Anschließend wurden $0.3 \mathrm{ml}$ Natriumacetat-Lösung (2 M; $\mathrm{pH}$ 4.0), $3 \mathrm{ml}$ Phenol (wassergesättigt; $\mathrm{pH} \mathrm{4.3)} \mathrm{und} 0.6 \mathrm{ml}$ Chloroform/Isoamylalkohol (49:1) zugegeben und die Ansätze kräftig geschüttelt. Die Ansätze wurden bis zur Phasentrennung (etwa $10 \mathrm{~min}$ ) auf Eis stehengelassen und anschließend für $20 \mathrm{~min}$ bei $7740 \mathrm{xg}$ und $4{ }^{\circ} \mathrm{C}$ in einem JA 20 Festwinkelrotor zentrifugiert. Die obere wäßrige Phase, in der sich die RNA befand, wurde vorsichtig abgenommen, in ein weiteres steriles Röhrchen überführt und zur Fällung der RNA mit $3 \mathrm{ml}$ Isopropanol versetzt. Die Ansätze wurden dann für mindestens $3 \mathrm{~h}$ bei $-20^{\circ} \mathrm{C}$ gefällt. Nach einer weiteren Zentrifugation bei $4{ }^{\circ} \mathrm{C}$ und $15.000 \times \mathrm{g}$ für $30 \mathrm{~min}$ wurde der Überstand verworfen und das erhaltene Sediment in $1.5 \mathrm{ml}$ GTC-Lösung resuspendiert. Die erhaltene Lösung wurde mit $2 \mathrm{ml}$ Isopropanol versetzt und für mindestens $3 \mathrm{~h}$ bei $-20^{\circ} \mathrm{C}$ gefällt. Die Ansätze wurden erneut für $30 \mathrm{~min}$ bei $15000 \times \mathrm{g}$ und $4{ }^{\circ} \mathrm{C}$ zentrifugiert, die Überstände dekantiert und die Sedimente mit $2 \times 1 \mathrm{ml} 70$ \%-igem Ethanol gespült, um Salze herauszulösen. Schließlich wurde die RNA in 20-40 $\mu$ l autoklaviertem Aqua bidest. aufgenommen, in flüssigem Stickstoff schockgefroren und bei $-80{ }^{\circ} \mathrm{C}$ gelagert.

\subsection{Gesamt-RNA aus Gewebe}

Gesamt-RNA wurde aus unterschiedlichen Geweben der Ratte und aus humaner Leber isoliert. Die frisch entnommenen Organe wurden unverzüglich mit einem sterilen Skalpell zerteilt und in flüssigem Stickstoff schockgefroren. Anschließend wurden sie in einem ebenfalls mit flüssigem Stickstoff vorgekühlten Mörser zerstoßen und unter ständiger Stickstoffkühlung zu feinem Pulver zerrieben. 3-5 Minispatelspitzen dieses Organpulvers wurden mit $3 \mathrm{ml}$ Guanidiniumthiocyanat (GTC)-Lösung in einem sterilen $13 \mathrm{ml}$ PolypropylenZentrifugenröhrchen versetzt und sofort kräftig gemischt, bis eine homogene Suspension entstand. Die weitere Aufarbeitung erfolgte analog zur Isolierung von Gesamt-RNA aus Zellkulturen $(\rightarrow 2 \cdot 2 \cdot 2 \cdot 4.1)$.

RNA-Proben wurden zur Konzentrationsbestimmung in autoklaviertem Aqua bidest. 1:1000 verdünnt. 


\subsubsection{Konzentrationsbestimmung von Nukleinsäuren}

Die photometrische Konzentrationsbestimmung der Nukleinsäuren wurde in einem Biophotometer (Eppendorf) vorgenommen. Die Extinktionswerte wurden bei $230 \mathrm{~nm}, 260 \mathrm{~nm}$ $280 \mathrm{~nm}$ und $320 \mathrm{~nm}$ gemessen und die Quotienten $\mathrm{OD}_{260 / 280}$ und $\mathrm{OD}_{260 / 230}$ ermittelt. Eine Extinktion (OD) von 1.0 bei $260 \mathrm{~nm}$ entspricht einer RNA-Konzentration von $40 \mathrm{ng} / \mu \mathrm{l} \mathrm{bzw}$. einer DNA-Konzentration von $50 \mathrm{ng} / \mu \mathrm{l}$. Auf Grundlage dieser Definitionen wurden die Konzentrationen der jeweiligen Nukleinsäure errechnet. Die Quotienten $O_{260 / 280}$ und $\mathrm{OD}_{260 / 230}$ sind ein Maß für die Protein- bzw. Salzkontamination $\left(\mathrm{OD}_{\max }\right.$ für Proteine bei $280 \mathrm{~nm}$ ) und sollten $>1.8$ und $<2.0$ betragen.

\subsubsection{Enzymatische Modifikationen von Nukleinsäuren}

\subsubsection{Restriktionsspaltung von Plasmid-DNA}

Plasmid-DNA wurde durch Restriktionsendonukleasen (RE) verschiedener Hersteller gespalten und weiterverarbeitet. Die Restriktionsansätze enthielten im Standardprotokoll 1/10 Volumenanteil des entsprechenden Pufferkonzentrats und maximal 1/10 Volumenanteil des vorgesehenen Restriktionsenzyms. Analytische Restriktionsansätze hatten ein Gesamtvolumen von $10 \mu \mathrm{l}$, präparative Ansätze bis zu $50 \mu \mathrm{l}$. Je nach Reaktionsdauer und Herstellerempfehlung wurden Restriktionsenzyme im Überschuß eingesetzt (i.d.R. 2-10 U $\mathrm{RE} / \mu \mathrm{g} \mathrm{DNA}$ ). Für die simultane Verwendung von zwei unterschiedlichen Enzymen wurde, soweit möglich, ein mit beiden Enzymen kompatibler Puffer eingesetzt. Wenn dies nicht möglich war, wurde die DNA zwischen beiden Reaktionen präzipitiert $(\rightarrow 2.2 .4 .3)$, um einen Pufferwechsel zu ermöglichen. BSA wurde entsprechend den Herstellerempfehlungen in einer Endkonzentration von $100 \mu \mathrm{g} / \mathrm{ml}$ benutzt. Die Reaktion erfolgte über $1-4 \mathrm{~h}$ im Temperaturoptimum des verwendeten Enzyms. Anschließend wurde das Enzym entweder durch Hitze (20 min bei $65-80{ }^{\circ} \mathrm{C}$ ) inaktiviert, oder der Ansatz direkt auf ein DNA-Agarosegel aufgetragen (hitzeresistente $\mathrm{RE}, \rightarrow$ 2.2.8.1).

\subsubsection{Herstellung von blunt-end DNA-Fragmenten}

Durch die Behandlung von DNA-Molekülen mit Restriktionsendonukleasen entstehen DNAFragmente, die entweder glatte Enden (blunt-end), 5'-überhängende oder 3'-überhängende Enden (sticky-end) besitzen. Für eine blunt-end Ligation müssen daher DNA-Fragmente mit überhängenden Enden aufgefüllt oder überhängende Nukleotide enzymatisch entfernt werden.

\subsection{Auffüllen von 5'-überhängenden DNA-Enden durch Klenow-Behandlung}

Für das Auffüllen von 5'-überhängenden DNA-Enden wurde das Enzym DNA-Polymerase I Large Fragment (Klenow Enzym) verwendet. Der präzipitierte Restriktionsansatz mit $10 \mu \mathrm{g}$ Plasmid-DNA wurde in $37 \mu \mathrm{l}$ autoklaviertem Aqua bidest. aufgenommen. Nach Zugabe von $5 \mu \mathrm{l}$ dNTPs $(2 \mathrm{mM}), 5 \mu \mathrm{l}$ Klenow Pufferkonzentrat (10x) und $3 \mu \mathrm{l}$ Klenow Fragment $(10 \mathrm{u} / \mu \mathrm{l})$ 
wurde der Ansatz gut gemischt und $1 \mathrm{~h}$ bei $37^{\circ} \mathrm{C}$ inkubiert. Die Inaktivierung des Enzyms erfolgte bei $75^{\circ} \mathrm{C}$ für $10 \mathrm{~min}$. Je nach Erfordernis wurde der Reaktionsansatz elektrophoretisch aufgereinigt $(\rightarrow 2.2 .8 .1)$ oder direkt präzipitiert $(\rightarrow 2.2 .4 .3)$.

\subsection{Entfernen von 3'-überhängenden DNA-Enden mit T4 DNA-Polymerase}

Da 3'-überhängende DNA-Enden nicht durch enzymatische Behandlung aufgefüllt werden können, wird die 3' $\rightarrow$ ' Exonukleaseaktivität der T4 DNA-Polymerase genutzt, um diese Überhänge zu entfernen. Der präzipitierte Restriktionsansatz mit $10 \mu \mathrm{g}$ Plasmid-DNA wurde in $12 \mu \mathrm{l}$ autoklaviertem Aqua bidest. aufgenommen. Nach Zugabe von $1 \mu \mathrm{l}$ dNTPs (10 mM), $4 \mu \mathrm{l}$ T4 DNA-Polymerase Pufferkonzentrat (5x) und $3 \mu \mathrm{l}$ T4 DNA-Polymerase (5 u/ $\mu \mathrm{l})$ wurde der Ansatz gut gemischt und $1 \mathrm{~h}$ bei RT inkubiert. Die Inaktivierung des Enzyms erfolgte bei $75^{\circ} \mathrm{C}$ für $10 \mathrm{~min}$. Je nach Erfordernis wurde der Reaktionsansatz elektrophoretisch aufgereinigt $(\rightarrow 2.2 .8$ ) oder direkt präzipitiert $(\rightarrow 2.2 .4 .3)$.

\subsubsection{Dephosphorylierung von Vektor-DNA}

Die Calf Intestinal Alkaline Phosphatase (CIAP) katalysiert die Entfernung der 5'Phosphatgruppe von DNA, RNA sowie Ribo- und Desoxyribonukleosidtriphosphaten, wodurch eine Religation von Vektor-DNA nach erfolgreichem Restriktionsverdau verhindert wird. Die Dephosphorylierung von Vektor-DNA wurde direkt im Anschluß an den Restriktionsverdau durchgeführt. Zum hitzeinaktiviertem Restriktionsansatz $(\rightarrow 2.2 .3 .1)$ wurden $6 \mu l$ CIAP-Pufferkonzentrat (10x) und $3 \mu \mathrm{l} \mathrm{CIAP-Enzym} \mathrm{(3} \mathrm{u/ \mu l)} \mathrm{gegeben} \mathrm{und} \mathrm{der} \mathrm{Ansatz} \mathrm{auf} 60 \mu \mathrm{l}$ mit autoklaviertem Aqua bidest. aufgefüllt. Zum Entfernen von 5'-Phosphatgruppen an doppelsträngiger DNA mit 5'-Überhang wurde dieser Reaktionsansatz $1 \mathrm{~h}$ bei $37^{\circ} \mathrm{C}$, an doppelsträngiger DNA mit 3'-Überhang oder blunt-end $1 \mathrm{~h}$ bei $56^{\circ} \mathrm{C}$ inkubiert. Die Reaktion wurde durch eine 10 -minütige Inkubation bei $75^{\circ} \mathrm{C}$ beendet. Anschließend wurde die VektorDNA nach elektrophoretischer Auftrennung mit dem QIAquick Gel Extraction Kit (Qiagen) isoliert $(\rightarrow 2.2 .4 .1)$ und in Aliquots von $25 \mathrm{ng} / \mu$ l Vektor in Tris-Puffer bei $-80{ }^{\circ} \mathrm{C}$ gelagert.

\subsubsection{Digoxygenin-Markierung von cRNA-Sonden (in vitro Transkription von cDNA)}

Zur Generierung der Digoxygenin-markierten cRNA-Sonden wurde der DIG RNA Labeling Kit (Roche) verwendet. Als cDNA-Template für die Sonde RISH1 $(\rightarrow$ 2.1.7.7) diente ein Plasmid (pCR4-TOPO), in das ein PCR-amplifiziertes 308 bp (RF6, RR12, $\rightarrow$ 2.1.7.6) Fragment aus rAbca5 eingebracht worden war $(\rightarrow 2.2 .5)$. Dieses Plasmid wurde in zwei getrennten Restriktionsansätzen mit den Restriktionsendonukleasen Bcul oder Notl linearisiert $(\rightarrow$ 2.2.3.1), um unspezifische Plasmid-DNA vor der in vitro Transkriptionsreaktion über den T3- bzw. T7-Promotor zu entfernen. Die Gesamtlänge der RISH1-Sonden (AntiSense, Sense) betrug durch restriktionsbedingte Vektorfragmente $375 \mathrm{bp}$ bzw. $354 \mathrm{bp}$. Alternativ wurde für RISH2 $(\rightarrow$ 2.1.7.7) als cDNA-Vorlage (Template) ein über S-300 Mikrospin-Säulen (Amersham) gereinigter RT-PCR Ansatz verwendet, der die gewünschte 
Sondensequenz, flankiert von der T7/T3-Promotorsequenzen am 5'/3'-Ende enthielt $(\rightarrow 2$ 2.6.1.4). Bedingt durch die 20 bp-Promotorüberhänge an den Primern (RISH F1 und RISHR1) betrug die Gesamtlänge der RISH2-Sonden (Anti-Sense, Sense) 272 bp. Folgende Reagenzien wurden unter Eiskühlung zum Reaktionsansatz pipettiert:

$\begin{array}{lll} & 10 \mu \mathrm{l} & \text { gereinigter PCR-Ansatz (cDNA Template) } \\ \text { oder } & 1 \mu \mathrm{g} & \text { linearisierte Plasmid-DNA } \\ 2 \mu \mathrm{l} & \text { Transkriptionspuffer 10x } \\ 2 \mu \mathrm{l} & \text { DIG RNA Labeling Mix } \\ 1 \mu \mathrm{l} & \text { RNAse Inhibitor } \\ 1 \mu \mathrm{l} & \text { T7/T3 RNA-Polymerase } \\ \operatorname{ad} 20 \mu \mathrm{l} & \text { DEPC-Wasser }\end{array}$

Diese Ansätze wurden bei einer zweiten Zugabe von je $1 \mu l$ der entsprechenden RNAPolymerase für $4 \mathrm{~h}$ bei $37^{\circ} \mathrm{C}$ inkubiert. Die Template-Degradation wurde durch Zugabe von $2 \mu \mathrm{l}$ DNAse und einer 15 -minütigen Inkubation bei $37^{\circ} \mathrm{C}$ bewirkt. Diese Reaktion wurde durch Zugabe von $2 \mu \mathrm{l}$ einer $0.2 \mathrm{M}$ EDTA-Lösung in DEPC behandeltem Aqua bidest. (pH 8.0) gestoppt und der Ansatz durch Zugabe von 1/10 Volumenanteil $4 \mathrm{M} \mathrm{LiCl-Lösung}$ und 3 Volumenanteilen absoluten Ethanols bei $-20^{\circ} \mathrm{C}$ ü.N. gefällt. Das durch Zentrifugation erhaltene RNA-Pellet $\left(21910 \times \mathrm{g}, 15 \mathrm{~min}, 4^{\circ} \mathrm{C}\right)$ wurde mit kaltem, sterilem $70 \%$ Ethanol gewaschen, in der Vakuumzentrifuge getrocknet und in $20 \mu \mathrm{l}$ autoklaviertem Aqua bidest. aufgenommen. Zur Überprüfung der RNA-Integrität wurden $1 \mu \mathrm{l}$ dieses Reaktionsansatzes auf ein 1\% Agarosegel geladen und elektrophoretisch analysiert. Zum Abschätzen der Fragmentlänge wurde der $1 \mathrm{~kb}$ DNA-Leiterstandard (Invitrogen) verwendet. Die Lagerung dieser Stammlösung für die in situ Hybridisierung erfolgte bei $-80^{\circ} \mathrm{C}$.

\subsubsection{Dot-Blot-Analyse der cRNA-Sonden}

PBS-Puffer (7.4)

$136 \mathrm{mM} \mathrm{NaCl}$

$2.68 \mathrm{mM} \mathrm{KCl}$

$8.2 \mathrm{mM} \mathrm{Na}_{2} \mathrm{HPO}_{4}$

Blockierungspuffer

$1 \%(\mathrm{v} / \mathrm{v}) \mathrm{FKS}$

$1 \%(w / v)$ Blockierungsreagenz aus TSA Biotin Kit in PBS

NTM-Puffer $(\mathrm{pH} 9.5)$

$$
\begin{aligned}
& 100 \mathrm{mM} \mathrm{NaCl} \\
& 100 \mathrm{mM} \text { Tris } \\
& 50 \mathrm{mM} \mathrm{MgCl}_{2}
\end{aligned}
$$

Die Effizienz der Markierungsreaktion wurde mittels des Dot-Blot-Verfahrens überprüft. Dazu wurde aus der cRNA-Stammlösung eine Verdünnungsreihe $(1: 10,1: 20,1: 40,1: 80$ und 
1:160, Aqua bidest.) hergestellt und $1 \mu \mathrm{l}$ jeder Verdünnungsstufe mit einer Pipettenspitze auf eine Nylonmembran (ca. $3 \times 6 \mathrm{~cm}$ ) aufgebracht. Nach UV-Fixierung der RNA im Crosslinker mit $0.120 \mathrm{~mJ}$ wurde die Membran $5 \mathrm{~min}$ in $10 \mathrm{ml}$ PBS-Puffer gewaschen und mindestens $10 \mathrm{~min}$ in $10 \mathrm{ml}$ Blockierungspuffer inkubiert. Nach Zugabe von $4 \mu \mathrm{l}$ des Alkalische-Phosphatase-gekoppelten Anti-DIG-Antikörpers wurde die Membran für 30 min bis zu $2 \mathrm{~h}$ inkubiert und anschließend dreimal je $5 \mathrm{~min}$ in $10 \mathrm{ml}$ PBS-Puffer gewaschen. Zur Vorbereitung der Chromogenreaktion wurde die Membran zweimal je 5 min in $10 \mathrm{ml}$ NTM-Puffer gewaschen und nachfolgend in $10 \mathrm{ml}$ NTM-Puffer mit $200 \mu \mathrm{l}$ NBT/BCIP-Konzentrat ohne Schütteln inkubiert. Die Signale wurden nach wenigen Sekunden sichtbar. Die Chromogenreaktion wurde durch kräftiges Spülen mit Aqua bidest. beendet und die Membran zwecks Aufbewahrung getrocknet.

\subsubsection{Radioaktive Markierung von Oligonukleotiden}

Zur radioaktiven Markierung von Oligonukleotiden wurde die endständige Phosphatgruppe von $\left[\gamma_{-}{ }^{32} \mathrm{P}\right]$-ATP mittels T4-Polynukleotidkinase auf das 5'-Ende von Oligonukleotiden übertragen. Die Markierung der verwendeten Oligonukleotide wurde in einem Gesamtvolumen von $10 \mu \mathrm{l}$ durchgeführt. Der Markierungsansatz bestand aus $50 \mathrm{pmol}$ Oligonukleotid, autoklaviertem Aqua bidest. ad $3 \mu \mathrm{l}, 1 \mu \mathrm{l}$ T4-Polynukleotidkinase Pufferkonzentrat (10x, Endkonzentration: $10 \mathrm{mM} \mathrm{MgCl}_{2}, 5 \mathrm{mM}$ Dithiothreitol, $70 \mathrm{mM}$ Tris- $\mathrm{HCl}$ ), sowie $5 \mu \mathrm{l}$ (entspricht $1,85 \mathrm{mBq}$ ) $\left[\gamma^{3}{ }^{32} \mathrm{P}\right]-$ ATP (spezifische Aktivität: $222 \mathrm{TBq} / \mathrm{mmol}$ ). Die

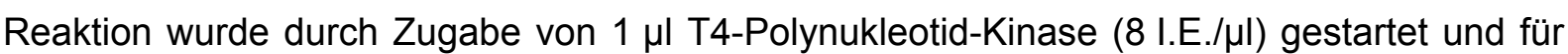
$1 \mathrm{~h}$ bei $37^{\circ} \mathrm{C}$ im Heizblock inkubiert.

Zur Trennung von markierten Oligonukleotiden und freiem $\left[\gamma_{-}{ }^{32} \mathrm{P}\right]-\mathrm{ATP}$ wurden G-25 MicroSpin Sephadex-Säulen (Pharmacia) eingesetzt. Das Säulenmaterial wurde zunächst durchmischt und die Säule nach Entfernung des Verschlusses in einem Reaktionsgefäß für $1 \mathrm{~min}$ bei $735 \mathrm{xg}$ zentrifugiert. Die Markierungsreaktion wurde durch Zugabe von $40 \mu \mathrm{l}$ 100 mM EDTA-Lösung gestoppt, der vollständige Ansatz mittig auf die Oberfläche der Säule aufgegeben und erneut für $2 \mathrm{~min}$ bei $735 \mathrm{xg}$ zentrifugiert. Das erhaltene Eluat wurde anschließend mit $300 \mu \mathrm{l}$ denaturierter Heringssperma-DNA (Stammlösung $10 \mathrm{mg} / \mathrm{ml}$ ) versetzt und für die Hybridisierung eingesetzt. Die Effizienz der Markierungsreaktion wurde durch Bestimmung der Radioaktivität im Eluat überprüft.

\subsubsection{Isolierung von DNA-Fragmenten aus Agarosegelen}

Diese Methode wurde eingesetzt, um DNA-Fragmente weiteren Experimenten (z.B. $\rightarrow$ 2.2.3.1 bis 2.2.3.3) zugänglich zu machen. Hierbei wurden der QIAquick Gel Extraction Kit (Qiagen) oder die Low-Melting-Methode (Isolierung von DNA aus Low Melting Agarose durch Agaraseverdau) angewendet. 
Die entsprechende DNA-Bande wurde nach gelelektrophoretischer Auftrennung in einem Agarose- oder LM-Agarosegel auf einem Transilluminator unter langwelligem UV-Licht $(366 \mathrm{~nm})$ mit einem sterilen Skalpell herausgeschnitten und wie folgt weiter behandelt:

\subsubsection{QIAquick Gel Extraction Kit}

Zur in Agarose eingebetteten DNA-Bande wurde eine hochmolare Lösung des chaotropen Salzes Natriumperchlorat $\left(\mathrm{NaClO}_{4}\right)$ zugegeben, die die Agarose bei $50{ }^{\circ} \mathrm{C}$ innerhalb von 10 Minuten irreversibel auflöste. Diese Lösung wurde zur Adsorption der DNA auf eine Anionenaustauschsilikat-Säule gegeben und die DNA nach dem Waschen mit einem weiteren Puffer bei pH 8.5 eluiert.

\subsubsection{Low-Melting-Methode}

Die LM-Agarose mit der eingebetteten DNA-Bande wurde für $5-10 \mathrm{~min}$ bei $65^{\circ} \mathrm{C}$ geschmolzen und anschließend auf $42^{\circ} \mathrm{C}$ abgekühlt. Bei dieser Temperatur wurden zügig $1 \mathrm{u} \beta$-Agarase/100 mg LM-Agarose (bei 1\% LM-Gelen) zugegeben, der Ansatz für $1 \mathrm{~h}$ bei $42{ }^{\circ} \mathrm{C}$ inkubiert und anschließend präzipitiert $(\rightarrow 2.2 .4 .3)$.

\subsubsection{DNA-Präzipitation}

Hierzu wurde die zu präzipitierende DNA-Lösung mit $1 \mu$ l einer Glykogenlösung $(20 \mathrm{mg} / \mathrm{ml})$, 1/10 Volumenanteil einer $3 \mathrm{M}$ Natriumacetatlösung ( $\mathrm{pH}$ 4.6) und 2 Volumenanteilen Isopropanol versetzt und gut gemischt. Nach Zentrifugation für 20 min bei $21910 \mathrm{xg}$ und $4{ }^{\circ} \mathrm{C}$ wurde das DNA-Pellet mit $80 \%$ Ethanol gewaschen und 5 min bei $4{ }^{\circ} \mathrm{C}$ und $21910 \mathrm{xg}$ zentrifugiert. Die DNA wurde in der Vakuumzentrifuge getrocknet und in autoklaviertem Aqua bidest. aufgenommen.

\subsubsection{Klonierung von DNA-Fragmenten}

\subsubsection{TOPO-Ligation}

Diese von Invitrogen patentierte Methode erlaubt die direkte Ligation von gereinigten PCRProdukten in diverse Klonierungs- und Expressionsvektoren (z.B. pCR-XL-TOPO, pcDNA3.1/N5-His TOPO TA) mit einer wesentlich höheren Ligationseffizienz als die klassische Ligation mit T4-Ligase. TOPO-Vektorlösungen enthalten linearisierten Vektor mit 3'-T-Überhängen, die komplementär zu den von der Taq-DNA-Polymerasen erzeugten 5'-AÜberhängen sind. Die Ligation wird von einer mit den Vektorenden assoziierten Topoisomerase vermittelt. Für die Ligationsreaktion nach Herstellerprotokoll wurden PCRProdukt und Vektorlösung in einem Gesamtvolumen von $6 \mu \mathrm{l}$ gemischt, 5 min bei RT inkubiert und die Reaktion mit einer konzentrierten Salzlösung $\left(0.3 \mathrm{M} \mathrm{NaCl}, 0.06 \mathrm{M} \mathrm{MgCl}_{2}\right.$ ) gestoppt. Das Ligationsprodukt wurde entweder direkt zur Elektroporation (Transformation) eingesetzt oder vorher einer Isopropanolpräzipitation $(\rightarrow$ 2.2.4.3) unterzogen, um den Salzgehalt und damit eine erhöhte Leitfähigkeit der Ligationslösung zu reduzieren (zur 
Vermeidung eines Kurzschlusses während des Hochspannungspulses bei der Elektroporation elektrokompetenter E.coli, $\rightarrow$ 2.2.5.4).

\subsubsection{Ligation mit T4-DNA-Ligase}

Restriktionsenzymatisch gespaltene, isolierte und bei Bedarf enzymatisch modifizierte DNAFragmente konnten direkt in die komplementären Restriktionsschnittstellen des nach Bedarf dephosphorylierten Vektors ligiert werden. Dafür wurde das Verhältnis der DNA : Vektor auf ca. 3 : 1 eingestellt und in einer $20 \mu$ l-Reaktion mit $2 \mu$ Ligasepuffer (10x) und $1 \mu$ T4-DNALigase $(5 \mathrm{u} / \mu \mathrm{l})$ vermischt. Der Ansatz wurde ü.N. bei $12{ }^{\circ} \mathrm{C}$ inkubiert und die Reaktion durch Hitzeinaktivierung für $10 \mathrm{~min}$ bei $65^{\circ} \mathrm{C}$ beendet. Zur Reinigung und Konzentration des Ligationsprodukts schloß sich eine DNA-Fällung mit Isopropanol an $(\rightarrow 2.2 .4 .3)$, die pelletierte DNA wurde in 5-10 $\mu$ lautoklaviertem Aqua bidest. aufgenommen.

\subsubsection{Herstellung elektrokompetenter E.coli Zellen}

Eine Vorkultur aus $20 \mu \mathrm{l}$ Bakterienstock (Bakterienstämme $\rightarrow$ 2.1.7.2) in $6 \mathrm{ml}$ LB-Medium ohne Antibiotikum wurde ü.N. unter Schütteln bei $37^{\circ} \mathrm{C}$ inkubiert und anschließend gleichmäßig auf $3 \times 200 \mathrm{ml}$ LB-Medium aufgeteilt. Diese Kultur wurde bis zum Erreichen einer $\mathrm{OD}_{600}=0.65-0.8$ vermehrt, auf Eis abgekühlt und auf 12 vorgekühlte $50 \mathrm{ml}$-Röhrchen (Sarstedt) verteilt. Alle weiteren Arbeitsschritte wurden unter Eiskühlung oder bei $4{ }^{\circ} \mathrm{C}$ (Zentrifuge) ausgeführt. Nach Zentrifugation für 10 min bei $3220 \times$ g wurden die Pellets in je $1 \mathrm{ml}$ eiskaltem 10\% Glycerin (in autoklaviertem Aqua bidest.) resuspendiert, auf $30 \mathrm{ml}$ mit $10 \%$ Glycerin aufgefüllt und erneut 10 min bei $3220 \times$ g zentrifugiert. Nach Resuspension in je $1 \mathrm{ml}$ eiskaltem 10\% Glycerin wurden je 2 Pellets in $30 \mathrm{ml} \mathrm{10 \%} \mathrm{Glycerin} \mathrm{vereinigt} \mathrm{und} \mathrm{die}$ Zentrifugation wiederholt (6 Röhrchen). Es erfolgte eine Resuspension in $30 \mathrm{ml} \mathrm{10 \%} \mathrm{Glycerin}$ und Zentrifugation für $10 \mathrm{~min}$ bei $3220 \mathrm{xg}$ und eine weitere Vereinigung der Pellets (3 Röhrchen). Nach einer finalen Resuspension in $30 \mathrm{ml} 10 \%$ Glycerin und Zentrifugation für $10 \mathrm{~min}$ bei $3220 \mathrm{xg}$ wurden die drei Bakterien-Pellets vorsichtig in je $400 \mu 10 \%$ Glycerin resuspendiert. Die elektrokompetenten Bakterien wurden in vorgekühlte Eppendorf-Gefäße $(60 \mu \mathrm{l})$ aliquotiert, in flüssigem Stickstoff schockgefroren und bei $-80^{\circ} \mathrm{C}$ gelagert.

\subsubsection{Transformation durch Elektroporation}

Für die Transformation eines Ligationsansatzes wurde ein Aliquot (60 $\mu$ l) elektrokompetenter E. coli $(\rightarrow 2.2 .5 .3)$ für $30 \mathrm{~min}$ auf Eis aufgetaut und mit 2-4 $\mu \mathrm{l}$ des Ligationsprodukts vorsichtig gemischt. Die Mischung wurde in eine vorgekühlte Elektroporationsküvette (Elektrodenabstand $2 \mathrm{~mm}$ ) überführt und die gefüllte Küvette im Elektroporator unverzüglich mit einem Hochspannungspuls ( $2500 \mathrm{~V}, 25 \mu \mathrm{F}, 200 \Omega$ ) behandelt. Nach Zugabe von $500 \mu \mathrm{l}$ vorgewärmtem SOC-Medium in die Küvette wurde der gesamte Transformationsansatz in ein Falcon-Röhrchen überführt und ca. $1 \mathrm{~h}$ bei $37^{\circ} \mathrm{C}$ geschüttelt. Anschließend erfolgte das Ausplattieren von 10-300 $\mu \mathrm{l}$ transformierter E.coli-Suspension auf Selektionsplatten (LBAgar mit dem entsprechenden Antibiotikum, $\rightarrow$ 2.1.6.1) und Inkubation im Trockeninkubator 
für $12-18 \mathrm{~h}$ bei $37^{\circ} \mathrm{C}$. Die entstandenen Kolonien wurden mittels einer Minipräparation $(\rightarrow$ 2.2.2.1) und nachfolgendem Restriktionsverdau oder einer Kolonie-PCR $(\rightarrow$ 2.2.6.5) analysiert und die isolierte Plasmid-DNA gegebenenfalls sequenziert $(\rightarrow 2.2 .7)$.

\subsubsection{PCR-Techniken}

Mit der Methode der Polymerase-Kettenreaktion (PCR) werden DNA-Matrizen (Templates) sequenzspezifisch amplifiziert. Dazu wird die DNA durch Hitze zunächst denaturiert. Im zweiten Schritt, der Anlagerungsreaktion, hybridisieren anschließend die Oligonukleotidprimer mit ihrem komplementären DNA-Strang (Anlagerung), worauf im dritten Schritt die DNA-Polymerase eine DNA-Neusynthese zwischen diesen Primern in 5' $\rightarrow$ '-Richtung vornimmt (Verlängerung). Der Zyklus aus Denaturierung, Anlagerung und Verlängerung wird 20-35mal wiederholt, wobei die neu synthetisierten Tochterstränge im nächsten Zyklus selbst als DNA-Matrizen fungieren. Schon ab dem dritten Zyklus entstehen so DNA-Doppelstränge, deren Länge dem Abstand zwischen den Primern entspricht. Mit jedem Zyklus erhöht sich der Anteil dieser DNA-Abschnitte mit der Zielsequenz auf etwa das doppelte, so daß theoretisch nach $n$ Zyklen eine Anzahl von maximal $2^{n}$ DNA-Molekülen dieser Länge im Reaktionsansatz enthalten ist. Dies entspricht einer logarithmischen Vervielfältigung der DNA-Zielsequenz. Alle PCR-Produkte wurden im Anschluß an die Reaktion elektrophoretisch auf einem DNA-Agarosegel analysiert $(\rightarrow 2.2 .8 .1)$.

\subsubsection{Reverse Transcription-PCR (RT-PCR)}

Bei dieser Variante ist mRNA die initiale PCR-Matrize und muß mittels einer reversen Transkription (RT) in copy oder complementary DNA (cDNA) übersetzt werden. Erfolgen reverse Transkription und PCR-Amplifikation ohne Isolierung der intermediären cDNA, spricht man von einem one-step Verfahren, in dem von Beginn an beide Enzyme (Reverse Transkriptase und DNA-Polymerase) vorhanden sind.

\subsection{Reverse Transkription (RT)}

Im Rahmen dieser Arbeit wurden verschiedene RT-Protokolle durchgeführt. Dabei wurden hitzelabile Transkriptasen, z.B. AMV Reverse Transcriptase, (Roche) und Superscript II Reverse Transcriptase, (Invitrogen) unter niedrigeren Reaktionstemperaturen $\left(42-55^{\circ} \mathrm{C}\right)$ mit kürzeren Primern oder statistischen Primermischungen zur Generierung von cDNA-Pools $(\rightarrow$ 2.2.6.1.2-2.2.6.3) verwendet. Thermostabile Transkriptasen, z.B. Thermoscript (Invitrogen) wurde bei höheren Reaktionstemperaturen (bis $65^{\circ} \mathrm{C}$ ) zur genspezifischen Selektion bei der cDNA-Synthese eingesetzt. Die einzelnen RT-Reaktionsprotokolle werden im Rahmen der entsprechenden PCR-Methode beschrieben. 


\subsection{One-step RT-PCR}

Hierzu wurde der one-step RT-PCR Kit (Invitrogen) eingesetzt, um mit genspezifischen Primern (i.d.R. 18-24 bp) cDNA-Fragmente bis zu $1.5 \mathrm{~kb}$ zu amplifizieren. Folgender Reaktionsansatz wurde unter Eiskühlung in einem $0.2 \mathrm{ml} \mathrm{PCR-Gefäß} \mathrm{hergestellt:}$

$\begin{array}{ll}16.2 \mu \mathrm{l} & \text { Autoklaviertes Aqua bidest. } \\ 1.8 \mu \mathrm{l} & \text { MgSO }_{4}-\text { Lösung }(50 \mathrm{mM}) \\ 2.5 \mu \mathrm{l} & \text { Sense Primer }(10 \mu \mathrm{M}) \\ 2.5 \mu \mathrm{l} & \text { Antisense Primer }(10 \mu \mathrm{M}) \\ 1 \mu \mathrm{l} & \text { RNA }(1 \mu \mathrm{g} / \mu \mathrm{l}) \\ 1 \mu \mathrm{l} & \text { DNA Polymerase/Reverse Transkriptase-Mix } \\ 25 \mu \mathrm{l} & 2 x \text { Reaktionsmix }\end{array}$

Es kam das folgende Temperatur-Protokoll zum Einsatz, wobei die reverse Transkriptase nach der initialen cDNA-Synthese bei hoher Temperatur denaturiert und simultan die DNAPolymerase aktiviert wurde:

cDNA-Synthese:

Denaturierung/Aktivierung

35 Zyklen:

Denaturierung

Anlagerung

Kettenverlängerung

Abschluß:
$45 \mathrm{~min}$ bei $45^{\circ} \mathrm{C}$

$1 \mathrm{~min}$ bei $96^{\circ} \mathrm{C}$

$15 \mathrm{~s}$ bei $96^{\circ} \mathrm{C}$

$30 \mathrm{~s}$ bei $60^{\circ} \mathrm{C}$

$1 \mathrm{~min} / \mathrm{kb}$ bei $72{ }^{\circ} \mathrm{C}$

5 min bei $72{ }^{\circ} \mathrm{C}$

\subsection{RT-PCR mit T3/T7-Promotorprimern}

Diese PCR-Technik wurde ebenfalls mit dem one-step RT-PCR Kit (Invitrogen) durchgeführt, um cDNA-Matrizen für die Generierung von Digoxygenin-markierten cRNA-Sonden über eine reverse-Transkriptionsreaktion zu erhalten $(\rightarrow 2$ 2.2.1.2). Um die cDNA beidseitig mit den T3/T7-Promotorsequenzen auszustatten, erhielt der Antisense-Primer am 5'-Terminus einen T3-Promotoranhang, der Sense-Primer am 3'-Ende einen T7- Promotoranhang (Primer $\rightarrow$ 2.1.7.6.6). Die amplifizierten cDNA-Fragmentlängen für die cRNA-Sonden betrugen 200$350 \mathrm{bp}$ und wurden nach dem Standardprotokoll amplifiziert $(\rightarrow 2.2 .6 .1 .2)$. Anschließend wurde das PCR-Produkt über eine Microspin S-300 Säule (Amersham) von überschüssigen Nukleotiden gereinigt. Dazu wurde der Inhalt der Microspin-Säule durch Vortexen homogenisiert und für 1 min bei $750 \mathrm{xg}$ und $4{ }^{\circ} \mathrm{C}$ zentrifugiert. Der PCR-Ansatz wurde in die Mitte des Säulenmaterials pipettiert und für $1 \mathrm{~min}$ bei $750 \mathrm{xg}$ und $4{ }^{\circ} \mathrm{C}$ in ein neues Eppendorfgefäß zentrifugiert. 


\subsubsection{5'-RACE-PCR}

Zur Erschließung der vollständigen kodierenden $A B C A 5$ cDNA-Sequenz (Accession Number AJ275973.1, $\rightarrow$ 2.2.6.1.3) wurde die RACE-Methode (Rapid Amplification of cDNA ends) nach FROHMAN et al. (1994) verwendet (5'/3'-RACE-Kit, Roche). Dazu wurde $1 \mu \mathrm{g}$ GesamtRNA aus HepG2-Zellen mit einem genspezifischen Primer auf Basis der partiellen ABCA5Sequenz AJ275973.1 (R6, $\rightarrow$ 2.1.7.6.2, $\rightarrow$ Abb. 3.1) zur reversen Trankription $1 \mathrm{~h}$ bei $55^{\circ} \mathrm{C}$ und 10 min bei $65^{\circ} \mathrm{C}$ in folgendem Reaktionsansatz inkubiert:

$\begin{array}{ll}2.75 \mu \mathrm{l} & \text { Autoklaviertes Aqua bidest. } \\ 4 \mu \mathrm{l} & \text { cDNA Synthesis buffer }(5 \mathrm{x}) \\ 10 \mu \mathrm{l} & \text { dNTPs }(2 \mathrm{mM}) \\ 1.25 \mu \mathrm{l} & \text { cDNA Synthese Primer R6 }(10 \mu \mathrm{M}) \\ 1 \mu \mathrm{l} & \text { HepG2 RNA }(1 \mu \mathrm{g} / \mu \mathrm{l}) \\ 1 \mu \mathrm{l} & \text { AMV Reverse Trankriptase }(20 \mathrm{u} / \mu \mathrm{l})\end{array}$

Zur Entfernung von überschüssigen Primern und Nukleotiden wurde eine Reinigung der cDNA nach dem Protokoll des High Pure PCR Purification Kit (Roche) vorgenommen. Danach erfolgte eine Markierung der cDNA-Enden mit einem homopolymeren A-Schwanz, um eine spezifische Anlagerung des GC-reichen poly-dT-Ankerprimers A1 $(\rightarrow$ 2.1.7.6.1) in der nachfolgenden PCR-Reaktion an den 5'-Terminus der generierten cDNA zu gewährleisten. Es wurden

$\begin{array}{ll}19 \mu \mathrm{l} & \text { gereinigte cDNA } \\ 2.5 \mu \mathrm{l} & \text { Reaktionspuffer } \\ 2.5 \mu \mathrm{l} & \text { dATP }(2 \mathrm{mM})\end{array}$

für $3 \mathrm{~min}$ bei $94^{\circ} \mathrm{C}$ denaturiert und auf Eis mit $1 \mu$ Terminaler Transferase $(10 \mathrm{u} / \mu \mathrm{l})$ vermischt. Diese Reaktion dauerte bei $37^{\circ} \mathrm{C} 30 \mathrm{~min}$ und wurde mittels Hitze (10 min bei $70^{\circ} \mathrm{C}$ ) beendet. Die polyA-markierte cDNA wurde anschließend als Matrize in einer PCR nach dem Expand Long Template Protokoll (Roche) mit einem Oligo-dT-Anker Primer A1 und einem genspezifischen Primer eingesetzt:

$\begin{array}{ll}5 \mu \mathrm{l} & \text { polyA-markierte cDNA } \\ 1 \mu \mathrm{l} & \text { Oligo dT-Anker Primer }(12.5 \mu \mathrm{M}) \\ 1.25 \mu \mathrm{l} & \text { genspezifischer Primer }(10 \mu \mathrm{M}) \\ 1 \mu \mathrm{l} & \text { dNTPs }(10 \mathrm{mM}) \\ 0.75 \mu \mathrm{l} & \text { Long Expand Enzym Mix (Taq/Pwo, 3.5 u/ } \mu \mathrm{l})) \\ 5 \mu \mathrm{l} & \text { Long Expand Puffer } 1 \\ 36 \mu \mathrm{l} & \mathrm{H}_{2} \mathrm{O}\end{array}$




\section{Amplifikation der poly-dA-markierten cDNA}

\begin{tabular}{|c|c|c|}
\hline \multirow[t]{3}{*}{10 Zyklen } & Denaturierung & $10 \mathrm{~s}$ bei $94^{\circ} \mathrm{C}$ \\
\hline & Anlagerung & $1 \mathrm{~min}$ bei $60^{\circ} \mathrm{C}$ \\
\hline & Verlängerung & $1 \mathrm{~min} / 1.5 \mathrm{~kb}$ bei $68^{\circ} \mathrm{C}$ \\
\hline \multirow[t]{4}{*}{ 20-35 Zyklen } & Denaturierung & $10 \mathrm{~s}$ bei $94^{\circ} \mathrm{C}$ \\
\hline & Anlagerung & $1 \mathrm{~min}$ bei $60^{\circ} \mathrm{C}$ \\
\hline & Verlängerung & $1 \mathrm{~min} / 1.5 \mathrm{~kb}$ bei $68^{\circ} \mathrm{C}$ \\
\hline & \multicolumn{2}{|c|}{+ Zyklusverlängerung um jeweils $20 \mathrm{~s}$ ab dem 11. Zyklus } \\
\hline Abschluß & Finale Verlängerung & $5 \mathrm{~min}$ bei $68^{\circ} \mathrm{C}$ \\
\hline
\end{tabular}

Konnten nach der 1. Amplifikation gelelektrophoretisch keine eindeutigen Produkte oder nur Produktmischungen detektiert werden, wurde mit dem verdünnten 1. PCR-Produkt (1:50) eine zweite Amplifkation (nested PCR) nach gleichem Protokoll mit einem weiter nach innen verschobenen genspezifischen Primer (nested primer) und einem Anker-Primer A2 $(\rightarrow$ 2.1.7.6.1) ohne dT-Schwanz (Roche) durchgeführt.

Das Expand Long Template Protokoll wurde ebenfalls verwendet, um den 3'-Terminus des neuen $A B C A-G e n s$ in einer Brücken-PCR zwischen dem ursprünglichen $A B C A 5$ cDNAFragment (AJ275973.1) und einer bereits vorher von ALLIKMETS et al. (1996) publizierten, 1346 bp-langen EST-Sequenz (EST96025) zu amplifizieren. Dazu wurde zunächst eine cDNA-Synthese mit dem Primer HR1 $(\rightarrow$ 2.1.7.6.2) nach obigem Protokoll vorgenommen und die resultierende cDNA nach Reinigung mit zwei genspezifischen Primern HF1 und HR1 $(\rightarrow$ 2.1.7.6) amplifiziert. Zur Erschließung der vollständigen ABCA5 cDNA-Sequenz wurden alle PCR Produkte in den PCR-XL-TOPO Vektor ligiert, in kompetenten E.coli Bakterien vermehrt und analysiert $(\rightarrow 2.2 .5 .1-2.2 .5 .4,2.2 .7)$. Die vollständige kodierende Sequenz wurde anschließend durch Zusammenfügen der überlappenden cDNA-Fragmente erstellt und mittels einer weiteren two-step RT-PCR überprüft $(\rightarrow 2.2 .6 .3)$.

\subsubsection{Two-step RT-PCR}

Zur reversen Transkription wurde die thermostabile Transkriptase Thermoscript (Invitrogen) benutzt. Zunächst erfolgte eine Denaturierung von $1 \mu \mathrm{g}$ RNA, $10 \mu \mathrm{dNTPs}(2 \mathrm{mM})$ und $1 \mu \mathrm{l}$ Primer $(10 \mu \mathrm{M})$ für $5 \mathrm{~min}$ bei $65^{\circ} \mathrm{C}$. Unter Eiskühlung wurden $4 \mu \mathrm{l}$ Synthesepuffer $(5 \mathrm{x}), 1 \mu \mathrm{l}$ Thermoscript $(15 \mathrm{u} / \mu \mathrm{l})$ und $3 \mu \mathrm{l}$ autoklaviertes Aqua bidest. hinzugegeben. Der Ansatz inkubierte für $30 \mathrm{~min}$ bei $60^{\circ} \mathrm{C}$ und $5 \mathrm{~min}$ bei $85^{\circ} \mathrm{C}$.

Die cDNA wurde in einer PCR-Reaktion mit dem High Fidelity Polymerase Mix (Invitrogen) oder mit dem Expand Long Template Mix (Roche) eingesetzt:

$\begin{array}{ll}2 \mu \mathrm{l} & \text { cDNA } \\ 1 \mu \mathrm{l} & \text { dNTPs }(10 \mathrm{mM})\end{array}$




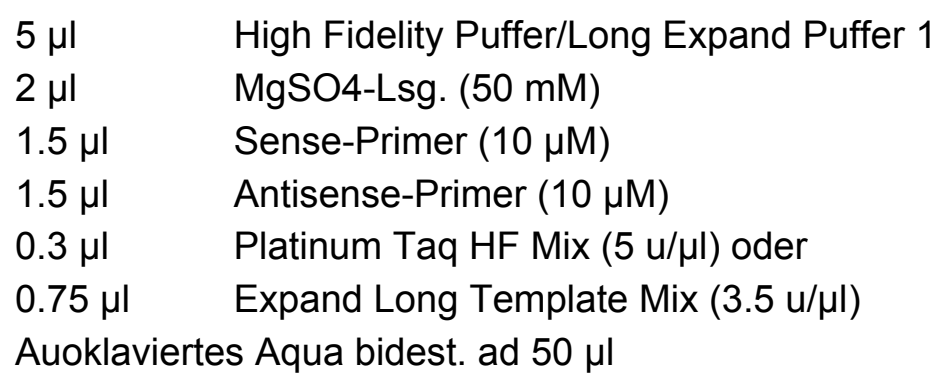

Folgendes Temperaturprotokoll wurde verwendet:

$\begin{array}{lll} & \text { Aktivierung/ Denaturierung } & 1 \mathrm{~min} \text { bei } 94^{\circ} \mathrm{C} \\ \text { 25-35 Zyklen } & \begin{array}{l}\text { Denaturierung } \\ \text { Anlagerung } \\ \end{array} & 30 \mathrm{~s} \text { bei } 94^{\circ} \mathrm{C} \\ & \text { Verlängerung } & 30 \mathrm{~s} \text { bei } 60^{\circ} \mathrm{C} \\ \text { Abschluß } & \text { Finale Verlängerung } 1 \mathrm{~min} / \mathrm{kb} \text { bei } 68^{\circ} \mathrm{C} \\ & & \text { ca. } 1 \mathrm{~min} / \mathrm{kb} \text { bei } 68^{\circ} \mathrm{C}\end{array}$

\subsubsection{Real-Time quantitative PCR (RTQ-PCR) I}

Diese Methode erlaubt es, den Verlauf einer PCR-Reaktion zu verfolgen und das gebildete Produkt relativ zu einem Standard zu quantifizieren. Nach HOLLAND et al. (1991) und LIVAK et al. (1995) benötigt man neben den üblichen Oligonukleotidprimern für die Amplifikation ein beidseitig markiertes Oligonukleotid (Taqman-Sonde) für die Detektion des gebildeten Produkts. Diese Markierung besteht hier aus dem nicht fluoreszierenden 3'-gebundenen Quencher Minor Groove Binder (MGB, Applied Biosystems) und dem fluoreszierenden 5'gebundenen 6-Carboxy-Fluorescein (FAM), das als Reporter fungiert (Abb. 2.1).

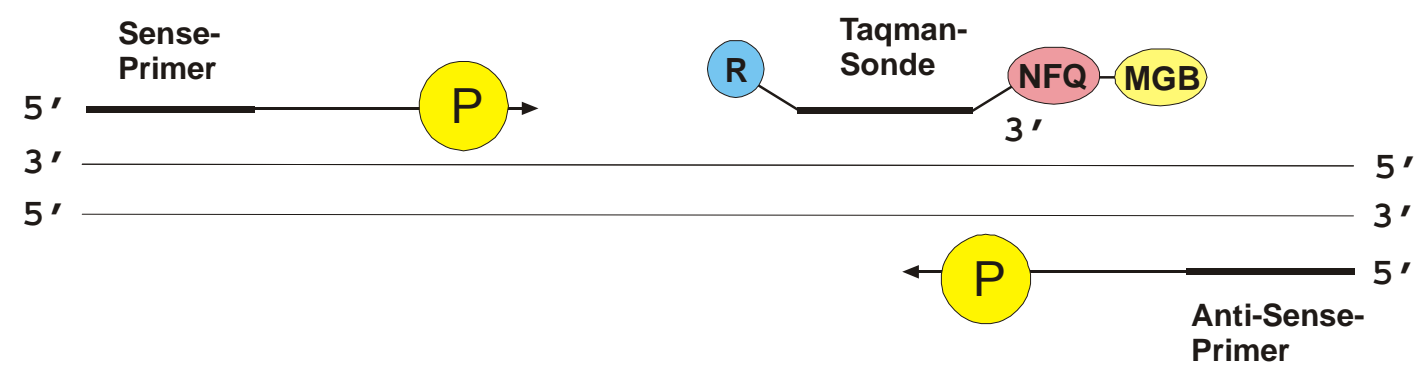

Abb. 2.1 Anlagerung der Primer und der Taqmansonde während der PCR. Die Taqmansonde kann je nach Syntheserichtung entweder mit dem Plus-Strang $\left(5^{\prime} \rightarrow\right.$ $\left.3^{\prime}\right)$ oder mit dem komplementären cDNA-Strang $\left(3^{\prime} \rightarrow 5^{\prime}\right)$ hybridisieren. Solange die Sonde intakt ist, wird durch den nicht-fluoreszierenden Quencher (NFQ) die Fluoreszenzstrahlung des Reporters $(R)$ unterdrückt. $P=$ DNA-Polymerase, MGB $=$ Minor Groove Binder (verankert die Sonde in der kleinen Furche der DNA und erlaubt eine spezifische Anlagerung trotz geringer Sondenlänge, ca. 13$17 \mathrm{bp})$. 
Wird die an die cDNA gebundene Sonde im Verlauf der DNA-Synthese durch die 5'-3'Exonukleaseaktivität der Taq-DNA-Polymerase abgespalten, wird der Reporter in zunehmendem Maß freigesetzt und entfernt sich räumlich vom Quencher. Während der PCR-Reaktion werden die freien Reportermoleküle durch regelmäßige Fluoreszenzeinstrahlung angeregt und geben ihrerseits Fluoreszenzstrahlung ab.
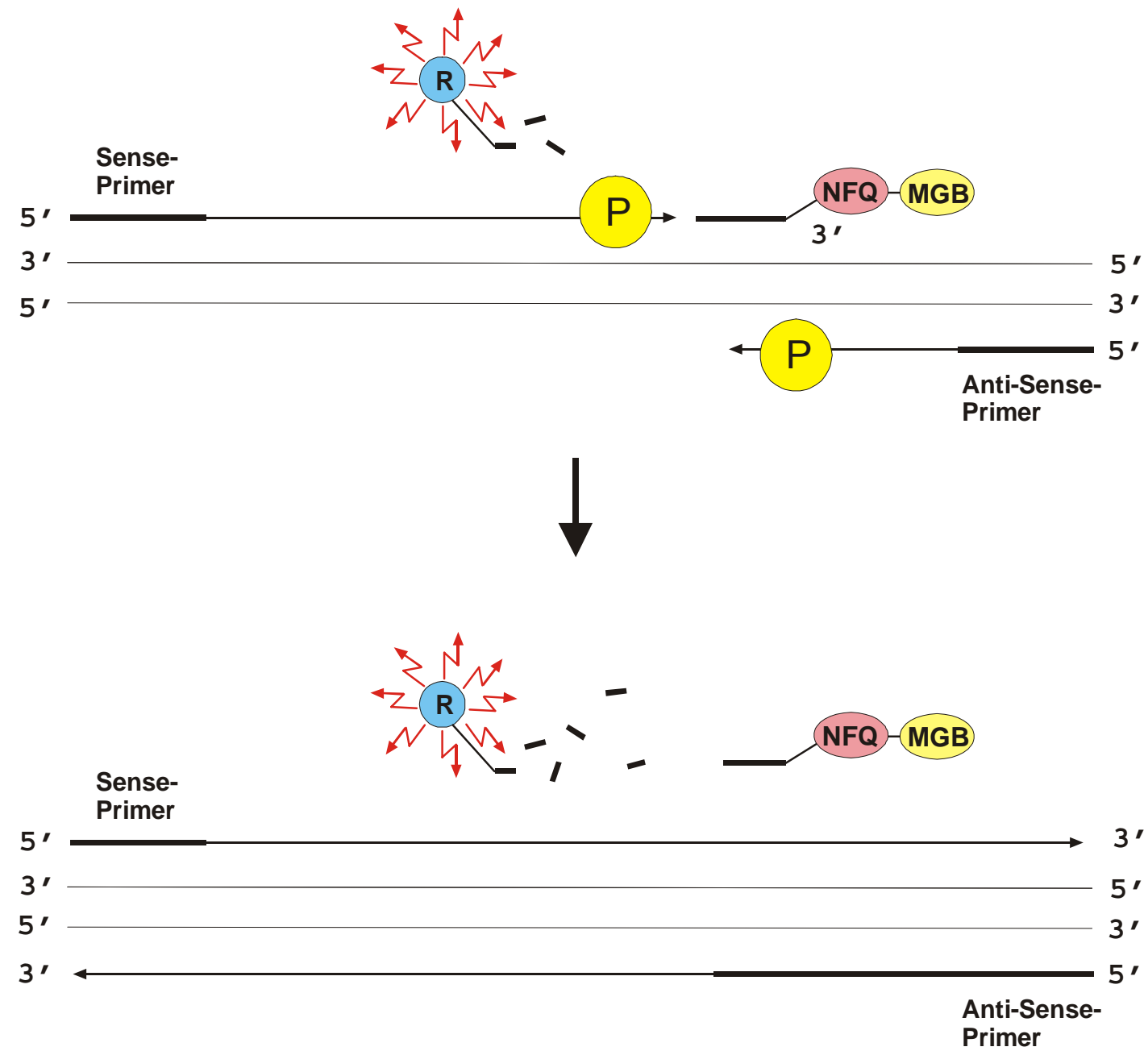

Abb. 2.2 Abspaltung der Taqmansonde und cDNA-Synthese. Die $5^{\prime} \rightarrow 3^{\prime}$-Exonukleaseaktivität der Taq-DNA-Polymerase führt zur Abspaltung der Sonde und Freisetzung des Reporters, der in räumlicher Entfernung vom Quencher bei Anregung Fluoreszenzstrahlung abgibt. Nur tatsächlich angelagerte Sondenmoleküle werden durch die Exonukleaseaktivität gespalten. Nach Abspaltung der Sonde wird die cDNAStrangsynthese fortgesetzt. Dieser Prozeß läuft in jedem PCR-Zyklus ab und interferiert nicht mit der exponentiellen Produktzunahme.

Das Ansteigen des Fluoreszenzsignals korreliert in der exponentiellen Phase der PCR direkt mit der Zunahme des PCR-Produktes. Mittels der SDS 2.1 Software (ABI) läßt sich die Zykluszahl ( $\mathrm{C}_{\mathrm{T}}$-Wert) bestimmen, bei der sich das Fluoreszenzsignal gerade deutlich vom Reaktionshintergrund abhebt. Führt man parallel zur eigentlichen Messung die gleiche Reaktion mit bekannten cDNA-Matrizenmengen durch (z.B. mit Referenzplasmiden), erhält 
man eine Standardkurve mit $\mathrm{C}_{\mathrm{T}}$-Werten, die einen Rückschluß auf die Produktmengen zulassen.

In dieser Arbeit wurde die Methode der real-time quantitative PCR benutzt, um auf mRNAEbene die relative Häufigkeit des Splicevariantengens rAbca5-V20+16 (SV) im Verhältnis zur Häufigkeit des Abca5-Transkripts der Ratte (VT) in verschiedenen Rattengeweben und einer Zellinie zu bestimmen. Da die mRNA-Sequenz des Abca5-Haupttranskripts und der Splicevariante sich nur in der 16 bp-Insertion in der mRNA der Splicevariante unterschieden, wurde ein rAbca5-cDNA-Fragment (198 bp) ausgewählt, an dessen 3'-Ende die 16 bpInsertion der Splicevariante lag, so daß das zu amplifizierende Fragment sich nur in der Zusammensetzung des Antisense-Primers unterschied, um für beide PCR-Reaktionen möglichst kinetisch identische Bedingungen zu schaffen (Primer RTQF1, RTQR1, RSVTQ R1 $\rightarrow$ 2.1.7.6.6, Abb. 2.1). Für beide PCR-Reaktionen wurde die gleiche TaqmanSonde (5'-6-FAM-TGCTGTGGTTCCCAT-MGB-3') benutzt, die im Zentrum des PCRFragments hybridisierte (Abb 2.1).

\begin{tabular}{|c|c|c|}
\hline rAbca5 & TCTGGAAGCAGCAAGTATCTACAATAGCAAAGTTTCATTTCCTCTCACTGAAGCGAGAAA & 2589 \\
\hline \multirow[t]{3}{*}{ SV } & TCTGGAAGCAGCAAGTATCTACAATAGCAAAGTTTCATTTCCTCTCACTGAAGCG $\overline{\overline{A G A A A}}$ & 2583 \\
\hline & $\begin{array}{lll}R T Q & \text { RTQ }\end{array}$ & \\
\hline & RTQ F1 & \\
\hline rAbca5 & GCAAATCAGTGCGCTCTGTGTTGCTTCTGCTTTTAATTTTTTTTGCAGTTCAGATTTTTA & 2649 \\
\hline \multirow[t]{2}{*}{ SV } & GCAAATCAGTGCGCTCT]GTGTTGCTTCTGCTTTTAATTTTTTTTGCAGTTCAGATTTTTA & 2643 \\
\hline & RTQ 1 & \\
\hline rAbca5 & TGTTTTTGGTCCATCATTCTTTTAAAAATGCTGTGGTTCCCATCAAGCTCGTTCCAGACT & 2709 \\
\hline SV & TGTTTTTGGTCCATCATTCTTTTAAAAA TGCTGTGGTTCCCATCAAGCTCGTTCCAGACT & 2703 \\
\hline rAbca5 & TGTATTTTCTAAAACCTGGAGATAAACCTCATAAATACAAAACAAGCCTGCTGCTTCAAA & 2769 \\
\hline \multirow[t]{3}{*}{ SV } & TGTATTTTCTAAAACCTGGAGATAAACCTCATAAATACAAAACAAGCCTGCTGCTTCAAA & 2763 \\
\hline & $\begin{array}{lll}\text { RTQ R1 } & \end{array}$ & \\
\hline & RTQ R1 & \\
\hline rAbca5 & ATTCTACTG - - - - - - - - - - ATTCAGATATCAATGATCTTATTGACTTTTTCACA & 2813 \\
\hline SV & $\begin{array}{l}\text { ATTCTACTGGTGAGAGCGTGTGAAGATTCAGATATCAATGATCTTATTGACTTTTTCACA } \\
\text { SVRTQ R1 }\end{array}$ & 2823 \\
\hline
\end{tabular}

Abb. 2.3 PCR-Bereich der real-time quantitative PCR auf rAbca5 (Genbank Accession No. AJ426052) und rAbca5 V+16 (AJ550165).

Die Primer und die Taqmansonde $(\rightarrow 2.1 .7 .6)$ wurden durch Positionsrahmen gekennzeichnet. Die PCR für rAbca5 wurde mit RTQ F1 und RTQ R1, die PCR für rAbca5 V+16 wurde mit RTQ F1 und SVRTQ R1 ausgeführt $(\rightarrow$ 2.2.6.4.2).

\subsection{Reverse Transkription der RNA-Proben}

Folgender Reaktionsansatz wurde nach 10-minütiger Denaturierung von RNA und Primer bei $70{ }^{\circ} \mathrm{C}$ für $1 \mathrm{~h}$ bei $42^{\circ} \mathrm{C}$ inkubiert:

$\begin{array}{ll}1 \mu \mathrm{g} & \text { Gesamt RNA auf } 12.5 \mu \mathrm{l} \text { mit autoklaviertem Aqua bidest. verdünnen } \\ 1 \mu \mathrm{l} & \text { Random Hexamer Primer (dN6) } \\ 6 \mu \mathrm{l} & \text { Superscript RT Puffer }(5 \mathrm{x}) \\ 3.5 \mu \mathrm{l} & \text { DTT }(0.1 \mathrm{M})\end{array}$




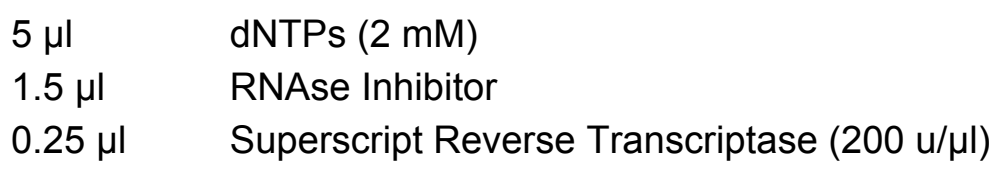

Die auf $10 \mathrm{ng} / \mu \mathrm{l}$ eingestellte cDNA-Lösung wurde bei $-80^{\circ} \mathrm{C}$ gelagert.

\subsection{Real-time quantitative PCR (RTQ-PCR) II}

Mit je einem Referenzplasmid für das rAbca5-Haupttranskript (VT) und das Splicevariantentranskript (SV) wurde eine 5-stufige Verdünnungsreihe erstellt, die als Standardkurve zur quantitativen Bestimmung der in den Proben gemessenen cDNA-Transkripte dienen sollte. Die Referenzplasmide enthielten den gesamten Leserahmen des rAbca5-Gens bzw. des rAbca5 V+16-Transkripts im pcDNA3.1/V5-His-TOPO-Vektor und wurden durch eine TOPOLigation von PCR-Produkten mit anschließender Vermehrung in elektrokompetenten $E$. coli Bakterien erhalten $(\rightarrow 2.2 .5)$.

\section{Rechenbeispiel für VT-Referenzplasmid}

Das verwendete VT-Referenzplasmid bestand aus 10463 bp (rAbca5-Insert + Vektor-DNA). Pro Basenpaar wurde ein genähertes Molgewicht von $660 \mathrm{~g} / \mathrm{mol}$ verwendet.

Daraus ergab sich für das gesamte Plasmid ein Molgewicht von

$$
10463 \times 660 \mathrm{~g} / \mathrm{mol}=6.906 \times 10^{6} \mathrm{~g} / \mathrm{mol}
$$

bzw. In 1 ng cDNA befanden sich

$$
1.448 \times 10^{-16} \times 6.022 \times 10^{23}=8.72 \times 10^{7} \text { cDNA-Moleküle. }
$$

oder Die Molekülzahl der ersten Verdünnungsstufe von $4.48 \times 10^{5}$ cDNA-Molekülen befand sich in $0.00514 \mathrm{ng}=5.14 \mathrm{pg}$ cDNA.

Die cDNA des VT-Referenzplasmids besaß eine Ausgangskonzentration von $2.1 \mu \mathrm{g} / \mu \mathrm{l}$ und wurde $1: 10000$ verdünnt $(c=0.21 \mathrm{ng} / \mu \mathrm{l})$. Von dieser Verdünnung wurden $1.22 \mu \mathrm{l}$ (=0.257 ng) mit autoklaviertem Aqua bidest. auf $500 \mu \mathrm{l}$ verdünnt. Damit enthielten $10 \mu \mathrm{l}$ dieser cDNA-Lösung 5.14 pg cDNA (= $4.48 \times 10^{5}$ cDNA-Moleküle). Ausgehend von dieser Stammlösung wurden vier weitere 1:5-Verdünnungen hergestellt $\left(8.96 \times 10^{4}, 17920,3584\right.$ und 717 cDNA-Moleküle/10 $\mu \mathrm{l}$ cDNA-Lösung). Folgender Reaktionsansatz wurde zur Erstellung der Standardkurve pro Probe in Doppelbestimmung angesetzt:

$\begin{array}{ll}10 \mu \mathrm{l} & \text { Plasmid DNA (für } 5 \text { Verdünnungsstufen, s.o.) } \\ 15 \mu \mathrm{l} & \text { Eurogentec Mastermix } 2 x \text { (Puffer, } \mathrm{MgCl}_{2} \text {, dNTPs, Enzym) } \\ 1 \mu \mathrm{l} & \text { Sense-Primer }(22.5 \mu \mathrm{M}) \\ 1 \mu \mathrm{l} & \text { Antisense-Primer }(22.5 \mu \mathrm{M}) \\ 1.5 \mu \mathrm{l} & \text { Taqman-Sonde }(5 \mu \mathrm{M}) \\ 1.5 \mu \mathrm{l} & \text { autoklaviertes Aqua bidest. }\end{array}$


und mit folgendem Temperaturprotokoll vermessen:

$\begin{array}{ll}\text { Start } & 2 \mathrm{~min} \text { bei } 50{ }^{\circ} \mathrm{C} \\ \text { Denaturierung } & 10 \mathrm{~min} \text { bei } 95^{\circ} \mathrm{C} \\ \text { Denaturierung } & 15 \mathrm{~s} \text { bei } 95^{\circ} \mathrm{C} \\ \text { Anlagerung und Verlängerung } & 1 \mathrm{~min} \text { bei } 60^{\circ} \mathrm{C}\end{array}$

Die cDNA-Proben der Ratte (40 ng) wurden in einem Gesamtvolumen von $30 \mu \mathrm{lmit}$ dem gleichen Temperaturprotokoll vermessen. Für alle Proben wurden Dreifachbestimmungen durchgeführt, aus denen der Mittelwert errechnet wurde. Zur Normalisierung der Proben wurde der 18S-RNA-Gehalt der Proben in unabhängigen PCR-Reaktionen mit Hilfe einer weiteren Standardkurve (s.o.) bestimmt. Die Auswertung erfolgte mit der SDS 2.1 Software und ergab den relativen Anteil der SV-Genexpression in Bezug auf die Expression des VT.

\subsubsection{Kolonie-PCR}

Diese PCR wurde an frisch von der LB-Agarplatte gepickten E. coli Kolonien als alternative Methode der Plasmid-DNA-Charakterisierung zur Minipräparation mit anschließender Restriktionsanalyse durchgeführt. Es wurden Amplifikate zwischen $500 \mathrm{bp}$ und $1 \mathrm{~kb}$ mit insertspezifischen Primern ausgewählt. Für $100 \mu \mathrm{l}$ Mastermix (5 Kolonien à $20 \mu \mathrm{l}$ pro Reaktion) wurde folgender Reaktionsansatz hergestellt:

$\begin{array}{ll}10 \mu \mathrm{l} & \text { Taq Puffer }(10 \mathrm{x}) \\ 2 \mu \mathrm{l} & \text { dNTPs }(10 \mathrm{mM}) \\ 1 \mu \mathrm{l} & \text { Sense-Primer }(100 \mu \mathrm{M}) \\ 1 \mu \mathrm{l} & \text { Antisense-Primer }(100 \mu \mathrm{M}) \\ 1 \mu \mathrm{l} & \text { Taq DNA-Polymerase } \\ 85 \mu \mathrm{l} & \text { autoklaviertes Aqua bidest. }\end{array}$

Nach Vorlegen des Mastermix' wurden die Kolonien mit sterilen Pipettenspitzen von der Agarplatte abgehoben und unter kräftigem Auf- und Abpipettieren in das PCRReaktionsgefäß $(0.2 \mathrm{ml})$ gegeben. Das Temperaturprofil erforderte eine längere Denaturierungsphase, um die Plasmid-DNA in den Bakterien einer Amplifikation zugänglich zu machen.

Initiale Denaturierung der Plasmid-DNA

30 Zyklen zur

Abschluß
Denaturierung

Anlagerung

Verlängerung

Finale Verlängerung
$5 \min$ bei $95^{\circ} \mathrm{C}$

$30 \mathrm{~s}$ bei $96^{\circ} \mathrm{C}$

$30 \mathrm{~s}$ bei $60^{\circ} \mathrm{C}$

$1 \mathrm{~min} / \mathrm{kb}$ bei $72{ }^{\circ} \mathrm{C}$

$5 \min$ bei $72{ }^{\circ} \mathrm{C}$ 


\subsubsection{Sequenzanalyse}

Sequenzierungen wurden entweder als Auftragsarbeiten bei der Firma Seqlab (Göttingen) oder in der Abteilung Klinische Pharmakologie selbst durchgeführt. Die auf dem KettenAbbruch-Verfahren basierende Sequenzierreaktion von SANGER et al. (1975) verwendete fluoreszenzmarkierte Didesoxynukleosid-5'-Triphosphate (ddNTPs) zur Erzeugung einer statistischen Mischung von synthetisierten DNA-Fragmenten. Für die PCR-Amplifikation wurden DNA-Mengen zwischen $200 \mathrm{ng}$ und $500 \mathrm{ng}$ pro $10 \mu \mathrm{l}$-Ansatz zusammen mit $1 \mu \mathrm{l}$ des entsprechenden Sequenzier-Primers $(10 \mu \mathrm{M})$ und $2 \mu \mathrm{l}$ BigDye-Mix (ddNTPs, DNAPolymerase, $\mathrm{MgCl}_{2}$ und Puffer) verwendet:

Start: 24 Zyklen:
Initiale Denaturierung

Denaturierung

Anlagerung

Kettenverlängerung

Abschluß:

Finale Kettenverlängerung
$2 \min$ bei $94{ }^{\circ} \mathrm{C}$

$15 \mathrm{~s}$ bei $96^{\circ} \mathrm{C}$

$15 \mathrm{~s}$ bei $56.5^{\circ} \mathrm{C}$

$4 \mathrm{~min}$ bei $60^{\circ} \mathrm{C}$

$4 \min$ bei $60^{\circ} \mathrm{C}$

Nach einer Sephadex-Filtration (Sephadex G-50 superfine, Amersham) wurde mit den erhaltenen Produkten das Standard-Leseweitenprogramm (700 bp) auf dem automatischen Sequenzierer 3100 Genetic Analyzer (ABI) gestartet. Die Auswertung der Sequenzdateien (.abi) erfolgte mit den PC-Software-Produkten Sequencing Analysis (PerkinElmer), Chromas (Technelysium), Staden Package und ClustalW (EBI). Vergleiche mit den Sequenzdatenbanken EMBL und Genbank wurden mit Hilfe des Blast-Programms (ALTSCHUL et al. 1998 ) über den Webserver www.ncbi.nlm.nih am NIH (USA) oder über den Fasta3-Server www.ebi.ac.uk am EBI (Cambridge, GB) vorgenommen. Zur Bestätigung neuer Sequenzen wurden mindestens zwei identische cDNA-Klone oder ein direkt sequenziertes PCR-Produkt benötigt.

\subsubsection{Agarose-Gelelektrophorese}

\subsubsection{DNA-Gelelektrophorese}

\begin{tabular}{|c|c|c|}
\hline TBE-Puffer 10x (pH 8.3) & $1 \mathrm{M}$ & Borsäure \\
\hline & $1 \mathrm{M}$ & Tris- $\mathrm{HCl}$ \\
\hline & $200 \mathrm{mM}$ & EDTA \\
\hline Tris-Acetat-Puffer 10x (pH 7.2) & $400 \mathrm{mM}$ & Tris \\
\hline & $200 \mathrm{mM}$ & Natriumacetat \\
\hline & $10 \mathrm{mM}$ & EDTA \\
\hline DNA-Auftragspuffer 6x & $60 \%(v / v)$ & 10x Tris-Acetat-Puffer $\mathrm{pH} 7.2$ \\
\hline & $30 \%(v / v)$ & Glycerin \\
\hline
\end{tabular}




$$
\begin{array}{ll}
0.15 \%(\mathrm{w} / \mathrm{v}) & \text { Bromphenolblau } \\
0.15 \%(\mathrm{w} / \mathrm{v}) & \text { Xylencyanol } \\
10 \%(\mathrm{v} / \mathrm{v}) & \text { Aqua bidest. }
\end{array}
$$

Mit dieser Methode wurden analytische DNA-Mengen $(\leq 1 \mu \mathrm{g})$ nach PCR-Reaktionen oder Restriktionsverdau und präparative DNA-Mengen $(\leq 10 \mu \mathrm{g})$ zum Zweck der Insertisolierung aufgetrennt. Je nach Größe der zu trennenden Fragmente wurden 0.7-2\%-ige Agarosegele in 1x TBE-Puffer hergestellt. Dazu wurde die entsprechende Agarosemenge in der Hälfte des benötigten Puffers durch Erhitzen bis zur Siedetemperatur gelöst und nach Abkühlen mit dem verbleibenden Puffer mit $5 \mu$ l Ethidiumbromid $(10 \mathrm{mg} / \mathrm{ml})$ versetzt. Dieser Gelmix wurde zur Polymerisation zügig und blasenfrei in den Gelträger $(14 \times 11 \times 0.7 \mathrm{~cm})$ gegossen. Nach 30-60 min bei RT konnte das Gel benutzt werden. In der Gelkammer wurde es mit 1x TBEPuffer überschichtet. Die DNA-Proben wurden mit 5-10 $\mu \mathrm{l}$ Auftragspuffer vermischt, aufgetragen und bei 45-100 mA getrennt. Auf einem UV-Durchlichttisch (302 nm) konnten die durch Interkalation von Ethidiumbromid sichtbar gemachten DNA-Banden fotografisch dokumentiert und ggf. mit dem Skalpell isoliert $(\rightarrow 2.2 .4)$ werden. Die Größenbestimmung der DNA-Fragmente erfolgte durch den Vergleich mit einer DNA-Standard-Leiter $(\rightarrow$ 2.1.7.9).

\subsubsection{Denaturierende RNA-Gelelektrophorese}

\subsection{Gelherstellung}

MOPS-Puffer (10x, pH 7.4):

$\begin{array}{ll}0.2 \mathrm{M} & \text { MOPS } \\ 50 \mathrm{mM} & \text { Natriumacetat } \\ 10 \mathrm{mM} & \text { EDTA }\end{array}$

Der Puffer wurde nach Einstellen des pH-Wertes autoklaviert. Die Gebrauchslösung wurde durch Verdünnen der Stammlösung mit autoklaviertem Aqua bidest. hergestellt.

Für die RNA-Analytik wurden $1 \%$-ige Agarosegele eingesetzt. In einem autoklavierten Gefäß wurde $1 \mathrm{~g}$ Agarose in $90 \mathrm{ml}$ 3-(N-Morpholino)-propansulfonsäure (MOPS)-Puffer durch Aufkochen vollständig gelöst. Nach Abkühlen der Lösung auf ca. $50{ }^{\circ} \mathrm{C}$ wurden $10 \mathrm{ml}$ $37 \%$-ige Formaldehydlösung zugegeben und das Gel $(14 \times 11 \times 0.7 \mathrm{~cm})$ nach Einsetzen der Kämme luftblasenfrei gegossen. Gelkammer und Kämme waren vorher zur Inaktivierung von RNase 30 Minuten in einer $50 \mathrm{mM} \mathrm{NaOH}$-Lösung inkubiert worden.

\subsection{Probenvorbereitung}

Blaupuffer:
$5 \mathrm{mM}$
$\mathrm{Na}_{2} \mathrm{HPO}_{4}$
$0.45 \%$
Bromphenolblau (w/v)
$13.7 \mathrm{mM}$
Glycerin 
Formamid-Mix:

$16.5 \mathrm{M}$

Formamid (deionisiert)

$13.2 \%$

MOPS (10x, v/v)

$2.7 \mathrm{M}$

Formaldehyd $(37 \%)$

Zur Deionisierung von Formamid wurden $50 \mathrm{ml}$ Formamid unter sterilen Bedingungen für $30 \mathrm{~min}$ mit $5 \mathrm{~g}$ Serdolit MB-1-lonenaustauscherharz gerührt und anschließend das Austauscherharz durch einen Faltenfilter abfiltriert. Die Lösung wurde aliquotiert und bei $-20{ }^{\circ} \mathrm{C}$ gelagert. Der fertige Probenpuffer konnte etwa 2-3 Wochen bei $4{ }^{\circ} \mathrm{C}$ aufbewahrt werden. Der verwendete Probenpuffer setzte sich aus Blaupuffer, Formamidmix und Ethidiumbromidlösung (10 $\mathrm{mg} / \mathrm{ml})$ in Volumenanteilen 50:250:1 zusammen.

Die RNA-haltigen Lösungen wurden zunächst auf Eis aufgetaut. Pro Bahn wurden 20-25 $\mu \mathrm{g}$ Gesamt-RNA eingesetzt und mit Aqua bidest auf ein einheitliches Volumen gebracht. Anschließend wurden jeder Probe $20 \mu$ l Probenpuffer zugesetzt, die Ansätze bei $65^{\circ} \mathrm{C}$ für 10 min denaturiert, sofort auf Eis abgekühlt, kurz zentrifugiert und auf das Gel aufgetragen.

\subsection{RNA-Elektrophorese}

Das auspolymerisierte Agarosegel wurde auf dem Gelträger fixiert und in die Elektrophoresekammer eingehängt. Nach Überschichtung mit 1x MOPS-Puffer wurden die Kämme vorsichtig entfernt. Zur Dichtigkeitsüberprüfung der Geltaschen belud man diese vor dem Auftragen der Proben mit je $2 \mu$ l Probenpuffer. Zum Einlaufen der Proben ins Gel wurde eine Stromstärke von $10 \mathrm{~mA}$ für 30-60 min angelegt. Die elektrophoretische Auftrennung erfolgte bei einer konstanten Stromstärke von 40-45 mA unter Umwälzung des Elektrophoresepuffers. Im Anschluß wurde die gleichmäßige Beladung der Bahnen mittels UV-Durchlicht überprüft und fotografisch dokumentiert. Das in die RNA interkalierende Ethidiumbromid ermöglicht es, die rRNA-Banden unter UV-Licht sichtbar zu machen. Die $18 \mathrm{~S}$ und $28 \mathrm{~S}$ rRNA Banden (1.9 kb bzw. $4.8 \mathrm{~kb}$ in der Ratte) dienten als interner Molekulargewichtsstandard.

\subsubsection{Transfer von Nukleinsäuren}

\subsubsection{RNA-Transfer auf Nylon-Membranen}

$\begin{array}{lll}\text { SSC (20x, pH 7.0): } & 3 \mathrm{M} & \mathrm{NaCl} \\ & 0.3 \mathrm{M} & \text { Trinatriumcitrat }\end{array}$

Der Puffer wurde vor Gebrauch autoklaviert.

Der Transfer von RNA aus dem Agarosegel auf eine Nylon-Membran (Northern Blotting) erfolgte in Anlehnung an eine von SOUTHERN (1975) beschriebene, auf Kapillarkräften beruhende Methode. Die verwendete Nylon-Membran (Porengröße $0.45 \mu \mathrm{m}$ ) wurde vor dem 
Transfer mit sterilem Aqua bidest. benetzt und wie die Filterpapiere für 5 min in $5 \times$ SSC

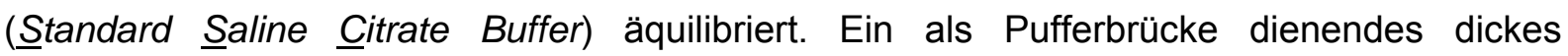
Filterpapier (Nr. 2668) wurde auf einer erhöhten Glasplatte so plaziert, daß beide Enden gleichmäßig in das darunter liegende mit 20x SSC gefüllte Pufferreservoir hineinragten. Auf der Pufferbrücke wurden von unten nach oben ein dickes Filterpapier, ein dünnes Filterpapier (Nr. 2043), das Gel mit den Taschen nach unten zeigend, die Membran, ein dünnes und wieder ein dickes Filterpapier (jeweils in der Größe des Gels) luftblasenfrei aufeinander geschichtet. Das Pufferreservoir wurde mit Parafilm abgedichtet und der Aufbau mit einer Lage von 10-15 cm saugfähigen Zellstofftüchern (Kleenex) überschichtet und mit ca. $10 \mathrm{~N}$ beschwert. Die Transferzeit betrug 16-24 h. Im Anschluß an den Transfer wurde jede Seite der Nylon-Membran mit 0.120 mJ UV-Licht bestrahlt, um die RNA stabil auf der Membran zu fixieren. Die Vollständigkeit des Transfers wurde durch Betrachtung des Gels und der Membran auf dem UV-Durchlichttisch überprüft und fotografisch dokumentiert. Die Membran wurde vor dem Trocknen bzw. der direkten Prähybridisierung zweimal mit $95{ }^{\circ} \mathrm{C}$ heißer $0.05 \%$-iger SDS-Lösung und ein- bis zweimal in heißem Aqua bidest. gewaschen, um Bromphenolblau, Ethidiumbromid und Salze zu entfernen.

\subsubsection{Radioaktive Hybridisierung von RNA an Northern Blots}

\subsubsection{Hybridisierung mit ${ }^{32}$ Phosphor-markierten Sonden}

\begin{tabular}{|c|c|c|}
\hline Denhardts-Lösung (100x): & $2 \%(w / v)$ & Ficoll (MW 400000) \\
\hline & $2 \%(w / v)$ & Polyvinylpyrrolidon \\
\hline & $2 \%(w / v)$ & Rinderserumalbumin \\
\hline Prähybridisierungslösung: & $0.9 \mathrm{M}$ & $\mathrm{NaCl}$ \\
\hline & $0.09 \mathrm{M}$ & Trinatriumcitrat \\
\hline & $12.5 \mathrm{M}$ & Formamid (deionisiert) \\
\hline & $17 \mathrm{mM}$ & SDS \\
\hline & $5 \%(v / v)$ & Denhardts-Lösung (100x) \\
\hline & $400 \mu \mathrm{g} / \mathrm{ml}$ & Heringssperma-DNA \\
\hline Waschpuffer 2x SSC & $300 \mathrm{mM}$ & $\mathrm{NaCl}$ \\
\hline & $30 \mathrm{mM}$ & Trinatriumcitrat \\
\hline & $0.1 \%$ & SDS \\
\hline Waschpuffer 1 x SSC & $150 \mathrm{mM}$ & $\mathrm{NaCl}$ \\
\hline & $15 \mathrm{mM}$ & Trinatriumcitrat \\
\hline & $0.1 \%$ & SDS \\
\hline Waschpuffer 0.1 x SSC & $15 \mathrm{mM}$ & $\mathrm{NaCl}$ \\
\hline & $1.5 \mathrm{mM}$ & Trinatriumcitrat \\
\hline & $0.1 \%$ & SDS \\
\hline
\end{tabular}


Denhardts-Lösung wurde nach dem Ansetzen in Aqua bidest. durch $5 \mu \mathrm{m}$ und $0,45 \mu \mathrm{m}$ Vorsatzfilter sterilfiltriert. Heringssperma-DNA $(10 \mathrm{mg} / \mathrm{ml})$ wurde vor Gebrauch mit Ultraschall behandelt, um DNA-Fragmente einer Größe von ca. $500-700 \mathrm{~kb}$ zu erhalten, aliquotiert und anschließend bei $-20{ }^{\circ} \mathrm{C}$ gelagert. Direkt vor der Verwendung wurde die HeringsspermaDNA durch 5-minütiges Erhitzen in siedendem Wasser und sofortiges Abkühlen auf Eis denaturiert.

Zur Absättigung freier Bindungsstellen wurden die Membranen für 2-3 Stunden bei $38^{\circ} \mathrm{C}$ im Hybridisierungsofen mit Prähybridisierungslösung inkubiert. Zur Einleitung der Hybridisierung wurden die Markierungsansätze $(\rightarrow$ 2.2.3.5) zur Prähybridisierungslösung pipettiert. Die Hybridisierung wurde für $16-24 \mathrm{~h}$ bei $38^{\circ} \mathrm{C}$ vorgenommen. Nach Beendigung der Hybridisierung wurden die Membranen zur Entfernung unspezifisch gebundener Oligonukleotide unter zunehmender Temperatur $\left(37-55 \mathrm{C}^{\circ}\right)$ und abnehmender lonenkonzentration des Waschpuffers (2x SSC/0.1\% SDS (w/v), 1 x SSC / $0.1 \%$ SDS (w/v), $0.1 \times$ SSC / $0.1 \%$ SDS (w/v) je 5 min unter Schütteln gewaschen. Waschtemperatur und Ionenkozentration waren von der verwendeten Sonde abhängig. Nach jedem Waschschritt wurde die verbliebene Aktivität mit einem Flächenzähler gemessen. Beim Erreichen einer konstanten Aktivität wurde die Waschprozedur abgebrochen und die Membranen feucht in Klarsichtfolie eingeschweißt. Zur Quantifizierung der gebundenen Radioaktivität wurde ein Bio-Imaging-Analyzer, BAS 1500, verwendet. Hierzu wurden $\left[{ }^{32} \mathrm{P}\right]-$ sensitive Nachweisplatten für 3-72 h der Stahlenexposition durch die hybridisierte Membran ausgesetzt. Mit der Software BAS-Reader konnten die einzelnen Signale ausgewertet werden. Anschließend wurden die Membranen zur autoradiographischen Darstellung mit aufgelegten Röntgenfilmen in einer Kassette mit Verstärkerfolien bis zu 3 Wochen bei $-80{ }^{\circ} \mathrm{C}$ gelagert. Anschließend wurden die Filme entwickelt.

\subsubsection{Nicht-radioaktive Hybridisierung - In situ Hybridisierung}

In situ cRNA/mRNA-Hybridisierungen an Gewebeschnitten wurden vorgenommen, um die zellspezifische Verteilung von mRNA-Transkripten zu untersuchen. Die im folgenden beschriebenen Protokolle wurden in der Abteilung Pathologie (Dr. P. Middel), Universität Göttingen, erlernt und durchgeführt. Die Herstellung der Paraffinschnitte wurde von Mitarbeiterinnen der Abteilung Pathologie übernommen.

\subsubsection{Herstellung von Paraffinschnitten}

Das frisch präparierte Organmaterial wurde ü.N. in einer 4\% Paraformaldehydlösung fixiert und durch eine aufsteigende Ethanolreihe in 70\%, 90\% und 100\% Ethanol dehydratisiert. Zur vollständigen Entfernung des Alkohols wurde das Gewebe in Xylol und anschließend $2 \mathrm{~h}$ in flüssigem Paraffin (ca. $60^{\circ} \mathrm{C}$ ) inkubiert. Alle diese Schritte wurden automatisiert in einer Einbettungsstation durchgeführt. Das Organblöckchen wurde in eine Ausgießstation eingebracht und härtete in wenigen Minuten aus. Das abgekühlte Material wurde in einem 
Mikrotom auf 0-2 $\mu \mathrm{m}$ geschnitten und auf Objektträger überführt. Paraffinblöcke und Schnitte wurden bei RT gelagert.

\subsubsection{Vorbehandlung und Hybridisierung}

Die Gewebeschnitte wurden zunächst $2 \times 10$ min bei RT in Xylol deparaffiniert und durch eine absteigende Ethanolreihe in DEPC- $\mathrm{H}_{2} \mathrm{O}$ (je $1 \mathrm{~min}$ in $100 \%, 90 \%$ und $70 \%$ ) rehydratisiert. Nach zwei Waschschritten (je $5 \mathrm{~min}$ ) in PBS wurden die Schnitte zum Blocken der endogenen Peroxidase für 10 min in $3 \%$-iger $\mathrm{H}_{2} \mathrm{O}_{2}$-Lösung in DEPC- $\mathrm{H}_{2} \mathrm{O}$ inkubiert. Darauf folgten zwei Waschschritte (je $5 \mathrm{~min}$ ) in DEPC- $\mathrm{H}_{2} \mathrm{O}$ und eine Behandlung mit $100 \mu \mathrm{l} / \mathrm{Schnitt}$ Proteinase K (1 Tropfen auf $1 \mathrm{ml}$ PBS), um die durch Gewebe und Proteine maskierte RNA für die Hybridisierung mit der DIG-RNA-Sonde zugänglich zu machen. Diese Reaktion wurde nach 5 min abgestoppt, die Schnitte 5 min in PBS gespült und zur Neutralisierung positiver Ladungen eine Acetylierungsreaktion angeschlossen. Dazu wurden die Schnitte für 10 min in $0.1 \mathrm{M}$ Tris-HCl-Puffer ( $\mathrm{pH}$ 8.0) mit 0.25\% Essigsäureanhydrid inkubiert. Zwei Waschschritte (je $5 \mathrm{~min}$ ) in PBS beendeten diese Reaktion. Nach einer Dehydratisierung durch eine aufsteigende Ethanolreihe in DEPC $-\mathrm{H}_{2} \mathrm{O}$ (je $1 \mathrm{~min}$ in $70 \%, 90 \%$ und $100 \%$ ) wurden die Schnitte für 20 min bei RT vor Staub geschützt getrocknet. Währenddessen wurde die Lachssperma-DNA, die zur Absättigung unspezifischer Bindungen während der Hybridisierung dient, bei $95^{\circ} \mathrm{C}$ für 10 min denaturiert, kurz auf Eis gekühlt und zum Hybridisierungspuffer gegeben (100 $\mu \mathrm{l}$ Puffer/Schnitt, davon 10\% Lachssperma-DNA). Die markierte Sonde (1:50 aus der Stammlösung, $\rightarrow 2$.2.3.4) wurde zum Puffer pipettiert und die Hybridisierungsansätze 5 min bei $55^{\circ} \mathrm{C}$ inkubiert. In jedem Experiment wurde eine separate Probe mit der Sense-cRNA-Sonde als Negativkontrolle hybridisiert. Die Hybridisierungsösung wurde blasenfrei auf den Schnitt pipettiert und mit einem sterilen Deckglas abgedeckt. Der Objektträger wurde zur Denaturierung von Sonde und RNA 5 min bei $85^{\circ} \mathrm{C}$ auf eine Heizplatte gelegt und anschließend in einer feuchten Kammer ü.N. bei $55^{\circ} \mathrm{C}$ inkubiert. Zur Minimierung unspezifischer Bindungen war diese Kammer zuvor außerdem mit deionisiertem Formamid/ DEPC- $\mathrm{H}_{2} \mathrm{O}$ (50/50) so gefüllt worden, daß der Boden bedeckt war. Zur Vorbereitung der Waschschritte am Folgetag, wurden $200 \mathrm{ml}$ deionisiertes Formamid/ DEPC- $\mathrm{H}_{2} \mathrm{O}$ (50/50), $150 \mathrm{ml}$ DEPC- $\mathrm{H}_{2} \mathrm{O}, 2$ Küvetten und ein Standzylinder (250ml) ü.N. bei Hybridisierungstemperatur angewärmt.

\subsubsection{Waschschritte und Antikörper-Inkubation}

\begin{tabular}{|c|c|c|}
\hline Waschpuffer 1 (1x SSC, 1\% SDS) & $\begin{array}{l}150 \mathrm{mM} \\
15 \mathrm{mM} \\
1 \%\end{array}$ & $\begin{array}{l}\mathrm{NaCl} \\
\text { Trinatriumcitrat } \\
\text { SDS }\end{array}$ \\
\hline Waschpuffer 2 (0.2x SSC, $2 \%$ SDS) & $30 \mathrm{mM}$ & $\mathrm{NaCl}$ \\
\hline In einer 50/50-Mischung aus & $3 \mathrm{mM}$ & SDS \\
\hline deionisiertem Formamid/DEPC- $\mathrm{H}_{2} \mathrm{O}$ & $2 \%$ & SDS \\
\hline
\end{tabular}


Die Waschpuffer wurden vor Beenden der Hybridisierung frisch angesetzt. Alle Waschschritte erfolgten unter Schütteln.

TBST-Puffer 10x (pH 7.4)

$\begin{array}{ll}50 \mathrm{mM} & \text { Tris- } \mathrm{HCl} \\ 150 \mathrm{mM} & \mathrm{NaCl} \\ 0.1 \% & \text { Tween 20 }\end{array}$

Blockierungspuffer ( $\mathrm{pH} 7.5)$
$0.1 \mathrm{M}$
Tris- $\mathrm{HCl}$
$0.15 \mathrm{M}$
$\mathrm{NaCl}$
$0.5 \%$
TNB-Blockierungsreagenz

Das Blockierungsreagenz wurde zum erwärmten Puffer gegeben (ca. $60{ }^{\circ} \mathrm{C}$ ) und mehrere Stunden unter Rühren gelöst.

Stoppuffer (pH 8.0)

$\begin{array}{ll}20 \mathrm{mM} & \text { Tris } \\ 5 \mathrm{mM} & \text { EDTA }\end{array}$

Meyers Hämalaun

$\begin{array}{ll}0.1 \%(\mathrm{w} / \mathrm{v}) & \text { Hämatoxylin } \\ 105 \mathrm{mM} & \mathrm{K} \mathrm{Al}\left(\mathrm{SO}_{4}\right)_{2} 12 \mathrm{H}_{2} \mathrm{O} \\ 1 \mathrm{mM} & \mathrm{Na}\left(\mathrm{IO}_{3}\right) \\ 3 \%(\mathrm{w} / \mathrm{v}) & \text { Chloralhydrat } \\ 0.1 \%(\mathrm{w} / \mathrm{v}) & \text { Zitronensäure }\end{array}$

Am ersten Tag wurden die ersten drei Komponenten in Aqua bidest. gelöst. Am zweiten Tag wurden die verbleibenden Komponenten hinzugefügt und der Puffer zum Sieden erhitzt.

Die Schnitte wurden einzeln in WP 1 geschwenkt, bis die Deckgläser von selbst abschwammen und in frischem WP 1 zweimal je 5 min bei RT gewaschen. Anschließend folgten 3 Waschschritte (je $20 \mathrm{~min}$ ) bei Hybridisierungstemperatur mit WP 2 (GFL 1083 Wasserschüttler). Die Schnitte wurden unter Schütteln auf RT abgekühlt und 2x 10 min in TBST-Puffer gewaschen. Zur Reduzierung des Reaktionshintergrunds wurden die Schnitte bei RT 30 min in Blockierungspuffer inkubiert (100 $\mu \mathrm{l} / \mathrm{Schnitt,} \mathrm{trockene} \mathrm{Kammer).} \mathrm{In} \mathrm{einer}$ feuchten Kammer (DEPC- $\left.\mathrm{H}_{2} \mathrm{O}\right)$ folgte die Inkubation mit dem Anti-DIG-HRP-gekoppelten Antikörper (50 $\mu \mathrm{l} / \mathrm{Schnitt,} \mathrm{1:300} \mathrm{in} \mathrm{Blockingpuffer)} \mathrm{für} 1 \mathrm{~h}$. Die Schnitte wurden $3 \times 3 \mathrm{~min}$ in TBST gewaschen und zur Signalamplifikation $10 \mathrm{~min}$ bei RT mit biotinyliertem TyramidReagenz (50 $\mathrm{l} / \mathrm{Schnitt,} \mathrm{1:50} \mathrm{in} \mathrm{Amplifikationsdiluent,} \mathrm{TSA} \mathrm{Biotin} \mathrm{Kit)} \mathrm{behandelt.} \mathrm{Die}$ immobilisierte Horseradish Peroxidase (HRP) katalysierte in diesem Schritt die kovalente Bindung des biotinylierten Tyramidreagenzes rund um den Signallokus und führte so zu einer vielfachen Signalamplifikation. Es folgten 3 Waschschritte (je $3 \mathrm{~min}$ ) in TBST-Puffer. Anschließend wurden die Schnitte $1 \mathrm{~h}$ bei RT mit Streptavidin-HRP-Konjugat ( $50 \mu \mathrm{l} / \mathrm{Schnitt}$, 1:100 in Blockierungspuffer) inkubiert. Das tetramere Streptavidin band an die immobilisierten Biotinmoleküle und ermöglichte durch das HRP-Konjugat die Bildung brauner Farbpräzipitate. 


\subsubsection{Waschschritte und Farbreaktion}

Nach 3 Waschschritten (je $3 \mathrm{~min}$ ) in TBST-Puffer wurden die Schnitte in einer DAB-Chromogenlösung (DAKO ChemMate, $50 \mu \mathrm{l} / \mathrm{Schnitt,} \mathrm{1:50} \mathrm{in} \mathrm{Chromogenpuffer)} \mathrm{unter} \mathrm{Sichtkontrolle}$ bis zu 15 min inkubiert, bis die gewünschte Signalintensität erreicht war. Die Reaktion wurde nach 5 min mit Stoppuffer beendet, die Schnitte kräftig mit Aqua bidest. gespült und eine Hämalaun-Gegenfärbung vorgenommen (2-5 min). Die Schnitte wurden für $5 \mathrm{~min}$ mit warmem Aqua bidest. gebläut und durch eine aufsteigende Ethanolreihe in $\mathrm{DEPC}-\mathrm{H}_{2} \mathrm{O}$ (je 1 min in $70 \%, 90 \%$ und 100\%) dehydratisiert. Zur vollständigen Entfernung des Alkohols wurden die Schnitte für $1 \mathrm{~min}$ in Xylol inkubiert und mit einem xylolhaltigen Eindeckmittel konserviert.

\subsubsection{Fotografische Auswertung}

Die in situ gefärbten Schnittpräparate wurden unter Durchlicht mikroskopisch analysiert und mit mit einer Digitalkamera fotografiert. Zur Bildbearbeitung wurden Adobe $®$ Photoshop und Corel ${ }^{\circledR}$ Photo Paint benutzt.

\subsubsection{Zellkultur}

\subsubsection{Kultur eukaryotischer Zellinien}

Nach dem Auftauen der Zellstocks wurden die Zellen in $10 \mathrm{ml}$ des entsprechenden Mediums $(\rightarrow 2.1 .6 .2 .1)$ resuspendiert und für $2 \mathrm{~min}$ bei $270 \mathrm{xg}$ (Rotanta/P) sedimentiert. Nach Absaugen des Überstands wurde das Sediment in $10 \mathrm{ml}$ Medium resuspendiert und die Suspension in Kulturflaschen (Nunc, $25 \mathrm{~cm}^{2}$ ) überführt. Caco-2-, HepG2-, HEK 293- und SER-W3-Zellen wurden in einer wassergesättigten Atmosphäre mit $5 \% \mathrm{CO}_{2}$ entsprechend der Pufferkapazität der verwendeten Medien kultiviert. Die Zellinien wurden nach 2-3 Tagen zum ersten Mal passagiert. Hierzu wurden die Caco-2, HepG2 und SER-W3 Zellen nach dem Absaugen des Mediums mit $5 \mathrm{ml}$ Trypsin/EDTA-Lösung (0.05\% Trypsin/0.02\% EDTA) in PBS überschichtet und für 5-7 min unter Kulturbedingungen inkubiert und mit $10 \mathrm{ml}$ Medium abgespült. HEK 293 Zellen wurden direkt mit frischem Medium von der Flaschenoberfläche abgelöst. Die Zellsuspensionen wurden 2 min bei $270 \times g$ und $4{ }^{\circ} \mathrm{C}$ zentrifugiert, in Medium resuspendiert und auf neue Kulturflaschen (Nunc, $75 \mathrm{~cm}^{2}$ ) überführt. Je nach Zellinie wurde alle 48-72 h ein Mediumwechsel vorgenommen. Die Zellinien wurden alle 3-4 Tage im Verhältnis $1: 6$ bis 1:10 verdünnt und passagiert. $(\rightarrow 2.2 .12 .1)$.

Von den ersten Passagen einer Zellinienkultur wurden Zellstocks angelegt. Nach Ablösung der konfluenten Zellen einer Kulturflasche (Nunc, $75 \mathrm{~cm}^{2}$ ) wurde die Zellsuspension 2 min bei $270 \times \mathrm{g}$ zentrifugiert und das Zellpellet in $4 \mathrm{ml}$ des entsprechenden Kulturmediums mit $20 \%$ FKS und 10\% DMSO aufgenommen. Die Zellsuspension wurde in vorgekühlten KryoRöhrchen aliquotiert und stufenweise auf $-80^{\circ} \mathrm{C}$ abgekühlt $\left(1 \mathrm{~h}\right.$ bei $-20^{\circ} \mathrm{C}, 24 \mathrm{~h}$ bei $\left.-80^{\circ} \mathrm{C}\right)$, bevor die Röhrchen in flüssigem Stickstoff gelagert wurden. 


\subsubsection{Kultur primärer Rattenhepatozyten}

\subsection{Isolierung von Rattenhepatozyten}

Rattenhepatozyten wurden durch in situ Kollagenaseperfusion der Leber in Anlehnung an von BERRY und FRIEND (1969) sowie SEGLEN (1976) beschriebene Methoden gewonnen.

$\begin{array}{lll}\text { Suspensionspuffer }(\mathrm{pH} \mathrm{7.6):} & 66 \mathrm{mM} & \mathrm{NaCl} \\ & 5.4 \mathrm{mM} & \mathrm{KCl} \\ & 1.6 \mathrm{mM} & \mathrm{CaCl}_{2} \times 2 \mathrm{H}_{2} \mathrm{O} \\ & 0.64 \mathrm{mM} & \mathrm{MgCl}_{2} \times 6 \mathrm{H}_{2} \mathrm{O} \\ & 1.1 \mathrm{mM} & \mathrm{KH}_{2} \mathrm{PO} 4 \\ & 0.7 \mathrm{mM} & \mathrm{Na}_{2} \mathrm{SO} 4 \\ & 30 \mathrm{mM} & \mathrm{Hepes} \\ & 17 \mathrm{mM} & \mathrm{TES} \\ & 36 \mathrm{mM} & \text { Tricin } \\ & & \\ \text { Vorperfusionspuffer }(\mathrm{pH} 7.4): & 142 \mathrm{mM} & \mathrm{NaCl} \\ & 10 \mathrm{mM} & \mathrm{Hepes} \\ & 6.7 \mathrm{mM} & \mathrm{KCl} \\ & & \\ \text { Kollagenasepuffer }(\mathrm{pH} \mathrm{7.6):} & 66 \mathrm{mM} & \mathrm{NaCl} \\ & 6.7 \mathrm{mM} & \mathrm{KCl} \\ & 4 \mathrm{mM} & \mathrm{CaCl} \\ & 100.7 \mathrm{mM} & \mathrm{Hepes}\end{array}$

Die zur Perfusion eingesetzten Puffer entsprachen der Vorschrift von SEGLEN et al. (1976). Der $\mathrm{pH}$-Wert aller Lösungen wurde mit $1 \mathrm{~N} \mathrm{NaOH}$ eingestellt, und die Puffer wurden vor Gebrauch durch Sartolab-P-plus Filterkartuschen $(0.2 \mu \mathrm{m})$ sterilfiltriert. Kollagenase Typ CLS II (172 I.E./mg) wurde dem sterilen Kollagenasepuffer unmittelbar vor der Perfusion zugesetzt. Die Kollagenasekonzentration betrug $0.6 \mathrm{mg} / \mathrm{ml}$.

Ratten wurden durch intraperitoneale Injektion von $50 \mathrm{mg} / \mathrm{kg}$ Pentobarbital $(25 \mathrm{mg} / \mathrm{ml}$ in $0.9 \% \mathrm{NaCl}$-Lösung) narkotisiert. Nach Eröffnung des Abdomens wurde die Leber freipräpariert und zur Vermeidung einer intravasalen Blutgerinnung Heparinlösung in die Vena portae injiziert (250 I.E. in $0.5 \mathrm{ml}$ ). Anschließend wurde der Thorax eröffnet, die Vena cava inferior unterhalb des Herzens mit einer lockeren Ligatur angeschlungen und selbige über den rechten Vorhof kanuliert. Nach Fixierung des Katheters mittels der Ligatur wurde das Organ unter Eröffnung der Vena portae und Unterbindung der Vena cava inferior unterhalb der Leber zunächst für 10 min mit Vorperfusionspuffer bei einer Flußrate von $10 \mathrm{ml} / \mathrm{min}$ vollständig blutleer gespült. Anschließend wurde zur Lösung der Zell-Zell-Kontakte die Leber für 10 bis 15 min mit Kollagenaselösung $(0.5 \mathrm{mg} / \mathrm{ml}$, entspricht ca. 100 I.E./ml) bei einer Flußrate von $10 \mathrm{ml} / \mathrm{min}$ perfundiert. Beide Perfusionslösungen waren auf $37^{\circ} \mathrm{C}$ temperiert. Im Anschluß wurde das Organ vorsichtig unter Schonung der Organkapsel 
herauspräpariert, mit Suspensionspuffer abgespült und in ein steriles $50 \mathrm{ml}$ Kunststoffröhrchen mit $4{ }^{\circ} \mathrm{C}$ kaltem Suspensionspuffer überführt.

Alle folgenden Schritte wurden unter sterilen Bedingungen durchgeführt. Nach Eröffnung der Organkapsel wurden die Hepatozyten durch Schwenken mit Suspensionspuffer freigesetzt. Zur groben Entfernung von Zellaggregaten, Bindegewebs- und Kapselbestandtteilen wurde die erhaltene Suspension durch ein Nylonnetz der Maschenweite $250 \mu \mathrm{m}$ filtriert. Anschließend wurde die Zellsuspension für $5 \mathrm{~min}$ in der 5810R Kühlzentrifuge (Eppendorf) bei $40 \mathrm{xg}$ zentrifugiert, um nicht-parenchymale Zellen und Zelltrümmer zu entfernen. Nach der Zentrifugation wurde der Überstand abgesaugt und das erhaltene Zellsediment in MX-82 Medium $+10 \%$ FKS (HoffMANN et al., 1989) resuspendiert. Die Zellen wurden anschließend durch ein Nylonnetz der Maschenweite $60 \mu \mathrm{m}$ filtriert, um eine homogene Zellsuspension zu erhalten. Die Zelldichte wurde in einer Fuchs-Rosenthal-Zählkammer ermittelt, und die Zellvitalität mittels Trypanblau-Ausschluß bestimmt. Dazu wurde der 1:100 verdünnten Zellsuspension ein äquivalentes Volumen einer $0.5 \%$-ige Lösung des Postvitalfarbstoffes Trypanblau zugesetzt. Die Zellvitalität betrug mindestens $90 \%$.

\subsection{Aussaat und Kultur primärer Rattenhepatozyten}

PBS (pH 7.4):

$\begin{array}{ll}136 \mathrm{mM} & \mathrm{NaCl} \\ 2.68 \mathrm{mM} & \mathrm{KCl} \\ 8.2 \mathrm{mM} & \mathrm{Na}_{2} \mathrm{HPO}_{4} \\ 1.47 \mathrm{mM} & \mathrm{KH}_{2} \mathrm{PO}_{4}\end{array}$

Die erhaltene Hepatozytensuspension $(\rightarrow 2.2 .12 .2 .1)$ wurde mit MX-82 Medium $+10 \%$ FKS $\left(\rightarrow\right.$ 2.1.6.2.2) auf eine Endkonzentration von $0.5 \times 10^{6}$ Zellen eingestellt. Die Kultur der Zellen erfolgte in unbeschichteten Polystyrol-Zellkulturschalen (Nunc) bei $37^{\circ} \mathrm{C}$ in einer Atmosphäre von $10 \% \mathrm{CO}_{2}$ und $90 \%$ relativer Luftfeuchte. Die Hepatozyten wurden in einer Dichte von $8.8 \times 10^{4}$ Zellen $/ \mathrm{cm}^{2}$ ausplattiert $\left(10 \mathrm{ml}\right.$ Suspension $\left./ 57 \mathrm{~cm}^{2}\right)$ und durch leichtes Schwenken gleichmäßig auf den Kulturschalen verteilt. Nach einer 2- bis 4-stündigen Anwachsphase wurden die Zellen mit sterilem PBS gewaschen und mit serumfreiem MX-83 Medium weiterkultiviert. Mediumwechsel wurden alle $24 \mathrm{~h}$ vorgenommen. Die Zellen wurden für maximal 4 Tage kultiviert. Je nach Versuchsansatz wurden dem Medium verschiedene Effektoren zugegeben.

\subsubsection{Abbruch der Kultivierung}

Zur Präparation von Zellsubfraktionen, Gesamtprotein oder RNA aus Zellkulturen wurde am Ende der gewünschten Kulturdauer das Kulturmedium entfernt, die Zellen mit sterilem PBS gewaschen und in flüssigem Stickstoff schockgefroren. Die Platten wurden anschließend entweder direkt den Präparationen zugeführt oder bis zur weiteren Verwendung bei $-80^{\circ} \mathrm{C}$ gelagert. 


\subsubsection{Transfektion von Zell-Linien mit Expressionsplasmiden}

Im Rahmen dieser Arbeit wurden verschiedene Zellinien mit Expressionsplasmiden transfiziert, um die subzelluläre Verteilung des Ratten Abca5-Gens zu untersuchen. Am Vortag der Transfektion wurden die Zellinien dazu passagiert und auf Kulturplatten $\left(21.9 \mathrm{~cm}^{2}\right)$ oder Six-Well-Platten $\left(6 \times 9.6 \mathrm{~cm}^{2}\right)$ ausplattiert.

Zur Transfektion wurde das Reagenz Fugene 6 (Roche) benutzt. Gemäß Herstellerprotokoll wurden pro Kulturschale $\left(21.9 \mathrm{~cm}^{2}\right) 6-12 \mu \mathrm{l}$ Fugene 6 in einem Gesamtvolumen von $100 \mu \mathrm{l}$ serumfreiem DMEM-Grundmedium $(\rightarrow$ 2.1.6.2.1) verdünnt und je nach Plasmid $2-4 \mu \mathrm{g}$ DNA dazugegeben. Zur Bildung des DNA-Lipidkomplexes wurde diese Lösung $30 \mathrm{~min}$ bei Raumtemperatur inkubiert, tropfenweise auf die Kulturplatte gegeben und durch leichtes Schwenken sorgfältig verteilt. Für die einzelnen Vertiefungen einer Six-Well-Platte wurde die Hälfte des DNA-Lipidkomplexes angesetzt. Bei jeder Transfektion wurde eine nichttransfizierte Kontrolle mitgeführt. Das Kulturmedium der Zellen wurden nach ca. $3 \mathrm{~h}$ gewechselt und der Verlauf der Transfektion mittels Fluoreszenz-Mikroskopie beobachtet. Spätestens $72 \mathrm{~h}$ nach der Transfektion wurde die Kultivierung der Zellen abgebrochen und je nach Bedarf eine Proteinisolierung und -analyse vorgenommen $(\rightarrow 2.2 .14)$.

\subsubsection{Proteinbiochemische Methoden}

\subsubsection{Subfraktionierung von Zellen}

Kerne, Mitochondrien und Plasmamembranen wurden aus Zellhomogenaten durch differentielle Zentrifugation nach einer Modifikation der von SIMPSON et al. (1983) beschriebenen Methode gewonnen.

\subsubsection{Homogenisation von Zellen}

Die vorkultivierten und mit PBS gewaschenen Zellen wurden unter Verwendung eines Gummiwischers mit TES-Puffer von den Kulturplatten geschabt und in ein Glashomogenisationsgefäß $(\rightarrow 2.2 .14 .3 .2)$ oder in ein $1.5 \mathrm{ml}$-Eppendorfgefäß $(\rightarrow 2.2 .14 .3 .1)$ überführt. Die Homogenisation erfolgte durch bis zu 45 Hübe bei 1400 UPM des entsprechenden Pistills (Teflon oder Edelstahl). Pro Kultur wurden ein bis zwei Kulturschalen $\left(21.9 \mathrm{~cm}^{2}\right.$ oder $56.7 \mathrm{~cm}^{2}$ ) eingesetzt.

\subsubsection{Fraktionierung der Zellhomogenate}

Je nach Bedarf wurde unterschiedliche Varianten der Zellfraktionierung durchgeführt. Bei der Grobfraktionierung wurden die Zellhomogenate von max. zwei Kulturplatten $\left(21.9 \mathrm{~cm}^{2}\right)$ in Kerne, Mitochondrien und eine die Plasmamembranen enthaltende zytoplasmatische Fraktion aufgetrennt $(\rightarrow 2$ 2.14.3.1). Bei der Feinfraktionierung wurden Zellhomogenate von mind. 2 Kulturplatten à $56.7 \mathrm{~cm}^{2}$ benutzt, um letztere Fraktion über einen Saccharosegradienten weiter aufzureinigen $(\rightarrow 2.2 .14 .3 .2)$. 


$\begin{array}{lll}\text { TES-Puffer }(\mathrm{pH} \mathrm{7.4):} & 20 \mathrm{mM} & \text { Tris } \\ & 1 \mathrm{mM} & \text { EDTA } \\ & 254 \mathrm{mM} & \text { Saccharose } \\ & 2 \mathrm{Tabl} / 100 \mathrm{ml} & \text { Complete Protease Inhibitor } \\ & & \\ \text { Saccharosekissen }(\mathrm{pH} 7.4): & 20 \mathrm{mM} & \text { Tris } \\ & 1 \mathrm{mM} & \text { EDTA } \\ & 1.12 \mathrm{M} & \text { Saccharose } \\ & 2 \mathrm{Tabl} / 100 \mathrm{ml} \text { Complete Protease Inhibitor } \\ & & \\ \text { TE-Puffer }(\mathrm{pH} 7.4): & 10 \mathrm{mM} & \text { Tris } \\ & 1 \mathrm{mM} & \text { EDTA }\end{array}$

Zur Hemmung von Serin-Proteasen enthielten das Saccharosekissen und der TES-Puffer den Protease-Inhibitor Complete (Mix verschiedener Protease-Inhibitoren von Roche), der als zerstoßene Tablette dem Puffer kurz vor Gebrauch zugesetzt wurde (Alternativ wurde ein 50x Protease Inhibitor Stock in TE-Puffer angesetzt und bei $4{ }^{\circ} \mathrm{C}$ aufbewahrt, 1 Tablette/ml TE). Der $\mathrm{pH}$-Wert dieser Lösungen wurde mit $1 \mathrm{~N} \mathrm{HCl}$ bei $4{ }^{\circ} \mathrm{C}$ eingestellt.

\subsection{Grobfraktionierung der Zellhomogenate}

Das Zellhomogenate von zwei Kulturplatten $\left(21.9 \mathrm{~cm}^{2}\right)$ mit $150 \mu \mathrm{l}$ TES-Puffer wurden bei $3000 \times \mathrm{g}$ und $4{ }^{\circ} \mathrm{C} 10 \mathrm{~min}$ zentrifugiert (22R Kühlzentrifuge, Hettich). Das Sediment wurde in $100 \mu \mathrm{l}$ TES-Puffer aufgenommen (Kerne), der Überstand wurde bei $10000 \times \mathrm{g} 30 \mathrm{~min}$ zentrifugiert. Das Sediment der zweiten Zentrifugation (Mitochondrien) wurde in $25 \mu$ TESPuffer resuspendiert und der Überstand als Plasmamembranhaltige Fraktion verwendet.

\subsection{Feinfraktionierung der Zellhomogenate zur Anreicherung der Plasmamembranfraktion}

Die Zellhomogenate wurden mit TES-Puffer auf ein Volumen von $12 \mathrm{ml}$ aufgefüllt und bei $4{ }^{\circ} \mathrm{C}$ für $20 \mathrm{~min}$ in einem JA20 Festwinkelrotor bei $12000 \mathrm{xg}$ zentrifugiert um die zytoplasmatische, mikrosomenhaltige Fraktion von der Plasmamembranen-, Kerne- und Mitochondrien-enthaltenden Fraktion zu trennen. Zur Isolation von Plasmamembranen wurden die Sedimente der $12000 \times \mathrm{g}$ Zentrifugation in $2 \mathrm{ml}$ TES-Puffer resuspendiert, in ein Glashomogenisationsgefäß überführt und durch 12 Hübe des Teflonpistills bei 1400 UPM homogenisiert. Glasgefäß und Pistill wurden anschließend durch 6 Hübe bei 1400 UPM mit 1 ml TES-Puffer gespült und die erhaltene Suspension mit dem Homogenat vereinigt. Dann wurde die Suspension vorsichtig auf ein 38.3\%-iges Saccharosekissen geschichtet und einer einstündigen Dichtegradientenzentrifugation bei $4{ }^{\circ} \mathrm{C}$ und $100000 \times \mathrm{g}$ in einem SW27 Ausschwingrotor unterzogen. Anschließend wurde die sich in der Interphase zwischen TESPuffer und Saccharosekissen befindliche, weißliche Plasmamembranfraktion vorsichtig mit einer Pipette abgenommen, mit $10 \mathrm{mM}$ TE-Puffer verdünnt und erneut für eine Stunde bei $4{ }^{\circ} \mathrm{C}$ und $100000 \mathrm{xg}$ zentrifugiert. Die so erhaltenen Sedimente wurden in 40-100 $\mu \mathrm{l} \mathrm{TE-}$ 
Puffer resuspendiert, aliquotiert, in flüssigem Stickstoff schockgefroren und bei $-80{ }^{\circ} \mathrm{C}$ bis zur weiteren Verwendung gelagert.

\subsubsection{Isolierung von Gesamt-Proteinextrakten}

\subsection{Isolierung von Gesamtprotein mit Lämmli Sample Buffer (LSB) 2x}

Lämmli Sample Buffer (LSB) A 2x

(pH 6.8)

$\begin{array}{ll}119 \mathrm{mM} & \text { Tris } \\ 4.76 \mathrm{mM} & \text { EDTA } \\ 132 \mathrm{mM} & \text { SDS } \\ 2.59 \mathrm{M} & \text { Glycerin } \\ 0.0476 \%(\mathrm{w} / \mathrm{v}) & \text { Bromphenolblau }\end{array}$

Der LSB-Puffer wurde aliquotiert und bei $-20^{\circ} \mathrm{C}$ gelagert. Zum Gebrauch wurde er mit $3 \%(w / v)$ Dithiothreitol versetzt.
Lysepuffer
$1.6 \mathrm{ml}$
LSB-Puffer A 2x
$48 \mathrm{mg}$
DTT
$32 \mu \mathrm{l}$
50x Complete-Protease-Inhibitor-Lsg.

Die vorkultivierten und mit PBS gewaschenen Zellen wurden unter Verwendung eines Gummiwischers mit max. $100 \mu \mathrm{l} / 56.7 \mathrm{~cm}^{2}$-Platte Lysepuffer heruntergeschabt und in ein Eppendorfgefäß überführt. Die Proben wurden zur Inaktivierung der Proteasen 5 min bei $95^{\circ} \mathrm{C}$ inkubiert, anschließend $5 \mathrm{~min}$ auf Eis abgekühlt, $5 \mathrm{~min}$ zur Homogenisierung der Zellsuspension mit Ultraschall behandelt, $5 \mathrm{~min}$ bei $95^{\circ} \mathrm{C}$ inkubiert, nochmals auf Eis abgekühlt und $10 \mathrm{~min}$ bei $21910 \mathrm{xg}$ und $18^{\circ} \mathrm{C}$ zentrifugiert (22R Kühlzentrifuge Hettich). Der Überstand wurde in ein neues Eppendorfgefäß überführt, 5 min bei $95^{\circ} \mathrm{C}$ inkubiert, 5 min auf Eis abgekühlt, 5 min mit Ultraschall behandelt und kurz zentrifugiert. Die Proben wurden in flüssigem Stickstoff schockgefroren und bei $-80^{\circ} \mathrm{C}$ gelagert. Diese Proben wurden ohne Proteinbestimmung im Western Blot eingesetzt und vor dem Auftragen 2 min bei $94{ }^{\circ} \mathrm{C}$ denaturiert, kurz auf Eis gekühlt und zentrifugiert.

\subsection{Isolierung von Gesamtprotein mit LSB-Puffer ohne DTT und Bromphenolblau}

Lämmli Sample Buffer (LSB) B 2x $(\mathrm{pH} 6.8)$

$\begin{array}{ll}119 \mathrm{mM} & \text { Tris } \\ 4.76 \mathrm{mM} & \text { EDTA } \\ 132 \mathrm{mM} & \text { SDS } \\ 2.59 \mathrm{M} & \text { Glycerin }\end{array}$

Protease-Inhibitor-Konzentrat 100x
1 Tablette $(60 \mathrm{mg})$ in $500 \mu \mathrm{l}$ Aqua bidest.

Vor Beginn des Versuchs wurde der LSB-Puffer 2x im Verhältnis 1:1 mit Aqua bidest. verdünnt und mit $10 \mu \mathrm{l}$ Inhibitorkonzentrat pro $\mathrm{ml}$ Puffer versetzt. 
Die vorkultivierten und mit PBS gewaschenen Zellen einer Kulturplatte $\left(21.9 \mathrm{~cm}^{2}\right)$ wurden unter Verwendung eines Gummiwischers mit 2 × $50 \mu$ LSB-Puffer B heruntergeschabt und in ein Eppendorfgefäß überführt. Zur Inaktivierung der Proteasen wurden die Proben 5 min bei $95^{\circ} \mathrm{C}$ inkubiert, anschließend 5 min auf Eis abgekühlt, 5 min mit Ultraschall behandelt, 5 min bei $95^{\circ} \mathrm{C}$ inkubiert, nochmals auf Eis abgekühlt und $10 \mathrm{~min}$ bei $21910 \mathrm{xg}$ und $18^{\circ} \mathrm{C}$ zentrifugiert (22R Kühlzentrifuge Hettich). Der Überstand wurde in ein neues Eppendorfgefäß überführt, $5 \mathrm{~min}$ bei $95^{\circ} \mathrm{C}$ inkubiert, $5 \mathrm{~min}$ auf Eis abgekühlt, $5 \mathrm{~min}$ zur Homogenisierung der Zellsuspension mit Ultraschall behandelt und kurz zentrifugiert. Die Proben wurden in flüssigem Stickstoff schockgefroren und bei $-80{ }^{\circ} \mathrm{C}$ gelagert. Zur Proteinbestimmung wurden die Proben im Verhältnis 1:1 mit 1x LSB-Puffer B verdünnt. Für die Gelauftragung wurden die Proben im Verhältnis 1:1 mit 1x LSB-Puffer A versetzt, 2 min bei $94{ }^{\circ} \mathrm{C}$ denaturiert, kurz auf Eis gekühlt und zentrifugiert.

\subsubsection{Proteinbestimmung}

Der Proteingehalt von Kern-, Mitochondrien-, Plasmamembran- und Gesamtproteinfraktionen wurde in Anlehnung an eine von LoWRY et al. (1951) publizierte Methode bestimmt.

Je nach Fraktion wurden Vorab-Verdünnungen im Verhältnis von 1:2 bis 1:5 vorgenommen und zwischen 2 und $5 \mu$ Proteinlösung eingesetzt. Die Proben wurden in Einmalküvetten mit Aqua bidest. auf ein Volumen von $50 \mu \mathrm{l}$ eingestellt und mit jeweils $150 \mu \mathrm{l} \mathrm{NaOH}(0.1 \mathrm{~N})$ versetzt. Es erfolgte die Zugabe von je $1 \mathrm{ml}$ Lowry-Gemisch. Nach 10-minütiger Inkubation bei RT wurden $200 \mu$ l Folin-Ciocalteus-Phenolreagenz (1:1 mit Aqua bidest. vorverdünnt) zugegeben, die Testansätze gut gemischt und nach einer 30-minütigen Inkubation bei RT die Absorption bei $578 \mathrm{~nm}$ gemessen. Es erfolgten jeweils Doppelbestimmungen.

Die Proteingehalte der Lösungen wurden mittels einer parallel durchgeführten Eichreihe (Eichkonzentrationen 0-25 $\mathrm{g} / \mathrm{ml}$ BSA) errechnet. Da Tris-Puffer die Proteinbestimmung nach LOWRY et al. (1951) beeinflussen kann, wurde jedem Eichwert das für die zu bestimmenden Werte eingesetzte Probenvolumen an TE-Puffer zugesetzt. Das Lowry-Gemisch (189 mM Na $\mathrm{CO}_{3} / 0.6 \mathrm{mM} \quad \mathrm{CuSO}_{4} / 0.7 \mathrm{mM}$ Kalium-Natrium-Tartrat) wurde für jede Bestimmung frisch aus den folgenden Stammlösungen 1, 2 und 3 in den Volumenanteilen $50+1+1$ zusammenpipettiert.

$\begin{array}{lll}\text { Lösung 1: } & 2 \%(\mathrm{w} / \mathrm{v}) & \mathrm{Na}_{2} \mathrm{CO}_{3} \text { in } 0.1 \mathrm{~N} \mathrm{NaOH} \\ \text { Lösung 2: } & 0.5 \%(\mathrm{w} / \mathrm{v}) & \mathrm{CuSO}_{4} \times 7 \mathrm{H}_{2} \mathrm{O} \\ \text { Lösung 3: } & 1 \%(\mathrm{w} / \mathrm{v}) & \text { Kalium-Natrium-Tartrat }\end{array}$

\subsubsection{Auftrennung von Proteinen durch SDS-Polyacrylamid-Gelelektrophorese}

Vor der immunchemischen Detektion im Western Blot wurden die Proteinfraktionen über SDS-Polyacrylamid-Gelelektrophorese unter denaturierenden Bedingungen nach dem von LÄMMLI (1970) beschriebenen Verfahren aufgetrennt. Es wurde ein diskontinuierliches 
Vertikal-Elektrophoresesystem verwendet. Je nach Anwendung wurden Acrylamidanteile im Trenngel zwische $7.5 \%$ und $12 \%$ eingesetzt. Das Sammelgel hatte einen konstanten Acrylamidanteil von $3.9 \%$.

\subsubsection{Herstellung von vertikalen SDS-Polyacrylamid-Minigelen}

$\begin{array}{lll}\text { Trenngelpuffer }(\mathrm{pH} 8.8): & 1.5 \mathrm{M} & \text { Tris } \\ & 14 \mathrm{mM} & \text { SDS } \\ & & \\ \text { Sammelgelpuffer }(\mathrm{pH} 6.8): & 14 \mathrm{mM} & \begin{array}{l}\text { Tris } \\ \text { SDS }\end{array} \\ & & \\ \text { Acrylamidlösung 4K (29/1): } & 4.1 \mathrm{M} & \text { Acrylamid } \\ & 0.65 \mathrm{M} & \text { N,N'-Methylenbisacrylamid }\end{array}$

Der $\mathrm{pH}$-Wert von Trenn- und Sammelgelpuffer wurde mit $1 \mathrm{~N} \mathrm{HCl}$ eingestellt. Die Lösungen konnten bei $4{ }^{\circ} \mathrm{C}$ gelagert werden. Ammoniumpersulfat wurde jeweils frisch in einer Konzentration von $0.5 \mathrm{mg} / \mu \mathrm{l}$ Aqua bidest. angesetzt.

SDS-Polyacrylamid-Minigele wurden in einer „Mighty Small SE Dual Gel Caster"-Kammer gegossen (Plattengröße: 83 × $101 \mathrm{~mm}$, Geldicke $1 \mathrm{~mm}$ ). Zur Herstellung der Gele wurden die in der folgenden Tabelle aufgeführten Lösungen bis auf N,N,N',N'-Tetramethylethylendiamin (TEMED) zusammenpipettiert und die Mischung für bis zu 2 min im Wasserstrahlvakuum entgast. Anschließend wurde durch Zusatz von TEMED die radikalische Polymerisation gestartet, das Trenngel gegossen und sofort mit $0.5 \%$-iger SDS-Lösung überschichtet, um unter Luftabschluß eine gleichmäßige Polymerisation und eine exakte Grenzschicht zu gewährleisten.

\begin{tabular}{llll}
\hline Trenngel & $7.5 \%$ & $10 \%$ & $12 \%$ \\
\hline Trenngelpuffer & $1.56 \mathrm{ml}$ & $1.56 \mathrm{ml}$ & $1.56 \mathrm{ml}$ \\
Aqua bidest. & $2.94 \mathrm{ml}$ & $2.44 \mathrm{ml}$ & $2.04 \mathrm{ml}$ \\
Acrylamidlösung $29 / 1$ & $1.5 \mathrm{ml}$ & $2.0 \mathrm{ml}$ & $2.4 \mathrm{ml}$ \\
Ammoniumpersulfat $(0.5 \mathrm{mg} / \mu \mathrm{l})$ & $12 \mu \mathrm{l}$ & $12 \mu \mathrm{l}$ & $12 \mu \mathrm{l}$ \\
TEMED & $6 \mu \mathrm{l}$ & $6 \mu \mathrm{l}$ & $6 \mu \mathrm{l}$ \\
\hline
\end{tabular}

Nach ca. 30 min war die Polymerisation abgeschlossen. Nach Entfernung der SDS-Lösung wurde ein Kamm (10 oder 15 Zähne) eingesetzt, Das Sammelgel wurde $90 \mathrm{~s}$ entgast, unter Zusatz von TEMED in folgender Zusammensetzung gegossen und ebenfalls für ca. 30 min polymerisiert. 


\begin{tabular}{ll}
\hline Sammelgel & $3.9 \%$ \\
\hline Sammelgelpuffer & $520 \mu \mathrm{l}$ \\
Aqua bidest & $1.22 \mathrm{ml}$ \\
Acrylamidlösung $29 / 1$ & $260 \mu \mathrm{l}$ \\
Ammoniumpersulfat $(0.5 \mathrm{mg} / \mu \mathrm{l})$ & $4 \mu \mathrm{l}$ \\
TEMED & $2 \mu \mathrm{l}$ \\
\hline
\end{tabular}

\subsubsection{Probenvorbereitung}

Lämmli Sample Buffer (LSB) A 2x $119 \mathrm{mM} \quad$ Tris

$(\mathrm{pH} 6.8)$

$\begin{array}{ll}4.76 \mathrm{mM} & \text { EDTA } \\ 132 \mathrm{mM} & \text { SDS } \\ 2.59 \mathrm{M} & \text { Glycerin } \\ 0.0476 \%(\mathrm{w} / \mathrm{v}) & \text { Bromphenolblau }\end{array}$

Der LSB-Puffer A $2 x$ wurde aliquotiert und bei $-20^{\circ} \mathrm{C}$ gelagert. Zum Gebrauch wurde er mit $3 \%$ $(w / v)$ Dithiothreitol versetzt.

Je nach Probe wurden zwischen 2 und $25 \mu \mathrm{g}$ Protein mit TE(S)-Puffer auf ein einheitliches Volumen gebracht und mit dem gleichen Volumen an 2x LSB-Puffer A $2 x$ versetzt (insgesamt max. $20 \mu \mathrm{l}$ ). Bei der Untersuchung sehr niedrig konzentrierter Proteinproben wurde 4x-Probenpuffer benutzt. Es wurden verschiedene Molekulargewichtsstandards eingesetzt $(\rightarrow 2.1 .7 .9)$ und stets als Referenz in den Außentaschen des Gels aufgetragen $\left(\rightarrow\right.$ 2.2.14.9.2). Die Proben wurden anschließend für $2 \mathrm{~min}$ im Heizblock bei $95^{\circ} \mathrm{C}$ denaturiert, für $30 \mathrm{~s}$ auf Eis gekühlt, kurz zentrifugiert und auf das Gel aufgetragen. Der Colour Burst Protein-Marker wurde ohne Denaturierung aufgetragen.

\subsubsection{Elektrophorese}

$\begin{array}{lll}\text { Elektrophoresepuffer 8x }(\mathrm{pH} 8.4) & 0.2 \mathrm{M} & \text { Tris } \\ & 1.54 \mathrm{M} & \text { Glycin } \\ & 0.1 \%(\mathrm{w} / \mathrm{v}) & \text { SDS }\end{array}$

Die Elektrophorese wurde in einer "Mighty Small II“ Vertikal-Elektrophorese-Kammer unter Wasserkühlung und Verwendung eines einheitlichen Puffers durchgeführt. Die Proben wurden mittels Gel Saver-Spitzen aufgetragen und durchliefen das Sammelgel bei einer Stromstärke von $10 \mathrm{~mA} / \mathrm{Gel}$ in ca. $1 \mathrm{~h}$. Die Dauer der Auftrennung im Trenngel betrug bei $20 \mathrm{~mA} / \mathrm{Gel}$ ca. $2 \mathrm{~h}$. Nach dem Austritt der Bromphenolblaufront aus dem Gel wurde die Elektrophorese abgebrochen. 


\subsubsection{Nachweis von Proteinen im Western-Blot}

Nach der SDS-Polyacrylamid-Gelelektrophorese wurden aufgetrennte Proteine über einen Semidry-Transfer aus dem Gel eluiert und auf Polyvinylidendifluorid-Membranen (PVDF) immobilisiert, um sie immunologischen Analysen zugänglich zu machen (Western Blotting).

\subsection{Semidry-Transfer}

Transferpuffer ( $\mathrm{pH} 9.0)$

$\begin{array}{ll}48 \mathrm{mM} & \text { Tris } \\ 39 \mathrm{mM} & \text { Glycin } \\ 1.3 \mathrm{mM} & \text { SDS } \\ 15 \%(\mathrm{v} / \mathrm{v}) & \text { Methanol }\end{array}$

Der Puffer wurde vor Gebrauch für 10 min im Ultraschallbad entgast, um der Bildung von Luftblasen während des Transfers vorzubeugen.

Der Transfer der aufgetrennten Proteine auf eine PVDF-Membran basierte auf einer ursprünglich von KYHSE-ANDERSEN (1984) beschriebenen Methode. Für das SemidryVerfahren wurde eine Transferkammer mit einer Edelstahlkathode und einer Glas/ Graphitanode benutzt. Im Gegensatz zu dem von KYHSE-ANDERSEN (1984) beschriebenen Verfahren kam ein kontinuierliches Puffersystem zum Einsatz.

Nach abgeschlossener Elektrophorese wurde zunächst das Sammelgel mit einem Skalpell abgetrennt und das Trenngel für 10 min in Transferpuffer äquilibriert. Die PVDF-Membran wurde für $10 \mathrm{~s}$ in Methanol aktiviert, $5 \mathrm{~min}$ in Aqua bidest. gespült und ebenfalls in Transferpuffer für $10 \mathrm{~min}$ äquilibriert. Zeitgleich wurden 9 dicke und 2 dünne Filterpapiere $(5.2 \times 8.3 \mathrm{~cm})$ in Transferpuffer getränkt. Das "Transfer-Sandwich“ wurde nach gleichmäßiger Befeuchtung der Elektroden mit Aqua bidest. wie folgt zusammengesetzt:

ANODE (+) oben

6 Filterpapiere Nr. 2668

1 Filterpapier Nr. 2043

PVDF-Membran

Polyacrylamidgel

1 Filterpapier Nr. 2043

3 Filterpapiere Nr. 2668

KATHODE (-) unten 
Luftblasen wurden beim Aufbau des Sandwiches mit einer Gummiwalze entfernt. Der Transfer erfolgte für $1.5 \mathrm{~h}$ bei RT oder $4{ }^{\circ} \mathrm{C}$ bei einer konstanten Stromstärke von $0.8-$ $1 \mathrm{~mA} / \mathrm{cm}^{2}$ (ca. $40 \mathrm{~mA} / \mathrm{Gel}$ ).

\subsection{Färbungen}

$\begin{array}{lll}\text { Ponceau-S-Färbelösung: } & 0.25 \%(\mathrm{w} / \mathrm{v}) & \text { Ponceau-S } \\ & 40 \%(\mathrm{v} / \mathrm{v}) & \text { Methanol } \\ & 15 \%(\mathrm{v} / \mathrm{v}) & \text { Eisessig } \\ & 1 \%(\mathrm{w} / \mathrm{v}) & \text { Coomassie-Brilliantblau R } 250 \\ \text { Coomassie-Blau-Stammlösung: } & 5 \%(\mathrm{v} / \mathrm{v}) & \text { Methanol } \\ & 50 \%(\mathrm{w} / \mathrm{v}) & \text { Trichloressigsäure } \\ & 10 \%(\mathrm{v} / \mathrm{v}) & \text { Methanol } \\ \text { Entfärber-Lösung: } & 7.6 \%(\mathrm{v} / \mathrm{v}) & \text { Eisessig }\end{array}$

Die Gebrauchslösung wurde durch 1:7 Verdünnung mit 50\% (w/v) Trichloressigsäure hergestellt. Die Gebrauchslösung konnte mehrfach verwendet werden. Beide Färbelösungen wurden vor Gebrauch durch Faltenfilter filtriert.

Nach abgeschlossenem Transfer wurde der Bereich der PVDF-Membran, welcher den Molekulargewichtsstandard enthielt, von der restlichen Membran abgetrennt und für 1 min einer Ponceau-S-Proteinfärbung unterzogen. Die Hintergrundsfärbung der Membran wurde durch Waschen mit Aqua bidest. entfernt. Die Proteinbanden (rot) wurden zur Molekulargewichtsbestimmung markiert. Um Effizienz und Gleichmäßigkeit des Transfers zu überprüfen, wurde das Polyacrylamidgel für $5 \mathrm{~min}$ in Coomassie-Blau-Lösung gefärbt und anschließend ü.N. mittels Entfärber differenziert. Die PVDF-Membran wurde für 10 min in Aqua bidest. gewaschen und entweder für eine spätere Immunreaktion getrocknet oder wie folgt weiterbehandelt.

\subsection{Immunchemischer Nachweis}

$\begin{array}{lll}\text { Puffer A (pH 7.4): } & 10 \mathrm{mM} & \text { Tris } \\ & 154 \mathrm{mM} & \mathrm{NaCl} \\ & & \\ \text { Puffer B (pH 7.0): } & 154 \mathrm{mM} & \mathrm{NaCl} \\ & 7 \mathrm{mM} & \text { SDS } \\ & 0.5 \%(\mathrm{w} / \mathrm{v}) & \text { Triton X } 100 \\ & 0.5 \%(\mathrm{w} / \mathrm{v}) & \text { Rinderserumalbumin } \\ & & \\ \text { Puffer C } & \text { Puffer A mit } & \\ & 0.05 \%(\mathrm{w} / \mathrm{v}) & \text { Tween } 20\end{array}$


Die PVDF-Membran wurde ü.N. bei $4{ }^{\circ} \mathrm{C}$ in Puffer $\mathrm{C}$ mit $5 \%$ Magermilchpulver $(1 \mathrm{~g}$ Fett $/ 100 \mathrm{~g}$ Granulat) inkubiert, um freie Proteinbindungsstellen auf der Membran abzusättigen. Die folgenden Wasch- und Inkubationsschritte erfolgten unter leichtem horizontalen Schwenken. Die abgesättigte Membran wurde zunächst $3 \times 5$ min in Puffer A gewaschen. Es folgte eine Inkubation mit dem primären Antikörper in Puffer $C$ für $1.5 \mathrm{~h}$ (nach Bedarf wurde 5\% Magermilchpulver zugesetzt). Zur Entfernung von überschüssigem Antikörper schlossen sich Waschschritte von $2 \times 5$ min mit Puffer A, $2 \times 5$ min mit Puffer B und $2 \times 5$ min mit Puffer $A$ an. Anschließend wurde die Membran für $1.5 \mathrm{~h}$ mit sekundärem, peroxidasegekoppelten Antikörper (Verdünnung 1:8000 bis 1:10000) in Puffer $C$ inkubiert. Die Membran wurde erneut $2 \times 5$ min mit Puffer A, $2 \times 5$ min mit Puffer $B$ und $2 \times 5$ min mit Puffer $A$ gewaschen und mit Filterpapier vorsichtig von überschüssiger Flüssigkeit befreit. Gleiche Volumina (1-2 ml) des Peroxidasesubstrats Luminol und des Co-Substrates $\mathrm{H}_{2} \mathrm{O}_{2}$ (Lösungen 1 und 2 des ECL-Systems, Amersham) wurden vermischt und die noch nebelfeuchte Membran unter leichtem Schütteln $5 \mathrm{~min}$ darin inkubiert. Überschüssige Substratlösung wurde mit Filterpapier vorsichtig aufgenommen und die feuchte Membran in Frischhaltefolie eingeschweißt. Die unter enzymatischer Umsetzung der Substrate auftretende Chemilumineszenz im Bereich der Immunkomplexe wurde durch Exposition von ECL-Filmen in einer Autoradiographie-Kassette bei Raumtemperatur bis zur gewünschten Filmschwärzung detektiert. Je nach Intensität waren Expositionszeiten von wenigen Sekunden bis zu einigen Minuten notwendig. Die optimalen Verdünnungsverhältnisse für die primären Antikörper waren im Vorfeld im Verhältnis zur eingesetzten Proteinmenge und zur Verdünnung des sekundären Antikörpers ausgetestet worden (EGFP-Antikörper 1:1000). 


\section{Ergebnisse}

\subsection{Vorarbeiten}

Zu Beginn der vorliegenden Arbeit war ein humanes cDNA-Fragment (392 bp) eines putativen neuen Gens aus der Familie der ATP-binding-cassette Transporter bekannt (HIRSCH-ERNST et al., 2000). Aufgrund von Homologieanalysen wurde das Genfragment der bisher weitgehend unerforschten ABCA-Subfamilie zugeordnet. Im Rahmen der vorliegenden Arbeit sollte die vollständige, kodierende Sequenz des Gens zunächst auf experimentellem Weg erschlossen werden.

Das hohe Maß an Sequenzkonservierung zwischen orthologen $A B C$-Genen verschiedener Spezies legte die Existenz einer Entsprechung von humanem ABCA5 in der Ratte nahe. Dieses sollte ebenfalls identifiziert werden, um für spätere funktionelle Betrachtungen auf verschiedene Zellsysteme zurückgreifen zu können.

\subsection{Charakterisierung eines neuen humanen $A B C A-G e n s$}

Als experimentelle Basis für die vollständige Sequenzanalyse des neuen $A B C A-G e n s$ wurde das 392 bp-Genfragment (AJ275973.1) aus dem Bereich einer ATP-Bindungskassette mittels one-step RT-PCR $(\rightarrow$ 2.2.6.1.2) aus Gesamt-RNA $(\rightarrow$ 2.2.2.4 $)$ der humanen Hepatom-Zellinie HepG2 (Primer HF3, HR6, $\rightarrow$ 2.1.7.6) amplifiziert und damit die Anwesenheit des Transkripts in diesem Zellmodell bestätigt. Diese RNA wurde in allen weiteren PCR-Reaktionen als Matrize zur Erschließung der kodierenden cDNA-Sequenz des neuen $A B C A-G e n s$ benutzt. Zur Ermittlung der Gesamtlänge der bisher unbekannten mRNA wurden Northern-Blot-Untersuchungen durchgeführt. Sie ergaben ein schwaches Signal von $2.6 \mathrm{~kb}$ (ohne Abb.), was eine Abweichung zu bisher beschriebenen mRNA-Transkripten für ABCA1 (6.9 kb, LUCIANI et al., 1994) und ABCA4 (7.3 kb, AZARIAN et al., 1997) der ABCASubfamilie darstellte.

\subsubsection{Isolierung des humanen $A B C A 5-G e n s$}

Kodierende Gensequenzen von Wirbeltieren weisen besonders in der Nähe des 5'-Terminus und im 5'-untranslatierten Bereich häufig GC-reiche Regionen auf. Während der reversen Transkription im Rahmen eines RACE-Experiments führt dies bei Temperaturen $<50{ }^{\circ} \mathrm{C}$ zur verstärkten Ausbildung von Sekundärstrukturen, die in einem Abbruch der Reaktion und damit unvollständigen cDNA-Transkripten resultieren können.

Mehrere 5'-RACE-Schritte wurden mit AMV Reverser Transkriptase und versetzten genspezifischen Primern bei $55^{\circ} \mathrm{C}$ durchgeführt, um intakte cDNAs für den 5 '-Terminus des neuen $A B C A-G e n s$ zu generieren und mittels PCR zu amplifizieren. Dazu wurde mit einer 
DNA-Polymerasemischung gearbeitet, die für die Amplifikation langer cDNA-Bereiche geeignet sein sollte (Long Expand System von Roche). Zwecks Sequenzanalyse wurden alle PCR-Fragmente in den PCR $®$ XL-TOPO-Vektor ligiert und die Plasmide in elektrokompetenten E.coli Zellen $(\rightarrow 2.1 .7 .2)$ vermehrt $(\rightarrow 2.2 .5 .4)$. Nach Isolierung der Plasmid-DNA aus den selektierten Bakterienkolonien $(\rightarrow$ 2.2.2.1) erfolgte eine Sequenzierung der PlasmidInserts $(\rightarrow 2.2 .7)$ und eine Kombination der cDNA-Fragmente zu einer kontinuierlichen cDNA zwischen AJ275973.1 und dem Translationsstart (Abb 3.1).
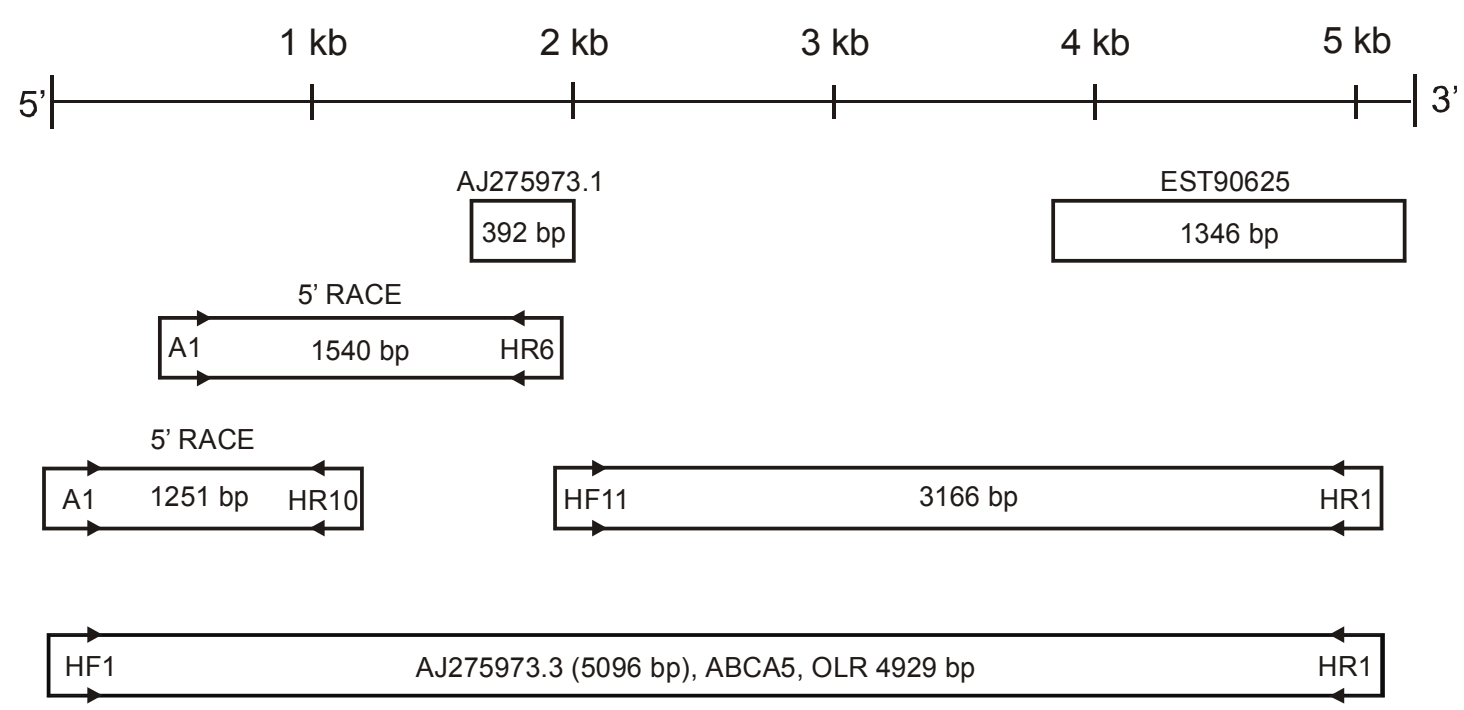

Abb. 3.1 Klonierungs-Strategie für humane ABCA5-cDNA. Die vollständige $A B C A 5-$ cDNA wurde aus mit 5'RACE-generierten und PCR-amplifizierten cDNAFragmenten zusammengesetzt. Reverse Transkriptionen erfolgten mit AMV Reverser Transkriptase und Thermoscript $(\rightarrow 2.2 .6 .2 f$.). A1 ist ein kommerzieller oligo-dT-Ankerprimer, HR1, HR6, HR10 sowie HF1 und HF11 sind ABCA5spezifische Primer $(\rightarrow$ 2.1.7.6). bp = Basenpaare, OLR $=$ Offener Leserahmen.

Das Syntheseoptimum der verwendeten reversen Transkriptase lag bei einer maximal möglichen Reaktionstemperatur von $55^{\circ} \mathrm{C}$ zwischen 500 und $1500 \mathrm{bp}$. Infolge dessen stellte sich dieses Enzym als nur bedingt geeignet heraus, den $>3$ kb-langen 3'-Terminus ausgehend von AJ275973.1 mit einer 3'-RACE-Reaktion zu erschließen. Diese Methode basierte darauf, cDNA-Transkripte ausgehend vom natürlichen poly-A-Schwanz der mRNASpezies mit dem oligo-dT-Ankerprimer $\mathrm{A} 1(\rightarrow 2.1 .7 .6 .1)$ zu synthetisieren und anschließend in einer PCR-Reaktion mit dem Anker-Primer A2 und einem genspezifischen Primer auf Basis von AJ275973.1 zu amplifizieren. Experimente nach diesem Protokoll führten nicht zu genspezifischen PCR-Produkten.

Homologierecherchen mit dem Blastn-Algorithmus (http://www.ncbi.nlm.nih.gov/BLAST/) zeigten eine starke Ähnlichkeit des identifizierten 5'-Bereichs mit der ersten ATP-Bindungs- 
kassette der Sequenz für humanes ABCA8 (Acc. No. AB020629) von NAGASE et al. (1998) und ergaben, daß die entsprechenden Bereiche beider Gene auf Chromosom 17 lokalisiert waren. Nach einem Vergleich der ABCA8-Sequenz mit den Nukleotiddatenbanken von GenBank und EMBL wurden mit EST90625, (1346 bp, Abb. 3.1) von ALLIKMETS et al. (1996) und KIAA1888 von NAGASE et al. (2001) partielle Sequenzen humaner Gene identifiziert, die miteinander überlappten und einem, dem neuen $A B C A$ cDNA-Fragment benachbarten, genomischen Lokus auf Chromosom 17 (17q24.3) zugeschrieben wurden. Beide Sequenzen wiesen eine starke Ähnlichkeit zur zweiten ATP-Bindungskassette von ABCA8 auf (ca. 50\% Sequenzhomologie über 1300 bp). Mittels einer PCR zwischen AJ275973.1 und EST90625 mit den Primern HF11 und HR1 $(\rightarrow$ 2.1.7.6) wurde die Hypothese bestätigt, daß beide cDNA-Fragmente von verschiedenen Bereichen der gleichen mRNA abstammten (Abb.3.1). Da im Zuge der ABC-Klassifizierung der EST90625-Sequenz bereits das Gensymbol ABCA5 zugeteilt worden war (BROCCARDO et al., 1999), wurde mit diesem Experiment der 3'-Bereich des humanen $A B C A 5$ identifiziert. Die vollständig kodierende cDNA-Sequenz von $A B C A 5$ (AJ275973.3) wurde anschließend gemäß Abb.3.1 amplifiziert und sequenziert. Die experimentell bestätigte cDNA bestand aus $5096 \mathrm{bp}$, der offene Leserahmen umfaßte 4929 bp inklusive Stopkodon. Dies entspricht einem Polypeptid von 1642 Aminosäuren mit einem errechneten Molekulargewicht von ca. 180 kDa (Abb. 3.2).

aacagactgagcgcgtccaggcctgacagctctgcggctcgggccctgaggtttattcagaaaac 65 Q T E R V Q A - Q L C G S G P E V Y S E N atgtccactgcaattagggaggtaggagtttggagacagaccagaacacttctactgaagaatta 130 $\begin{array}{lllllllllllllllllllllll}M & S & T & A & I & R & E & V & G & V & W & R & Q & T & R & T & L & L & L & K & N & Y & 22\end{array}$ cttaattaaatgcagaaccaaaaagagtagtgttcaggaaattcttttccactatttttttat 195 $\begin{array}{lllllllllllllllllllllll}\mathrm{L} & \mathrm{I} & \mathrm{K} & \mathrm{C} & \mathrm{R} & \mathrm{T} & \mathrm{K} & \mathrm{K} & \mathrm{S} & \mathrm{S} & \mathrm{V} & \mathrm{Q} & \mathrm{E} & \mathrm{I} & \mathrm{L} & \mathrm{F} & \mathrm{P} & \mathrm{L} & \mathrm{F} & \mathrm{F} & \mathrm{L} & & 43\end{array}$ tttggttaatattaattagcatgatgcatccaaataagaaatatgaagaagtgcctaatatagaa 260

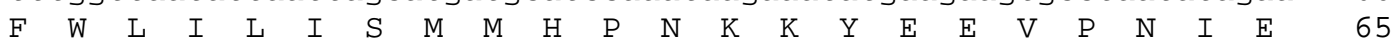
ctcaatcctatggacaagtttactcttctaatctaattcttggatatactccagtgactaatat 325 $\begin{array}{lllllllllllllllllllllll}\mathrm{L} & \mathrm{N} & \mathrm{P} & \mathrm{M} & \mathrm{D} & \mathrm{K} & \mathrm{F} & \mathrm{T} & \mathrm{L} & \mathrm{S} & \mathrm{N} & \mathrm{L} & \mathrm{I} & \mathrm{L} & \mathrm{G} & \mathrm{Y} & \mathrm{T} & \mathrm{P} & \mathrm{V} & \mathrm{T} & \mathrm{N} & \mathrm{I} & 87\end{array}$ tacaagcagcatcatgcagaaagtgtctactgatcatctacctgatgtcataattactgaagaat 390 $\begin{array}{lllllllllllllllllllllll}T & S & S & I & M & Q & K & V & S & T & D & H & L & P & D & V & I & I & T & E & E & & 108\end{array}$ atacaaatgaaaaagaaatgttaacatccagtctctctaagccgagcaactttgtaggtgtggtt 455 $\begin{array}{lllllllllllllllllllllll}Y & T & N & E & K & E & M & L & T & S & S & L & S & K & P & S & N & F & V & G & V & V & 130\end{array}$ ttcaaagactccatgtcctatgaacttcgttttttcctgatatgattccagtatcttctattta 520 $\begin{array}{lllllllllllllllllllllllllllllll} & \text { K } & \text { K } & S & M & S & Y & E & L & R & F & F & P & D & M & I & P & V & S & S & I & Y & 152\end{array}$ tatggattcaagagctggctgttcaaaatcatgtgaggctgctcagtactggtcctcaggtttca 585 $\begin{array}{llllllllllllllllllllll}M & D & S & R & A & G & C & S & K & S & C & E & A & A & Q & Y & W & S & S & G & F & 173\end{array}$ cagttttacaagcatccatagatgctgccattatacagttgaagaccaatgtttctctttggaag 650 $\begin{array}{lllllllllllllllllllllll}T & V & L & Q & A & S & I & D & A & A & \text { I } & \text { I } & \text { Q } & \text { L } & \text { K } & \text { T } & \text { N } & \text { V } & \text { S } & \text { L } & \text { W } & \text { K } & 195\end{array}$ gagctggagtcaactaaagctgttattatgggagaaactgctgttgtagaaatagatacctttcc 715

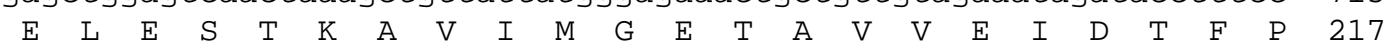
ccgaggagtaatttaatatacctagttatagcatttcacctttggatacttttggcaattc 780

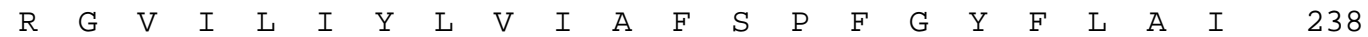
atatcgtagcagaaaaagaaaaaaaaataaaagaatttttaaagataatgggacttcatgatact 845 $\begin{array}{lllllllllllllllllllllll}H & I & V & A & E & K & E & K & K & I & K & E & F & L & K & I & M & G & L & H & D & T & 260\end{array}$ gcctttggcttcctgggttcttctatatacaagtttaattttcttatgtcccttcttatggc 910 $\begin{array}{lllllllllllllllllllllll}A & F & W & L & S & W & V & L & L & Y & T & S & L & I & F & L & M & S & L & L & M & A & 282\end{array}$ agtcattgcgacagcttctttgttatttcctcaaagtagcagcattgtgatatttctgctttttt 975

$\begin{array}{lllllllllllllllllllllllllll}V & I & A & T & A & S & L & L & F & P & Q & S & S & S & I & V & I & F & L & L & F & & 303\end{array}$ tccttatggattatcatctgtatttttgctttaatgctgacacctcttttaaaaatcaaaa 1040

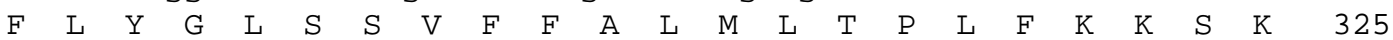
catgtgggaatagttgaatttttgttactgtggcttttggatttattggccttatgataatcct 1105 
$\begin{array}{lllllllllllllllllllllll}H & V & G & I & V & E & F & F & V & T & V & A & F & G & F & I & G & L & M & I & I & L & 347\end{array}$ catagaaagttttcccaaatcgttagtgtggctttcagtcctttctgtcactgtactttgtga 1170

$\begin{array}{llllllllllllllllllllll}I & E & S & F & P & K & S & L & V & W & L & F & S & P & F & C & H & C & T & F & V & 368\end{array}$ ttggtattgcacaggtcatgcatttagaagattttaatgaaggtgcttcatttcaaatttgact 1235 $\begin{array}{lllllllllllllllllllllll}I & G & I & A & Q & V & M & H & L & E & D & F & N & E & G & A & S & F & S & N & L & T & 390\end{array}$ gcaggccatatcctctaattattacaattatcatgctcacacttaatagtatattctatgtcct 1300 $\begin{array}{lllllllllllllllllllllll}A & G & P & Y & P & L & I & I & T & I & I & M & L & T & L & N & S & I & F & Y & V & L & 412\end{array}$ cttggctgtctatcttgatcaagtcattccaggggaatttggcttacggagatcatctttatatt 1365

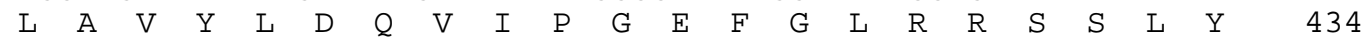
ttctgaagccttcatattggtcaaagagcaaaagaaattatgaggagttatcagagggcaatgtt 1430 $\begin{array}{lllllllllllllllllllllll}F & L & K & P & S & Y & W & S & K & S & K & R & N & Y & E & E & L & S & E & G & N & V & 456\end{array}$ aatggaaatattagttttagtgaaattattgagccagtttcttcagaatttgtaggaaaagaagc 1495 $\begin{array}{lllllllllllllllllllllll}N & G & N & I & S & F & S & E & I & I & E & P & V & S & S & E & F & V & G & K & E & A & 478\end{array}$ cataagaattagtggtattcagaagacatacagaaagaagggtgaaaatgtggaggctttgagaa 1560

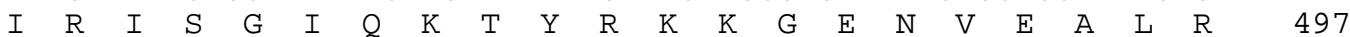
atttgtcatttgacatatatgagggtcagattactgccttacttggccacagtggaacaggaaag 1625 \begin{tabular}{lllllllllllllll|llllllll}
$N$ & $L$ & $S$ & $F$ & $D$ & $I$ & $Y$ & $E$ & $G$ & $Q$ & $I$ & $T$ & $A$ & $L$ & $L$ & $G$ & H & S & G & T & G & K & 519
\end{tabular}

\section{Walker A}

agtacattgatgaatattctttgtggactctgcccaccttctgatgggtttgcatctatatatgg 1690 \begin{tabular}{|lllllllllllllllllllllll}
\hline S & T & $L$ & L & $N$ & I & L & $C$ & $G$ & L & $C$ & $P$ & $P$ & $S$ & $D$ & $G$ & $F$ & $A$ & $S$ & $I$ & $Y$ & $G$ & 543
\end{tabular} W.A.

acacagagtctcagaaatagatgaaatgtttgaagcaagaaaaatgattggcatttgtccacagt 1755

$\begin{array}{llllllllllllllllllllll}H & R & V & S & E & I & D & E & M & F & E & A & R & K & M & I & G & I & C & P & Q & 564\end{array}$ tagatatacactttgatgttttgacagtagaagaaaatttatcaattttggcttcaatcaaaggg 1820 $\begin{array}{lllllllllllllllllllllll}L & D & I & H & F & D & V & L & T & V & E & E & N & L & S & I & L & A & S & I & K & G & 586\end{array}$ ataccagccaacaatataatacaagaagtgcagaaggttttactagatttagacatgcagactat 1885 $\begin{array}{lllllllllllllllllllllll}I & P & A & N & N & I & I & Q & E & V & Q & K & V & L & L & D & L & D & M & Q & T & I & 608\end{array}$ caaagataaccaagctaaaaaattaagtggtggtcaaaaaagaaagctgtcattaggaattgctg 1950

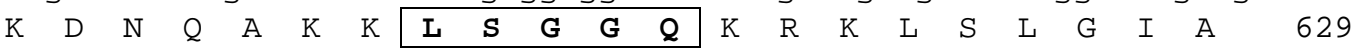
Signatur-Sequenz

ttcttgggaacccaaagatactgctgctagatgaaccaacagctggaatggacccctgttctcga 2015 \begin{tabular}{lllllll|llllllllllllllll}
$V$ & $L$ & $G$ & $N$ & $P$ & $K$ & $I$ & L & L & L & D & E & P & T & A & G & M & D & P & C & S & R & 651
\end{tabular} Walker B

catattgtatggaatctttaaaatacagaaaagccaatcgggtgacagtgttcagtactcattt 2080 $\begin{array}{lllllllllllllllllllllll}\text { H } & I & V & \text { W } & N & L & L & K & Y & R & K & A & N & R & V & T & V & F & S & T & H & F & 673\end{array}$ catggatgaagctgacattcttgcagataggaaagctgtgatatcacaaggaatgctgaaatgtg 2145

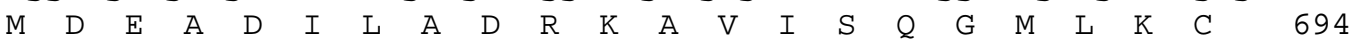
ttggttcttcaatgttcctcaaaagtaaatgggggatcggctaccgcctgagcatgtacatagac 2210 $\begin{array}{lllllllllllllllllllllll}V & G & S & S & M & F & L & K & S & K & W & G & I & G & Y & R & L & S & M & Y & I & D & 716\end{array}$ aatattgtgccacagaatctcttcttcactggttaaacaacatatacctggagctactttatt 2275 $\begin{array}{llllllllllllllllllllllll}K & Y & C & A & T & E & S & L & S & S & L & V & K & Q & H & I & P & G & A & T & L & L & 738\end{array}$ acaacagaatgaccaacaacttgtgtatagcttgcctttcaaggacatggacaaatttcaggtt 2340

$\begin{array}{llllllllllllllllllllll}Q & Q & N & D & Q & Q & L & V & Y & S & L & P & F & K & D & M & D & K & F & S & G & 759\end{array}$ tgttttctgccctagacagtcattcaaatttgggtgtcatttcttatggtgtttccatgacgact 2405

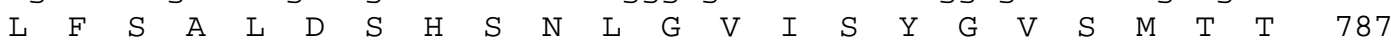
ttggaagacgtattttaaagctagaagttgaagcagaaattgaccaagcagattatagtgtatt 2470 $\begin{array}{lllllllllllllllllllllll}L & E & D & V & F & L & K & L & E & V & E & A & E & I & D & Q & A & D & Y & S & V & F & 809\end{array}$ tactcagcagccactggaggaagaaatggattcaaaatcttttgatgaaatggaacagagcttac 2535 $\begin{array}{llllllllllllllllllllll}T & Q & Q & P & L & E & E & E & M & D & S & K & S & F & D & E & M & E & Q & S & L & 830\end{array}$ ttattcttctgaaaccaaggcttctctagtgagcaccatgagcctttggaaacaacagatgtat 2600 $\begin{array}{lllllllllllllllllllllll}\text { L } & I & L & S & E & T & K & A & S & L & V & S & T & M & S & L & W & K & Q & Q & M & Y & 851\end{array}$ acaatagcaaagtttcatttctttaccttgaaacgtgaaagtaaatcagtgagatcagtgttgct 2665 $\begin{array}{lllllllllllllllllllllll}T & I & A & K & F & H & F & F & T & L & K & R & E & S & K & S & V & R & S & V & L & L & 873\end{array}$ tctgctttaattttttcacagttcagattttatgttttggttcatcactctttaaaaatg 2730

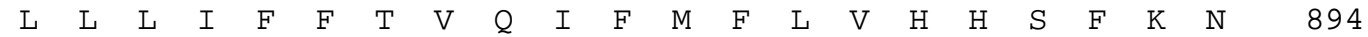
ctgtggttcccatcaaacttgttccagacttatatttctaaaacctggagacaaaccacataaa 2795 $\begin{array}{lllllllllllllllllllllll}A & V & V & P & I & K & L & V & P & D & L & Y & F & L & K & P & G & D & K & P & H & K & 916\end{array}$ tacaaaacaagtctgcttcttcaaaattctgctgactcagatatcagtgatcttattagcttttt 2860

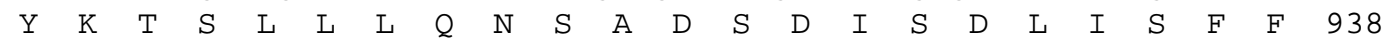
cacaagccagaacataatggtgacgatgattaatgacagtgactatgtatccgtggctccccata 2925

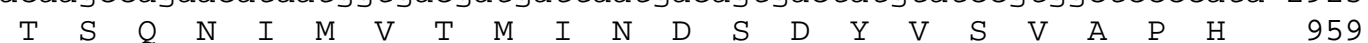
gtgcggctttaaatgtgatgcattcagaaaaggactatgttttgcagctgttttcaacagtact 2990 $\begin{array}{lllllllllllllllllllllll}S & A & A & L & N & V & M & H & S & E & K & D & Y & V & F & A & A & V & F & N & S & T & 987\end{array}$ atggtttattcttacctatattagtgaatatcattagtaactactatctttatcatttaaatgt 3055 $\begin{array}{llllllllllllllllllllllllllll}M & V & Y & S & L & P & I & L & V & N & I & I & S & N & Y & Y & L & Y & H & L & N & V & 1009\end{array}$ gactgaaaccatccagatctggagtaccccattctttcaagaaattactgatatagttttaaaa 3120 
$\begin{array}{llllllllllllllllllllll}T & E & T & I & Q & I & W & S & T & P & F & F & Q & E & I & T & D & I & V & F & K & 1030\end{array}$ ttgagctgtattttcaagcagctttgcttggaatcattgttactgcaatgccaccttactttgcc 3185 $\begin{array}{lllllllllllllllllllllll}I & E & L & Y & F & Q & A & A & L & L & G & I & I & V & T & A & M & P & P & Y & F & A & 1052\end{array}$ atggaaaatgcagagaatcataagatcaaagcttatactcaacttaaactttcaggtcttttgcc 3250 $\begin{array}{lllllllllllllllllllllll}M & E & N & A & E & N & H & \text { K } & \text { I } & \text { K } & \text { A } & \text { Y } & \text { T } & \text { Q } & \text { L } & \text { K } & \text { L } & \text { S } & \text { G } & \text { L } & \text { L } & \text { P } & 1072\end{array}$ atctgcatattggattggacaagctgttgttgatatccccttatttttatcattcttatttga 3315 $\begin{array}{llllllllllllllllllllll}S & A & Y & W & I & G & 0 & A & V & V & D & I & P & L & F & F & I & I & L & I & L & 1083\end{array}$ tgctaggaagcttattggcatttcattatggattatattttatactgtaaagttccttgctgtg 3380 $\begin{array}{lllllllllllllllllllllll}M & L & G & S & L & L & A & F & H & Y & G & L & Y & F & Y & T & V & K & F & L & A & V & 1105\end{array}$ gtttttgccttattggttatgttccatcagttattctgttcacttatattgcttctttcacctt 3445 $\begin{array}{lllllllllllllllllllllll}V & F & C & L & I & G & Y & V & P & S & V & I & L & F & T & Y & I & A & S & F & T & F & 1127\end{array}$ taagaaaattttaaataccaaagaattttggtcatttatctattctgtggcagcgttggcttgta 3510

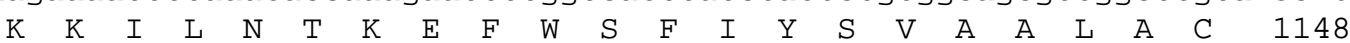
ttgcaatcactgaaataactttctttatgggatacacaattgcaactattcttcattatgccttt 3575

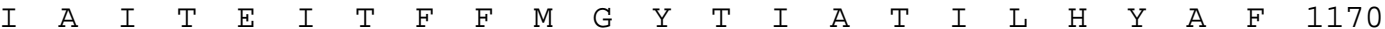
tgtatcatcattccaatctatccacttctaggttgcctgatttctttcataaagatttcttggaa 3640 $\begin{array}{lllllllllllllllllllllll}\text { C } & \text { I } & \text { I } & \text { I } & \text { P } & \text { I } & \text { Y } & \text { P } & \text { L } & \text { L } & \text { G } & \text { C } & \text { L } & \text { I } & \text { S } & \text { F } & \text { I } & \text { K } & \text { I } & \text { S } & \text { W } & \text { K } & 1192\end{array}$ gaatgtacgaaaaaatgtggacacctataatccatgggataggctttcagtagctgttatatcgc 3705

$\begin{array}{llllllllllllllllllllll}N & V & R & K & N & V & D & T & Y & N & P & W & D & R & L & S & V & A & V & I & S & 1213\end{array}$ cttacctgcagtgtgtactgtggattttcctcttacaatactatgagaaaaaatatggaggcaga 3770 $\begin{array}{lllllllllllllllllllllll}P & Y & L & Q & C & V & L & W & I & F & L & L & Q & Y & Y & E & K & K & Y & G & G & R & 1235\end{array}$ tcaataagaaaagatcccttttcagaaacctttcaacgaagtctaaaaataggaagcttccaga 3835 $\begin{array}{lllllllllllllllllllllll}S & I & R & K & D & P & F & F & R & N & L & S & T & K & S & K & N & R & K & L & P & E & 1257\end{array}$ accaccagacaatgaggatgaagatgaagatgtcaaagctgaaagactaaaggtcaaagagctga 3900

$\begin{array}{llllllllllllllllllllll}P & P & D & N & E & D & E & D & E & D & V & K & A & E & R & L & K & V & K & E & L & 1278\end{array}$ tgggttgccagtgttgtgaggagaaaccatccattatggtcagcaatttgcataaagaatatgat 3965 $\begin{array}{lllllllllllllllllllllll}M & G & C & Q & C & C & E & E & K & P & S & I & M & V & S & N & L & H & K & E & Y & D & 1300\end{array}$ gacaagaaagatttcttcttcaagaaaagtaaagaaagtggcaactaaatacatctctttctg 4030 $\begin{array}{lllllllllllllllllllllll}D & K & K & D & F & L & L & S & R & K & V & K & K & V & A & T & K & Y & I & S & F & C & 1322\end{array}$ tgtgaaaaaaggagagatcttaggactattgggtccaaatggtgctggcaaaagcacaattatta 4095 \begin{tabular}{lllllllllll|llllllllllll}
$V$ & $K$ & $K$ & $G$ & $E$ & $I$ & $L$ & $G$ & $L$ & $L$ & $G$ & P & N & G & A & G & K & S & T & I & I & 1343
\end{tabular} Walker A

atattctggttggtgatattgaaccaacttcaggccagatattttaggagattattcttcagag 4160 $\begin{array}{lllllllllllllllllllllll}N & I & L & V & G & D & I & E & P & T & S & G & Q & \text { I } & F & L & G & D & Y & S & S & E & 1365\end{array}$ tcaagtgaagatgatgattcactgaagtgtatgggttactgtcctcagataaaccctttgtggcc 4225 $\begin{array}{lllllllllllllllllllllll}S & S & E & D & D & D & S & L & K & C & M & G & Y & C & P & Q & I & N & P & L & W & P & 1387\end{array}$ agatactacattgcaggaacattttgaaatttatggagctgtcaaaggaatgagtgcaagtgaca 4290

$\begin{array}{lllllllllllllllllllllllll}D & T & T & L & Q & E & H & F & E & I & Y & G & A & V & K & G & M & S & A & S & D & 1408\end{array}$ tgaaagaagtcataagtcgaataacacatgcacttgatttaaaagaacatcttcagaagactgta 4355 $\begin{array}{lllllllllllllllllllllll}M & K & E & V & I & S & R & I & T & H & A & L & D & L & K & E & H & L & Q & K & T & V & 1430\end{array}$ aagaaactacctgcaggaatcaaacgaaagttgtgtttgctctaagtatgctagggaatcctca 4420 $\begin{array}{lllllllllllllllllllllll}K & \text { K } & \text { L } & \text { P } & \text { A } & \text { G } & \text { I } & \text { K } & \text { R } & \text { K } & \text { L } & \text { C } & \text { F } & \text { A } & \text { L } & \text { S } & \text { M } & \text { L } & \text { G } & \text { N } & \text { P } & \text { Q } & 1452\end{array}$ gattactttgctagatgaaccatctacaggtatggatcccaaagccaaacagcacatgtggcgag 4485

\begin{tabular}{ll|lllllllllll|lllllllll} 
I & $T$ & L & L & D & E & P & S & T & G & M & D & P & K & A & K & Q & H & M & W & R & 1473
\end{tabular}
Walker B

caattcggactgcatttaaaaacagaaagcgggctgctattctgaccactcactatatggaggag 4550 $\begin{array}{llllllllllllllllllllllll}\text { A } & I & R & T & A & F & K & N & R & K & R & A & A & I & L & T & T & H & Y & M & E & E & 1495\end{array}$ gcagaggctgtctgtgatcgagtagctatcatggtgtctgggcagttaagatgtatcggaacagt 4615 $\begin{array}{lllllllllllllllllllllll}\text { A } & E & A & V & C & D & R & V & A & I & M & V & S & G & Q & L & R & C & I & G & T & V & 1517\end{array}$ acaacatctaaagagtaaatttggaaaaggctacttttggaaattaaattgaaggactggatag 4680

$\begin{array}{llllllllllllllllllllll}Q & H & L & K & S & K & F & G & K & G & Y & F & L & E & I & K & L & K & D & W & I & 1538\end{array}$ aaaacctagaagtagaccgccttcaaagagaaattcagtatatttcccaaatgcaagccgtcag 4745

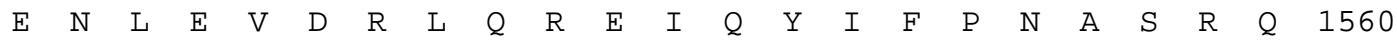
gaaagttttcttctatttggcttataaaattcctaaggaagatgttcagtcccttcacaatc 4810

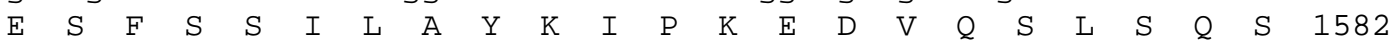
ttttttaagctggaagaagctaaacatgcttttgccattgaagaatatagctttctcaagcaa 4875

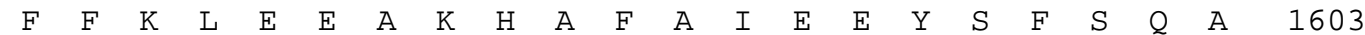
cattggaacaggttttgtagaactcactaaagaacaagaggaggaagataatagttgtggaact 4940 $\begin{array}{lllllllllllllllllllllll}T & L & E & Q & V & F & V & E & L & T & K & E & Q & E & E & E & D & N & S & C & G & T & 1625\end{array}$ ttaaacagcacactttggtgggaacgaacacaagaagatagagtagtattt tgaatttgtattgt 5005 $\begin{array}{lllllllllllllllllll}\text { L } & N & S & T & L & W & W & E & R & T & Q & E & D & R & V & V & F & - & 1642\end{array}$ tcggtctgcttactgggacttctttcttttcacttaatttaactttggtttaaaaagttttt 5070 attggaatggtaactggagaaccaag 
Abb. 3.2 Nukleotidsequenz der isolierten cDNA des ABCA5-Gens und die abgeleitete Aminosäuresequenz des offenen Leserahmens. Die Sequenz des kodierenden Stranges der cDNA ist in Kleinbuchstaben angeführt. Die abgeleitete Aminosäuresequenz ist unterhalb der Nukleotidsequenz angeordnet. Das Startkodon (atg), das Stopkodon (tga) und die charakteristischen Motive der Nukleotidbindungskassetten (Walker A, Signatur-Sequenz und Walker B) sind fett markiert und mit Rahmen hervorgehoben. Die Numerierung entspricht dem Genbank-Eintrag AJ275973.3.

\subsubsection{Genomische Struktur von ABCA5}

Die in dieser Arbeit identifizierte ABCA5 cDNA von 5096 bp repräsentiert eins von bisher mehr als 30 verschiedenen, teilweise unvollständigen cDNA-Transkripten. Eine BLASTStrukturanalyse des humanen Genoms ergab die Aufteilung der kodierenden Sequenz in 39 Exons, die sich über eine genomische Region von ca. $80 \mathrm{~kb}$ auf dem Chromosom 17q24.3 erstrecken (Abb.3.3).

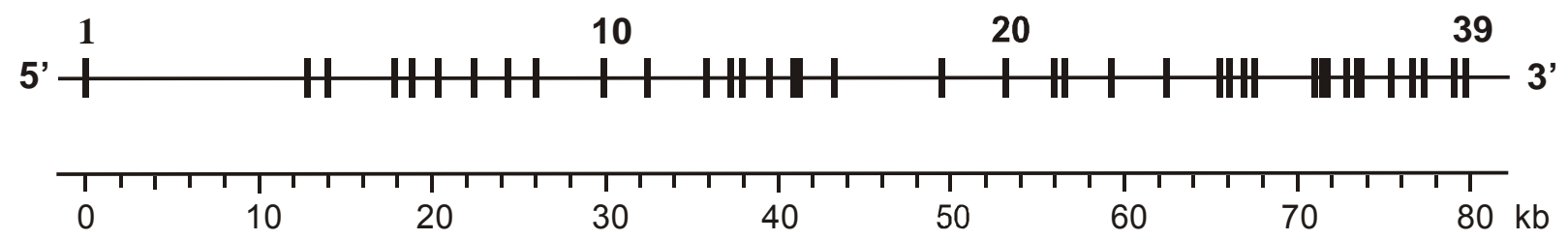

Abb. 3.3 Genomische Organisation des ABCA5-Gens in der Chromosomalregion 17q24.3. Die Exons sind in aufsteigender Reihenfolge vom 5'-Terminus numeriert und werden trotz der Größenunterschiede als gleich große schwarze Balken gekennzeichnet. Das Exon-Intron-Schema ist mit einer metrischen Skala unterlegt.

Die individuellen Exongrößen variierten zwischen 52 bp und $233 \mathrm{bp}$, die Intronlängen zwischen 96 bp und 12678 bp, wobei sich das größte Intron zwischen Exons 1 und 2 befand (Tabelle 3.1). In Exon 2 wurde mit dem Sequenzmotiv AACATGT (Nukleotide 63-68 in AJ275973.3) ein Signal detektiert, das nach KOZAK (1986) dem Konsensusmotiv für den eukaryotischen Translationsstart entspricht.

Im Abstand von nur 7 bp zum 3'-Terminus von Exon 37 wurde eine unvollständige Variante dieses Exons (genannt Exon 37') detektiert, dessen Transkription zu einem vorzeitigen Translationsabbruch und damit zu einem verkürzten Proteinprodukt (1608 Aminosäuren) führen würde. 


\begin{tabular}{|c|c|c|c|c|c|}
\hline Exon & $\begin{array}{c}\text { Exonlänge } \\
\text { in bp }\end{array}$ & $\begin{array}{c}\text { Intronlänge } \\
\text { in bp }\end{array}$ & Exon & $\begin{array}{c}\text { Exonlänge } \\
\text { in bp }\end{array}$ & $\begin{array}{c}\text { Intronlänge } \\
\text { in bp }\end{array}$ \\
\hline 1 & 52 & 12678 & 21 & 130 & 409 \\
\hline 2 & 120 & 1015 & 22 & 141 & 2548 \\
\hline 3 & 207 & 3668 & 23 & 122 & 3079 \\
\hline 4 & 163 & 892 & 24 & 175 & 2984 \\
\hline 5 & 91 & 1324 & 25 & 116 & 357 \\
\hline 6 & 233 & 1908 & 26 & 153 & 711 \\
\hline 7 & 151 & 1760 & 27 & 77 & 540 \\
\hline 8 & 191 & 1427 & 28 & 93 & 3421 \\
\hline 9 & 152 & 3776 & 29 & 129 & 305 \\
\hline 10 & 172 & 2476 & 30 & 121 & 96 \\
\hline 11 & 61 & 3329 & 31 & 98 & 1050 \\
\hline 12 & 112 & 1177 & 32 & 175 & 445 \\
\hline 13 & 179 & 564 & 33 & 77 & 125 \\
\hline 14 & 120 & 1424 & 34 & 102 & 1701 \\
\hline 15 & 141 & 1297 & 35 & 121 & 1124 \\
\hline 16 & 96 & 182 & 36 & 152 & 486 \\
\hline 17 & 144 & 1818 & 37 & 86 & 1582 \\
\hline 18 & 127 & 6109 & $37^{\prime}$ & 80 & 1496 \\
\hline 19 & 206 & 3507 & 38 & 60 & 614 \\
\hline 20 & 175 & 2669 & 39 & 212 & \\
\hline
\end{tabular}

Tabelle 3.1 Intron-Exon-Organisation für das ABCA5-Gen des Menschen (AJ275973.3). Die Strukturanalyse wurde mit dem BLAST-Genom-Programm durchgeführt. Die Exons sind fortlaufend numeriert, das zugehörige Intron folgt dem entsprechenden Exon. Exons 37 und 37' sind auf dem Genom nebeneinander angeordnet. Das Signal für den Translationsstop befindet sich in Exon 39 und beginnt an Position 4992. Die vorhergesagten Exongrenzen überlappen um bis zu 16 bp.

\subsubsection{Identifizierung einer ABCA5-Splicevariante ABCA5 V20+16}

Im Rahmen der Sequenzanalyse verschiedener $A B C A 5$ cDNA-Klone wurde ein neues $A B C A 5$-Transkript mit einer 16 bp-Insertion detektiert ( $A B C A 5$ V20+16). Es wurde angenommen, daß es sich dabei um ein Produkt eines alternativen Splice-Ereignisses während der RNA-Prozessierung handelte. Der 3'-Terminus des Exons 20 ist um 16 bp der nachfolgenden Intronsequenz verlängert, woraus eine Verschiebung des offenen Leserahmens und 
ein vorzeitiger Abbruch der Translation nach 2775 bp in bezug auf das Startkodon resultierten (Abb. 3.4).

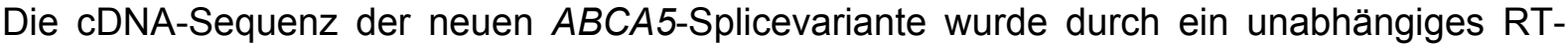
PCR-Experiment mit insertionsspezifischen Primern (HSV R1, $\rightarrow$ 2.1.7.6.5, F1, $\rightarrow$ 2.1.7.6.1) an Gesamt-RNA aus HepG2-Zellen und humaner Leber bestätigt und in der Datenbank unter der Accession Number AJ512612 abgelegt. In Datenbankrecherchen wurden zwei weitere, die identische Insertion tragende, Teilsequenzen aus humanem Leber- (AV653472) und Kleinhirn-Gewebe (AK094416.1) identifiziert. Darüber hinaus enthielt AK094416.1 eine zusätzliche 31 bp-Insertion am 3'-Terminus von Exon 23.

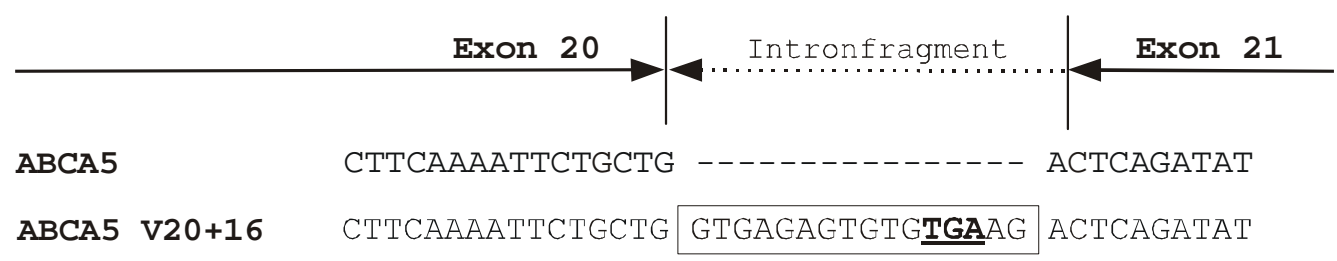

Abb. 3.4 Ausschnitt aus der ABCA5-cDNA in der Region zwischen Exons 20 und 21. Die 16 bp-Insertion (Rahmenbox) führt bei dem alternativen $A B C A 5-c D N A-$ Transkript $(A B C A 5$ V20+16) zu einem vorzeitigen Stopkodon (TGA) und somit zu einem Translationsabbruch nach 2775 bp.

\subsubsection{Isolierung des orthologen Abca5-Gens der Ratte}

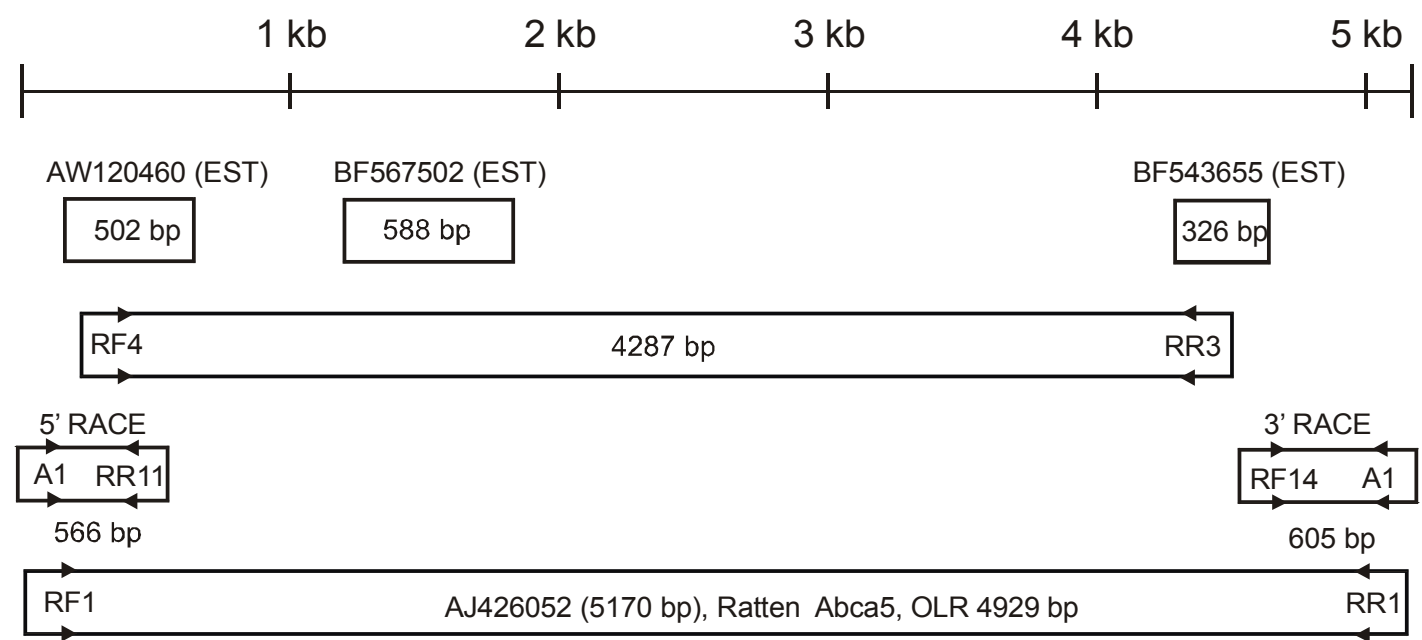

Abb.3.5 Klonierungsstrategie für die Abca5-cDNA der Ratte (rAbca5). Die vollständige rAbca5-cDNA wurde aus mit 5'/3' RACE-generierten und PCR-amplifizierten cDNA-Fragmenten zusammengesetzt. Reverse Transkriptionen erfolgten mit AMV Reverser Transkriptase und Thermoscript $(\rightarrow$ 2.2.6.2f.). A1 ist ein kommerzieller 
oligo-dT-Ankerprimer, RF1, RF4, RF14 sowie RR3 und RR11 sind rAbca5spezifische Primer $(\rightarrow 2.1 .7 .6)$. bp = Basenpaare, OLR $=$ Offener Leserahmen.

BROCCARDO et al. (1999) beschrieben schon für die ersten ABCA-Gene (ABCA1, ABCA4) einen hohen Konservierungsgrad zwischen verschiedenen Säugetier-Spezies. Auf Grundlage der humanen ABCA5-cDNA ( $h A B C A 5)$ wurden daher Datenbankrecherchen nach cDNA-Fragmenten eines orthologen Gens der Ratte durchgeführt. Zwei ESTs der Ratte (BF567502, BF543655) und ein EST der Maus (AW120460) zeigten Sequenzhomologien zu $h A B C A 5$ von $>86 \%$. Sie wurden zur Generierung sequenzspezifischer Primer verwendet, um mittels PCR zu überprüfen, ob diese EST-Sequenzen von einem zu $h A B C A 5$ orthologen Gen der Ratte abstammten. Mit den Primern RF4 und RR3 $(\rightarrow$ 2.1.7.6) wurde ein cDNAProdukt von $4287 \mathrm{bp}$ amplifiziert (Abb. 3.5). Nach Klonierung des Fragments in den pCR $®$ XL-TOPO-Vektor und anschließender Sequenzanalyse wurde die Existenz eines neuen Abca5-Gens der Ratte bestätigt ( $r A b c a 5)$. Mittels RACE-PCR mit den Primern A1, RR11 und RR14 ( $\rightarrow 2.1 .7 .6)$ erhielt man zwei cDNA-Fragmente (566 bp und 605 bp), die zur Vervollständigung des 5'- bzw. 3'-Terminus' dienten.

Im 3'-untranslatierten Bereich des rAbca5-Gens wurde 188 bp abwärts des Translationsstops ein putatives Polyadenylierungssignal (Poly-AS) AATAAA detektiert, obwohl nach BEAUDOING et al. (2000) die Existenz weiterer Polyadenylierungsloki im 3'-Terminus der mRNA nicht ausgeschlossen werden konnte. Gemäß Abb. 3.5 wurde die vollständig kodierende cDNA-Sequenz des Abca5-Gens der Ratte (Genbank Accession Number AJ426052) amplifiziert und sequenziert. Die experimentell bestätigte cDNA bestand aus $5170 \mathrm{bp}$, der offene Leserahmen umfaßte mit dem Stopkodon $4929 \mathrm{bp}$. Dies entsprach einem Polypeptid von 1642 Aminosäuren mit einem errechneten Molekulargewicht von ca. $180 \mathrm{kDa}$.

1

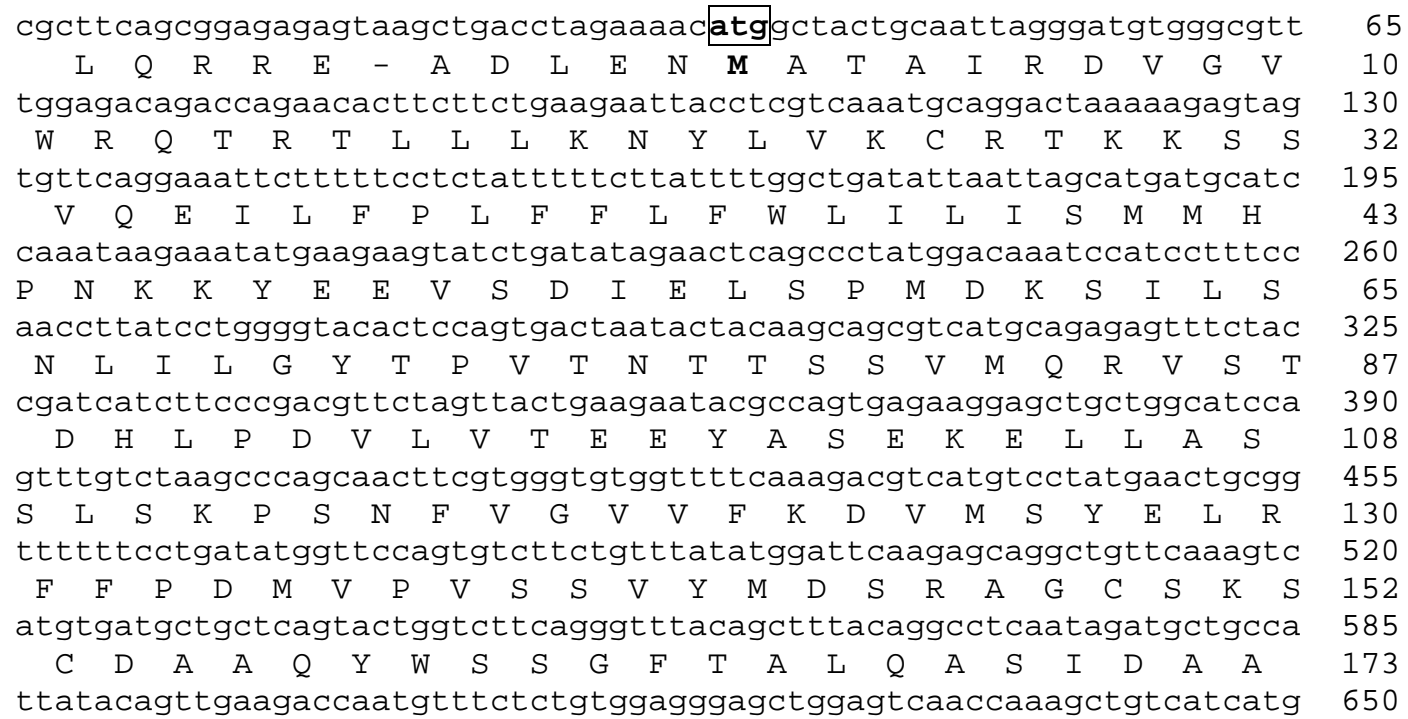


1691

543

1756

564

1821

586

1886

608

1951

629

2016

651

2081

673

2146

694

2211

716

2276

738

2341

759

2406

781

2471
$\begin{array}{lllllllllllllllllllllll}I & I & Q & L & K & T & N & V & S & L & W & R & E & L & E & S & T & K & A & V & I & M & 195\end{array}$ ggggaagctgcggtcgtggagattgacaccttcccacgaggggtcatcctcatctacctcgtcat 715 $\begin{array}{lllllllllllllllllllllll}G & E & A & A & V & V & E & I & D & T & F & P & R & G & V & I & L & I & Y & L & V & I & 217\end{array}$ agccttctcgcccttcgggtactttctggcaattcacattgtagcagaaaaggaaaagaggttaa 780

$\begin{array}{llllllllllllllllllllll}A & F & S & P & F & G & Y & F & L & A & I & H & I & V & A & E & K & E & K & R & L & 238\end{array}$ aggagttttaaagataatgggacttcacgacactgcttttggctgtcctgggttcttctgtac 845 $\begin{array}{lllllllllllllllllllllll}K & E & F & L & K & I & M & G & L & H & D & T & A & F & W & L & S & W & V & L & L & Y & 260\end{array}$ acgagtttgatcttccttatgtcccttcttatggccgtcattgcaacagcgtcctcgttattccc 910 $\begin{array}{lllllllllllllllllllllll}T & S & L & I & F & L & M & S & L & L & M & A & V & I & A & T & A & S & S & L & F & P & 282\end{array}$ tcagagtagcagcatcgtgattttctgctcttcttcctgtacggattgtcatctgtgttttttg 975 $\begin{array}{llllllllllllllllllllll}Q & S & S & S & I & V & I & F & L & L & F & F & L & Y & G & L & S & S & V & F & F & 303\end{array}$ ctttaatgttgacgcctcttttaaaaaatcaaagcacgtgggagtcgttgagtttttgtcacc 1040

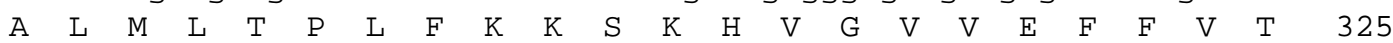
gtggtgtttggctttgtcggcctgttgatagtcctcgtagaaagtttccccaggtcgctagtgtg 1105

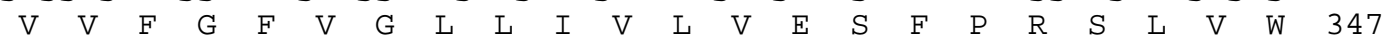
gctcttcagtcctttgtgtcagtgcgccttctgattgggattgcacaggtcatgcatttagaag 1170

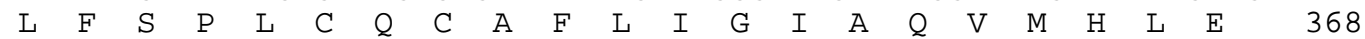
atttcaatgaaggagccttattttctagtttgactgaaggcccctacccgctaattatcaccctt 1235 $\begin{array}{lllllllllllllllllllllll}D & F & N & E & G & A & L & F & S & S & L & T & E & G & P & Y & P & L & I & I & T & L & 390\end{array}$ accatgctcgctctggacagtgtgttctatgccetgctggctgtgtaccttgatcaggtcatccc 1300 $\begin{array}{lllllllllllllllllllllllll}T & M & L & A & L & D & S & V & F & Y & A & L & L & A & V & Y & L & D & Q & V & I & P & 412\end{array}$ aggggaatttggcttgaggaggtcatctttgtacttcctaaagccatcatattggtcaaaaaaca 1365

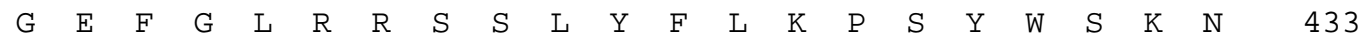
aaaggaactataaggagctatcagagggcaacatcaatgggaatattagtctcaatgaaattgtt 1430 $\begin{array}{lllllllllllllllllllllll}K & R & N & Y & K & E & L & S & E & G & N & I & N & G & N & I & S & L & N & E & I & V & 455\end{array}$ gagcccgtttcttcagaatttataggaaaagaagctataagaataagtggtattcagaaagccta 1495

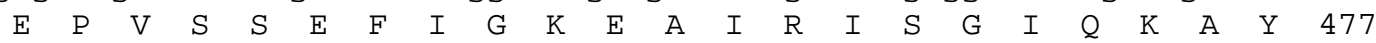
taggaagaagaatgagaccgtggaggctttgagaaatttgtcgtttgacatctatgaaggccaga 1560

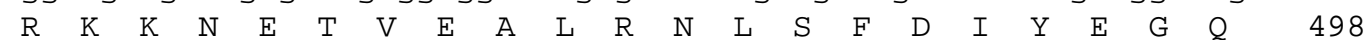
ttactgctctgctgggccacagtggaacaggaaaaagcacactaatgaatattctgtgtggactg 1625 \begin{tabular}{llllll|lllllllllllllllllll} 
& $\mathrm{I}$ & $\mathrm{T}$ & $\mathrm{A}$ & $\mathrm{L}$ & $\mathrm{L}$ & $\mathbf{G}$ & $\mathbf{H}$ & $\mathbf{S}$ & $\mathbf{G}$ & $\mathbf{T}$ & $\mathbf{G}$ & $\mathbf{K}$ & $\mathbf{S}$ & $\mathbf{T}$ & $\mathrm{L}$ & $\mathrm{M}$ & $\mathrm{N}$ & $\mathrm{I}$ & $\mathrm{L}$ & $\mathrm{C}$ & $\mathrm{G}$ & $\mathrm{L}$ & 520
\end{tabular} Walker A

tgcccaccttctgatgggtttgcttctatatatggacacagagtctctgaaatagatgaaatgtt 1690 $\begin{array}{lllllllllllllllllllllll}C & P & P & S & D & G & F & A & S & I & Y & G & H & R & V & S & E & I & D & E & M & F & 542\end{array}$ tgaagcgaggaaaatgattggcatatgtccacagtcagatatgaactttgatgttctgacagtag 1755

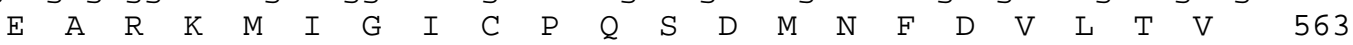
aagaaaatt tatcaattttggcttcagtcaaaggaataccagccaacaacataattcaggaagta 1820

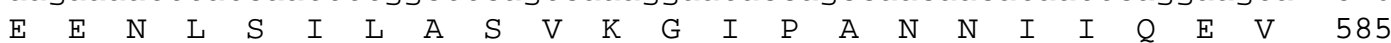
cagaaagttttactggatttggacatgcaagccatcaaagataatcaagcgaaaaaactaagtgg 1885 $\begin{array}{llllllllllllllllllllllll}Q & K & V & L & L & D & L & D & M & Q & A & I & K & D & N & Q & A & K & K & & \text { L } & \text { S } & \text { G } & 607\end{array}$ Signatur -

tggccaaaagagaaagctgtctttaggaattgcagttcttgggaatccaaagatcctcctgctag 1950 \begin{tabular}{lllllllllllllllllll|lllll}
$\mathbf{G}$ & $\mathbf{Q}$ & $\mathbf{K}$ & $\mathrm{R}$ & $\mathrm{K}$ & $\mathrm{L}$ & $\mathrm{S}$ & $\mathrm{L}$ & $\mathrm{G}$ & $\mathrm{I}$ & $\mathrm{A}$ & $\mathrm{V}$ & $\mathrm{L}$ & $\mathrm{G}$ & $\mathrm{N}$ & $\mathrm{P}$ & $\mathrm{K}$ & $\mathrm{I}$ & $\mathbf{L}$ & $\mathbf{L}$ & $\mathbf{L}$ & & 628
\end{tabular} Sequenz W.B.

atgagccgacagcaggaatggaccctgctctcgccacattgtttggaatcttctcaagtacagg 2015 \begin{tabular}{|lllllllllllllllllllllllll}
\hline $\mathbf{D}$ & $\mathbf{E}$ & $\mathbf{P}$ & $\mathbf{T}$ & $\mathbf{A}$ & $\mathbf{G}$ & $\mathbf{M}$ & $\mathbf{D}$ & $\mathbf{P}$ & $\mathbf{C}$ & $\mathrm{S}$ & $\mathrm{R}$ & $\mathrm{H}$ & $\mathrm{I}$ & $\mathrm{V}$ & $\mathrm{W}$ & $\mathrm{N}$ & $\mathrm{L}$ & $\mathrm{L}$ & $\mathrm{K}$ & $\mathrm{Y}$ & $\mathrm{R}$ & 650
\end{tabular} Walker B

aaggctaaccgagtgacagtcttcagcactcacttcatggatgaggccgacattcttgccgacag 2080 $\begin{array}{lllllllllllllllllllllllll}K & A & N & R & V & T & V & F & S & T & H & F & M & D & E & A & D & I & L & A & D & R & 672\end{array}$ gaaagctgtcatatcacaaggaatgctgaaatgtgttggttcttcaattttcctgaaaagtaaat 2145

$\begin{array}{llllllllllllllllllllll}K & A & V & I & S & Q & G & M & L & K & C & V & G & S & S & I & F & L & K & S & K & 693\end{array}$ ggggaatcggctaccgtctgagcatgtatatagacaggtactgtgccacagagtcgctctcgtcg 2210 $\begin{array}{llllllllllllllllllllllll}W & G & I & G & Y & R & L & S & M & Y & I & D & R & Y & C & A & T & E & S & L & S & S & 715\end{array}$ ctggttagacagcacatccctgcggccgctctgctgcagcagaatgaccagcagattgtctatag 2275 $\begin{array}{lllllllllllllllllllllll}L & V & R & Q & H & I & P & A & A & A & L & L & Q & Q & N & D & Q & Q & I & V & Y & S & 737\end{array}$ cttgccettcaaagacatggacaaatttcaggcttgtttctgctctagacattcattcaaacc 2340

$\begin{array}{lllllllllllllllllllllllll} & L & P & F & K & D & M & D & K & F & S & G & L & F & S & A & L & D & I & H & S & N & & 758\end{array}$ tgggtgtaatttcttatggtgtttccatgacgacattggaagacgtgtttttaaagctagaagtt 2405 $\begin{array}{lllllllllllllllllllllll}L & G & V & I & S & Y & G & V & S & M & T & T & L & E & D & V & F & L & K & L & E & V & 780\end{array}$ gaagcagaaattgaccaagcagattatagtgtatttacccagcagccacgggaggaagaaacaga 2470 $\begin{array}{lllllllllllllllllllllllllllllllllll}E & A & E & I & D & Q & A & D & Y & S & V & F & T & Q & Q & P & R & E & E & E & T & D & 802\end{array}$ ttcaaagtctttgatgaaatggaacagagtttacttattctctctgaaaccaaagcttctctag 2535 $\begin{array}{llllllllllllllllllllll}S & K & S & F & D & E & M & E & Q & S & L & L & I & L & S & E & T & K & A & S & L & 823\end{array}$ tgagcaccatgagtctctggaagcagcaagtatctacaatagcaaagtttcatttcctctcactg 2600 $\begin{array}{lllllllllllllllllllllll}V & S & T & M & S & L & W & K & Q & Q & V & S & T & I & A & K & F & H & F & L & S & L & 845\end{array}$ aagcgagaaagcaaatcagtgcgctctgtgttgcttctgcttttaatttttttgcagttcagat 2665 
2991

986

3056

1008

3121

1029

3186

1051

3251

1073

3316

1094

3381

1116

3446

1138

3511

1159

3576

1181

3641

1203

3706

1224

3771

1246

3836

1268

3901

1289

3966

1311

4031

1333

4196

1354

4161

1376

4226

1398

4291

1419

4356

1441

4421

1463

4486

1484

4551

1506

4616

1528
$\begin{array}{llllllllllllllllllllllll}K & \mathrm{R} & \mathrm{E} & \mathrm{S} & \mathrm{K} & \mathrm{S} & \mathrm{V} & \mathrm{R} & \mathrm{S} & \mathrm{V} & \mathrm{L} & \mathrm{L} & \mathrm{L} & \mathrm{L} & \mathrm{L} & \mathrm{I} & \mathrm{F} & \mathrm{F} & \mathrm{A} & \mathrm{V} & \mathrm{Q} & \mathrm{I} & 877\end{array}$ ttttatgttttggtccatcattcttttaaaatgctgtggttcccatcaagctcgttccagact 2730

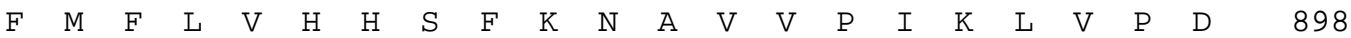
tgtatttctaaaacctggagataaacctcataaatacaaaacaagcctgctgcttcaaaattct 2795 $\begin{array}{lllllllllllllllllllllll}\mathrm{L} & \mathrm{Y} & \mathrm{F} & \mathrm{L} & \mathrm{K} & \mathrm{P} & \mathrm{G} & \mathrm{D} & \mathrm{K} & \mathrm{P} & \mathrm{H} & \mathrm{K} & \mathrm{Y} & \mathrm{K} & \mathrm{T} & \mathrm{S} & \mathrm{L} & \mathrm{L} & \mathrm{L} & \mathrm{Q} & \mathrm{N} & \mathrm{S} & 920\end{array}$ actgattcagatatcaatgatcttattgacttttcacacagcagaacataattgtggccatgtt 2860 $\begin{array}{lllllllllllllllllllllll}T & D & S & D & I & N & D & L & I & D & F & F & T & Q & Q & N & I & I & V & A & M & F & 942\end{array}$ taatgacagtgactatgtgtctgctgctcctcatagtgcggctctcaatgtggtgcagtcagaaa 2925

$\begin{array}{llllllllllllllllllllll}N & D & S & D & Y & V & S & A & A & P & H & S & A & A & L & N & V & V & Q & S & E & 963\end{array}$ aggactatgttttactgctgttt tcaacagtactatggtttattcttgccagtaatgatgaac 2990 $\begin{array}{lllllllllllllllllllllll}K & D & Y & V & F & T & A & V & F & N & S & T & M & V & Y & S & L & P & V & M & M & N & 985\end{array}$ atcattagtaactactatctctatcatttaaatgtgactgacactatccagatctggagtacccc 3055

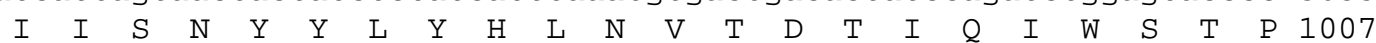
gttcattcaggaaattactgacattgtttttaaagttgagctatatttcaagcagctttgcttg 3120

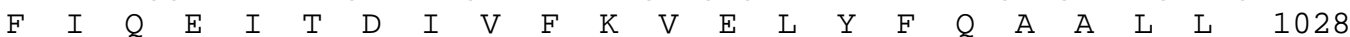
gaatcattgttactgcaatgccaccttactttgccatggaaaatgcagagaatcataagatcaaa 3185 $\begin{array}{lllllllllllllllllllllll}G & I & I & V & T & A & M & P & P & Y & F & A & M & E & N & A & E & N & H & K & I & K & 1050\end{array}$ gcttacactcagcttaaactttcaggtctttgccatccgcctactggattggacaggctgtggt 3250 $\begin{array}{llllllllllllllllllllllll}A & Y & T & Q & L & K & L & S & G & L & L & P & S & A & Y & W & I & G & Q & A & V & V & 1072\end{array}$ ggacattcccotgtttttgttgttctgactttgatgctgggaagtttatttgcctttcatcacg 3315

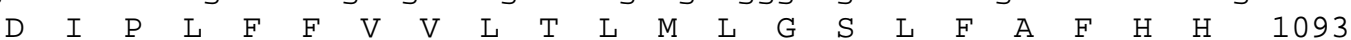
gactgtattttatcctgtaaagtttcttgctgtggtttttgcctcattgcttatgtgccetcg 3380 $\begin{array}{lllllllllllllllllllllll}G & L & Y & F & Y & P & V & K & F & L & A & V & V & F & C & L & I & A & Y & V & P & S & 1115\end{array}$ gttattctgttcacttatatagcttcgttcacctttaagaaaattttaaataccaaggaattttg 3445 $\begin{array}{lllllllllllllllllllllll}V & I & L & F & T & Y & I & A & S & F & T & F & K & K & I & L & N & T & K & E & F & W & 1137\end{array}$ gtcatttatctattctgtgacagcattggcttgtgtcgcagtcacggaaataactttctttctgg 3510

$\begin{array}{llllllllllllllllllllll}S & F & I & Y & S & V & T & A & L & A & C & V & A & V & T & E & I & T & F & F & L & 1158\end{array}$ ggtatggagttacggctgttttcattacaccttctgcatagccatcccaatctaccogctcctg 3575 $\begin{array}{lllllllllllllllllllllll}G & Y & G & V & T & A & V & F & H & Y & T & F & C & I & A & I & P & I & Y & P & L & L & 1180\end{array}$ ggttgtctgattcttcataaagggttcttggaagaatataccaaaaactgagaatgcctacaa 3640 $\begin{array}{lllllllllllllllllllllll}G & C & L & I & S & F & I & K & G & S & W & K & N & I & P & K & T & E & N & A & Y & N & 1202\end{array}$ tccotgggacagacttttagttgctgtaatcatgccetacctgcagtgtgtactgtggattttcc 3705

$\begin{array}{llllllllllllllllllllll}P & W & D & R & L & L & V & A & V & I & M & P & Y & L & Q & C & V & L & W & I & F & 1223\end{array}$ tcttacaacactatgagaaaaaacatggaggcagatcaataagaaaggatccgctttcagggcc 3770 $\begin{array}{llllllllllllllllllllllllllll}L & L & Q & H & Y & E & K & K & H & G & G & R & S & I & R & K & D & P & L & F & R & A & 1245\end{array}$ ctctcacaaaaagccaaacataagaagtttccagaaccacccatcaatgaggatgaagatgaaga 3835 $\begin{array}{llllllllllllllllllllllllllll}L & S & Q & K & A & K & H & K & K & F & P & E & P & P & I & N & E & D & E & D & E & D & 1267\end{array}$ tgtcaaagcggaaaggttgaaggttaaagagctgatgggttgccagtgttgtgaggagaaaccgg 3900

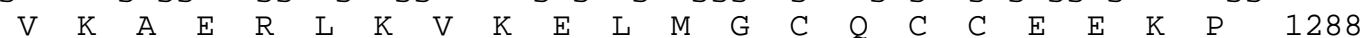
ccattatggtatacaatttgcataaagaatatgatgacaagaaagatttccttcactcaaggaaa 3965 $\begin{array}{lllllllllllllllllllllll}\text { A } & I & M & V & Y & N & L & H & K & E & Y & D & D & K & K & D & F & L & H & S & R & K & 1310\end{array}$ acaacaaaagtagcaacaaaatacgtctctttctgtgtgaaaaaaggagagatcttgggactgtt 4030 $\begin{array}{lllllllllllllllllllllllllllll}T & T & K & V & A & T & K & Y & V & S & F & C & V & K & K & G & E & I & L & G & L & L & 1332\end{array}$ gggtccaaatggtgctggcaaaagcacgattattaatattcttgttggggatgttgaaccaactt 4095 \begin{tabular}{lllllllll|lllllllllllll}
$\mathbf{G}$ & $\mathbf{P}$ & $\mathbf{N}$ & $\mathbf{G}$ & $\mathbf{A}$ & $\mathbf{G}$ & $\mathbf{K}$ & $\mathbf{S}$ & $\mathbf{T}$ & $\mathrm{I}$ & $\mathrm{I}$ & $\mathbf{N}$ & $\mathrm{I}$ & $\mathrm{L}$ & $\mathrm{V}$ & $\mathrm{G}$ & $\mathbf{D}$ & $\mathrm{V}$ & $\mathrm{E}$ & $\mathrm{P}$ & $\mathrm{T}$ & 1353
\end{tabular} Walker $A$

caggcaagatatttctaggagattatggttcacattcaaatgaagatgatgaatccaccaagtgt 4160 $\begin{array}{lllllllllllllllllllllll}S & G & K & I & F & L & G & D & Y & G & S & H & S & N & E & D & D & E & S & T & K & C & 1375\end{array}$ atgggttactgccccagacaaacccactctggccagatattactctgcaagaacatttgaaat 4225 $\begin{array}{lllllllllllllllllllllll}M & G & Y & C & P & Q & T & N & P & L & W & P & D & I & T & L & Q & E & H & F & E & I & 1397\end{array}$ ttatggagctgtgaaagggatgagttcaggtgacatgaaggaagtaatcagtcgaataacaaaag 4290

$\begin{array}{llllllllllllllllllllll}Y & G & A & V & K & G & M & S & S & G & D & M & K & E & V & I & S & R & I & T & K & 1418\end{array}$ cccttgatttgaaagaacatcttcagaaaactgtaaagaaactccctgcagggatcaagcgaaag 4355 $\begin{array}{llllllllllllllllllllllll}A & L & D & L & K & E & H & L & Q & K & T & V & K & K & L & P & A & G & I & K & R & K & 1440\end{array}$ ctgtgtttgctctcagtatgctggggaatcctcaggtgacactgctggatgagccgtctacagg 4420

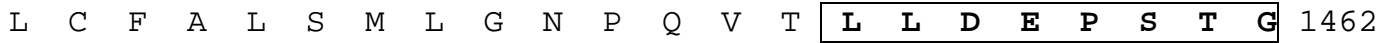

\section{Walker B}

tatggaccccagagccaaacagcacatgtggcgagccattcgaactgcgtttaaaaacaagaagc 4485 $\begin{array}{llllllllllllllllllllll}\text { M } & \text { D } & \text { P } & \text { R } & \text { A } & K & \text { Q } & H & \text { M } & \text { W } & \text { R } & \text { A } & \text { I } & \text { R } & \text { T } & \text { A } & \text { F } & \text { K } & \text { N } & \text { K } & \text { K } & 1483\end{array}$ W.B.

gggctgccctcctcactacgcattacatggaagaggcggaggctgtctgtgacagggtggccatc 4550 $\begin{array}{lllllllllllllllllllllll}R & A & A & L & L & T & T & H & Y & M & E & E & A & E & A & V & C & D & R & V & A & I & 1505\end{array}$ atggtgtccgggcagctaagatgcattggaacagtacaacatctaaagagcaagtttggcaaagg 4615 $\begin{array}{lllllllllllllllllllllll}M & V & S & G & Q & L & R & C & I & G & T & V & Q & H & L & K & S & K & F & G & K & G & 1527\end{array}$ ctacttttagaaattaaactaaaggactggatagaaaacctggaaatagatcgccttcaaagag 4680

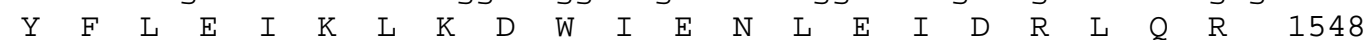


4681 aaattcaatatatttcccaaatgcaagccgccaagagagcttctcttctattctggcttataaa 4745

$\begin{array}{llllllllllllllllllllllll}1549 & E & I & Q & Y & I & F & P & N & A & S & R & Q & E & S & F & S & S & I & L & A & Y & K & 1570\end{array}$

4746 attccaaaagaagatgtccagtctctctcacagtcctttgctaagttggaggaagcaaaacacac 4810

$\begin{array}{llllllllllllllllllllllll}1571 & I & P & K & E & D & V & Q & S & L & S & Q & S & F & A & K & L & E & E & A & K & H & T & 1592\end{array}$

4811 tttgccattgaagaatacagctttctcaagcaaccctggaacaggtttttgtagaacttacta 4875

$\begin{array}{lllllllllllllllllllllll}1593 & F & A & I & E & E & Y & S & F & S & Q & A & T & L & E & Q & V & F & V & E & L & T & 1613\end{array}$

4876 aggagcaggaggaggaagataatagctgcgggactttaaacagcacgctctggtgggaaagaagg 4940

$\begin{array}{llllllllllllllllllllllll}1614 & K & E & Q & E & E & E & D & N & S & C & G & T & L & N & S & T & L & W & W & E & R & R & 1635\end{array}$

4941 caggaagacagagtcgtgttctgalatgtctgcgctcacccogcctgctgaccctgaacttactct 5005

1636 Q E D R V V F - 1642

5006 ttttatttgttttccttctttatcttaacttgatttaaaagtttattacttgaatagtc 5070

5071 acaaaacatgaaagcacttggaaatttcctaaactccttaatttatgcaccatggttattatgt 5135

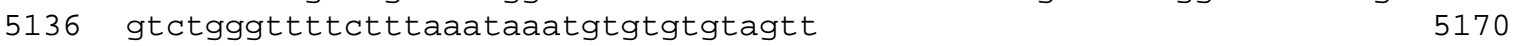

Abb. 3.6 Nukleotidsequenz der isolierten cDNA des Abca5-Gens der Ratte und die abgeleitete Aminosäuresequenz des offenen Leserahmens. Die Sequenz des kodierenden Stranges der cDNA ist in Kleinbuchstaben angeführt. Die abgeleitete Aminosäuresequenz ist unterhalb der Nukleotidsequenz angeordnet. Das Startkodon (atg), das Stopkodon (tga) und die charakteristischen Motive der Nukleotidbindungskassetten (Walker A, Signatur-Sequenz und Walker B) sind fett markiert und mit Rahmen hervorgehoben. Die Numerierung entspricht dem Genbank-Eintrag AJ426052.

Eine kürzlich durchgeführte Datenbankrecherche mit dem 5'-Terminus des rAbca5-Gens führte zur Detektion eines cDNA-Klon der Länge $347 \mathrm{bp}$ aus mRNA der Hypophyse einer weiblichen Wistarratte (CB808508 von FITZPATRICK et al. 2003). Das Fragment überlappt mit den ersten 192 bp des rAbca5-Gens und komplettiert die 5'-untranslatierte Region (UTR) der unter der Zugangsnummer AJ426052 abgelegten rAbca5-Sequenz. Der überdurchschnittliche GC-Gehalt des cDNA-Klons von 68\% bietet auch eine mögliche Erklärung für den vorzeitigen Abbruch der 5'-UTR der von uns isolierten cDNA-Sequenz. Eine genomische Analyse des cDNA-Klons mittels Blast bestätigte die gemeinsame Abstammung beider Sequenzen vom Chromosom 10 der Ratte und die Existenz eines 8478 bp aufwärts vom bisherigen Exon 1 gelegenen untranslatierten Exons analog dem Exon 1 des ABCA5-Gens des Menschen.

\subsubsection{Genomische Struktur des Abca5-Gens der Ratte}

Die Analyse der genomischen Organisation von rAbca5 wurde auf Basis der vorläufigen Version 2.1 des Ratten-Genoms (April 2004) vorgenommen. Danach wurde das Gen, das sich auf Chromosom 10 der Ratte über eine genomische Region von ca. 68 kb erstreckte (NW_047343.1), in 39 Exons aufgeteilt.

Die Exongrößen variieren zwischen 61 bp und 317 bp, die Intronlängen zwischen 92 bp und 8815 bp, wobei sich das größte Intron zwischen den Exons 28 und 29 befand (Tabelle 3.2). Ein mit dem Konsensusmotiv für den eukaryotischen Translationsstart kompatibles Sequenzmotiv AACATGG (Nukleotide 33-38 in AJ426052) wurde in Exon 2 detektiert. 


\begin{tabular}{|c|c|c|c|c|c|}
\hline Exon & $\begin{array}{c}\text { Exonlänge } \\
\text { in bp }\end{array}$ & $\begin{array}{c}\text { Intronlänge } \\
\text { in bp }\end{array}$ & Exon & $\begin{array}{c}\text { Exonlänge } \\
\text { in bp }\end{array}$ & $\begin{array}{c}\text { Intronlänge } \\
\text { in bp }\end{array}$ \\
\hline 1 & 174 & 8478 & 21 & 134 & 766 \\
\hline 2 & 123 & 1147 & 22 & 141 & 1074 \\
\hline 3 & 207 & 1142 & 23 & 119 & 2124 \\
\hline 4 & 163 & 6499 & 24 & 175 & 1669 \\
\hline 5 & 91 & 2430 & 25 & 115 & 339 \\
\hline 6 & 233 & 2381 & 26 & 137 & 750 \\
\hline 7 & 146 & 1061 & 27 & 77 & 1945 \\
\hline 8 & 191 & 1911 & 28 & 94 & 8815 \\
\hline 9 & 152 & 883 & 29 & 139 & 369 \\
\hline 10 & 171 & 622 & 30 & 121 & 92 \\
\hline 11 & 61 & 2455 & 31 & 94 & 736 \\
\hline 12 & 112 & 1177 & 32 & 178 & 528 \\
\hline 13 & 180 & 553 & 33 & 77 & 114 \\
\hline 14 & 120 & 974 & 34 & 102 & 781 \\
\hline 15 & 141 & 1122 & 35 & 121 & 1504 \\
\hline 16 & 92 & 170 & 36 & 152 & 863 \\
\hline 17 & 147 & 1375 & 37 & 86 & 879 \\
\hline 18 & 126 & 1467 & 38 & 74 & 746 \\
\hline 19 & 206 & 1564 & 39 & 317 & \\
\hline 20 & 170 & 2062 & & & \\
\hline
\end{tabular}

Tabelle 3.2 Intron-Exon-Organisation für das Abca5-Gen der Ratte (AJ426052). Die Strukturanalyse wurde mit dem BLAST-Genom-Programm auf Grundlage des Rat Genome Build 2.1 (April 2004) durchgeführt. Die Exons sind fortlaufend numeriert, das zugehörige Intron folgt dem entsprechenden Exon. Das Signal für den Translationsstop befindet sich in Exon 39 und beginnt an Position 4962. Die vorhergesagten Exongrenzen überlappen um bis zu 18 bp. Exon 1 wurde als Ergebnis einer Datenbankrecherche zugeordnet und noch nicht experimentell bestätigt.

\subsubsection{Identifizierung einer rAbca5-Splicevariante $r A b c a 5 V+16$}

Dieses alternative mRNA-Transkript des rAbca5-Gens der Ratte wurde im Rahmen der Sequenzanalyse detektiert. Es umfaßte wie ABCA5 V20+16 die Länge der vollständig kodierenden cDNA und besaß ebenfalls ein um 16 bp verlängertes Exon 20, das sich von der Insertion im humanen $A B C A 5-G e n$ in nur einer Base an Position $8(T \rightarrow C)$ unterschied. Die Insertion verursachte eine Verschiebung des offenen Leserahmens und einen vorzeitigen Abbruch der Translation (Abb. 3.7). 


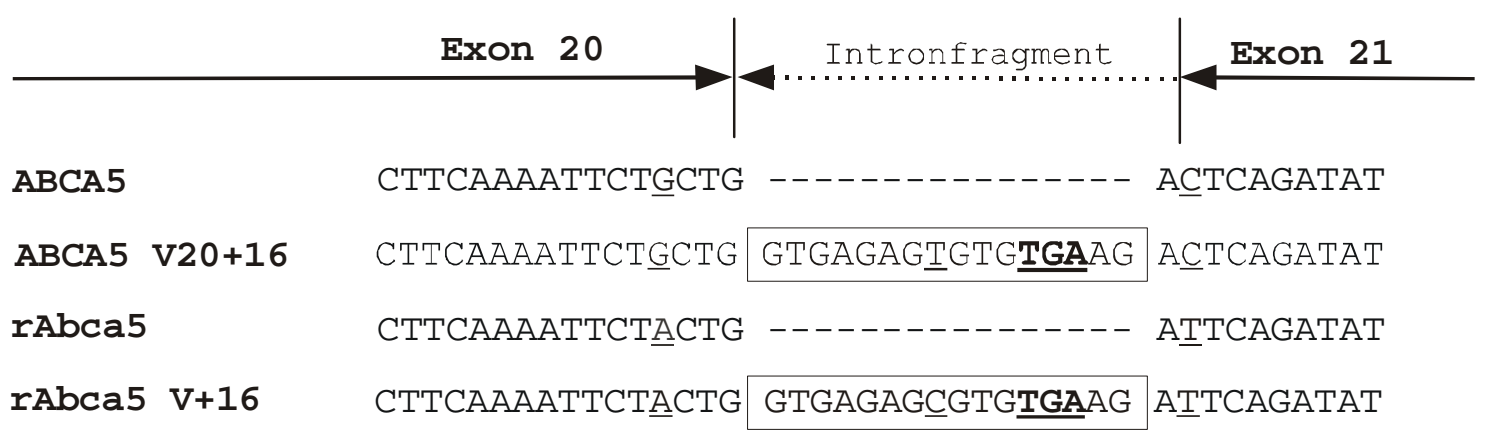

$16 \mathrm{bp}$

Abb. 3.7 Ausschnitt aus der rAbca5 cDNA in der Region zwischen Exons 19 und $20 \mathrm{im}$ Vergleich zu $A B C A 5$ und $A B C A 5$ V20+16. Die 16 bp-Insertion (Rahmenbox) führt bei dem alternativen rAbca5-cDNA-Transkript $(r A b c a 5 V+16)$ zu einem vorzeitigen Stopkodon (TGA) und somit zu einem Translationsabbruch nach 2775 bp bezogen auf das Startkodon.

Die cDNA-Sequenz der neuen rAbca5-Splicevariante wurde durch zwei unabhängige RTPCR-Amplifikationen mit insertionsspezifischen Primern (RF1 und RSV R1, RSV F1 und $\mathrm{RR} 1, \rightarrow$ 2.1.7.6) an Gesamt-RNA aus Testisgewebe der Ratte bestätigt und in der EMBLGendatenbank abgelegt (Accession Number AJ550165).

\subsubsection{Untersuchungen zur Membran-Topologie}

Untersuchungen zur Lokalisation und Orientierung von Membransegmenten wurden mit SOSUI (http://sosui.proteome.bio.tuat.ac.jp/sosuimenu0.html), TopPred (http://bioweb.pasteur.fr/seqanal/interfaces/toppred.html) von HEIJNE et al. (1992, 1994), PSORT II (http://psort.nibb.ac.jp/form.html) von NAKAI UND HORTON (1999) und TMHMM2.0 (http://www.cbs.dtu.dk/services/TMHMM-2.0/) von KROGH et al. (2001) durchgeführt. Diese Programme basieren auf der Annahme, daß hydrophobe Sequenzabschnitte in Membranproteinen als alpha-helikale Membranstrukturen lokalisiert sein können. Mithilfe des Analysealgorithmus wurden anhand von Hydrophobizitätswerten für die einzelnen Aminosäuren Durchschnittswerte für Peptidabschnitte zwischen 20 und 23 Substituenten errechnet und daraus putative Membransegmente für das gesamte Protein vorausgesagt.

\subsubsection{Membransegmente in ABCA5 und ABCA5 V20+16}

Eine Analyse der hydrophoben Regionen in ABCA5 ergab eine maximal mögliche Anzahl von 15 Membransegmenten (MS) zwischen 20 und 23 Aminosäuren. Die ersten 7 Segmente befanden sich im ersten Viertel des Proteins (Aminosäuren 31 bis 416), die zweite Membranregion mit maximal 8 Segmenten im dritten Viertel (Aminosäuren 862 bis 1225). An die Membranregionen schlossen sich die hydrophileren Sequenzbereiche der ATP- 
Bindungskassetten an. Damit erfüllte $\mathrm{ABCA5}$ die topologischen Voraussetzungen für einen ABC-Volltransporter.

\begin{tabular}{ccccc}
\hline Helix & N-Terminus & Transmembranregion & C-Terminus & Länge \\
\hline 1 & 31 & SSVQEILFPLFFLFWLILISM & 51 & 21 \\
2 & 223 & IYLVIAFSPFGYFLAIHIVAEK & 244 & 22 \\
3 & 265 & SWVLLYTSLIFLMSLLMAVIATA & 287 & 23 \\
4 & 298 & VIFLLFFLYGLSSVFFALMLTPL & 320 & 23 \\
5 & 327 & VGIVEFFVTVAFGFIGLMIILIE & 349 & 23 \\
6 & 355 & LVWLFSPFCHCTFVIGIAQVMHL & 377 & 23 \\
7 & 394 & YPLIITIIMLTLNSIFYVLLAVY & 416 & 23 \\
8 & 862 & VRSVLLLLLIFFTVQIFMFLVHH & 884 & 23 \\
9 & 967 & VFAAVFNSTMVYSLPILVNIISN & 989 & 23 \\
10 & 1018 & KIELYFQAALLGIIVTAMPPYFA & 1040 & 23 \\
11 & 1068 & GQAVVDIPLFFIILILMLGSLLA & 1090 & 23 \\
12 & 1103 & LAVVFCLIGYVPSVILFTYIASF & 1125 & 23 \\
13 & 1136 & FWSFIYSVAALCIAITEITFFMG & 1158 & 23 \\
14 & 1166 & HYAFCIIIPIYPLLGCLISFIKI & 1188 & 23 \\
15 & 1206 & LSVAVISPYLCCVLIFLLQ & 1225 & 20 \\
\hline
\end{tabular}

Tabelle 3.3 Putative Membransegmente im ABCA5-Protein. Die Evaluation der hydrophoben Sequenzregionen wurde mit TopPred, SOSUI, PSORT II und THMM2.0 vorgenommen. Je nach Programm variierten die Längen der putativen Membransegmente um bis zu 3 Aminosäuren. Es wurden nur die von allen vier Programmen erkannten Membransegmente dargestellt.

Die Polypeptidsequenz für ABCA5 V20+16 betrug 925 Aminosäuren und war mit Ausnahme der vier terminalen Aminosäuren mit dem entsprechenden Sequenzbereich auf ABCA5 identisch. Für ABCA5 V20+16 wurden 8 Membransegmente vorhergesagt, gefolgt von einer hydrophilen Region, in der sich die ATP-Bindungskassette befand. Diese Membransegmente entsprachen den ersten 8 Segmenten in Tabelle 3.3.

\subsubsection{Membransegmente in rAbca5 und rAbca5 V+16}

Die Anzahl der maximal möglichen Membransegmente in rAbca5 betrug ebenfalls 15. Die Längen dieser Sequenzabschnitte betrugen zwischen 21 und 23 Aminosäuren. Die erste Membrandomäne (MD) enthielt 7 Segmente (Aminosäuren 31 bis 415), die zweite MD befand sich mit 8 Membransegmenten zwischen den Aminosäuren 862 und 1227 des Gesamtproteins. An die Membranregionen schlossen sich wie in ABCA5 hydrophilere Sequenzbereiche an, in denen die ATP-Bindungskassetten lokalisiert waren. Damit erfüllte Abca5 die topologischen Voraussetzungen für einen $A B C$-Volltransporter. 


\begin{tabular}{ccccc}
\hline Helix & N-Terminus & Transmembranregion & C-Terminus & Länge \\
\hline 1 & 31 & SSVQEILFPLFFLFWLILISM & 51 & 21 \\
2 & 223 & IYLVIAFSPFGFLAIHIVAEK & 244 & 22 \\
3 & 264 & LSWVLLYTSLIFLMSLLMAVIAT & 286 & 23 \\
4 & 297 & IVIFLLFFLYGLSSVFFALMLTP & 319 & 23 \\
5 & 327 & VGVVEFFVTVVFGFVGLIVLVE & 349 & 23 \\
6 & 355 & LVWLFSPLCQCAFLIGIAQVMHL & 377 & 23 \\
7 & 393 & PYPLIITLTMLALDSVFYALLAV & 415 & 23 \\
8 & 862 & VRSVLLLLLIFFAVQIFMFLVHH & 884 & 23 \\
9 & 966 & YVFTAVFNSTMVYSLPVMMNI & 986 & 23 \\
10 & 1018 & KVELYFQAALLGIIVTAMPPYFA & 1040 & 23 \\
11 & 1067 & IGQAVVDIPLFFVVLTLMLGSLF & 1089 & 23 \\
12 & 1102 & FLAVVFCLIAYVPSVILFTYIAS & 1124 & 23 \\
13 & 1139 & FIYSVTALACVAVTEITFFLGYG & 1161 & 23 \\
14 & 1169 & TFCIAIPIYPLLGCLISFIKGSW & 1191 & 23 \\
15 & 1205 & DRLLVAVIMPYLQCVLWIFLLQH & 1227 & 23 \\
\hline
\end{tabular}

Tabelle 3.4 Putative Membransegmente im rAbca5-Protein. Die Untersuchung der hydrophoben Sequenzregionen erfolgte mit TopPred, SOSUI, PSORT II und THMM2.0. Je nach Programm variierten die Längen der putativen Membransegmente um bis zu 3 Aminosäuren. Es wurden nur die von allen vier Programmen erkannten Membransegmente dargestellt.

Die Polypeptidsequenz für rAbca5 V+16 umfaßte wie im humanen Ortholog 925 Aminosäuren und war mit Ausnahme der fünf terminalen Aminosäuren mit dem entsprechenden Sequenzbereich auf rAbca5 identisch. Für Abca5 V+16 wurden 8 Membransegmente vorhergesagt, gefolgt von einer hydrophilen Region, in der sich die ATP-Bindungskassette befand. Diese Membransegmente entsprachen den ersten 8 Segmenten in Tabelle 3.4.

\subsection{Untersuchungen zur mRNA-Gewebeverteilung von hABCA5 und rAbca5}

\subsubsection{Expression des humanen ABCA5-Gens}

Die Untersuchung der Expression von humaner $A B C A 5-m R N A$ erfolgte mittels NorthernBlot-Analysen $(\rightarrow 2.2 .10)$ mit einem kommerziell erhältlichen Humangewebeblot $(\rightarrow 2.1 .2)$. Die Hybridisierung mit einer ABCA5-spezifischen Oligonukleotidsonde zeigte ein Signal bei $6.2 \mathrm{~kb}$ im Skelettmuskel, das ebenfalls in Niere, Leber und Plazenta detektiert werden konnte (Abb. 3.8). Das gleiche Signal wurde in RNA aus der humanen Kolonkarzinomzell-Linie Caco-2 detektiert. Northern-Blot-Untersuchungen an diversen humanen Neuroblastom- und Leukämiezellinien ergaben ein längeres Transkript von $>9 \mathrm{~kb}$ (ohne Abb.). Das in ersten 
Northern-Blot-Experimenten in Gesamt-RNA aus Hep-G2-Zellen ermittelte Signal von $2.6 \mathrm{~kb}$ konnte in späteren Versuchen nicht bestätigt werden und war entweder Zeichen einer zellspezifischen RNA-Degradation oder ein unspezifisches Hybridisierungsergebnis.
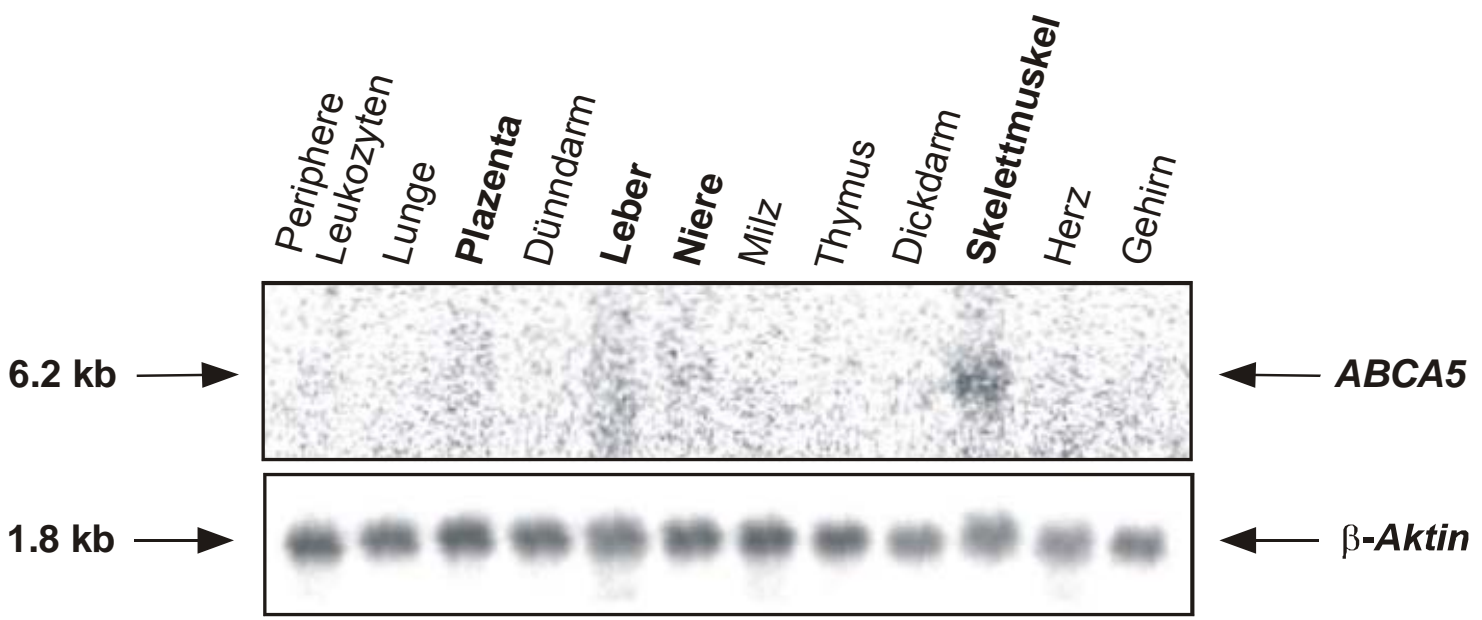

Abb. 3.8 Expression der ABCA5-mRNA in einer Auswahl von humanen Geweben. Für die Northern-Blot-Hybridisierung wurde ein Human 12-Lane Blot (Clontech) verwendet. Die genspezifische Hybridisierung erfolgte mit einer ${ }^{32} \mathrm{P}$-markierten Oligonukleotidsonde (HR8, $\rightarrow 2 \cdot 1.7 .6 .2$ ) bei $38^{\circ} \mathrm{C}$. Eine Kontrollhybridisierung mit einer $\beta$-Aktinsonde zeigte, daß die polyA-RNA-Proben in Bezug auf ihren $\beta$-Aktin mRNA-Gehalt normalisiert worden waren.

\subsubsection{Expression des Abca5-Gens der Ratte}

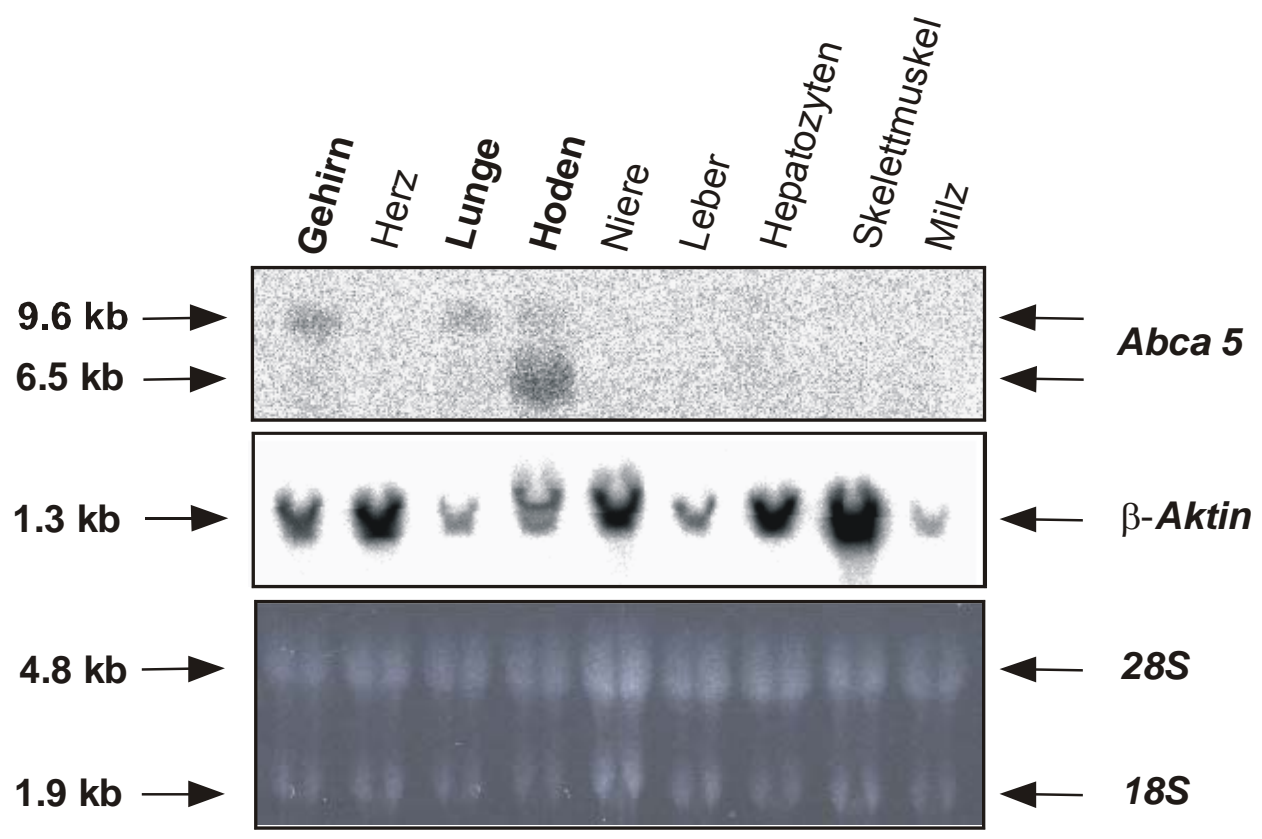


Abb. 3.9 Expression des rAbca5-Gens der Ratte in verschiedenen Geweben desselben Versuchstieres. Pro Bahn wurden $25 \mu \mathrm{g}$ Gesamt-RNA gelelektrophoretisch aufgetrennt. Die genspezifische Hybridisierung erfolgte mit ${ }^{32} \mathrm{P}$-markierten Oligonukleotidsonden (RR8, RR13, $\rightarrow$ 2.1.7.6.4). Eine Kontrollhybridisierung mit einer $\beta$-Aktinsonde der Ratte $(\rightarrow 2.1 .7 .7)$ wurde vorgenommen und zeigt den natürlich variablen $\beta$-Aktingehalt in den verschiedenen Organen.

Zur Untersuchung der mRNA-Expression des Abca5-Gens der Ratte wurde ein mRNAOrganblot aus frisch isolierten Rattenorganen hergestellt $(\rightarrow 2.2 .2 .4 .2,2.2 .8 .2 .3 \mathrm{ff}$.) und mit zwei verschiedenen $r A b c a 5$-spezifischen Oligonukleokleotidsonden hybridisiert. Eine besonders starke rAbca5-mRNA-Expression wurde im Testis (Hoden) detektiert, wobei neben dem erwarteten Transkript bei ca. $6.5 \mathrm{~kb}$ ein zweites Signal von ca. $9.6 \mathrm{~kb}$ auftrat. Dieses Transkript wurde auch in Lunge und Gehirn gefunden(Abb. 3.9).

\subsection{Zellspezifische Verteilung der rAbca5-mRNA in Organen der Ratte}

Voraussetzung für eine spätere funktionelle Aufklärung des neuen Abca5-Gens der Ratte war eine genaue Kenntnis der zellspezifischen Lokalisation. Zu diesem Zweck wurden Paraffinschnitte aus frisch isolierten Rattenhoden (Testis) und Nebenhoden (Epididymis) bei $55^{\circ} \mathrm{C}$ einer in-situ Hybridisierung mit Digoxygenin-markierten cRNA-Sonden (DIG-Sonden, $\rightarrow 2$ 2.2.4) unterzogen. Die Signaldetektion erfolgte indirekt über eine Signalamplifikation $(\rightarrow$ 2.2.11) mit dem TSA Biotin System (PerkinElmer).

Alle in situ Hybridisierungsexperimente wurden im Rahmen einer Kooperation mit Dr.P. Middel in der Abteilung Pathologie der Georg-August-Universität Göttingen durchgeführt.

\subsubsection{Generierung der DIG-cRNA-Sonden}

Zur Vermeidung von Kreuzhybridisierungen mit anderen Abca-Genen der gleichen Subgruppe wurde eine Sondenregion auf rAbca5 ausgewählt, die im Bereich der zweiten Transmembranregion lag. Die Matrizen-cDNA für die cRNA-Sonden (copy oder complementary RNA) wurden entweder durch Klonierung eines RT-PCR-Fragments (308 bp) in den pCR4-TOPO Vektor und Restriktionslinearisierung (RISH1) oder direkt durch RT-PCR mit Primern generiert, die die für die in vitro Transkription nötigen Promotorsequenzen (T3 und T7) als Überhänge besaßen (RISH2). In situ Hybridisierungen mit cRNA-Sonden, die durch eine in vitro Transkription von Plasmid-DNA hergestellt worden waren, führten wiederholt zu hohen Hintergrundsignalen im Bereich der Zellkerne. Aus diesem Grund wurden die cRNA- 
Sonden im Verlauf der Experimente auf Basis der direkten RT-PCR Methode generiert $(\rightarrow 2.2 .3 .4)$.

\subsubsection{Morphologie des Testis der Ratte}

Die in der Hodenkapsel gelegenen Hodenkanälchen (Tubuli seminiferi) sind nach außen durch eine Basalmembran, eine Kollagenschicht und eine Schicht kontraktiler Myoepithelzellen begrenzt, die zusammen als Tunica propria bezeichnet werden. Das Lumen der Tubuli seminiferi trägt ein sich aktiv erneuerndes Keimepithel, in dem sich eine Population von Stützzellen, den Sertolizellen, befindet, die außer der Stützfunktion diverse phagozytäre und sekretorische Aufgaben haben. Die Spermatogenese (Spermatozytogenese, Meiose und Spermiogenese) verläuft in Wellen spiralförmig in den Tubuli seminiferi von außen nach innen ab. Das interstitielle Gewebe zwischen den Tubuli ist ein lockeres Maschenwerk aus kollagenfaserigem Gewebe und besteht aus Fibroblasten, Kollagen mit gelegentlich eingelagerten Makrophagen und Mastzellen, Blut- und Lymphgefäßen sowie Gruppen interstitieller Zellen, den Leydigzellen (Abb. 3.10).

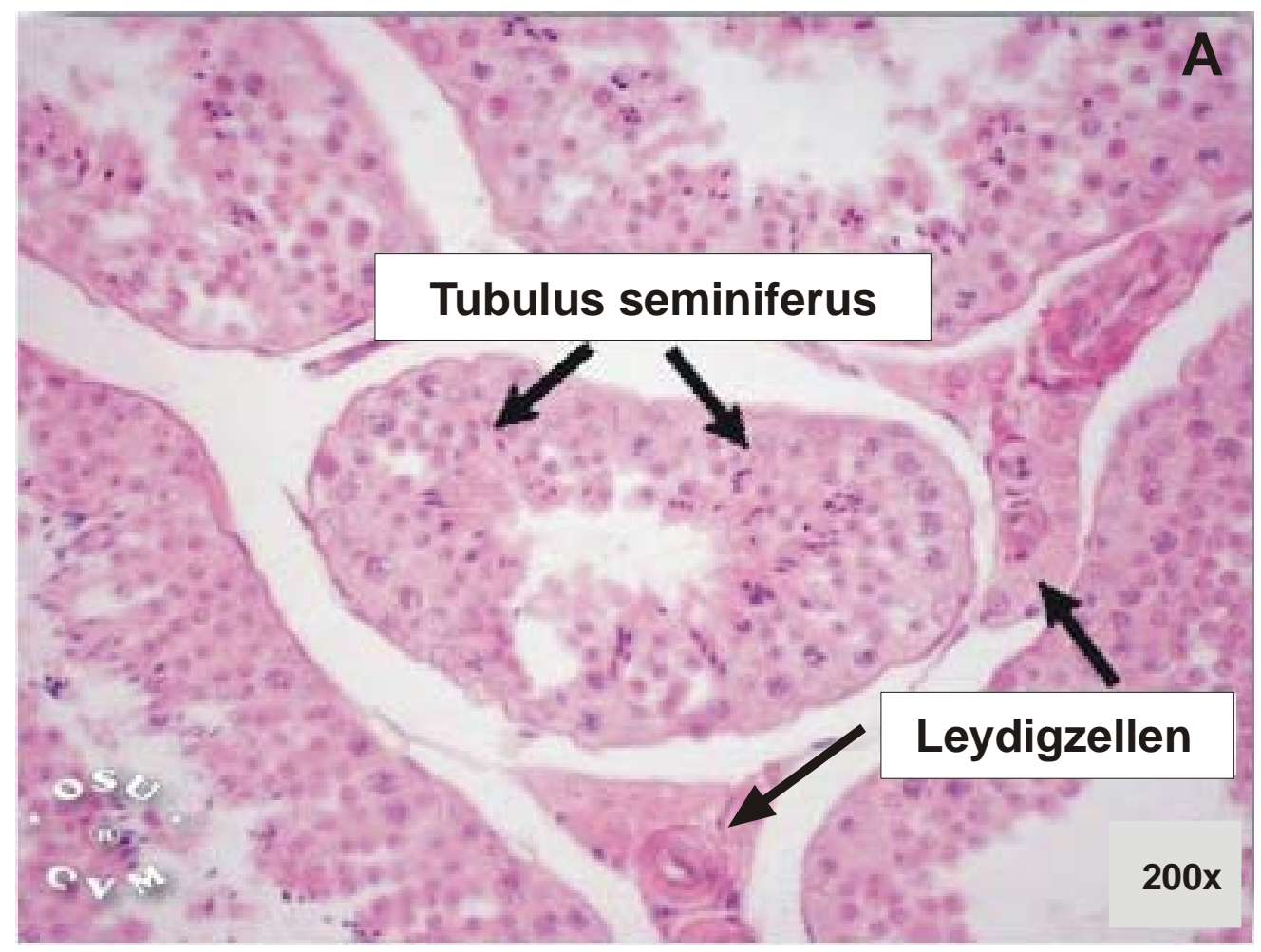

Abb. 3.10A Morphologie des Testis (200x). Es wurde der grundlegende Aufbau des adulten Testis aus Tubuli seminiferi mit Basalmembran, ausgewählten Spermien-Entwicklungsstadien und Interstitium mit Leydigzellen dargestellt. Die Abbildung wurde nach einer Vorlage von OWNBY et al. (2002) angefertigt und das Abdrucken in dieser Arbeit ausdrücklich genehmigt. 


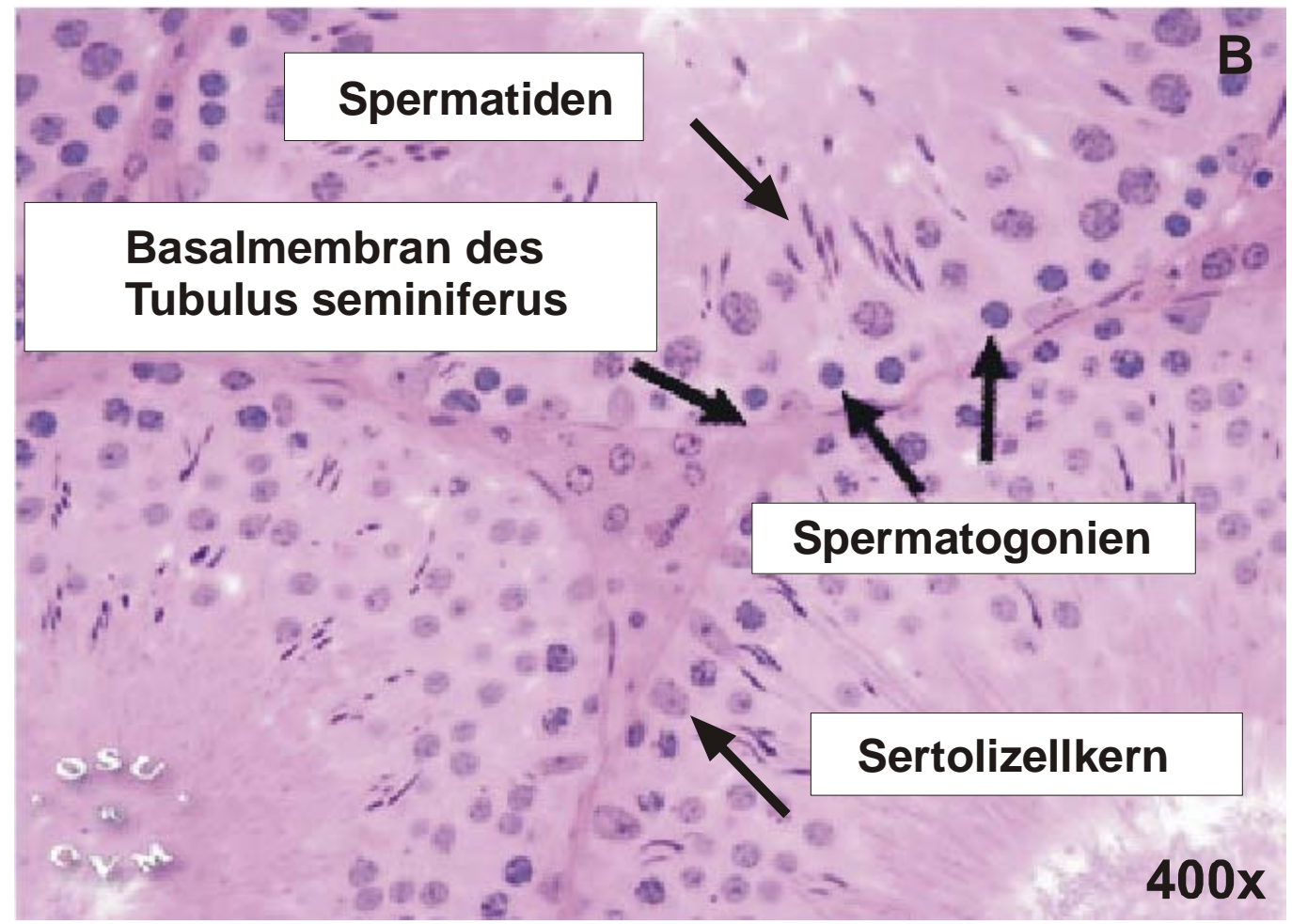

Abb. 3.10B Morphologie des Testis (400x). Nahe der Basalmembran befinden sich frühe Entwicklungsstadien der Spermien, die Spermatogonien (Spermatozytogenese). Die im Rahmen der Spermiogenese zu Spermatozoen reifenden Spermatiden haben sich bereits von der Basalmembran entfernt. Die Abbildung wurde nach einer Vorlage von OWNBY et al. (2002) angefertigt, das Abdrucken in dieser Arbeit ausdrücklich genehmigt.

\subsubsection{Expression des rabca5-Gens im Testis der Ratte}

Die in situ Hybridisierung des adulten Testis des Ratte mit einer DIG-markierten cRNASonde für $r A b c a 5$ (RISH2-Antisense) bei $55^{\circ} \mathrm{C}$ zeigte deutliche Signale in der Tunica propria der Tubuli seminiferi (Abb. 3.11, B, E, F und G), wobei keine eindeutige Differenzierung zwischen den verschiedenen Schichten vorgenommen werden konnte. Eine starke rAbca5mRNA-Expression wurde im interstitiellen Raum detektiert, in dem sich Leydigzellen befinden (Abb. 3.11 C, E und F), die auch als Cluster auftreten können (C, E). Positive Hybridisierungssignale waren auch in Epithelzellen kleiner Blutgefäße sichtbar (ohne Abb.). Die Spezifität der Hybridisierungen wurde mittels einer Kontrollhybridisierung mit der RISH2Sense-Sonde überprüft (Abb. 3.11, A und D). 

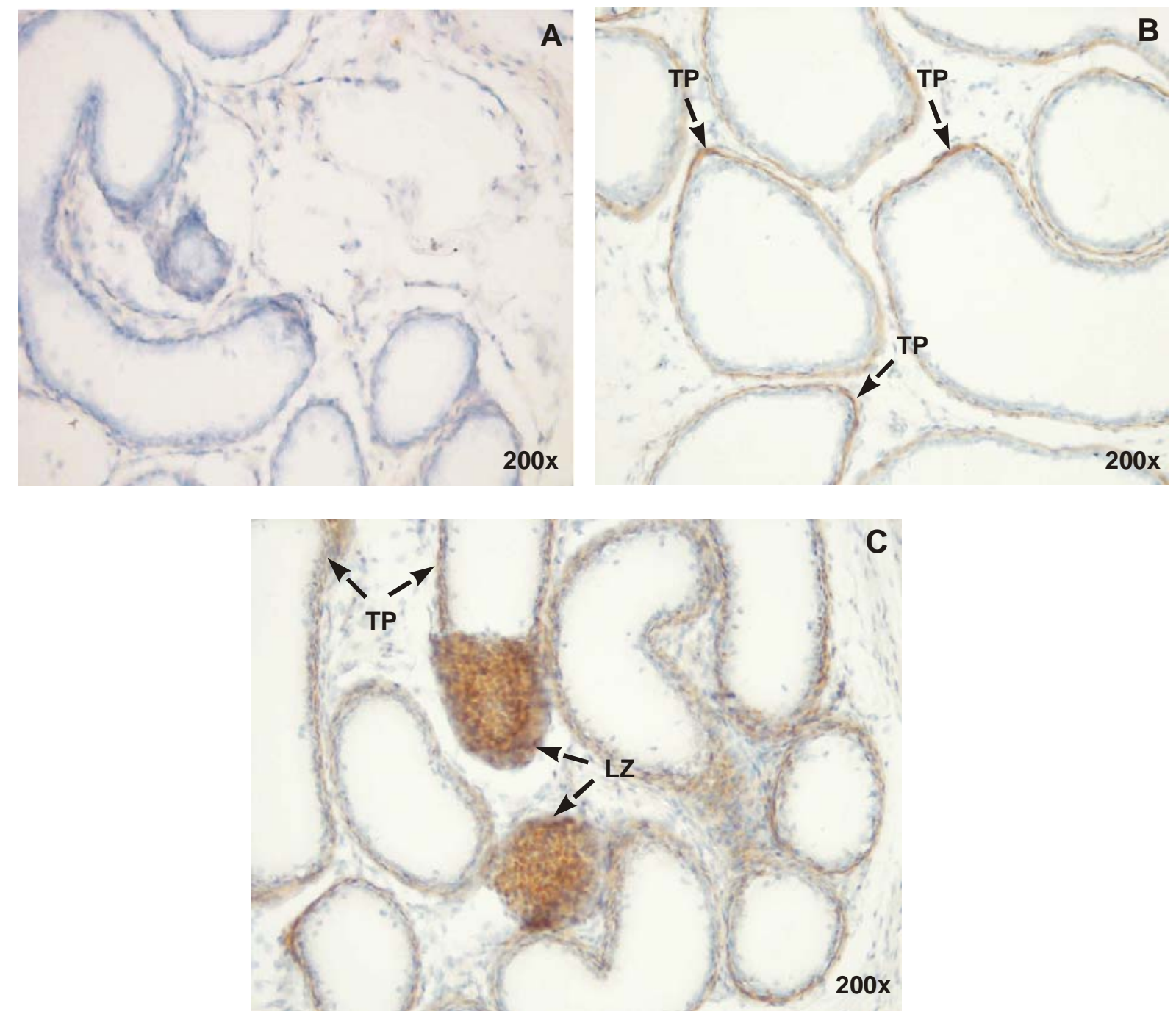

Abb. 3.11 A-C Testisspezifische Expression des rAbca5-Gens der Ratte (200x). Paraffinschnitte aus adultem Testis der Ratte wurden bei $55^{\circ} \mathrm{C}$ mit einer DIGmarkierten cRNA-Sonde RISH2 hybridisiert. Bild A zeigt das Ergebnis der Hybridisierung mit der RISH2-Sense-Sonde als Negativkontrolle. Hybridisierungen mit der RISH2-Antisense-Sonde sind in den Aufnahmen B und $\mathrm{C}$ dargestellt und mit Pfeilen markiert. Die blaue Gegenfärbung der Zellkerne wurde im Anschluß an die Chromogenentwicklung mit Meyers Hämalaun vorgenommen. Positive Hybridisierungssignale erscheinen in braun. TP = Tunica propria, LZ = Leydigzellen . 

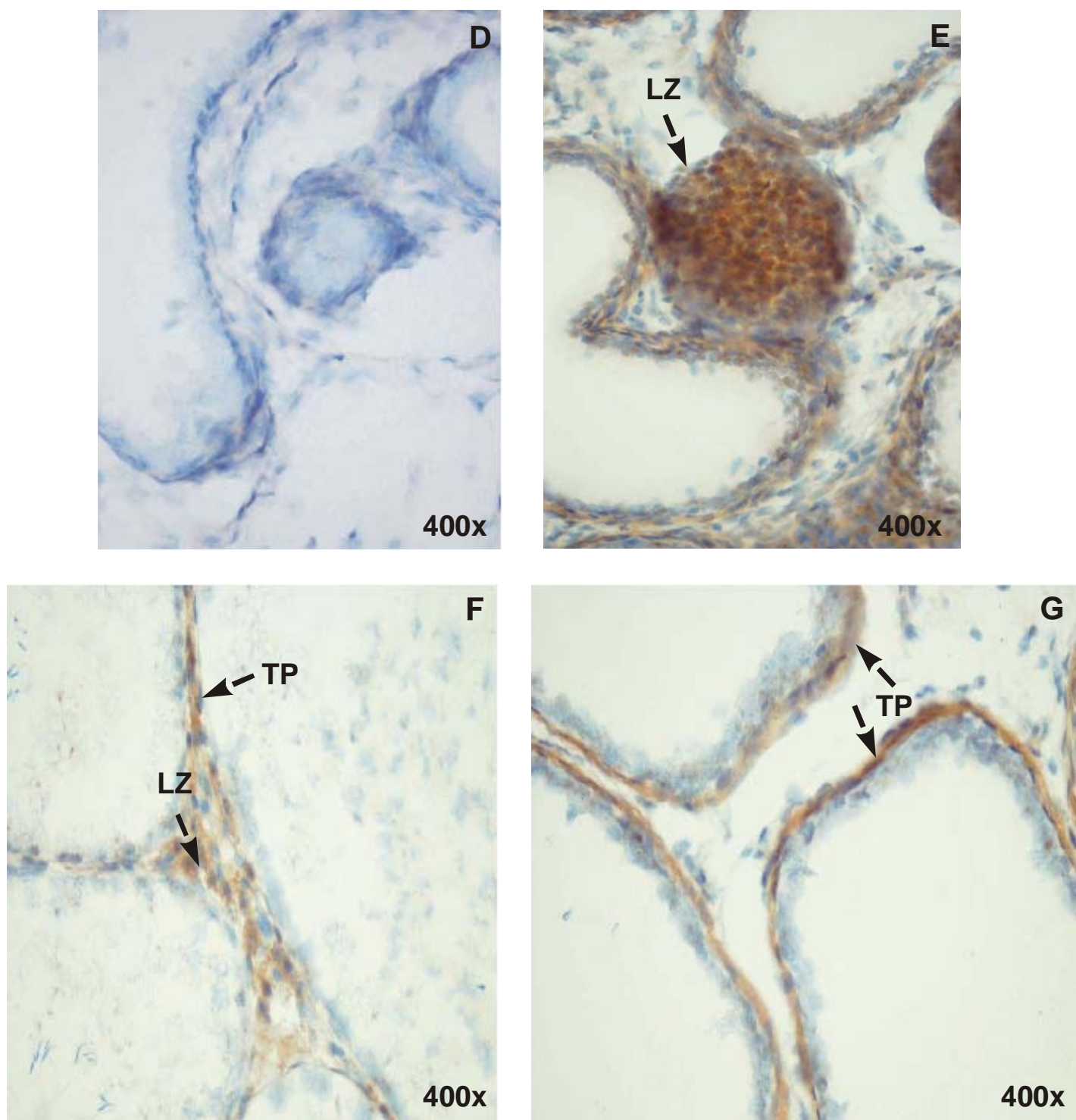

Abb. 3.11 D-G Testisspezifische Expression des rAbca5-Gens der Ratte (400x). Paraffinschnitte aus adultem Testis der Ratte wurden bei $55^{\circ} \mathrm{C}$ mit einer DIGmarkierten cRNA-Sonde RISH2 hybridisiert. Aufnahme D zeigt das Ergebnis der Hybridisierung mit der RISH2-Sense-Sonde als Negativkontrolle. Hybridisierungen mit der RISH2-Antisense-Sonde sind in den Aufnahmen E bis $\mathrm{F}$ dargestellt und mit Pfeilen markiert. Die blaue Gegenfärbung der Zellkerne wurde im Anschluß an die Chromogenentwicklung mit Meyers Hämalaun vorgenommen. Positive Hybridisierungssignale erscheinen in braun. TP = Tunica propria, LZ = Leydigzellen . 


\subsubsection{Morphologie der Epididymis der Ratte}

Der von einer straffen kollagenfaserigen Kapsel geschützte Nebenhodengang (Ductus epididymidis) ist in ein lockeres Stützgewebe aus Fibroblasten, Fibrozyten, Kollagen und eine Glykosaminoglykanmatrix eingebettet und wird durch ein hochprismatisches Zylinderepithel mit basalen Kernen begrenzt, das außen einen schmalen Saum glatter Muskulatur trägt. Das Zylinderepithel enthält atypisch lange Mikrovilli $(40-80 \mu \mathrm{m})$, die wie die SertoliZellen im Testis verschiedene resorbierende, phagozytierende und sezernierende Funktionen (Abb. 3.12) haben.

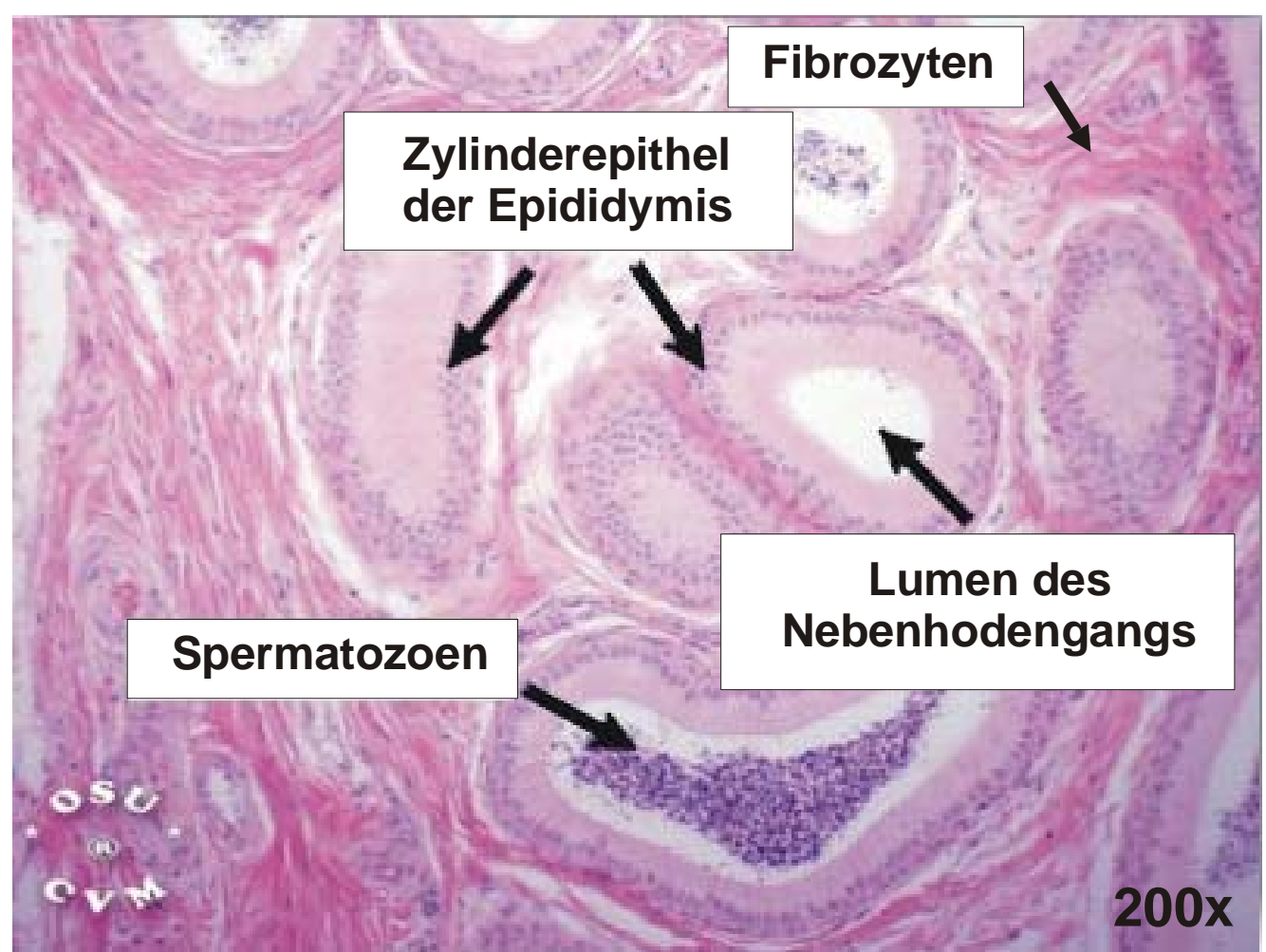

Abb. 3.12 Morphologie der Epididymis der Ratte (200x). Es wurde der grundlegende Aufbau der Epididymis der Ratte aus Ductus epididymidis und Stützgewebe dargestellt. Die Abbildung wurde nach einer Vorlage von OWNBY et al. (2002) angefertigt und das Abdrucken in dieser Arbeit ausdrücklich genehmigt. 


\subsubsection{Expression des rAbca5-Gens in der Epididymis der Ratte}

Die Expression der rAbca5-mRNA war besonders stark im Zylinderepithel ausgeprägt und erstreckte sich bis in die Mikrovilli. Positive Signale wurden auch in den länglichen Fibrozyten des Stützgewebes detektiert (Abb. 3.13).
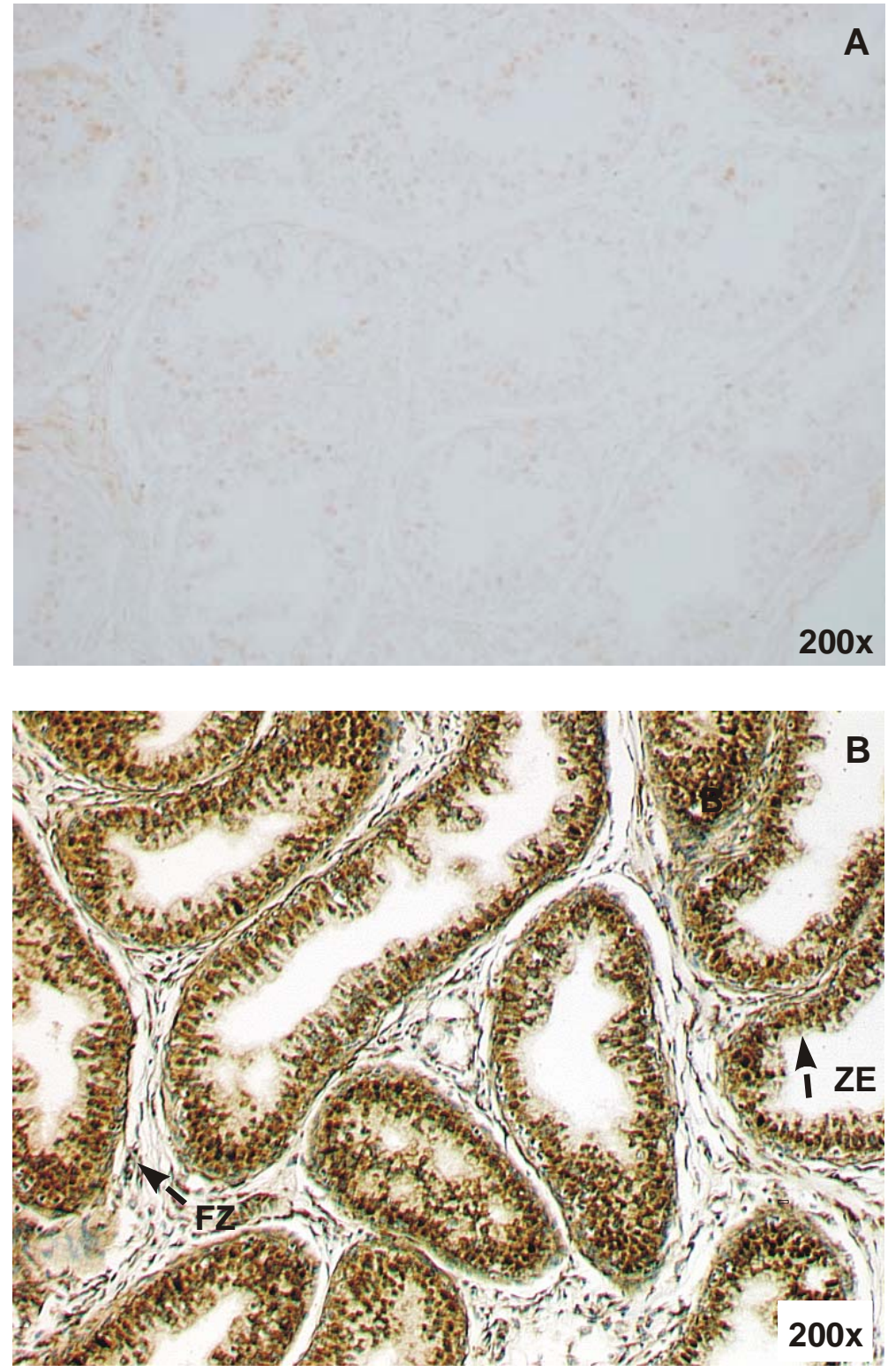

Abb. 3.13 A,B Epididymisspezifische Expression des rAbca5-Gens der Ratte. Paraffinschnitte aus adulter Epididymis der Ratte wurde bei $55^{\circ} \mathrm{C}$ mit einer DIGmarkierten cRNA-Sonde RISH1 hybridisiert. A zeigt das Ergebnis der Hybridisierung mit der RISH1-Sense-Sonde als Negativkontrolle (200x). Die Hybridisierung mit der RISH1-Antisense-Sonde ist in B dargestellt, positive Signale sind mit Pfeilen markiert. Die blaue Gegenfärbung der Zellkerne wurde im Anschluß an die Chromogenentwicklung mit Meyers Hämalaun vorgenommen. Positive Hybridisierungssignale erscheinen in braun. FZ= Fibrozyten, ZE = Zylinderepithel. 


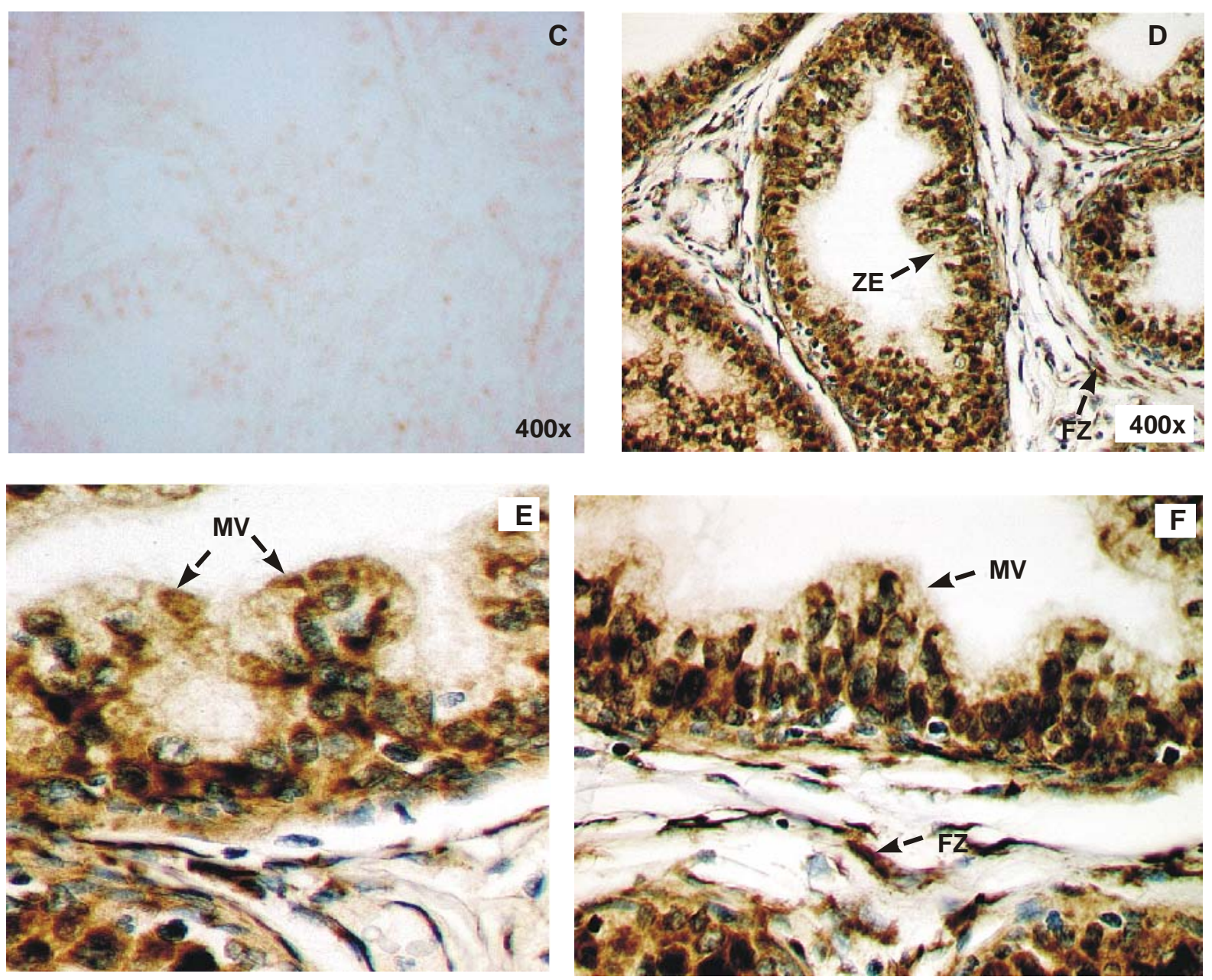

Abb. 3.13 C-F Epididymisspezifische Expression des rAbca5-Gens der Ratte (400x). Paraffinschnitte aus adulter Epididymis der Ratte wurde bei $55^{\circ} \mathrm{C}$ mit einer DIG-markierten cRNA-Sonde RISH1 hybridisiert. C zeigt das Ergebnis der Hybridisierung mit der RISH1-Sense-Sonde als Negativkontrolle (400x). Die Hybridisierung mit der RISH1-Antisense-Sonde ist in den Aufnahmen D-F im Detail dargestellt und zeigt die rAbca5-mRNA-Expression in den Fibrozyten $(F Z)$ und den Mikrovilli des Zylinderepithels. $F Z=$ Fibrozyten, $Z E=$ Zylinderepithel, MV = Mikrovilli.

Die Hybridisierungen des Nebenhoden der Ratte wurden mit der cRNA-Sonde RISH1 durchgeführt, die zu Hintergrundsignalen im Bereich der Zellkerne führte $(\rightarrow 3.4 .1)$. Diese sind auch in Abbildung A (Negativkontrolle, Hybridisierung mit RISH1-Sense-Sonde) erkennbar (Abb. 3.13, A und C) und erschwerten die zellspezifische Zuordnung der Hybridisierungssignale. Daher sind weitere Experimente mit alternativen cRNA-Sonden (z.B. RISH2) nötig, um diese Ergebnisse zu verifizieren. 


\subsection{Expression des Abca5-Gens der Ratte in Kulturen primärer Hepatozyten}

In den vergangenen 5 Jahren wurden verschiedene Oxysterole als Aktivatorliganden für den Transkriptionsfaktor liver $X$ receptor (LXR) identifiziert (EDWARDS et al. 2002). Zu den aktivierten Zielgenen gehörte neben den $A B C$-Transportergenen $A B C G 5$ und $A B C G 8$ mit $A B C A 1$ auch ein Mitglied der ABCA-Subfamilie. Da auch für andere $A B C A$-Vertreter ( $A B C A 6, A B C A 7, A B C A 9)$ eine Regulation im Rahmen der Lipidhomöostase vermutet wird (KLUCKEN et al. 2000, KAMINSKI et al. 2000, PIEHLER et al. 2002 ), sollte das rAbca5-Gen im Zellkulturmodell primärer Hepatozyten der Ratte im Hinblick auf eine mögliche Regulation durch LXR-Aktivatoren untersucht werden. Dieses Zellkulturmodell erlaubt unter geeigneten Kulturbedingungen $(\rightarrow$ 2.2.12.2) die Aufrechterhaltung differenzierter Funktionen wie der Albuminsekretion (HOFFMANN et al. 1989) und der Induzierbarkeit von Cytochrom-P450Isoenzymen (AUBRECHT et al. 1993, 1996).

Primäre Hepatozyten der Ratte wurden für 4 Tage mit einem Oxysterol inkubiert. Eine nachfolgende Untersuchung der rAbca5-mRNA Expression mittels einer Northern-BlotAnalyse $(\rightarrow 2.2 .10)$ zeigte den Einfluß des eingesetzten Effektors. Von den verwendeten Oxysterolen (20- $\alpha$-Hydroxycholesterol, 25-Hydroxycholesterol, 22- $R$-Hydroxycholesterol) konnte nur unter dem potentesten Aktivator, 22-R-Hydroxycholesterol, ein Effekt beobachtet werden. 


\subsubsection{Einfluß von 22-R-Hydroxycholesterol auf die rAbca5-mRNA- Expression}

Eine Konzentration von $10 \mu \mathrm{M}$ 22-R-Hydroxycholesterol (Bahn 3) bewirkte in kultivierten primären Hepatozyten der Ratte nach 4 Tagen einen Anstieg der rAbca5-mRNA-Expression um $43 \%$ relativ zur ethanolhaltigen Kontrollprobe (Bahn 2). Unter Inkubation mit $20 \mu \mathrm{M} 22-R$ Hydroxycholesterol betrug dieser Anstieg 76\% (Bahn 4). Unter Standardbedingungen kultivierte Rattenhepatozyten (Bahn 1) zeigten relativ dazu eine um $41 \%$ niedrigere $r A b c a 5$ mRNA-Expression (Abb. 3.14).

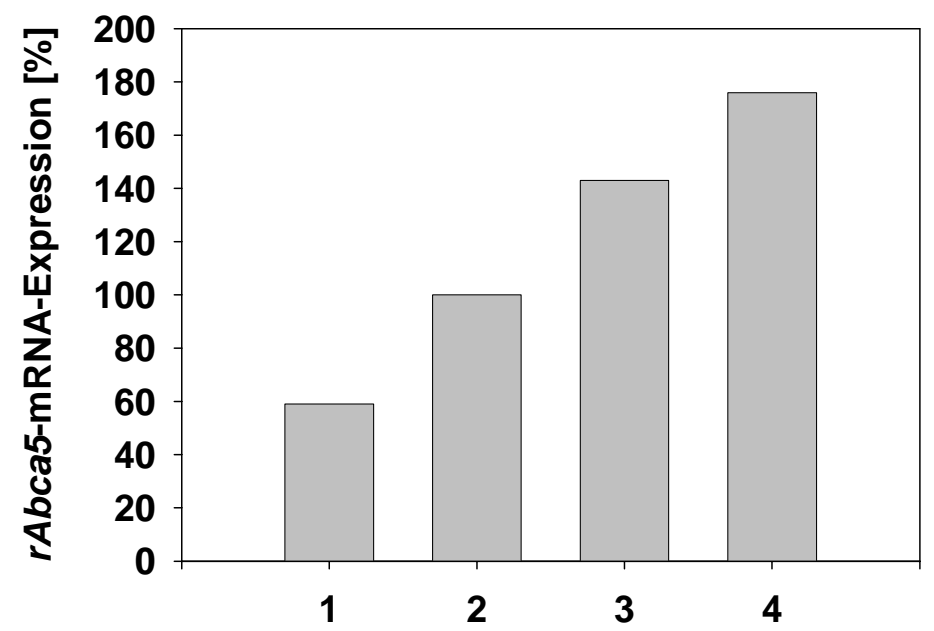

Abb. 3.14 Induktion von rAbca5-mRNA durch 22-R-Hydroxycholesterol. Rattenhepatozyten wurden für 4 Tage in Gegenwart von 22-R-Hydroxycholesterol kultiviert. Dargestellt ist die densitometrische Auswertung eines repräsentativen Northern Blots. Pro Probe wurden $25 \mu \mathrm{g}$ Gesamt-RNA gelelektrophoretisch aufgetrennt und rAbca5-mRNA mittels einer genspezifischen Oligonukleotidsonde (RR13, $\rightarrow$ 2.1.7.6.4) nachgewiesen. Zur Kontrolle wurde der Blot mit einer GAPDH-genspezifischen Sonde rehybridisiert. Die ethanolhaltige Kontrolle nach 4 Tagen wurde gleich $100 \%$ gesetzt. Für die Säulen im Diagramm gelten folgende Zuordnungen: $\mathbf{1}=$ Kontrolle, $\mathbf{2}=$ Kontrolle $+0.15 \%(\mathrm{v} / \mathrm{v})$ Ethanol, $\mathbf{3}=10 \mu \mathrm{M}$ 22- $R$-Hydroxycholesterol, $4=20 \mu \mathrm{M}$ 22-R-Hydroxycholesterol.

\subsubsection{Einfluß von 22-R-Hydroxycholesterol und 9-cis-Retinsäure auf die rAbca5-mRNA Expression}

Zur Aktivierung von Zielgenen binden LXR-Rezeptoren mit dem Heterodimerisierungspartner RXR (retinoid $X$ receptor) an spezifische Bindungselemente im Promotor des Zielgens. Um den Effekt des RXR-Liganden 9-cis-Retinsäure auf die Induktionseffekte der rAbca5-mRNA mit 22-R-Hydroxycholesterol zu untersuchen, wurden primäre Hepatozyten der Ratte für 4 Tage gleichzeitig mit beiden Liganden behandelt. 


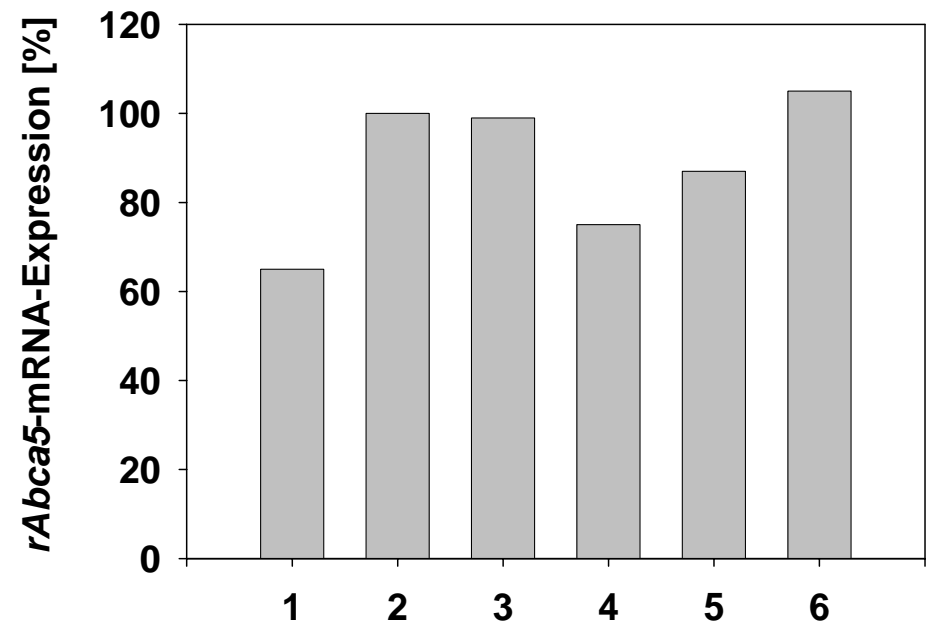

Abb. 3.15 Induktion von rAbca5-mRNA durch 22-R-Hydroxycholesterol und 9-cisRetinsäure. Rattenhepatozyten wurden für 4 Tage in Gegenwart von 22-RHydroxycholesterol und 9-cis-Retinsäure kultiviert. Dargestellt ist die densitometrische Auswertung eines repräsentativen Northern Blots. Pro Probe wurden $25 \mu \mathrm{g}$ Gesamt-RNA gelelektrophoretisch aufgetrennt und rAbca5-mRNA mittels einer genspezifischen Oligonukleotidsonde (RR13, $\rightarrow$ 2.1.7.6.4) nachgewiesen. Zur Kontrolle wurde der Blot mit einer $\beta$-Aktin-spezifischen Sonde rehybridisiert. Der ethanolhaltige Kontrollwert nach 4 Tagen wurde gleich $100 \%$ gesetzt. Für die Säulen im Diagramm gelten folgende Zuordnungen: $1=$ Kontrolle, $2=$ Kontrolle $+0.15 \% \quad(\mathrm{v} / \mathrm{v})$ Ethanol, $\quad 3=1 \mu \mathrm{M} \quad 9$-cis-Retinsäure $/ 10 \mu \mathrm{M} \quad 22-R$ Hydroxycholesterol, $\quad 4=1 \mu \mathrm{M}$ 9-cis-Retinsäure/20 $\mu \mathrm{M} \quad 22-R$-Hydroxycholesterol, $\mathbf{5}=10 \mu \mathrm{M} \quad$ 9-cis-Retinsäure $/ 10 \mu \mathrm{M} \quad 22-R$-Hydroxycholesterol, $\quad \mathbf{6}=10 \mu \mathrm{M} \quad$ 9-cisRetinsäure/20 $\mu \mathrm{M}$ 22-R-Hydroxycholesterol.

Die 4-tägige Inkubation primärer Hepatozyten der Ratte mit 9-cis-Retinsäure und 22-RHydroxycholesterol führte relativ zur ethanolhaltigen Kontrolle (Bahn 2) zu uneinheitlichen Ergebnissen. Während die Expression der rAbca5-mRNA unter Zugabe von $1 \mu \mathrm{M}$ 9-cisRetinsäure und $10 \mu \mathrm{M}$ 22-R-Hydroxycholesterol (Bahn 3) auf dem Niveau der Kontrolle verharrte, sank dieser Wert um 25\%, wenn die Oxysterolkonzentration verdoppelt wurde (Bahn 4). Wurden äquimolare Mengen $(10 \mu \mathrm{M})$ beider Liganden eingesetzt, war noch immer eine Hemmung auf $87 \%$ gegenüber der Kontrolle zu beobachten (Bahn 5). Erneute Verdoppelung der Oxysterolkonzentration auf $20 \mu \mathrm{M}$ ließ die rAbca5-mRNA-Expression auf $105 \%$ des Kontrollniveaus steigen (Abb. 3.15).

\subsubsection{Einfluß eines synthetischen LXR-Agonisten auf die rAbca5-mRNA Expression}

Für die Expression von ABCA1-mRNA konnten SPARROW et al. (2002) in THP-1 Makrophagen (aus einer humanen Leukämiezellinie) eine um den Faktor 1000 höhere Potenz des synthetischen LXR $\alpha / \beta$-Agonisten Acetyl-podocarpic dimer (APD) im Vergleich zu 22-R-Hydroxycholesterol zeigen. Um den Effekt dieses LXR-Agonisten auf die rAbca5- 
mRNA-Expression im Rattensystem zu untersuchen, wurden primäre Hepatozyten der Ratte für vier Tage mit APD inkubiert.

Unter Inkubation mit 100 nM APD (gelöst in DMSO) betrug die rAbca5-mRNA-Expression am vierten Tag 296\% des DMSO-haltigen Kontrollwertes (Bahn 3). Die rAbca5-mRNAExpression unter Standardbedingungen (Bahn 1) stieg im gleichen Zeitraum relativ zum Kontrollwert um 92\% (Abb. 3.16).

A

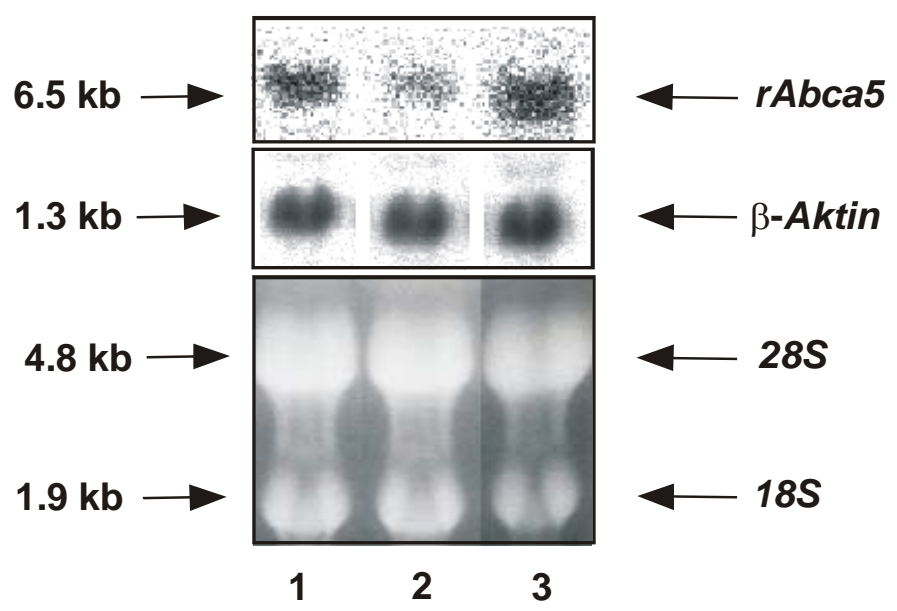

B

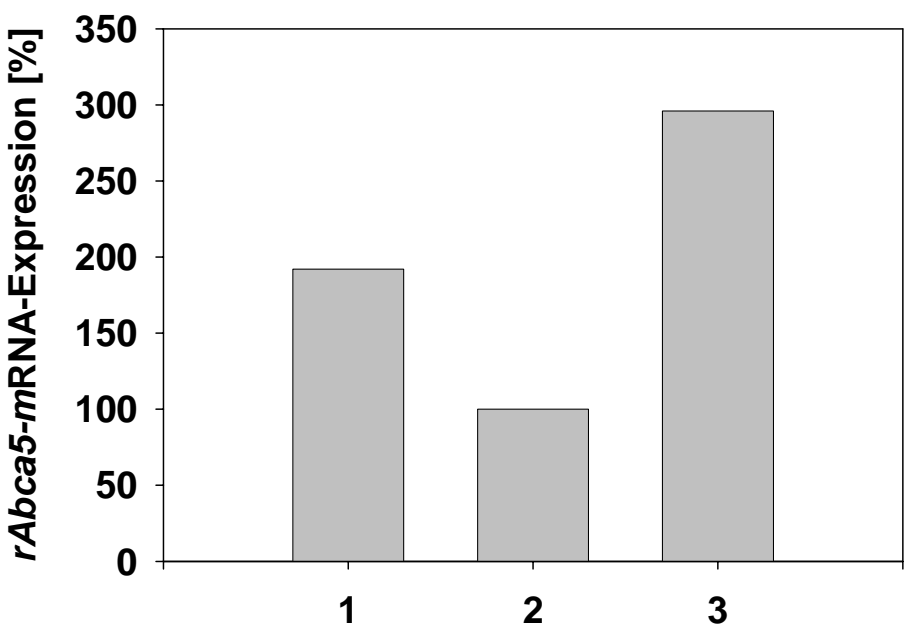

Abb. 3.16 Induktion von rAbca5-mRNA durch Acetyl-podocarpic dimer (APD). Rattenhepatozyten wurden für 4 Tage in Gegenwart von APD kultiviert.

A Dargestellt ist ein repräsentativer Northern Blot. Pro Probe wurden $25 \mu \mathrm{g}$ Gesamt-RNA gelelektrophoretisch aufgetrennt und rAbca5-mRNA mittels einer genspezifischen Oligonukleotidsonde (RR13, $\rightarrow$ 2.1.7.6.4) nachgewiesen. Zur Kontrolle wurde der Blot mit einer $\beta$-Aktin-genspezifischen Sonde rehybridisiert.

B Dargestellt ist die densitometrische Auswertung eines repräsentativen Northern Blots. Der Kontrollwert mit vergleichbarer DMSO-Konzentration nach 4 Tagen wurde gleich $100 \%$ gesetzt. Für die Probenauftragung und die Säulen im Diagramm gelten folgende Zuordnungen: $1=$ Kontrolle unter Standardbedingungen, 2 = Kontrolle $+0.15 \%(v / v)$ DMSO, $3=100 \mathrm{nM} \mathrm{APD}$ in DMSO. 


\subsubsection{Zeitabhängige Zunahme der rAbca5-mRNA-Expression}

Im Rahmen der Induktionsversuche mit verschiedenen LXR-Liganden wurde auch die zeitabhängige Entwicklung der rAbca5-mRNA in Kulturen primärer Hepatozyten unter Standardbedingungen untersucht. Über 4 Tage wurde unter Kontrollbedingungen eine stetige Zunahme der Expression beobachtet. Am zweiten Tag des Experiments lag die rAbca5mRNA-Expression bereits bis zu 20\% über dem Ausgangswert. Tag 3 zeigte einen geringeren Expressionsanstieg um weitere 10\%. Am vierten Tag war der deutlichste Anstieg zu verzeichnen, so daß die Gesamtzunahme der Expression über 4 Tage bis zu $75 \%$ betrug (Abb. 3.17).

A

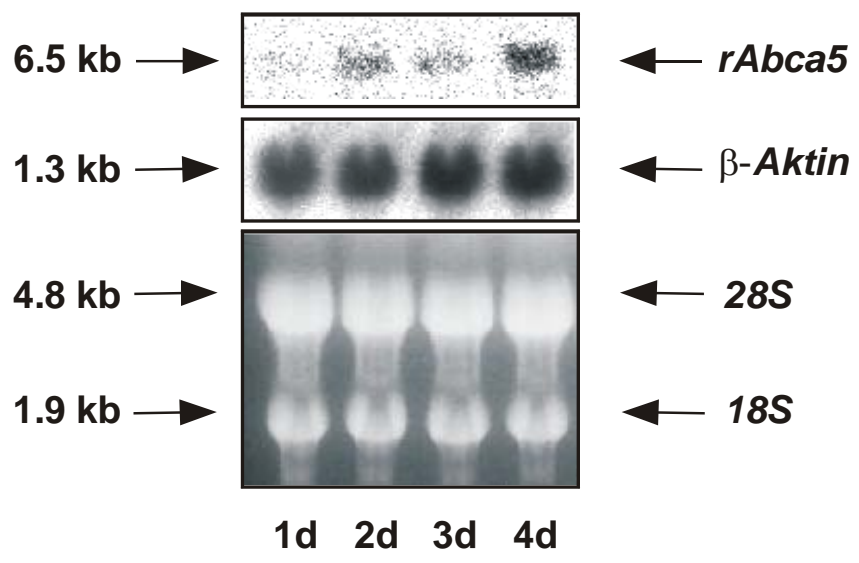

B

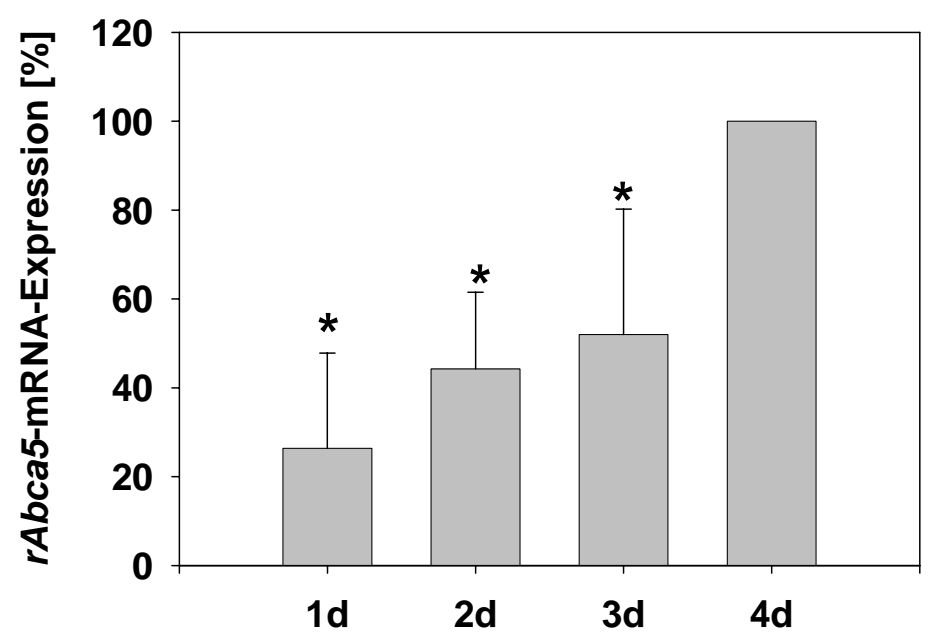

Abb. 3.17 Zeitabhängige Hochregulation der rAbca5-mRNA Expression unter Kontrollbedingungen. Primäre Hepatozyten der Ratte wurden für vier Tage unter Kontrollbedingungen kultiviert.

A Dargestellt ist ein repräsentativer Northern Blot. Pro Probe wurden $25 \mu \mathrm{g}$ Gesamt-RNA gelelektrophoretisch aufgetrennt und rAbca5-mRNA mittels einer 
genspezifischen Oligonukleotidsonde (RR13, $\rightarrow$ 2.1.7.6.4) nachgewiesen. Zur Kontrolle wurde der Blot mit einer $\beta$-Aktin-genspezifischen Sonde rehybridisiert.

B Dargestellt sind die arithmetischen Mittelwerte der densitometrischen Auswertungen \pm Standardabweichung aus vier unabhängigen Experimenten. Die rAbca5-mRNA Expression nach 4d wurde gleich $100 \%$ gesetzt. Signifikanzniveau: ${ }^{*}, p<0.05$, t-Test für ungepaarte Werte.

\subsection{Quantitative Analyse der Expression von rAbca5 V+16}

Das Auftreten von alternativen mRNA-Transkripten ist für viele Genfamilien ein häufiges Phänomen, und es erfordert weitere Untersuchungen, um die physiologische Relevanz eines alternativen Transkripts $\mathrm{zu}$ bewerten. Aus diesem Grund wurde die Häufigkeit der rAbca5 V+16-mRNA (SV) im Verhältnis zur rAbca5-mRNA (VT) in SER-W3 Zellen, frisch isolierten Hepatozyten und 9 verschiedenen Organen der Ratte mittels quantitativer RT-PCR bestimmt.

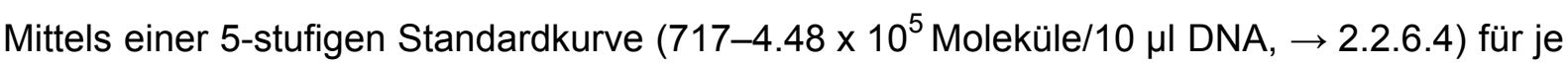
ein Referenzplasmid des Volltransporters (VT) und der Splicevariante (SV) wurde bestätigt, daß die PCR-Experimente für beide Amplifikate unter vergleichbaren kinetischen Bedingungen verliefen (vergleichbare Standardkurve, ohne Abb.). Im weiteren Verlauf des Experimentes wurde daher die Standardkurve für eines der beiden Referenzplasmide (VT) bestimmt, um die absolute Menge an Transkripten in den Proben zu berechnen (Abb. 3.18).

A

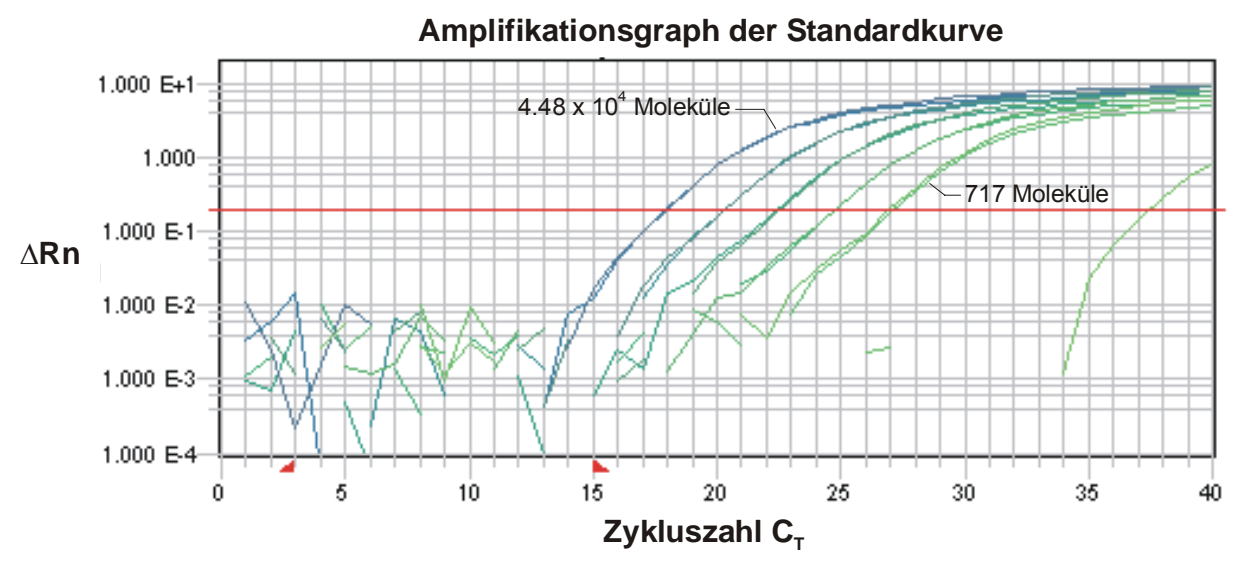

Abb. 3.18A Amplifikationsgraph der Standardkurve für das Referenzplasmid VT. Der Graph zeigt eine Auftragung des Anstiegs des normalisierten Reportersignals $(\Delta \mathrm{Rn})$ vs. die Amplifikationskurven der einzelnen Standardlösungen mit bekannter cDNA-Molekülzahl $\left(717,3584,17920,8.96 \times 10^{4}\right.$ und $4.48 \times 10^{5}$ Moleküle). Die Abbildung wurde der Analysesoftware SDS 2.1 entnommen.

Je mehr cDNA-Moleküle als Matrize in der PCR-Reaktion enthalten waren, desto schneller wurde ein Fluoreszenzsignal detektiert, das sich vom Reaktionshintergrund abhob. Der 
Threshold (waagerechte rote Linie), an dem der $\mathrm{C}_{\mathrm{T}}$-Wert abgelesen wurde, befand sich im Bereich der exponentiellen Reaktionsphase, die weitgehend frei von störenden Nebenreaktionen war.

B

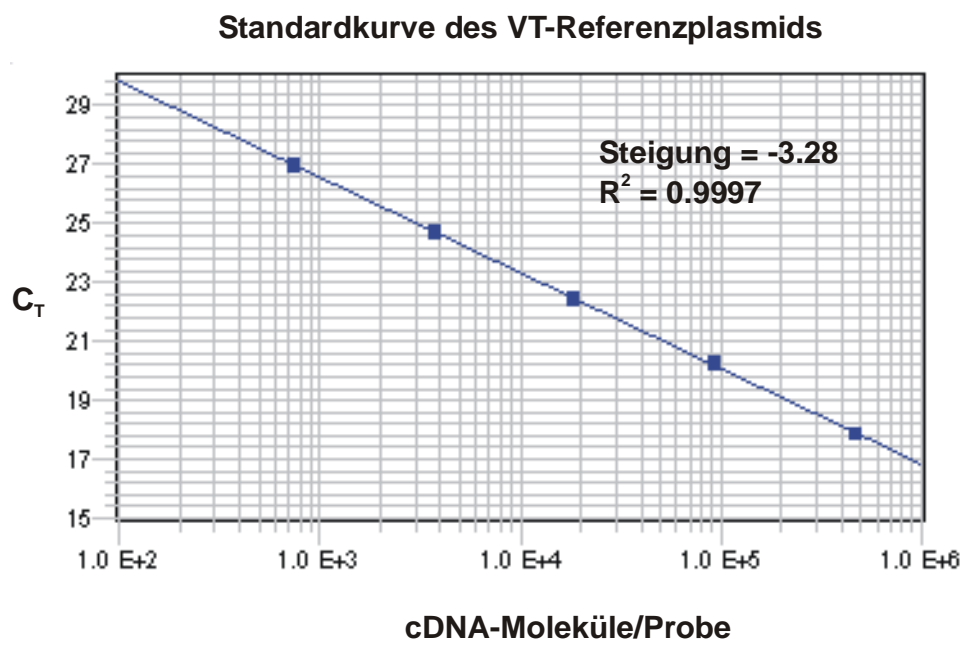

Abb. 3.18B Aus dem Amplifikationsgraphen errechnete Standardkurve für das VTReferenzplasmid. Gezeigt ist die Auftragung der abgelesenen $\mathrm{C}_{\mathrm{T}}$-Werte (Zykluszahl, an der das Reportersignal sich vom Rekationshintergrund abhebt) vs. die eingesetzen cDNA-Moleküle der Standardlösungen. Alle Meßwerte wurden durch eine Doppelbestimmung erhalten und als Mittelwerte dargestellt.

Die errechnete Standardkurve für das VT-Referenzplasmid verdeutlicht, daß die $\mathrm{C}_{\mathrm{T}}$-Werte mit sinkender Molekülzahl der cDNA-Matrizenlösung anstiegen, um ein vergleichbares Reportersignal zu produzieren (negative Steigung). Der hohe Korrelationskoeffizient $\mathrm{R}^{2}$ zeigt die gute Reproduzierbarkeit der in Doppelbestimmung erhaltenen Datenpunkte.

\begin{tabular}{|c|c|c|c|c|}
\hline Probe & $\begin{array}{l}\text { Anzahl der cDNA- } \\
\text { Transkripte }\end{array}$ & $\begin{array}{l}\text { Anzahl der 18S- } \\
\text { Transkripte }\end{array}$ & $\begin{array}{l}\text { Anzahl der Transkriptel } \\
10^{5} 18 S \text { Moleküle }\end{array}$ & $\%$ SV \\
\hline Gehirn_SV & 2881.3 & 421168 & 684 & 2.6 \\
\hline Gehirn_VT & 110270 & 421168 & 26182 & \\
\hline Hepatos_SV & 1390.8 & 518862 & 268 & 3.8 \\
\hline Hepatos_VT & 36830 & 518862 & 7098 & \\
\hline Herz_SV & 0 & 629 & 0 & 0 \\
\hline Herz_VT & 574.59 & 629 & 91329 & \\
\hline Leber_SV & 366.25 & 358555 & 102 & 3.6 \\
\hline Leber_VT & 10071 & 358555 & 2809 & \\
\hline Lunge_SV & 12912 & 1074598 & 1202 & 6.0 \\
\hline Lunge_VT & 214240 & 1074598 & 19937 & \\
\hline
\end{tabular}




$\begin{array}{ccccc}\text { Milz_SV } & 449.60 & 168919 & 266 & \mathbf{9 . 9} \\ \text { Milz_VT } & 4529.4 & 168919 & 2681 & \\ \text { Muskel_SV } & 704.01 & 243367 & 289 & 4.5 \\ \text { Muskel_VT } & 15676 & 243367 & 6442 & \\ \text { Niere_SV } & 656.99 & 134298 & 489 & \mathbf{4 . 6} \\ \text { Niere_VT } & 14265 & 134298 & 10622 & \\ \text { Pankreas_SV } & 149.84 & 500800 & 30 & \mathbf{1 1 . 2} \\ \text { Pankreas_VT } & 1339.6 & 500800 & 267 & \mathbf{3 . 4} \\ \text { Testis_SV } & 11517 & 2022700 & 569 & \\ \text { Testis_VT } & 334160 & 2022700 & 16520 & \mathbf{1 0 . 2} \\ \text { SER-W3_SV } & 2954.8 & 819420 & 360.60 & 3528.8 \\ \text { SER-W3_VT } & 28916 & 819420 & & \end{array}$

Tabelle 3.5 Quantifizierung der erfaßten cDNA-Transkripte für rAbca5, rAbca5 V+16 und 18S-RNA in 9 verschiedenen Organen der Ratte, frisch isolierten Hepatozyten und SER-W3 Zellen. Mittels der Standardkurve $(\rightarrow$ Abb. 3.18) wurden die absoluten Molekülzahlen/Probe (in $40 \mathrm{ng}$ cDNA) bestimmt und daraus der relative Gehalt des Splicevarianten-Transkripts (SV) in bezug auf den rAbca5-mRNAGehalt abgeleitet. Als interner Standard wurde der 18S-RNA-Gehalt aller Proben bestimmt und auf ein 18S-Standardplasmid (zur Verfügung gestellt von Uta Ferch, Abt. Humangenetik Göttingen) bezogen.

Die relativen Anteile der cDNA-Transkripte der Splicevariante rAbca5 V+16-mRNA in bezug auf die cDNA-Transkripte der rAbca5-mRNA schwankten zwischen 2.6\% im Gehirn der Ratte und $11 \%$ im Pankreas. Die mRNA-Proben aus dem Herz der Ratte zeigten keinerlei Expression der Splicevariante bei gleichzeitig niedrigem 18S RNA-Gehalt. Leber und frisch isolierte Hepatozyten hatten mit 3.6\% und 3.8\% eine annähernd gleiche Expression der Splicevariante wie der Testis der Ratte mit 3.4\%. In der Sertolizellinie SER-W3 wurden ein 10.2\%-iger Anteil der Splicevariante in Bezug auf die mRNA des Volltransporters gemessen und damit ein mit dem Pankreas und der Milz (9.9\%) vergleichbarer Wert. Mittlere Anteile der Splicevariante wurden in Niere (4.6\%), Muskel (4.5\%) und Lunge (6.0\%) detektiert.

\subsection{Untersuchungen zur subzellulären Lokalisation}

Die Versuche zur subzellulären Lokalisation des rAbca5-Proteins und der Splicevariante rAbca5 V+16 wurden in transient transfizierten Kulturen von drei verschiedenen Zellinien auf der Basis einer Überexpression von Epitop-getaggten Fusionsproteinen durchgeführt $(\rightarrow$ 2.2.12f). Die SER-W3-Linie stammte aus Sertolizellen einer 17-Tage-alten Ratte und stellte ein homologes Expressionssystem mit einer endogenen rAbca5-Expression dar. Als heterologe Zellsysteme wurden die humane HEK 293-Linie aus Nierenepithelzellen und die 
humane Kolonkarzinom-Linie Caco-2 verwendet. Beide Zellinien wiesen eine endogene Expression des humanen $A B C A 5$ auf.

\subsubsection{Generierung von V5-Expressionsklonen für rAbca5 und rAbca5 V+16}

Für die Herstellung der Expressionplasmide wurden die kodierenden Sequenzen für rAbca5 und rAbca5 V+16 mittels PCR aus Gesamt-RNA des Testis der Ratte amplifiziert $(\rightarrow$ 2.2.6.3). Zur Reduktion von Taq-Polymerase-bedingten Punktmutationen wurde eine Polymerasemischung mit Korrektur-Aktivität benutzt (Expand Long Template System aus Pfu oder Pwo + Taq-Polymerase) und die Zahl der PCR-Zyklen auf 10 begrenzt. Für nachfolgende Ligationsreaktionen wurden für das rAbca5-cDNA-Amplifikat 30 PCR-Ansätze auf $4 \mu \mathrm{l}$ konzentriert.

\subsubsection{Herstellung von Konstrukten mit V5-Epitop}

Der pcDNA3.1/V5-His TOPO Expressions-Vektor (Invitrogen) erlaubte die direkte Ligation der obigen PCR-Produkte nach der TOPO-Methode $(\rightarrow$ 2.2.5.1). Nach Transformation in elektrokompetente E.coli $(\rightarrow 2.2 .5 .4)$ und Restriktionsanalyse der Kolonien wurden Klone mit intakten Inserts zwecks detaillierter Sequenzüberprüfung vollständig sequenziert. Sequenzdateien wurden mit den PC-Softwareprogrammen Chromas (Technelysium), Staden Package und ClustalW (EBI) ausgewertet. Um verläßliche Ergebnisse über die subzelluläre Lokalisation zu erhalten, konnten nur fehlerfreie Expressionsklone verwendet werden, deren rAbca5-cDNA im Plasmid zur nativen rAbca5-Aminosäuresequenz im exprimierten Fusionsprotein führen würden. Von 54 sequenzierten rAbca5-V5-Klonen wurde ein fehlerfreier Klon detektiert. Für rAbca5 V+16 wurde auf dem gleichen Weg ein korrekter Expressionsklon rAbca5 V+16-V5 gewonnen. Das Abca-Gen stand in diesem Vektor unter Kontrolle des humanen Cytomegalie Virus-Promotors (CMV). Im Anschluß an den C-Terminus des ligierten Inserts ( $\mathrm{AAbca5}$, rAbca5 V+16) befand sich eine Linkerregion von 22 Aminosäuren, an die sich das V5-Epitop (14 Aminosäuren), und nach einem Arg-Thr-Gly-Linker die Polyhistidin-Region mit 6 Histidin-Substituenten anschlossen.

\begin{tabular}{ccc}
\hline & rAbca5 (VT) & rAbca5 V+16 (SV) \\
\hline cDNA-Amplifikat & $4940 \mathrm{bp}$ & $2789 \mathrm{bp}$ \\
Primer & RF3, RR2 & RF3, KRSV R1 \\
Resultierendes Peptid & $1642 \mathrm{AS}, \mathrm{ca} .180 \mathrm{kDa}$ & $925 \mathrm{AS}, 102 \mathrm{kDa}$ \\
V5-Konstrukt & $10463 \mathrm{bp}$ & $8312 \mathrm{bp}$ \\
V5-Fusionsprotein & $1678 \mathrm{AS}, 185 \mathrm{kDa}$ & $961 \mathrm{AS}, 107 \mathrm{kDa}$ \\
\hline
\end{tabular}

Tabelle 3.6 V5-Expressionplasmide für rAbca5 und rAbca5 V+16. Diese Tabelle faßt die Herstellung der V5-Expressionskonstrukte für rAbca5 und rAbca $V+16$ zusammen. $\mathrm{VT}=$ Volltransporter, $\mathrm{SV}=$ Splicevariante. 


\subsubsection{2 Überexpression der V5-Konstrukte}

Nach Transfektion von VT-V5 und SV-V5 in Caco-2- und SER-W3-Zellen wurden die Zellen nach $48 \mathrm{~h}$ geerntet und die Zellfraktionen im Western Blot untersucht. Der Nachweis des entsprechenden Fusionsproteins sollte mit einem Antikörper gegen das V5-Epitop erfolgen. Weder für VT-V5 noch für SV-V5 konnten spezifische Proteinbanden detektiert werden.

\subsubsection{Herstellung von Konstrukten mit EGFP-Epitop}

Um einen direkten Nachweis des exprimierten Fusionsproteins in der Zellkultur zu ermöglichen, wurden für rAbca5 und rAbca5 V+16 Konstrukte mit einem EGFP-Epitop-Tag generiert. Dazu wurde der pEGFP-N1-Vektor (BD Biosciences) verwendet. Aus VT-V5 und SV-V5 wurden durch präparative Restriktion mit den Enzymen Sacl und Sacll das jeweilige Insert isoliert und in den pEGFP-N1-Vektor ligiert. Nach Transformation in elektrokompetente E.coli $(\rightarrow$ 2.2.5.4) und Restriktionsanalyse der Kolonien wurden je ein Klon für rAbca5-EGFP und rAbca5 V+16-EGFP ausgewählt und beide zur Überprüfung des Inserts sequenziert. Die Abca-Gene $r A b c a 5$ und $r A b c a 5 V+20$ der Ratte standen in diesem Vektor unter der Kontrolle des humanen Cytomegalie Virus-Promotors (CMV). An den C-Terminus des jeweiligen Inserts schloß sich eine Linkerregion von 28 Aminosäuren und darauf das EGFP-Epitop (239 Aminosäuren) an.

\begin{tabular}{ccc}
\hline & rAbca5 (VT) & rAbca5 V+16 (SV) \\
\hline cDNA-Insert aus V5-Vektor & $5033 \mathrm{bp}$ & $2882 \mathrm{bp}$ \\
EGFP-Konstrukt & $9734 \mathrm{bp}$ & $7583 \mathrm{bp}$ \\
EGFP-Fusionsprotein & $1909,215 \mathrm{kDa}$ & $1192 \mathrm{AS}, 135 \mathrm{kDa}$ \\
\hline
\end{tabular}

Tabelle 3.7 EGFP-Expressionsplasmide für rAbca5 und rAbca5 V+16. Diese Tabelle faßt die Herstellung der EGFP-Expressionskonstrukte für rAbca5 und rAbca $V+16$ zusammen. VT = Volltransporter, SV = Splicevariante.

\subsubsection{Expression der EGFP-Konstrukte}

Die transienten Transfektionen der EGFP-Expressionsplasmide VT-EGFP und SV-EGFP wurden in Caco-2-, SER-W3- und HEK293-Zellen durchgeführt und nach 24 h, 48 h und 72 h fluoreszenzmikroskopisch untersucht. Dabei erwies sich die Expression der EGFPKonstrukte in den SER-W3-Zellen als zu gering, um eine Detektion der Fusionsproteine zu ermöglichen. Im weiteren Verlauf der Transfektionsexperimente wurden daher ausschließlich HEK293-Zellen und Caco-2-Zellen verwendet. 


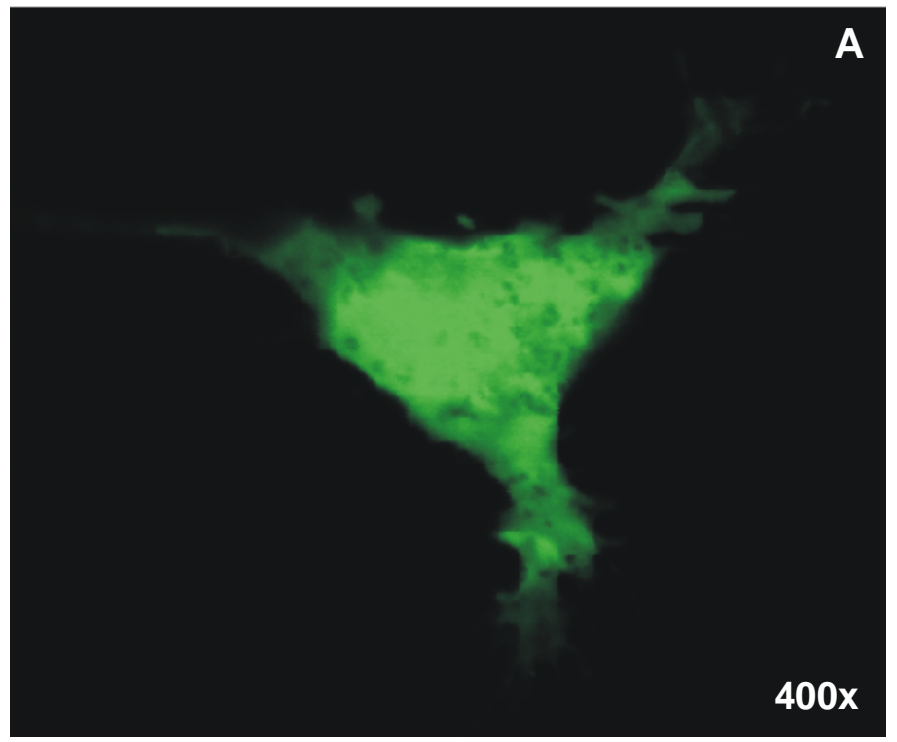

Abb. 3.19A Expression der EGFP-Kontrollplasmids in transient transfizierten HEK293Zellen (400x). EGFP verteilt sich in der gesamten Zelle inklusive Zellkern. Die Zellen wurden in einem konfokalen Lasermikroskop betrachtet und digital fotografiert (Leica Irbe).
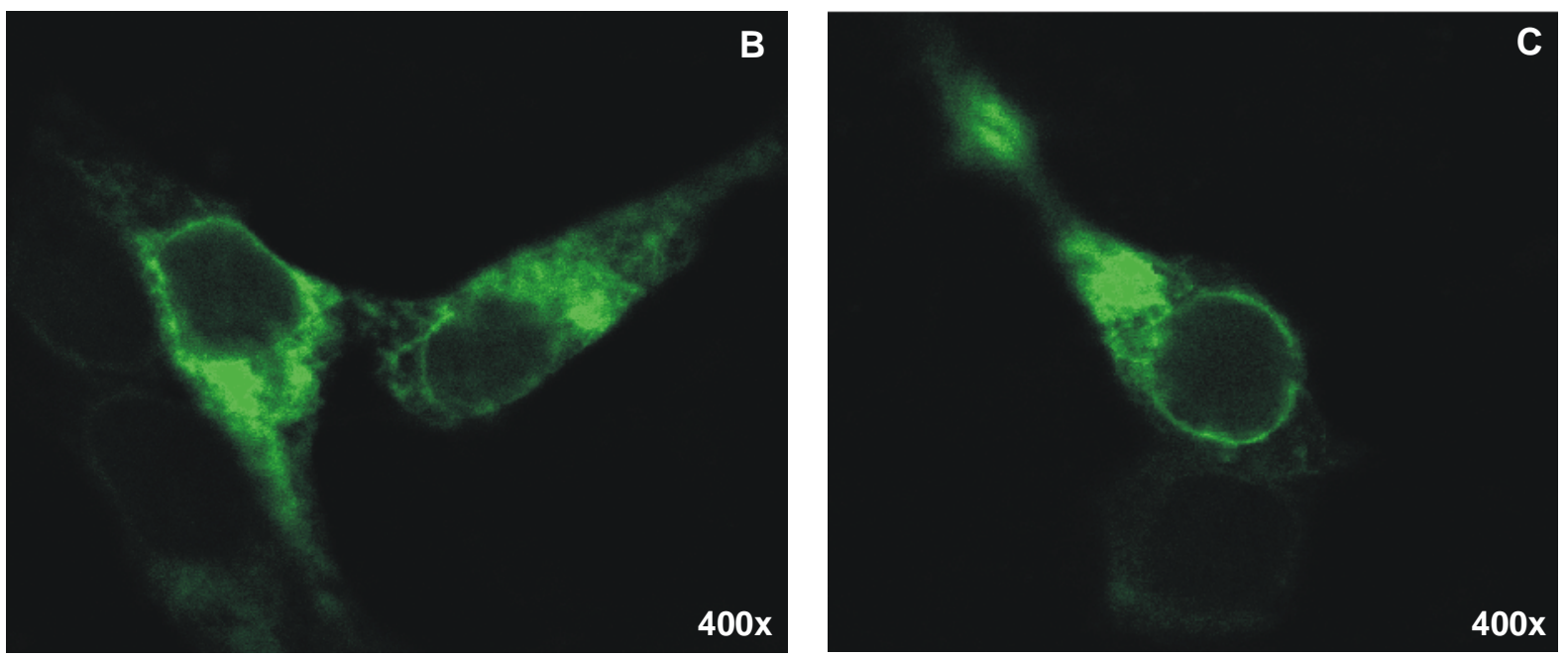

Abb. 3.19B,C Expression der EGFP-Fusionsplasmide in transient transfizierten HEK293Zellen (400x). Sowohl VT-EGFP als auch SV-EGFP weisen eine intrazelluläre Verteilung auf. Die Zellen wurden in einem konfokalen Lasermikroskop betrachtet und digital fotografiert (Leica Irbe).

$24 \mathrm{~h}$ nach der Transfektion wurde eine maximale Expression der EGFP-Konstrukte beobachtet, die in den Kontrolltransfektionen (EGFP) nach visueller Beurteilung eine Effizienz von ca. $30 \%$, in den Transfektionen für VT-EGFP und SV-EGFP jedoch nur eine Effizienz von < $5 \%$ aufwies. Das ca. $30 \mathrm{kDa}$-große EGFP-Protein verteilte sich im gesamten Zytoplasma der HEK293-Zellen (Abb. 3.19 A). Beide Fusionsproteine wiesen eine ähnliche, um den Zellkern zentrierte Verteilung auf (Abb.3.19 B-C). Auch in Teilen des Zytoplasmas in 
Kernnähe war eine starke Expression zu beobachten. Es wurden keine Hinweise auf eine Lokalisierung von rAbca5-EGFP und rAbca5 V+16 in der Zytoplasmamembran gefunden.
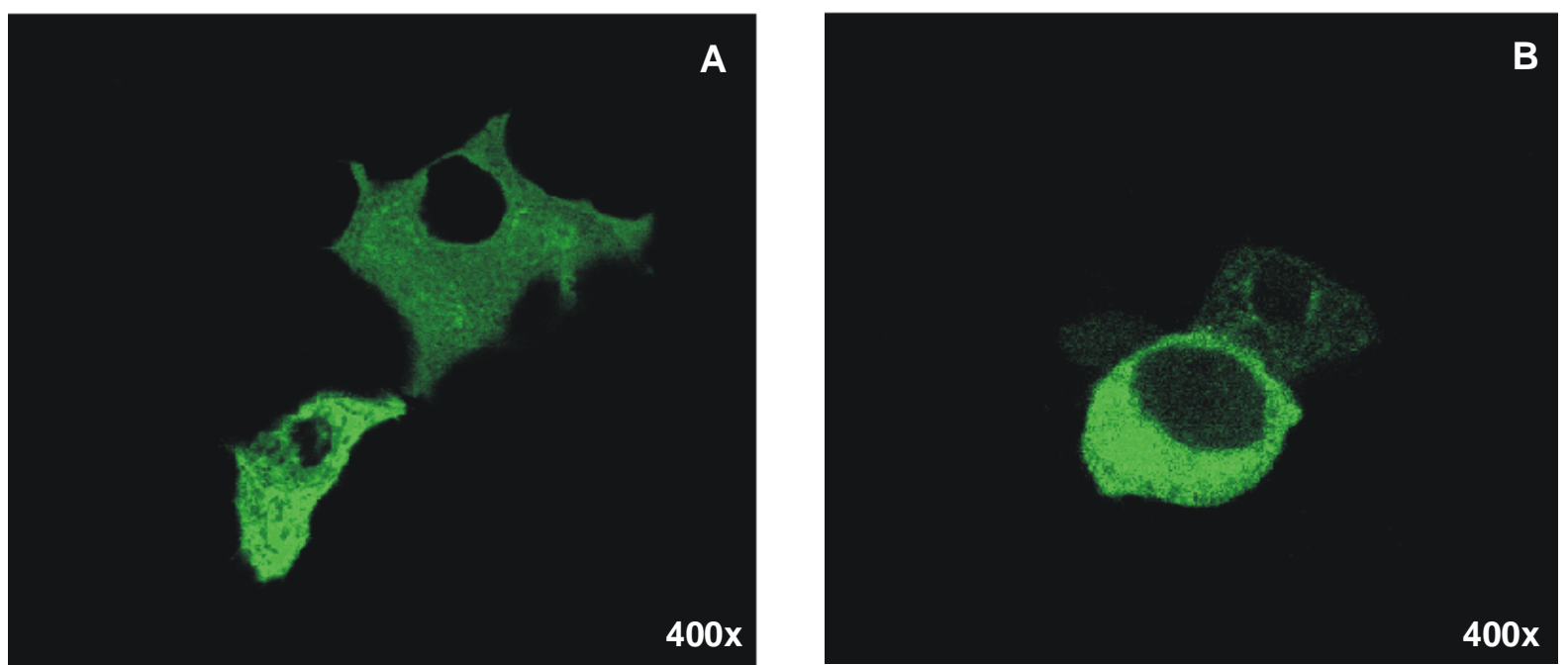

Abb. 3.20 Expression der EGFP-Konstrukte in transient transfizierten Caco-2-Zellen.

A Das EGFP-Kontrollplasmid verteilt sich im gesamten Zytoplasma, nicht jedoch im Zellkern.

B Das Fusionsprotein VT-EGFP ist in einer Kappe rund um den Zellkern erkennbar.

In den Caco-2-Zellen wurde das Expressionsmaximum $24 \mathrm{~h}$ nach der Transfektion erreicht und war für alle Konstrukte deutlich geringer als in den HEK293-Zellen. Das Expressionskonstrukt der Splicevariante rAbca5 V+16 konnte mittels Fluoreszenzmikroskopie nicht detektiert werden. EGFP verteilte sich im Zytoplasma, ohne jedoch den Kern zu penetrieren (Abb. 3.20 A). Das Fusionsprotein rAbca5-EGFP verteilte sich in einer Kappe rund um den Zellkern (Abb. 3.20 B). Auch in den Caco-2 Zellen wurden keine Hinweise auf eine Lokalisierung von rAbca5-EGFP und rAbca5 V+16 in der Zytoplasmamembran gefunden. 
Diskussion

Die vorliegende Arbeit basiert auf einem experimentellen Ansatz zur Isolierung eines neuen $A B C A-G e n s$ und nutzte die in wachsendem Maß zur Verfügung stehenden Sequenzen aus Gendatenbanken vor allem zu vergleichenden Analysen mit den experimentell erzeugten Daten. Auf diese Weise sollten die neu identifizierten Gene hABCA5 und rAbca5 in einem möglichst physiologischen Kontext erschlossen werden, um geeignete Voraussetzungen für spätere funktionelle Untersuchungen zu schaffen.

Seit Beginn dieses Projekts wurden neben ABCA5 acht weitere der bisher bekannten 12 humanen Gene der ABCA-Subfamilie identifiziert (KAMINSKI et al. 2001, DEAN et al. 2001, ANNILO et al. 2002, TSURUOKA et al. 2002, PieHLER et al. 2002, PRADES et al. 2002, WenZEL et al. 2003). Diese Entwicklung wurde durch den Fortschritt des Humangenomprojekts entscheidend beinflußt und erleichterte die Vorhersage kodierender Sequenzen auf Grundlage des Vergleichs verschiedener öffentlicher (EMBL, Genbank) und privater (Celera) Datenbanken (in silico Klonierung). Im Verlauf der Arbeiten wurde wiederholt festgestellt, daß experimentell erhobenen Daten aus physiologischen Systemen entscheidend zu einem besseren Verständnis des neu identifizierten Gens beitragen, das allein mit Datenbankrecherchen nicht erreicht werden kann.

\subsection{Screening von Testis-RNA mittels degenerierter RT-PCR (Vorarbeiten)}

Die hier von HIRSCH-ERNST et al. (1998) verwendete Strategie stellte eine Variante der RTPCR Methode nach LEIGHTON et al. (1995) dar, die den hohen Konservierungsgrad der ATPBindungskassetten zwischen den ABC-Genen ausnutzte (Abb. 4.1). Die degenerierten PCRPrimer (S1.for, S2.rev $\rightarrow$ 2.1.7.6.6) entsprachen den am stärksten konservierten Sequenzmotiven, Walker A bzw. Walker B und bestanden aus statistischen Desoxy-NukleotidMischungen, um eine Vielzahl von Amplifikaten zu generieren.

ABCA9

ABCA10

ABCA6

ABCA5

AJ275973.1
TALLGHSGAGKTTLLNILSGLSVPTSGSVTVYNHTLSRMADIENISKFTGFCPQSNVQ 570 TAILGHNGAGKSTLLNILSGLSVSTEGSATIYNTQLSEITDMEEIRKNIGFCPQFNFQ 580 TAILGHSGAGKSSLLNILNGLSVPTEGSVTIYNKNLSEMQDLEEIRKITGVCPQFNVQ 567 TALLGHSGTGKSTLMNILCGLCPPSDGFASIYGHRVSEIDEMFEARKMIGICPQLDIH 567 - . - - - SGCGKSTLMNILCGLCPPSDGFASIYGHRVSEIDEMFEARKMIGICPQLDIH 52 $* * * * * * * * * * * * * *$ * Walker A

ABCA9 ABCA10 ABCA6 ABCA5 AJ275973.1
FGFLTVKENLRLFAKIKGILPHEVEKEVQRVVQELEMENIQDILAQNLSGGQNRKLTF 628 FDFLTVRENLRVFAKIKGIDQPKEVEQEVKRI IMELDMQSIQIIAKKLSGGQKRKLTL 638 FDILTVKENLSLFAKIKGIHLKEVEQEVQRILLELDMQNIQDNLAKHLSEGQKRKLTF 625 FDVLTVEENLSILASIKGIPANNIIQEVQKVLLDLDMQTIKDNQAKKLSGGQKRKLSL 625 FDVLTVEENLSILASIKGIPANNIIQEVQKVLLDLDMQTIKDNQAKKLSGGQKRKLSL 110 
ABCA9 GIAILGDPQVLLLDEPTAGLDPLSRHRIWNLLKEGKSDRVILF 671

ABCA10 GIAILGDPQVLLLDEPTAGLDPFSRHRVWSLLKEHKVDRLILF 681

ABCA6 GITILGDPQILLLDEPTTGLDPFSRDQVWSLLRERRADHVILF 668

ABCA5 GIAVLGNPKILLLDEPTAGMDPCSRHIVWNLLKYRKANRVTVF 668

AJ275973.1

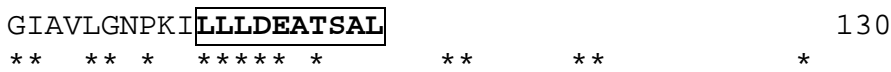

Walker B

Abb. 4.1 Sequenzgegenüberstellung der 1. ATP-Bindungskassette von 4 ABCATransportern sowie dem aus Testis-RNA mittels degenerierter RT-PCR isolierten ABCA5-Fragment AJ275973.1. Die konservierten Walker Motive $A$ und $B$ sind fett markiert, der Bereich der degenerierten Primer wurde zusätzlich umrahmt. ABCA 6, 9 und 10 waren zum Zeitpunkt dieser Arbeiten nicht bekannt.

Aus humaner Testis-RNA wurde neben diversen bekannten $A B C$-Gen-Fragmenten ein neues cDNA-Fragment (392 bp) isoliert, das einem neuen $A B C A-G e n$ entsprach (AJ275973.1). Dieses Fragment wies mit den bereits vollständig charakterisierten ABCATransportern Sequenzhomologien von 39\% (ABCA1) und 36\% (ABCA4) auf.

\subsection{ABCA5 des Menschen und Abca5 der Ratte}

\subsubsection{Zur Struktur des ABCA5-Gens des Menschen}

Für das $A B C A 5-G e n$ des Menschen verzeichnen die Gendatenbanken aktuell zwei vollständige mRNA-Sequenzen (NM_018672 und NM_172232). NM_018672 (7044bp) stellt das größte Transkript dar und unterscheidet sich von NM_172232 (5939 bp) in der Länge und Zusammensetzung der 5'-untranslatierten Region (5'-UTR). Die im Rahmen dieser Arbeit isolierte ABCA5-cDNA-Sequenz (5096 bp, AJ275973.3) ist identisch mit NM_172232, endet jedoch 65 bp vor dem Translationsstart und 102 bp nach dem Translationsstop.

Das $A B C A-G e n$ umfaßt ohne regulatorischen Bereich eine genomische Region von ca. $80 \mathrm{~kb}$. Dies entspricht den genomischen Größen der am nächsten verwandten $A B C A-G e n e$ ABCA10 (97 kb), ABCA9 (85 kb), ABCA8 (74 kb) und ABCA6 (62 kb) des ABCA-Clusters. Von den 39 Exons kodieren 38 für den offenen Leserahmen von 4929 bp. Exon 1 wird durch ein Insert von 12.6 kb Länge von Exon 2 getrennt und besteht aus $100 \mathrm{bp}$, von denen in den vorliegenden Experimenten 52 bp mittels RACE-PCR erfaßt wurden. Exon 2 enthält das mit dem Konsensusmotiv von KOZAK (1986) kompatible Signal AACATGT für den putativen Translationsstart. Die 3'-untranslatierten Regionen (3'-UTR) der beiden ABCA5-mRNA Transkripte (NM_018672 und NM_172232) sind identisch und umfassen jeweils 897 b. Eine Analyse der 3'-UTR nach BEAUDOING et al. (2000) ergab 11 putative Polyadenylierungssignale (Poly-AS), wovon das am stärksten in natürlichen mRNA-Molekülen konservierte Poly-AS-Hexamer AATAAA dreimal vorkam: 170 bp, 375 bp und 867 bp abwärts des StopSignals. Das letzte Poly-AS befindet sich damit -15 nt aufwärts des Transkriptendes. Die 3'- 
UTR der von uns isolierten cDNA (AJ275973.3) endet 36 bp nach einem möglichen Poly-AS TTTAAA, das von BEAUDOING et al mit einer Häufigkeit von $1.2 \%$ detektiert wurde. Dieser Befund und die Präsenz weiterer putativer Poly-AS in der 3'-UTR des ABCA5-Gens sprechen für die Benutzung diverser Poly-AS bei der mRNA-Prozessierung und/oder regulatorische Funktionen dieser Signale.

\subsubsection{Das $A B C A 5-G e n$ ist Bestandteil eines $A B C A-G e n c l u s t e r s$}

Das ABCA5-Gen ist auf Chromosom 17q24.3 lokalisiert und ist Bestandteil eines ABCAGenclusters (ARNOULD et al. 2001) in der genomischen Region 17q24.2-3. Der Cluster besteht aus fünf Mitgliedern, ABCA5, 6, 8, 9 und ABCA10, und stell DEAN et al. (2001) zufolge eine phylogenetisch distinkte Subgruppe innerhalb der ABCA-Subfamilie dar (Abb. 4.2), die sich auch im Konservierungsgrad der Intron-Exon-Übergänge äußert. Die $A B C A-$ Gene des Clusters bestehen im Gegensatz zu den übrigen $A B C A-G e n e n$ aus 38 kodierenden Exons, während die auf 6 verschiedene Chromosomen verteilten $A B C A-G e n e$ $A B C A 1$ (9q22-q31), ABCA2 (9q34), ABCA3 (16p13.3), ABCA4 (1p22), ABCA7 (19p13.3), $A B C A 12$ (2q35) und $A B C A 13$ (7p11-q11) zwischen 50 (ABCA4) und 62 (ABCA13) Exons besitzen. Es wird angenommen, daß alle $A B C A-G e n e$ des Clusters durch Genduplikation von einem Eltern-Gen entstanden sind. $A B C A 5$-orthologe Gene wurden bisher in Ratte und Maus charakterisiert, $A B C A 5$-ähnliche Gene wurden auch im japanischen Kugelfisch fugu rubripe (ANNILO et al. 2003) und im Genom der Anophelesmücke Anopheles gambiae str. PEST (THE ANOPHeles GenOME Sequencing Consortium, Genbank XM_311531) detektiert, so daß $A B C A 5$ das Eltern-Gen des Clusters auf Chromosom 17 sein könnte.

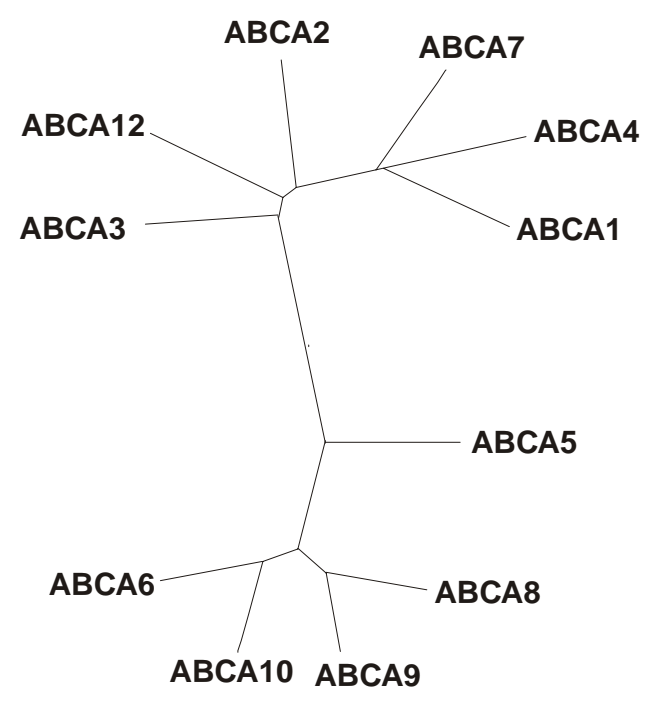

Abb. 4.2 Phylogenetische Analyse der ABCA-Gene. Die Abbildung wurde nach DEAN et al. (2001) angefertigt und zeigt das Ergebnis eines Sequenzvergleichs der $A B C A-$ 
Gene mit dem Programm PILEUP auf Basis der neighbor-joining method nach SAITOU et al. (1987).

\subsubsection{Zur Struktur des Abca5-Gens der Ratte}

Die im Rahmen dieser Arbeit isolierte cDNA für das Abca5-Gen der Ratte umfaßt 5170 bp und stellt aktuell das einzig bekannte, für das vollständige $r A b c a 5-G e n$ kodierende Transkript dar (AJ426052 = NM_173307). Über den kodierenden Bereich von 4929 Nukleotiden (nt) weist es eine Sequenzhomologie mit dem ABCA5-Gen des Menschen von 86\% auf, die auf Aminosäurenebene $90 \%$ beträgt. Die 3'-UTR besteht aus 206 nt und zeigt zum entsprechenden Bereich der 3'-UTR von ABCA5 eine Ähnlichkeit von 59\%. Die 3'-UTR endet $13 \mathrm{nt}$ abwärts eines zwischen beiden Spezies konservierten Poly-AS AATAAA $(\rightarrow$ 4.2.1), das 188 nt nach dem Translationsstop beginnt. Die 3'-UTR enthält zusätzlich eine mögliche PolyAS-Variante TTTAAA $81 \mathrm{nt}$ nach dem Translationsstop, das eine Entsprechung zu einem Signal gleicher Sequenz 62 nt nach dem Stop-Signal im humanen ABCA5-Gen darstellen könnte.

Die 5'-untranslatierte Region (5'-UTR) des charakterisierten Gens endet bereits -35 nt vor dem AACATGG-Signal für den putativen Translationsstart, was einen experimentell bedingten Abbruch der reversen Transkription von der mRNA-Matrize vermuten ließ und durch die kürzlich im Rahmen einer Datenbankrecherche gefundenen cDNA-Sequenz, die vermutlich einen Teil der 5'-UTR darstellt, bestätigt werden konnte $(\rightarrow 3.2 .3)$. Das rAbca5Gen erstreckt sich über einen genomischen Bereich von ca. $68 \mathrm{~kb}$ und gliedert sich wie ABCA5 des Menschen in 38 kodierende Exons, von denen 23 bezüglich der Exongröße zwischen den Spezies Mensch und Ratte konserviert sind.

Das Abca5-Gen der Ratte ist eins von bisher fünf charakterisierten rAbca-Genen. Untersuchungen von ANNILO et al. (2003) über Abca-Gene der Maus lassen vermuten, daß rAbca5 ebenso wie hABCA5 und das Abca5-Gen der Maus Teil eines Genclusters ist, das sich für die Ratte auf Chromosom 10 zu befinden scheint.

\subsubsection{Zur Struktur der Proteine hABCA5 und rAbca5}

Die ABCA-Gene hABCA5 und rAbca5 besitzen einen identischen offenen Leserahmen von 4929 bp (inklusive Stopkodon). Daraus resultieren zwei Polypeptide von 1642 Aminosäuren mit einer zu 90\% identischen Primärstruktur, in der sich nur 150 von 1642 Aminosäuren voneinander unterscheiden. Beide Proteine bestehen aus zwei Membrandomänen (MD) reich an unpolaren Aminosäuren und aus zwei hydrophilen, im Zytoplasma gelegenen Nukleotidbindungsregionen (NBR), den ATP-Bindungskassetten. Sie weisen damit die Struktur eines typischen ABC-Volltransporters auf (MD-NBR-MD-NBR). Die erste Membrandomäne beginnt nach einem kurzen $\mathrm{N}$-Terminus (31 AS) und erstreckt sich über etwa 380 Aminosäuren, die zu 88\% zwischen Ratte und Mensch konserviert ist. Die zweite 
Membrandomäne ist mit etwa 362 Aminosäuren etwas kürzer und zwischen den beiden Spezies zu $86 \%$ identisch. Der bereits hier zwischen den orthologen Proteinen zweier Organismen erkennbare Trend zur größeren Variabilität der Membrandomänen im Vergleich zur Gesamthomologie ist zwischen verschiedenen ABC-Transportern wesentlich stärker ausgeprägt und eine strukturelle Voraussetzung für die Ausbildung einer Substratspezifität. Die jeweils einer Membrandomäne folgenden Nukleotidbindungsregionen in hABCA5 und rAbca5 liegen in einem hydrophilen Bereich von ca. 450 Aminosäuren (1. NBR) bzw. 417 Aminosäuren (2. NBR). Dabei ist die erste NBR mit 93\% stärker konserviert als die zweite NBR (91\%). Die charakteristischen Sequenzmotive beider ATP-Bindungskassetten Walker A (AS 514-522, GHSGTGKST, AS 633-641, GPNGAGKST), die Signatursequenz (AS 615619, LSGGQ) und die Walker B Motive (AS 636-647, LLLDEPTAGMDP, AS 1455-1465 LLDEPSTGMDP) sind vollständig zwischen den Spezies Ratte und Mensch konserviert. Die Signatursequenz kommt wie in allen humanen ABCA-Proteinen des ABCA-Subclusters in der 2. NBR nur noch in degenerierter Form (AS 1437-1140, LPAGI) vor, während in den übrigen ABCA-Transportern zumindest das Kernmotiv SGG mit dem kürzlich als für die ATPProzessierung kritisch erkannten Serin-Substituent erhalten ist (HOPFNER et al. 2003, MONCALIAN et al. 2004). Das Phänomen einer strukturellen Asymmetrie der Signaturmotive in einem ABC-Volltransporter ist bereits von GAUDET et al. (2001) für das aus den beiden ABCB-Halbtransportern TAP1 und TAP2 gebildete TAP-Protein beschrieben worden und kann in der Primärsequenz zahlreicher ABC-Transporter verschiedener Organismen detektiert werden, ohne daß funktionelle Auswirkungen bereits bekannt wären (TAKADA et al. 1998, HRYCYNA et al. 1999, PROFF et al. 2001).

Die Existenz zweier Nukleotidbindungsregionen wurde lange zum Anlaß genommen, über eine mögliche Abstufung bezüglich ihrer funktionellen Bedeutung bei der ATP-Hydrolyse zu spekulieren. Inzwischen gilt es durch Strukturaufklärung bakterieller ABC-Transporter (Hopfner et al. 2000, CHANG et al. 2001, 2003 und LOCHER et al. 2002) jedoch als gesichert, daß ein ATP-Molekül im substrataktivierten Zustand an der Grenzfläche eines Dimers aus der Signatursequenz der einen NBR mit dem sogenannten P-Loop (Walker A Motiv) der anderen NBR gebunden ist. In Abwesenheit von ATP scheint die räumliche Nähe der Nukleotidbindungsregionen merklich reduziert, womit die Hypothese der ATP-abhängigen Dimerisierung der NB-Regionen eine Erklärung dafür bietet, daß am Ende der Strukturaufklärung isoliert kristallisierter ATP-Bindungskassetten (d.h. in Abwesenheit von ATP) meistens monomer auftretende ABC-Domänen standen (LOCHER et al. 2004). Eine ebenso essentielle Kopplung wird zwischen der Bindung des Transportsubstrats im Bereich der Membrandomänen und der durch Konformationsänderungen vermittelten ATP-Bindung und -Hydrolyse vermutet. An diesen Prozessen scheinen auch konservierte Elemente der Membrandomänen (L-Loop) und weitere Motive der Nukleotidbindungsregionen (z.B. QLoop, AS 564-572, 1382-1390) aktiv beteiligt zu sein (JONES et al. 2002). 
Auf Grundlage der Analyse von hydrophoben Regionen $(\rightarrow 3.2 .6)$ kann ein topologisches Modell für hABCA5 und rAbca5 erstellt werden, das der intrazellulären Lokalisation der Nukleotidbindungsregionen und der Verankerung der Membrandomänen in einer zellulären Membran Rechnung trägt, ohne die räumliche Anordnung der Proteindomänen in einem funktionsfähigen Transporter widerspiegeln zu können. Die genaue Anzahl der die Membran kreuzenden $\alpha$-helikalen Segmente läßt sich dabei nicht vorhersagen, sondern bedarf einer strukturellen Aufklärung durch kristallographische Verfahren, die aufgrund der Proteingröße der ABC-Proteine und der hydrophoben Natur der Membrandomänen bisher nur limitiert angewandt werden konnten.

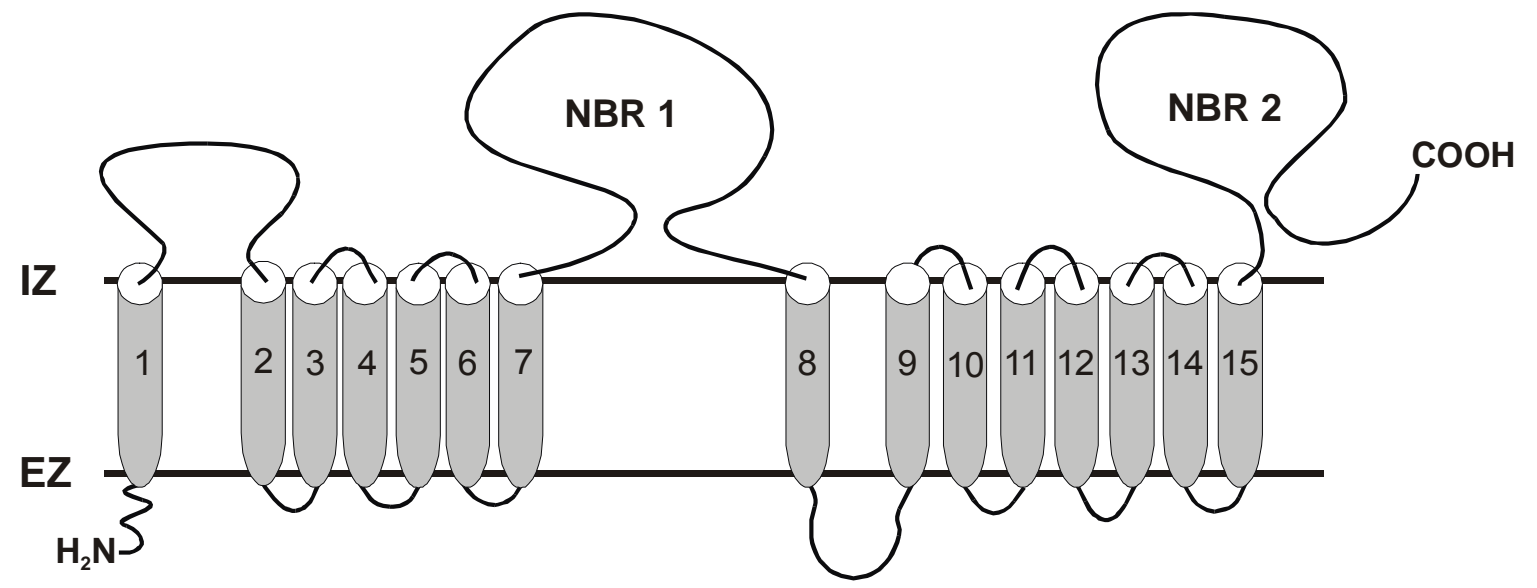

Abb. 4.3 Zweidimensionales topologisches Modell des hABCA5/rAbca5-Proteins. Das Polypeptid besteht aus 2 Membrandomänen und 2 Nukleotidbindungsregionen (NBR), die auf cytoplasmatischen Membranseite liegen. Die Membrandomänen bestehen aus 7 bzw. 8 Membransegmenten (MS) und enthalten zwei größere Loops zwischen MS 1 und MS 2 (127 AS, intrazellulär) und MS 8 und MS 9 (82 AS, extrazellulär). $E Z$ = Extrazellulärraum, $I Z=$ Intrazellulärraum.

\subsubsection{Zur Struktur der Splicevariantengene ABCA5 V20+16 und rAbca5 $\mathrm{V}+16$}

Beide Gene unterscheiden sich durch eine 16 nt-Insertion am 3'-Ende des Exon $20(\rightarrow 3.2 .3$, 3.2.5), die durch eine Verschiebung des offenen Leserahmens zu einem vorzeitigen Translationsende nach 925 Aminosäuren führt. Im ABCA5 V20+16-Gen stammt diese Insertion aus den ersten $16 \mathrm{nt}$ des $2669 \mathrm{nt}$-langen Introns zwischen den Exons 20 und 21, das die klassischen Intron-Exon-Grenzen aufweist (5'-GT...Intronsequenz..AG-3'). In rAbca5 V+16 ist dieses Exon 2050 nt lang und enthält die identischen konservierten Intron-Exon-Grenzen. Die Insertion in der Splicevariante der Ratte ist bis auf einen Austausch eines Nukleotids $(\mathrm{T} \rightarrow \mathrm{C})$ identisch mit der entsprechenden Insertion im humanen Gen der ABCA5-Splicevariante. Die Konservierung dieses alternativen Spliceprodukts spricht gegen eine zufällige Existenz dieses mRNA-Transkripts und für eine funktionelle Bedeutung dieser Splicevariante 
in den ABCA5/Abca5-Genen beider Spezies. Im Rahmen der Sequenzanalyse wurde für rAbca5 V+16 ein cDNA-Klon identifiziert, der die Länge des gesamten kodierenden Bereichs des rAbca5-Haupttranskripts mit einer bis auf die Insertionsstelle identischen IntronExonstruktur umfaßt. Für die humane Splicevariante wurde anhand von RT-PCR-Versuchen gezeigt, daß ein ähnlich langes kontinuierliches cDNA-Transkript vorlag, so daß die Existenz einer vollständigen mRNA für die konservierte Splicevariante angenommen werden kann.

\subsubsection{Zur Struktur der putativen Proteine hABCA5 V20+16 und rAbca5 V+16}

Die putativen Polypeptide der Splicevarianten hABCA5 V20+16 und rAbca5 V+16 enden jeweils nach 925 Aminosäuren. Dies entspräche der Größe eines typischen ABC-Halbtransporters mit einer Membrandomäne und einer nachfolgenden Nukleotidbindungsregion mit den für die Volltransporter bereits beschriebenen Sequenzmotiven ( $\rightarrow$ 4.2.6, Abb. 4.4).

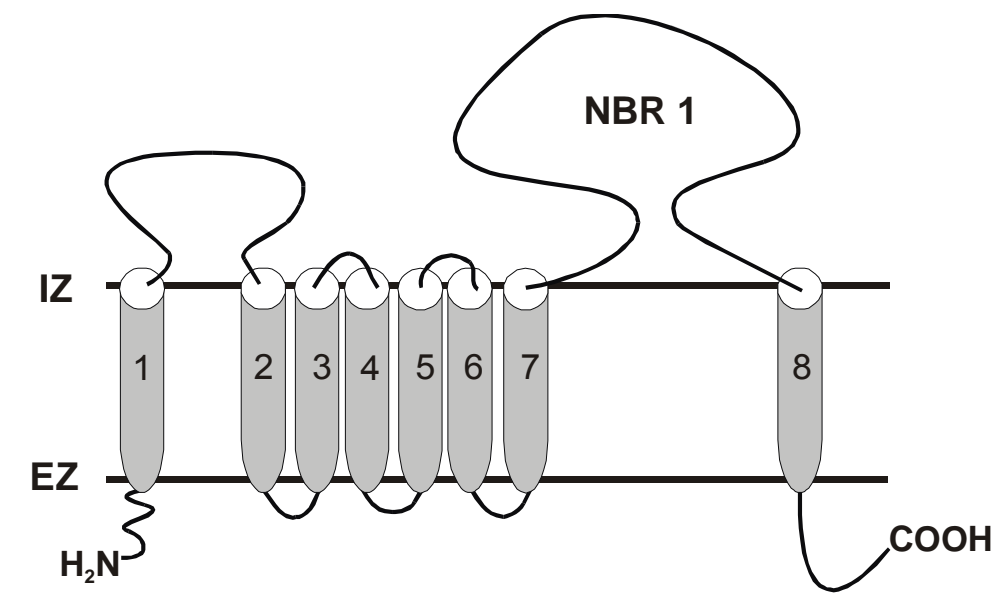

Abb.4.4 Zweidimensionales topologisches Modell eines putativen Proteins hABCA5 V20+16/rAbca5 V+16. Das Polypeptid entspricht der ersten Hälfte des Volltransporterproteins ( $\rightarrow$ Abb. 4.3) mit einem zusätzlich vorhergesagten Membransegment (MS 8) nach der Nukleotidbindungsregion (NBR). EZ = Extrazellulärraum, $I Z=$ Intrazellulärraum.

Es ist bekannt, daß die Stabilität membranständiger $\alpha$-helikaler Strukturen durch die Anwesenheit benachbarter $\alpha$-Helices positiv beeinflußt wird. Die tatsächliche Existenz des vorhergesagten 8. Membransegments bedarf daher einer experimentellen Bestätigung ebenso wie die physiologische Stabilität und Funktion eines putativen Splicevariantenproteins, das als Halbtransporter, ausgehend vom aktuellen Verständnis von ABC-Transportern, einen Dimerisierungspartner benötigt, um funktionelle Aktivität zu erlangen. 
Untersuchungen von WELLINGTON et al. (2002) zur Bedeutung von natürlich vorkommenden Mutationen des ABCA1-Gens ergaben eine deutliche Suppression des durch Oxysterole induzierten nativen ABCA1-Proteins auch in heterozygoten Individuen, wenn die Mutation zur Co-Expression einer verkürzten ABCA1-Variante führte. Es konnte gezeigt werden, daß dieser regulatorische Effekt nicht auf mRNA-Ebene, sondern auf Proteinebene stattfand, wobei offen blieb, ob die reprimierten ABCA1-Spiegel die Folge einer verminderten Proteinsynthese oder einer vorzeitigen Proteindegradation waren. Der bemerkenswerte regulatorische Effekt der verkürzten ABCA1-Varianten verdeutlicht die Relevanz der für viele Proteine bekannten Varianten, ohne daß zwingend ein offensichtlicher Phänotyp zugeordnet werden kann.

\subsection{Gewebeverteilung von hABCA5 und rAbca5}

Die gewebespezifische mRNA-Expression für hABCA5 und rAbca5 wurde mittels der Northern-Blot-Methode untersucht und ergab eine für bestimmte Gewebe variierende Verteilung. Für die Expressionsanalyse des humanen ABCA5-Gens wurde ein kommerzieller Northern Blot mit RNA aus verschiedenen humanen Organen diverser humaner Spender verwendet, der auf den $\beta$-Aktingehalt der einzelnen Organproben normalisiert war $(\rightarrow \mathrm{Abb}$. 3.8). Die höchste Expression wurde im Skelettmuskel detektiert, niedrige Expressionsniveaus konnten in Niere, Leber und Plazenta gezeigt werden. Aus früheren Experimenten war bereits die starke Expression der hABCA5-mRNA im Testis bekannt, die hier nicht nochmals untersucht wurde.

Für die Expressionsanalyse des rAbca5-Gens der Ratte wurde ein Blot aus gleichen Mengen Gesamt-RNA $(25 \mu \mathrm{g})$ hergestellt, die aus frisch isolierten Organen eines einzelnen Individuums stammten. Die Kontrollhybridisierung $(\rightarrow$ Abb. 3.9) zeigt den deutlich zwischen verschiedenen Organproben variierenden $\beta$-Aktingehalt und limitiert damit die quantitative Vergleichbarkeit mit den humanen Organproben, deren inhomogene Herkunft aus verschiedenen Individuen eine geringere Aussagekraft haben als die selbst gewonnenen RNA-Proben der Ratte. Eine dominante Expression des rAbca5-Gens der Ratte wurde im Testis festgestellt und bestätigt die Ergebnisse für $h A B C A 5$. Für die Expression der höhermolekularen rAbca5-mRNA Spezies in Testis, Lunge und Gehirn konnte im humanen OrganSystem keine Entsprechung detektiert werden. Ein vergleichbares Signal wurde jedoch im Rahmen früherer Experimente in der RNA verschiedener Neuroblastomzellinien und Caco-2Zellen gefunden, das auf die Präsenz mehrerer mRNA-Spezies in humanen Geweben und Geweben der Ratte hinweist.

Im Rahmen der quantitativen mRNA-Analyse der Splicevariante rAbca5 V+16 in Geweben der Ratte mittels real-time quantitative PCR $(\rightarrow 3.6)$ wurde auch die Expression der rAbca5mRNA Spezies in 9 Rattenorganen und einer Sertolizellinie (SER-W3) untersucht. Bezogen auf bekannte Mengen eines Referenzplasmids wurden in allen Geweben rAbca5-mRNA Transkripte detektiert, wobei die Expressionswerte in schwach exprimierenden Organen wie 
dem Herz und in expressionsstarken Gewebe wie Testis, Lunge und Gehirn um drei Größenordnungen (Faktor 1000) divergierten. Der Gehalt an rAbca5-mRNA in der Sertolizellinie betrug ca. 10\% der Testisexpression und war damit auf vergleichbarem Niveau wie in isolierten Hepatozyten. Diese Ergebnisse bestätigen die mittels Northern- BlotUntersuchungen ermittelten dominanten Expressionssignale und validieren die mittels unterschiedlicher Analyseverfahren gewonnenen Daten trotz der sehr unterschiedlichen Empfindlichkeiten der verwendeten Methoden

Das von ANNILO et al. (2003) publizierte Expressionsprofil des Abca5-Gens der Maus spricht für eine Konservierung der starken Expression im Testis zwischen den Spezies: in den mittels quantitativer RT-PCR analysierten Proben (Herz, Gehirn, Milz, Lunge, Leber, Skelettmuskel, Niere, Testis, 4 Embryoentwicklungsstadien) betrug die Expression im Testis der Maus ein vielfaches der übrigen untersuchten Proben.

\subsection{Zellspezifische Verteilung des rAbca5-Gens der Ratte}

\subsection{1 rAbca5-mRNA Expression im Testis}

Die Expression der rAbca5-mRNA im Testis war am stärksten in den interstitiellen Leydigzellen ausgeprägt, die teilweise als Zellcluster auftraten $(\rightarrow 3.4 .3)$. In Leydigzellen wird unter dem Stimulus des von der Hypophyse gebildeten luteinisierenden Hormons (LH) Testosteron gebildet. Das androgene Sexualsteroid stimuliert seinerseits die Samenbildung in Sertolizellen, fördert die Entwicklung der sekundären Geschlechtsmerkmale und stimuliert die Talgdrüsenfunktion. Aufgrund der hydrophoben Natur des Steroidgerüsts erfolgt der Testosterontransport im Blut in Proteinkomplexen mit Albumin, dem Glykoprotein Sexualsteroidhormon-bindenden Globulin (SHBG) und in Sertolizellen mit dem SHBG-ähnlichen Androgen-bindenden Protein (ABP). ABC-Transporter sind darauf spezialisiert, Moleküle durch Membranen zu schleusen, die über Diffusionsmechanismen diese Barrieren nicht überwinden können. Von Steroiden wurde lange angenommen, sie könnten Membranen aufgrund ihrer hydrophoben Grundstruktur durch Diffusion durchqueren. Der Nachweis von SHBG-Bindungsstellen auf der Plasmamembran verschiedener Zelltypen durch ROSNER et al. (1992) legt jedoch einen komplexeren Transportmechanismus nahe, an dem rAbca5 möglicherweise beteiligt sein könnte. Die Relevanz von ABCA-Transportern im Testis, insbesondere den Sertoli- und Leydigzellen wurde unlängst von Selva et al. (2004) beschrieben, die für ABCA1 eine Relevanz im interzellulären Steroidtransport postulieren.

\subsection{2 rAbca5-mRNA Expression in der Epididymis}

Der Nebenhoden (Epididymis) dient als Speicher für die in den Tubuli seminiferi des Testis gereiften Spermatozoen. Die rAbca5-mRNA Expression verteilte sich im gesamten Zylinder- 
epithel mit seinen länglichen Mikrovilli, die als Stütz- und Nährzellen der Spermatozoen ähnlich den Sertolizellen im Testis gelten. In den Mikrovilli laufen eine Vielzahl von Transportvorgängen (Import und Export einer Vielzahl von Substraten zur Versorgung der Spermatozoen) ab, so daß eine Rolle von rAbca5 als Vermittler einer Transportaktivität innerhalb dieser Kaskade angenommen werden könnte.

\subsection{Quantitative Analyse der Expression von rAbca5 V+16}

Die Bedeutung der vielfach auftretenden alternativen mRNA-Spliceprodukte ist für viele Gene ungeklärt. Um die quantitative Relevanz der konserviert in Ratte und Mensch gleichermaßen auftretenden Splicevariante zu bewerten, wurde mittels real-time quantitative PCR (RTQ-PCR) der Anteil an rAbca5 $V+16-m R N A$ relativ zur rAbca5-mRNA in neun verschiedenen Organen der Ratte, isolierten Hepatozyten und einer Sertolizellinie (SER-W3) bestimmt. Außer im Herz konnten Splicevariantentranskripte in allen untersuchten Proben nachgewiesen werden, wobei die relativen Anteile zwischen $2.6 \%$ im Gehirn und $11.2 \%$ im Pankreas schwankten. Die Abwesenheit von Transkripten der Splicevariante im Herz geht einher mit einer insgesamt geringen rAbca5-mRNA und 18S-RNA-Expression in diesem Gewebe und deutet darauf hin, daß mit dieser Probe aus nicht geklärten Gründen am Rand der Nachweisgrenze gearbeitet wurde (Degradation, keine Expression in diesem Gewebe). Alle übrigen Proben zeigen eine signifikante rAbca5 V+16-mRNA Expression, womit die Hypothese einer funktionellen Bedeutung der Splicevariante weiter unterstützt wird, welche Gegenstand weiterer Untersuchungen sein wird. Das ursprünglich angestrebte Normalisierungsverfahren auf den 18S-RNA-Gehalt der Proben wurde aufgrund organabhängig stark schwankender 18S-Werte nicht angewendet, was die Aussagekraft der durchgeführten Messungen nicht vermindert, da die Bestimmung der cDNA-Transkripte für Hauptranskript und Splicevariante an cDNA gleichen Ursprungs vorgenommen wurde. Untersuchungen von Vandesompele (2002), Bustin (2002) and Lossos (2003) diskutieren Verfahren zur Normalisierung diverser RTQ-Daten und bestätigen die im Verlauf der eigenen Experimente gewonnene Einsicht, daß die Berücksichtigung der Expression nur eines house-keeping genes zu einer signifkanten Verfälschung der Meßdaten führen muß. Es wird vorgeschlagen, entweder geometrische Mittelwerte mehrerer house-keeping genes zu verwenden und/oder die eingesetzte RNA-Menge so genau wie möglich zu bestimmen.

\subsection{Einfluß der Kulturbedingungen auf die rAbca5-mRNA Expression in Kulturen primärer Hepatozyten der Ratte}

Primär kultivierte Hepatozyten der Ratte zeigten unter Standardkulturbedingungen $\left(8.8 \times 10^{4}\right.$ Zellen $/ \mathrm{cm}^{2}$, unbeschichtete Polystyrolmatrix, serumfreies MX-83 Medium mit $1 \mu \mathrm{M}$ Rinderinsulin und $20 \mu \mathrm{M}$ Hydrocortisonhemisuccinat) eine zeitabhängige, intrinsische Steigerung der rAbca5-mRNA ( $\rightarrow$ 3.5.4). Eine ähnliche Induktion wurde von HIRSCH-ERNST et al. (1995) 
im gleichen Zellkulturmodell für das multidrug resistance Gen der Ratte $m d r 1 b$ beobachtet. Es konnte nachgewiesen werden, daß diese Induktion nicht auf einer generellen Steigerung der Transkriptionsrate in primär kultivierten Rattenhepatozyten beruhte, sondern charakteristisch für das mdr1b-Gen war. Basierend auf diesen Ergebnissen wurden Kontrollhybridisierungen mit sogenannten house-keeping genes ( $\beta$-Aktin, GAPDH) durchgeführt, die durch eine stabile Expression über mehrere Tage belegten, daß die zeitabhängige Induktion des rAbca5-mRNA ein genspezifisches Phänomen darstellte. Die Vermittler der Hochregulation sind derzeit noch nicht geklärt. Vorläufige Untersuchungen mit bekannten $m d r 1 b$-regulierenden Streßfaktoren (ZIEMANN et al. 1999) wie reaktiven Sauerstoffspezies, Cytokinen und Prostaglandinen zeigten auf die rAbca5-mRNA-Expression keine deutliche Wirkung.

\subsection{Einfluß von LXR-Liganden auf die rAbca5-mRNA-Expression in Kulturen primärer Hepatozyten der Ratte}

\subsubsection{Induktion der rAbca5-mRNA-Expression mit 22-R-Hydroxycholesterol}

Die Oxysterol-induzierte Aktivität der Liver X Rezeptoren ist für die Hochregulation diverser Gene der hepatischen und extrahepatischen Cholesterolhomöostase verantwortlich, darunter auch das am reversen Cholesteroltransport beteiligte ABCA1. Um eine mögliche Rolle des rAbca5-Gens im hepatischen Lipidstoffwechsel zu untersuchen, wurden primäre Hepatozyten der Ratte mit verschiedenen endogenen Oxysterolen behandelt und die mRNAExpression mittels Northern Blot untersucht. Bezogen auf die ethanolhaltige Kontrollprobe war nach vier Tagen in Gegenwart von $10 \mu \mathrm{M}$ 22-R-Hydroxycholesterol eine um 40\% gesteigerte rAbca5-mRNA Expression, bei doppelter Konzentration eine um $70 \%$ erhöhte rAbca5-mRNA Expression festzustellen ( $\rightarrow$ 3.5.1). Es bleibt festzuhalten, daß eine deutliche Induktion der rAbca5-mRNA beobachtet wurde, die jedoch hinter für ABCA1 gemessenen Induktionswerten in humanen Hepatozyten zurückblieb (5-fache Induktion nach $30 \mathrm{~h}$ bei $15 \mu \mathrm{M}$ 22-R-Hydroxycholesterol mittels quantitativer RT-PCR, MENKE et al. 2002). Dies läßt sich möglicherweise mit speziesabhängigen Unterschieden in der LXR-regulierten Genaktivierung erklären, die z.B. für das Enzym Cholesterol-7 $\alpha$-Hydroxylase (CYP7a) von MENKE et al. (2002) beschrieben wurden und eine variierende Ansprechbarkeit der nuclearhormone-Rezeptoren postulieren.

\subsubsection{Induktion der rAbca5-mRNA mit 22-R-Hydroxycholesterol und 9-cis-Retinsäure}

Die Inkubation primärer Hepatozyten der Ratte mit je einem Antagonisten für den Liver $X$ Rezeptor ( $L X R)$ und den Retinoid X Rezeptor (RXR) zeigt keine eindeutigen Ergebnisse. Starke vom individuellen Versuchstier abhängige Schwankungen in der Hochregulation der ethanolhaltigen Kontrolle führten zu einer Repression der rAbca5-mRNA Expression unter Einwirkung von $1 \mu \mathrm{M}$ 9-cis-Retinsäure und $10 \mu \mathrm{M}$ bzw. $20 \mu \mathrm{M}$ 22-R-Hydroxycholesterol. Eine 
Verzehnfachung der eingesetzten Menge an 9-cis-Retinsäure zeigte keine signifikante Veränderung, so daß die Hypothese einer transkriptionellen LXR/RXR-Genaktivierung für rAbca5 durch diese Versuche nicht bestätigt werden konnte. Vielmehr scheint die unter Inkubation mit 22-R-Hydroxycholesterol gezeigte Induktion der rAbca5-mRNA Expression durch 9-cis-Retinsäure gehemmt zu werden, was auf eine konkurrierende Interaktion des RXR-Liganden mit anderen Transkriptionsfaktoren schließen läßt und nur durch weitere Experimente bestätigt werden könnte.

\subsubsection{Induktion der rAbca5-mRNA mit Acetyl-podocarpic Dimer (APD)}

Für diesen synthetischen Agonisten beider LXRs ( $\alpha$ und $\beta$ ) konnte von SPARROW et al. (2002) in Induktionsstudien mit primären Hepatozyten des Menschen nach $24 \mathrm{~h}$ mittels quantitativer RT-PCR eine ca. 5-fache Induktion der ABCA1-mRNA gezeigt werden (100 nM APD). Vergleicht man diese Experimente mit der in der gleichen Arbeitsgruppe durchgeführten Untersuchung zur Induktion von ABCA1 im identischen Zellsystem durch 22$R$-Hydroxycholesterol $(\rightarrow 4.5 .1$ ), scheint der synthetische LXR-Agonist APD eine um den Faktor 150 höhere Potenz als 22-R-Hydroxycholesterol zu besitzen.

Nach 4-tägiger Inkubation der primären Hepatozyten der Ratte mit 100 nM APD war, bezogen auf die DMSO-haltige Kontrollprobe, eine 3-fache Induktion durch den synthetischen LXR-Agonisten mittels Northern-Blot-Analysen zu beobachten. Vergleicht man diese Induktion mit der ca. 1.5-fachen Expressionssteigerung nach 4-tägiger Inkubation mit $10 \mu \mathrm{M}$ 22-R-Hydroxycholesterol ist auch in Bezug auf die rAbca5-mRNA Expression eine 200-fach höhere Induktionspotenz durch APD festzustellen, die einer erneuten experimentellen Reproduktion bedarf.

Aus den Induktionsergebnissen für 22-R-Hydroxycholesterol und den synthetischen LXRAgonisten APD läßt sich eine Regulation der rAbca5-mRNA Transkription über den LXRRezeptor vermuten. Weitere Untersuchungen stehen noch aus, um die Rolle des RXRLiganden 9-cis-Retinsäure aufzuklären.

\subsection{Subzelluläre Lokalisation von rAbca5 und rAbca5 V+16 in Zell- linien}

Die Expression von EGFP-getaggten Fusionsproteinen für rAbca5 und rAbca5 V+16 zeigte ähnliche Expressionsmuster in beiden untersuchten Zellinien HEK 293 und Caco-2. Die tatsächliche Expression des verkürzten rAbca5-Proteins in einem Zellsystem untermauert die physiologische Relevanz dieses alternativen Spliceprodukts und gibt Anlaß zu weiteren funktionellen Untersuchungen. Die ausschließlich intrazelluläre Lokalisierung beider Konstrukte in Kernnähe und Teilen des Zytoplasmas schließt eine Verteilung in der 
Zytoplasmamembran ähnlich $\mathrm{ABCA} 1$ aus. Möglicherweise ist $\mathrm{ABCA5}$ und die untersuchte Splicevariante im Bereich des Golgi-Apparates oder des Endoplasmatischen Retikulums lokalisiert. Für detaillierte Aufklärung der subzellulären Verteilung der Fusionskonstrukte ist es nötig, eine Co-Expression der Fusionsproteine mit verschiedenen Organellmarkern vorzunehmen, um Zellkompartimente genau zu definieren und eine Zuordnung der exprimierten Fusionsproteine für rAbca5 und rAbca5 V+16 zu ermöglichen.

\subsection{Weiterführende Arbeiten}

Die Ergebnisse dieser Arbeit eröffnen vielfältige Möglichkeiten für weitere Forschungsarbeiten. Ein bedeutender Schritt wird die detaillierte Aufklärung der subzellulären Verteilung des rAbca5-Proteins und des verkürzten Proteins rAbca5 V+16 sein, um weitere Hinweise hinsichtlich der Proteinfunktion zu erhalten. Die Lokalisationsdaten sind die Basis für Transportversuche mit verschiedenen Substraten in einem rAbca5-überexprimierenden Zellsystem. Dazu gehört auch die Visualisierung des Proteins im Western Blot, die Aufschluß über posttranslationale Modifikationen geben könnte und damit weitere Hinweise zur subzellulären Lokalisation liefern könnte.

Die Ergebnisse zur Induktion des rAbca5-Gens durch Oxysterole oder andere LXRAgonisten sind vorläufig, und weitere Versuche mit anderen Effektoren, z.B. Gonadotropinen (LH, FSH) sind notwendig, um z.B. eine mögliche regulierende Funktion der Splicevariante ähnlich der der verkürzten ABCA1-Varianten zu untersuchen. Im Zusammenhang damit wäre auch eine gezielte Promotoranalyse interessant, um funktionell relevante Promotorelemente aufzufinden.

Die dominante Expression des rAbca5-Gens im Testis und der Epididymis und besonders in den Leydigzellen sollte Anlaß sein, die entwicklungsgenetische Relevanz der rAbca5-mRNA Expression näher zu untersuchen. Derzeit werden Maus-RNAs verschiedener TestisEnwicklungsstadien und daraus generierte Mutanten in Bezug auf ihre Expression des rAbca5-Gens untersucht. Diese Experimente könnten genauere Hinweise auf die funktionelle Bedeutung des rAbca5-Gens zulassen. 


\section{$5 \quad$ Zusammenfassung und Ausblick}

Aus Gesamt-RNA der humanen Hepatomzellinie HepG2 wurde mit ABCA5 ein neues Mitglied der ABCA-Subfamilie aus der Superfamilie der ABC-Proteine isoliert. Dazu wurde ein vorher in dieser Arbeitsgruppe identifiziertes Genfragment (AJ275973.1) von $392 \mathrm{bp}$ Länge mittels einer kombinierten Strategie aus RACE-PCR, Klonierungen und Sequenzierung der isolierten Genfragmente vervollständigt. Das ABCA5-Gen umfaßt einen offenen Leserahmen von 4926 bp und kodiert für ein Protein der Länge von 1642 Aminosäuren. Die mittels Computermodellen vorhergesagte Proteintopologie ergibt die für ABC-Transporter typische Struktur eines Volltransporters mit zwei Membrandomänen und zwei Nukleotidbindungsregionen (ABC-Kassetten). Anhand von Northern-Blot-Analysen konnte gezeigt werden, daß das humane $A B C A 5-G e n$ am stärksten im Skelettmuskel, der Niere, Leber und der Plazenta exprimiert wird. Es wurde ein Produkt eines alternativen Splicevorgangs isoliert und charakterisiert, das sich durch eine 16 bp-Insertion am 3'-Terminus des Exon 20 unterscheidet $(A B C A 5$ V20+16). Diese Insertion verursacht eine Verschiebung des offenen Leserahmens und infolge den Translationsabbruch nach 925 Aminosäuren. Die putative Struktur von ABCA5 V20+16 entspräche der eines ABC-Halbtransporters mit einer Membrandomäne und einer Nukleotidbindungsregion.

Aus Gesamt-RNA des Testis der Ratte (Wistar) wurde das vermutlich orthologe Gen Abca5 mittels einer ähnlichen experimentellen Strategie isoliert und charakterisiert. Das Abca5-Gen der Ratte ( $r A b c a 5)$ besitzt einen identischen offenen Leserahmen von 4926 bp und zeigt eine Sequenzidentität zum humanen ABCA5-Gen von 90\% auf Basis der Aminosäureabfolge. Das mittels Northern-Blot-Analysen bestimmte mRNA-Expressionsprofil für rAbca5 zeigt eine dominante Expression im Testis und hohe Expressionsniveaus in Lunge und Gehirn. Die rAbca5-mRNA Expression in Testis und Epididymis (Nebenhoden) wurde mithilfe von in situ Hybridisierungen mit DIG-markierten cRNA-Sonden eingehender betrachtet und zeigte Signale in Leydigzellen und in der Basalschicht der Tubuli seminiferi (Testis) sowie in Fibroblasten (interstitieller Raum) und im Tubulusepithel des Nebenhodens.

Auch für rAbca5 wurde eine Splicevariante rAbca5 $V+16$ isoliert, die eine bis auf einen Substituenten identische 16 bp-Insertion am 3'-Terminus des Exon 20 enthält und die Relevanz dieser Splicevariante in beiden Spezies unterstreicht. Die Häufigkeit der Splicevariante rAbca5 V+16 im Verhältnis zum vollständigen rAbca5-Gen wurde in verschiedenen Geweben der Ratte und einer Zellinie mittels quantitativer RT-PCR evaluiert und ergab prozentuale mRNA-Anteile der Splicevariante bis zu 11\%.

Die Regulationsstudien in Kulturen primärer Hepatozyten der Ratte haben gezeigt, daß das rAbca-Gen offenbar keine statische Expression aufweist, sondern durch verschiedene Faktoren, z.B. durch die Kulturdauer und LXR-Aktivatoren, beinflußt wird. 
Zur Klärung der subzellulären Lokalisation des Abca5-Transporters der Ratte wurden das vollständige Gen und die Splicevariante in Expressionsvektoren mit Epitop-Tag (V5, EGFP) eingebracht und als Fusionsproteine in verschiedenen Zellsystemen exprimiert. Die EGFPFusionsproteine für den Volltransporter (rAbca5) und die Splicevariante (rAbca5 V+16) wurden in HEK293- und Caco-2-Zellen mittels Fluoreszenzmikroskopie detektiert. Die Lokalisation beschränkt sich für beide Konstrukte auf intrazelluläre Kompartimente in Kernnähe und soll mittels Kollokalisationsstudien mit verschieden Organellmarkern als Basis einer zukünftigen funktionellen Charakterisierung weiter differenziert werden.

Für andere ABCA-Vertreter wurde eine Bedeutung als Phospholipidtransporter (ABCA1 als Flippase) zur Vermittlung des Cholesterol- und Steroidtransports gezeigt bzw. postuliert ( $A B C A 2$ und $A B C A 3)$. $A B C A 2$ und $A B C A 3$ weisen anders als $A B C A 1$ beide eine intrazelluläre Verteilung auf, in die sich $A B C A 5$ bzw. rAbca5 damit einreihen würden. Die dominante Expression im Testis stellt eine wichtige Voraussetzung für weitere funktionelle Untersuchungen dar, da außer ABCA1 keine weiteren ABCA-Vertreter eine starke Expression in diesem Zellsystem aufweisen. Der Beweis der Hypothese (oder ihre Widerlegung) einer für mehrere ABCA-Vertreter spezifischen Flippasefunktion im komplexen Bereich des Lipidtransports stellt eine aufregende Fragestellung für zukünftige Arbeiten an diesem neuen ABCA-Transporter dar. 


\section{Literaturverzeichnis}

\section{S. Abe-Dohmae, Y. Ikeda, M. Matsuo, M. Hayashi, K. OKuhiRa, K. Ueda, S.Yokoyama,} Human ABCA7 supports apolipoprotein-mediated release of cellular cholesterol and phospholipid to generate high density lipoprotein, J. Biol. Chem. 279 (2004) 604-611.

D.P. Aden, A. Fogel, S. Plotkin, I. Damjanov, B.B. Knowles, Controlled synthesis of HBsAg in a differentiated human liver carcinoma-derived cell line, Nature 282 (1979) 615616.

R. Allikmets, B. Gerrard, A. Hutchinson, M. Dean, Characterization of the human ABC superfamily: isolation and mapping of 21 new genes using the expressed sequence tags database. Hum. Mol. Genet. 5 (1996) 1649-1655.

R. Allikmets, N. Singh, H. Sun, N.F. Shroyer, A. Hutchinson, A. Chidambaram, B. Gerrard, L. Baird, D. Stauffer, A. Peiffer, A. Rattner, P. Smallwood, Y. Li, K.L. ANDERSON, R.A. LeWIS, J. NATHANS, M. LePPERT, M. DEAN, J.R. LUPSKI, A photoreceptor cell-specific ATP-binding transporter gene (ABCR) is mutated in recessive Stargardt macular dystrophy, Nat. Genet. 15 (1997) 236-246.

\section{R. Allikmets, W.H. Raskind, A. Hutchinson, N.D. Schueck, M. Dean, D.M. Koeller,} Mutation of a putative mitochondrial iron transporter gene $(A B C 7)$ in $X$-linked sideroblastic anemia and ataxia (XLSA/A), Hum. Mol. Genet. 8 (1999) 743-749.

S.F. ALTSChUL, E.V. Koonin, Iterated profile searches with PSI-BLAST - a tool for discovery in protein databases, Trends Biochem Sci. 23 (1998) 444-447.

C. AnjaRd, W.F. Loomis, Dictyostelium Sequencing Consortium, Evolutionary analyses of ABC transporters of Dictyostelium discoideum, Eukaryot. Cell. 1 (2002) 643-652.

\section{T. Annilo, S. Shulenin, Z.Q. Chen, I. Arnould, C. Prades, C. Lemoine, C. MaintouX-}

Larois, C. Devaud, M. Dean, P. Denefle, M. Rosier, Identification and characterization of a novel $A B C A$ subfamily member, $A B C A 12$, located in the lamellar ichthyosis region on $2 q 34$, Cytogenet Genome Res. 98 (2002) 169-176.

T. ANNILo, C. Zhang-Qun, S. Shulenin, M. DeAN, Evolutionary analysis of a cluster of ATPbinding cassette (ABC) genes, Mamm. Gen. 14 (2003) 7-20. 
J. AUBRECHT, G.F. KAHL, M.W. HöHNE, Regulation of fibrnectin mRNA expresssion in primary rat hepatocytes in response to EGF and phenobarbital, Biochem. Biophys. Res. Commun. 190 (1993) 1023-1028.

\section{J. Aubrecht, K.I. HiRsch-ERnst, V. Becker-Rabbenstein, G.F. Kahl, H. Taniguchi, M.W.} HÖHNE, Induction of cytochrome P-450 2B1-related mouse cytochrome P-450 and regulation of its expression by epidermal growth factor/ transforming growth factor $\alpha$ in primary rat hepatocyte cultures, Biochem. Pharmacol. 50 (1996) 781-785.

S.M. AzARIAN, G.H. TRAVIS, The photoreceptor rim protein is an ABC transporter encoded by the gene for recessive Stargardt's disease (ABCR), FEBS Lett. 409 (1997) 247-252.

\section{A. BACher, K. Griebl, S. Mackamul, R. Mitreiter, H. Muckter, Y. Ben-Shaul, Protease} inhibitors suppress the formation of tight junctions in gastrointestinal cell lines, Exp. Cell Res. 200 (1992) 97-104.

S.A. BarRos, R.W. TenNant, R.E. CANnON, Molecular structure and characterization of a novel murine ABC transporter, Abca13, Gene 307 (2003) 191-200.

E. Beaudoing, S. Freier, J. R. Wyatt, J.M. Claverie, D. Gautheret, Patterns of variant polyadenylation signal usage in human genes, Genome Res. 10 (2000) 1001-1010.

S. BeKRI, G. KISPAL, H. LANGE, E. FITZSImons, J. Tolmie, R. LILL, D.F. BISHOP, Human ABC7 transporter: gene structure and mutation causing $X$-linked sideroblastic anemia with ataxia with disruption of cytosolic iron-sulfur protein maturation, Blood. 96 (2000) 3256-3264.

M.N. BERRY, D.S. FRIEND, High yield preparation of isolated rat liver parenchymal cells, J. Cell. Biol. 43 (1969) 506-520.

C. Bisbal, C. Martinand, M. Silhol. B. Lebleu, T. Salehzada, Cloning and charakterization of a Rnase $L$ inhibitor. A new component of the interferon-regulated 2-5A pathway, J. Biol. Chem. 270 (1995) 13308-13317.

H.C. BiRnboim, J. Doly, A rapid alkaline extraction procedure for screening recombinant plasmid DNA, Nucleic Acid Res. (1979) 7 1513-1523.

C. Broccardo, M.-F. LUCIANI, G. ChiminI, The ABCA subclass of mammalian transporters, Biochim. Biophys. Acta 1461 (1999) 395-404. 
S.A. Bustin, Quantification of mRNA using real-time reverse transcription PCR (RT-PCR): trends and problems, J. Mol. Endocrinol. 29 (2002), 23-29.

M.G. Claros, G. von HeiJne, TopPred II: An Improved Software For Membrane Protein Structure Predictions. CABIOS 10 (1994) 685-686.

G. Chang, C.B. Roth, Structure of MsbA from E. coli: a homolog of the multidrug resistance ATP binding cassette (ABC) transporters, Science. 293 (2001) 1793-1800.

G. CHANG, Structure of MsbA from Vibrio cholera: a multidrug resistance ABC transporter homolog in a closed conformation, J. Mol. Biol. 330 (2003) 419-430.

P. ChomczYNSKI, N. SACCHI, Single-step method of RNA isolation by acid guanidinium thiocyanate-phenol-chloroform extraction, Anal. Biochem. 162 (1987) 156-159.

E. DASSA, P. BouIGE, The ABC of ABCs: a phylogenetic and functional classification of $A B C$ systems in living organisms, Res. Microbiol. 152 (2001) 211-229.

M. DeAN, A. RZHETSKY, R. AlLIKMETS, The human ATP-binding cassette (ABC) transporter superfamily, Genome Res. 11 (2001) 1156-1166.

M. DeAN, Y. Hamon, G. ChiminI, The human ATP-binding cassette (ABC) transporter superfamily, J. Lip. Res. 42 (2001) 1007-1017.

M.DEAN, The human ATP-Binding Cassette (ABC) Transporter Superfamily, Online Book (2002) National Library of Medicine, Bethesda, USA.

H. de la Salle, D. Hanau, D. Fricker, A. Urlacher, A. Kelly, J. Salamero, S.H. Powis, L. DonAto, H. BAUSINGER, M. LAFORET, Homozygous human TAP peptide transporter mutation in HLA class I deficiency, Science. 265 (1994) 237-241.

H. De la Salle, J. Zimmer, D. Fricker, C. AngenieuX, J.P. Cazenave, M. OKubo, H. Maeda, A. Plebani, M.M. Tongio, A. Dormoy, D. Hanau, HLA class I deficiencies due to mutations in subunit 1 of the peptide transporter TAP1, J Clin Invest. 103 (1999) Mar; R9-R13.

A. Dodd, S.A. Rowland, S.L HaWkes, M.A. Kennedy, D.R. Love, Mutations in the adrenoleukodystrophy gene, Hum. Mutat. 9 (1997) 500-511. 
L.A. Doyle, W. Yang, L.V. Abruzzo, T. Krogmann, Y. GaO, A.K. Rishi, D.D. Ross, A multidrug resistance transporter from human MCF-7 breast cancer cells, PNAS 95 (1998) 15665-15670.

P.A. Edwards, M.A. Kennedy, P.A. MAK, LXRs; Oxysterol-activated nuclear receptors that regulate genes controlling lipid homeostasis, Vasc. Pharmacol. 38 (2002) 249-256.

D. FITZPATRICK, W Rat pituitary adult female Wistar rat average insert size 2.1, Genbank Accession number CB808508, 2003.

D.R. FLowER, The lipocalin protein family: structure and function, Biochem. J. 318 (1996) 114.

J. Fogh, W.C. WRIGHT, AND J.D. Loveless, Absence of HeLa cell contamination in 169 cell lines derived from human tumors, J. Natl. Cancer Inst. 58 (1977) 209-14.

M.A. Frohman, On beyond classic RACE (rapid amplification of cDNA ends), Genome Res. (1994) 40-58.

R. GAUDET, D.C. WILEY, Structure fo the ABC ATPase domain of human TAP1, the transporter associated with antigen processing, EMBO 20 (2001) 4964-4972.

C.J. Gloeckner, P.U. MAyerhofer, P. Landgraf, A.C. Muntau, A. Holzinger, J.K. Gerber, S. KAMmerer, J. AdAMSKI, A.A. Roscher, Human adrenoleukodystrophy protein and related peroxisomal $A B C$ transporters interact with the peroxisomal assembly protein PEX19p, Biochem. Biophys. Res. Commun. 271 (2000) 144-150.

G.A. Graf, L. Yu, W.P. LI, R. Gerard, P.L. TUMA, J.C. Cohen, H.H. HobBs, ABCG5 and ABCG8 are obligate heterodimers for protein trafficking and biliary cholesterol excretion, $\mathrm{J}$. Biol. Chem. 278 (2003) 48275-48282.

F.L. Graham, J. SmiLey, W.C. RusselL, R. NAIRN, Characteristics of a human cell line transformed by DNA from human adenovirus type 5, J. Gen. Virol., Jul 36 (1977) 59-74.

Y. Hamon, C. Broccardo, O. Chambenoit, M.F. Luciani, F. Toti, S. Chaslin, J.M. Freyssinet, P.F. DevauX, J. McNeish, D. Marguet, G. Chimini, ABC1 promotes engulfment of apoptotic cells and transbilayer redistribution of phosphatidylserine, Nat. Cell. Biol. 2 (2000) 399-406. 
Y. Hamon, O. Chambenoit, G. Chimini, ABCA1 and the engulfment of apoptotic cells, Biochim. Biophys. Acta. 1585 (2002) 64-71.

G. von HeIJNE, Membrane Protein Structure Prediction: Hydrophobicity Analysis and the 'Positive Inside' Rule, J. Mol. Biol. 225 (1992) 487-494.

C.F. Higgins, I.D. HiLeS, G.P. SALmond, D.R. GiLL, J.A. Downie, I.J. EvanS, I.B. HolLand, L. GRAY, S.D. BuCKEL, A.W. BELL, M.A. HERMOdSON, A family of related ATP-binding subunits coupled to many distinct biological processes in bacteria, Nature 323 (1986) 448-450.

K.I. Hirsch-ERnst, C. Ziemann, C. Schmitz-SAlue, H. Foth, G.F. KaHL, Modulation of Pglycoprotein and mdr1b mRNA expression by growth factors in primary rat hepatocyte culture, Biochem. Biophys. Res. Commun. 215 (1995) 179-185.

K.I. HiRsch-ERnst, S. Gaini-RAhimi, B.-P. ERnst, C. Schmitz-SAlUe, S. Blume, G.F. KaHL, Molecular cDNA cloning and tissue distribution of mRNA encoding a novel ATP-binding cassette (ABC) half-transporter, Biochem. Biophys. Res. Commun. 249 (1998) 151-155.

K.I. HiRSCh-ERnSt, A. SchäFER,B.P. ERNSt, Identification of novel human ATP-binding cassette genes expressed in testis by degenerate RT-PCR, direct submission to Genbank (2000) AJ275973.

B. Hoffmann, A. Piasecki, D. PaUL, Proliferaton of fetal rat hepatocytes in response to growth factors and hormones in primary culture, J. Cell. Physiol. (1989)139 654-662.

P.M. Holland, R.D. Abramson, R. Watson, D.H. Gelfand, Detection of Specific Polymerase Chain Reaction Product by Utilizing the $5^{\prime} \rightarrow 3^{\prime}$ Exonuclease Activity of Thermus aquaticus DNA Polymerase, PNAS, 88 (1991) 7276-7280.

K.P. Hopfner, A. Karcher, D.S. Shin, L. Craig, L.M. ARthur, J.P. Carney, J.A. Tainer, Structural biology of Rad50 ATPase: ATP-driven conformational control in DNA doublestrand break repair and the ABC-ATPase superfamily, Cell. 101 (2000) 789-800.

K.-P. HopfNeR, J.A. TRAinER, Rad50/SMC proteins and ABC transporters: unifying concepts from high resolution structures, Curr. Opin. Struct. Biol. 13 (2003) 249-255.

C.A. Hrycyna, M. Ramachandra, U.A. Germann, P.W. Cheng, I. Pastan, M.M.Gottesman, Both ATP sites of human P-glycoprotein are essential but not symmetric, Biochemistry 38 (1999) 13887-13899. 
S.C. Hyde, P. Emsley, M.J. HARTShorn, M.M. MimmaCK, U. GILeAdi, S.R. Pearce, M.P. GaLlagher, D.R. GILL, R.E. HubBaRD, C.F. Higgins, Structural model of ATP-binding proteins associated with cystic fibrosis, multidrug resistance and baccterial transport, Nature 346 (1990) 362-365.

N. InAGAKI, T. GonoI, J.P. Clement, N. NAmbA, J. InAZAWA, G. Gonzalez, L. AguilaRBRYAN, S. SEINO, J. BRYAN, Reconstitution of IKATP: an inward rectifier subunit plus the sulfonylurea receptor, Science 270 (1995) 1166-1170.

N. Inagaki, T. Gonol, J.P. Clement, C.Z. Wang, L. Aguilar-Bryan, J. Bryan, S. Seino, A family of sulfonylurea receptors determines the pharmacological properties of ATP-sensitive K+ channels, Neuron 16 (1996) 1011-1017.

P.M. JoneS, A.M. GeORGE, Mechanism of ABC transporters: a molecular dynamics simulation of a well charakcterized nucleotide-binding subunit, PNAS 20 (2002) 1263912644.

J.W. Jonker, M. BuitelaAR, E. WAgenaAR, M.A. VAN Der Valk, G.L. SchefFer, R.J. SCHEPER, T. Plosch, F. Kuipers, R.P. Elferink, H. Rosing, J.H. BEIJNen, A.H. SCHINKel, The breast cancer resistance protein protects against a major chlorophyll-derived dietary phototoxin and protoporphyria, PNAS 99 (2002) 15649-15654.

W.E. Kaminski, A. Piehler, K. Pullmann, M. Porsch-Ozcurumez, C. Duong, G.M. Bared, C. BÜCHLER, G. SCHMITZ, Complete coding sequence, promoter region, and genomic structure of the human ABCA2 gene and evidence for sterol-dependent regulation in macrophages, Biophys. Res. Commun. 281 (2001) 249-258.

W.E. Kaminski, E. OrSo, W. Diederich, J. Klucken, W. DrobniK, G. SchmitZ, Identification of a novel human sterol-sensitive ATP-binding cassette transporter (ABCA7), Biochem. Biophys. Res. Commun. 273 (2000) 532-538.

M.A. Kennedy, A. Venkateswaran, P.T. TarR, I. Xenarios, J. Kudoh, N. Shimizu, P.A. EDWARDS, Characterization of the human ABCG1 gene: liver $X$ receptor activates an internal promoter that produces a novel transcript encoding an alternative form of the protein, J. Biol. Chem. 276 (2001) 39438-39447.

J. KLUCKen, C. BÜChleR, E. ORSO, W.E. KAMINSKI, M. PORSCH-OZCURUMEZ, G. LiebisCH, M. Kapinsky, W. Diederich, W. Drobnik, M. Dean, R. Allikmets, G. SChmitz, ABCG1 (ABC8), the human homolog of the Drosophila white gene, is a regulator of macrophage cholesterol and phospholipid transport, PNAS 97(2000) 817-822. 
B.B. KNOWLES, C.C. Howe, AND D.P. AdEN, Human hepatocellular carcinoma cell lines secrete the major plasma proteins and hepatitis B surface antigen, Science 209 (1980) 497499.

M. KozaK, Point mutations define a sequence flanking the AUG initiator codon that modulates translation by eukaryotic ribosomes, Cell 44 (1986) 283-292.

A. KRogh, B. LaRsson, G. von HeiJne, AND E.L.L. Sonnhammer, Predicting transmembrane protein topology with a hidden Markov model: Application to complete genomes, J. Mol. Biol. 305 (2001) 567-580.

J. KYHSE-ANDERSEN, Electroblotting of multiple gels: a simple apparatus without buffer tank for rapid transfer of proteins from polyacrylamide to nitrocellulose, J. Biochem. Biophys. Methods 10 (1984) 203-209.

U.K LAEMMLI, Cleavage of structural proteins during the assembly of the head of bacteriophage T4, Nature, 227 (1970) 680-685.

M.H. Lee, K. Lu, S. Hazard, H. Yu, S. Shulenin, H. Hidaka, H. Kojima, R. Allikmets, N. Sakuma, R. Pegoraro, A.K. Srivastava, G. Salen, M. Dean, S.B. Patel, Identification of a gene, ABCG5, important in the regulation of dietary cholesterol absorption, Nat. Genet. 27 (2001) 79-83.

C. LefeVre, S. Audebert, F. Jobard, B. BouAdjar, H. LAKHDAR, O. BoughdeneStambouli, C. Blanchet-Bardon, R. Heilig, M. Foglio, J. Weissenbach, M. Lathrop, J.F. PRUD'HOMme, J. FISCHER, Mutations in the transporter ABCA12 are associated with lamellar ichthyosis type 2, Hum. Mol. Genet. 12 (2003) 2369-2378.

J. LeIGHTON, G. SchATZ, An ABC transporter in the mitochondrial inner membrane is required for normal growth of yeast, EMBO J. 14 (1995) 188-195.

L.X. Liu, K. Janvier, V. Berteaux-Lecellier, N. Cartier, R. Benarous, P. Aubourg, Homo- and heterodimerization of peroxisomal ATP-binding cassette half-transporters, J. Biol. Chem. 274 (1999) 32738-32743.

K.J. LivaK, S.J. Flood, J. MARmaro, W. Giusti, And K. DeEtz, Oligonucleotides with fluorescent dyes at opposite ends provide a quenched probe system useful for detecting PCR product and nucleic acid hybridization, Genome Res. 4 (1995) 357-362. 
K.P. Locher, A.T. LeE, D.C.ReES, The E. coli BtuCD structure: a framework for ABC transporter architecture and mechanism, Science. 296 (2002) 1091-1098.

K.P. LOCHER, E. BORTHS, ABC transporter architecture and mechanism: implications from the crystal structures of BtuCD and BtuF, FEBS Lett. 564 (2004) 264-268.

I.S. Lossos, D.K. CzerWinsKI, M.A. WeCHSER, R. LeVY, Optimization of quantitative realttime RT-PCR data parameters for the study of lymphoid malignancies, Leukemia, 17 (2003) 789-795.

O.H. Lowry, N.J. Rosenbrough, A.L. FARR, R.J. RandalL, Protein measurement with the folin phenol reagent, J. Biol. Chem. 193 (1951) 265-275.

M.F. Luciani, F. Denizot, S. Savary S, M.G. Mattei, G. Chimini, Cloning of two novel ABC transporters mapping on human chromosome 9, Genomics 21 (1994) 150-159.

N.L. MATA, R.T. TZekov, X. LIU, J. Weng, D.G. BIRCH, G.H.Travis, Delayed dark-adaptation and lipofuscin accumulation in abcr+/- mice: implications for involvement of ABCR in agerelated macular degeneration, Invest Ophthalmol Vis Sci. 2001 Jul;42(8):1685-1690.

K.L. Mealey, S.A. BentJen, J.M. Gay, G.H. Cantor, Ivermectin sensitivity in collies is associated with a deletion mutation of the mdr1 gene, Pharmacogenetics 11 (2001) 727733.

J.G. Menke, K.L. Macnaul, N.S. Hayes, J. Baffic, Y.S. Chao, A. Elbrecht, L.J. Kelly, M.H. LAM, A. SchmidT, S. SAHOO, J. WANG, S.D. WRIGHT, P. XIN, G. ZHOU, D.E. MOLLER, C.P. SPARRow, A novel liver $X$ receptor agonist establishes species differences in the regulation of cholesterol 7alpha-hydroxylase (CYP7a), Endocrinology 143 (2002) 2548-2558.

N. Mitsuhashi, T. Miki, H. Senbongi, N. Yokoi, H. Yano, M. Miyazaki, N. Nakajima, T. Iwanaga, Y. Yokoyama, T. Shibata, S. Seino, MTABC3, a novel mitochondrial ATP-binding cassette protein involved in iron homeostasis, J. Biol. Chem. 275 (2000) 17536-17540.

G. Moncalian, B. Lengsfeld, V. Bhaskara, K.P. Hopfner, A. Karcher, E. Alden, J.A. TAINER, T.T. PAULL, The rad50 signature motif: essential to ATP binding and biological function, J. Mol. Biol. 335 (2004) 937-951.

T. Nagase, K. Ishikawa, M. Suyama, R. Kikuno, M. Hirosawa, N. Miyajima, A. Tanaka, H. KotanI, N. Nomura, O. OHARA, Prediction of the coding sequences of unidentified human 
genes. XII. The complete sequences of 100 new cDNA clones from brain which code for large proteins in vitro, DNA Res. 5 (1998) 355-364.

T. NAGASE, R. KIKUnO, O. OHARA, Prediction of the coding sequences of unidentified human genes. XXI. The complete sequences of 60 new cDNA clones from brain which code for large proteins, DNA Res. 8 (2001) 179-187.

K. NAKAI, AND M. KANEHISA, A knowledge base for predicting protein localization sites in eukaryotic cells, Genomics 14 (1992) 897-911.

M. ORAM, R.M. LAWN, ABCA1. The gatekeeper for eliminating excess tissue cholesterol, J. Lipid Res. 42 (2001) 1173-1179.

C. OWNBY, Oklahoma State University, College of Veterinary Medicine, http://www.cvm.okstate.edu/instruction/mm_curr/histology/HistologyReference/

M.R. Picciotto, J.A. Cohn, G. Bertuzzi, P. Greengard, A.C. NAiRn, Phosphorylation of the cystic fibrosis transmembrane conductance regulator, J Biol Chem. 267 (1992) 1274212752.

A. Piehler, W.E. Kaminski, J.J. Wenzel, T. Langmann, G. Schmitz, Molecular structure of a novel cholesterol-responsive A subclass $A B C$ transporter, ABCA9, Biochem. Biophys. Res. Commun. 295 (2002) 408-416.

F. Pognan, M.T. Masson, F. Lagelle, C. Charuel, Establishment of a rat Sertoli cell line that displays the morphological and some of the functional characteristics of the native cell, Cell. Biol. Toxicol. 13 (1997) 453-463.

C. Prades, I. Arnould, T. Annilo, S. Shulenin, Z.Q. Chen, L. Orosco, M. Triunfol, C. Devaud, C. Maintoux-Larois, C. Lafargue, C. Lemoine, P. Denefle, M. Rosier, M. Dean, The human ATP binding cassette gene ABCA13, located on chromosome $7 p 12.3$, encodes a 5058 amino acid protein with an extracellular domain encoded in part by a 4.8-kb conserved exon, Cytogenet Genome Res. 98 (2002) 160-168.

C. Proff, R. Kolling, Functional asymmetry of the two nucleotide binding domains in the ABC transporter Ste6, Mol. Gen. Genet. 264 (2001) 883-893.

C.R. Pullinger, H. Hakamata, P.N. Duchateau, C. Eng, B.E. Aouizerat, M.H. Cho, C.J. FIELDING, J.P. KANE, Analysis of hABC1 gene 5 ' end: additional peptide sequence, promoter region, and four polymorphisms, Biochem. Biophys. Res. Commun. 271 (2000) 451-455. 
P.M. Quinton, Physiological Basis of Cystic Fibrosis: A Historical Perspective, Physiol. Rev. 79 (1999) 3-22.

J.J. Repa, S.D. TuRley, J.A. Lobaccaro, J. Medina, L. LI, K. Lustig, B. Shan, R.A. HEYMAN, J.M. DIETSCHY, D.J. MANGELSDORF, Regulation of absorption and ABC1-mediated efflux of cholesterol by RXR heterodimers, Science. 289 (2000) 1524-1529.

W. RoSNer, D.J. HRYB, M.S. KHAN, A.M. NAKHLA, N.A. RomAS, Sex hormone-binding globulin. Binding to cell membranes and generation of a second messenger, J. Androl. 13 (1992) 101-106.

M. RouSSET, The human colon carcinoma cell lines HT-29 and Caco-2: two in vitro models for the study of intestinal differentiation, Biochimie 68 (1986) 1035-1040.

N. SAITOU, M. NEI, The neighbor-joining method : a new method for reconstructing phylogenetic trees, Mol. Biol. Evol. 4 (1987) 406-425.

J. SAMBROOK, E.F. FRITSCH, T. MANIATIS, Molecular cloning: a laboratory manual, 2nd Edition, Cold Spring Harbor Laboratory Press, Cold Spring Harbor, N.Y. (1989).

F. SANGer, S. NiCKLEN, A.R. Coulson, DNA sequencing wih the chain terminating inhibitors, Proc. Natl. Acac. Sci. U.S.A. 74 (1977) 5463-5467.

S. Santamarina-Fojo, A.T. Remaley, E.B. Neufeld, H.B. BreWer, Regulation and intracellular trafficking of the ABCA1 transporter, J. Lipid Res. 42 (2001) 1339-1345.

A.H. Schinkel, J.J. Smit, O. van Tellingen, J.H. Beinjen, E. WAgenaAR, L. VAN Deemter, C.A. Mol, M.A. VAn DeR VALK, E.C. Robanus-MandaAG, H.P te Riele, Disruption of the mouse mdr1a- P-glycoprotein gene leads to a deficiency in the blood-brain barrier and to increase sensitivity to drugs, Cell 77 (1994) 491-502.

A.H. Schinkel, U. MAYeR, E. WAgenaAR, C.A. Mol, L. VAN DeEMter, J.J. Smit, M.A. VAN DeR Valk, A.C. Voordouw, H. Spits, O. van Tellingen, J.M. ZiJlmans, W.E. FibBe, P. BORST, Normal viability and altered pharmacokinetics in mice lacking mdr1-type (drugtransporting) P-glycoproteins, PNAS 94 (1997) 4028-4033.

G. SCHMITZ, W.E. KAMINSKI, ABC transporters and cholesterol metabolism, Frontiers in bioscience 6(2001) 505-515. 
J.D. Schuetz, M.C. Connelly, D. Sun, S.G. OAibiR, P.M. Flynn, R.V. InivaS, A. Kumar, A. FRIDLAND, MRP4: a previously unidentified factor in resistance to nucleoside-based antiviral drugs, Nat. Med. 5 (1999) 1048-1051.

P.O. Seglen, Preparation of isolated rat liver cells in Methods in Cell Biology, vol 13 (1976) (Prescott DM Ed) Academic Press, N.Y., 29-33.

D.M. Selva, V. Hirsch-Reinshagen, B. Burgess, S. Zhou, J. Chan, S. MclsaAC, M.R. HAYDEN, G.L. Hammond, A.W. Vogl, C.L. Wellington, The ATP-binding cassette transporter ABCA1 mediates lipid efflux from Sertoli cells and influences male fertility, J Lipid Res. 2004 Mar 16 [Epub ahead of print].

\section{J.A. Simpson, D.R. YVER, P.J. Hissin, L.J. WardZALA, E. KARNieLI, L.B. SALENS, S.W.} CUSHMAN, Insulin stimulated translocation of glucose transporters in the isolated rat adipose cells: characterization of subcellular fractions, Biochem. Biophys. Acta 763 (1983) 393-407.

S. Shulenin, L.M. Nogee, T. Annilo, S.E. Wert, J.A. Whitsett, M. Dean, ABCA3 gene mutations in newborns with fatal surfactant deficiency, N. Engl. J. Med. 350 (2004) 12961303.

J.D. Smith, G. Freeman, M. Vogt, R. Dulbecco, The nucleic acid of polyoma virus, J. Biol. Chem. (1960) 264 12053-12062.

\section{J.J. Smit, A.H. Schinkel, R.P. OUde ElferinK, A.K. Groen, E. WAGenaAR, L. VAN} DeEmTer, C.A. MOL, R. OtTEnhoff, N.M. van DER Lugt, M.A. van RoON, Homozygous disruption of the murine mdr2 P-glycoprotein gene leads to a complete absence of phospholipid from bile and to liver disease, Cell. 75 (1993) 451-462.

S.S. Strautnieks, L.N. Bull, A.S. Knisely, S.A. Kocoshis, N. Dahl, H. ARnell, E. Sokal, K. Dahan, S. Childs, V. Ling, M.S. Tanner, A.F. Kagalwalla, A. Nemeth, J. Pawlowska, A. BAKER, G. Mieli-Vergani, N.B. Freimer, R.M. GaRdineR, R.J. Thompson, A gene encoding a liver-specific $A B C$ transporter is mutated in progressive familial intrahepatic cholestasis, Nat. Genet. 20 (1998) 233-238.

E.M. SOUTHERN, Detection of specific sequences among DNA fragments separated by gel electrophoresis, J. Mol. Biol. 98 (1975) 503-517.

C.P. SparRow, J. Baffic, M.H. Lam, E.G. Lund, A.D. Adams, X. Fu, N. Hayes, A.B. Jones, K.L. Macnaul, J. OndeYka, S. Singh, J. Wang, G. Zhou, D.E. Moller, S.D. Wright, J.G. 
MENKE, A potent synthetic LXR agonist is more effective than cholesterol loading at inducing ABCA1 mRNA and stimulating cholesterol efflux, J. Biol. Chem. 277 (2002) 10021-10027.

\section{T. Spies, M. Bresnahan, S. Bahram, D. Arnold, G. Blanck, E. Mellins, D. Pious, R.}

DEMARS, A gene in the human major histocompatibility complex class II region controlling the class I antigen presentation pathway, Nature 348 (1990) 744-747.

M. SUZUKI, H. SUZUKI, Y. SugImoto, Y. SugiYAMA, ABCG2 transports sulfated conjugates of steroids and xenobiotics, J. Biol. Chem. 278 (2003) 22644-22649.

Y. Takada, K. Yamada, Y. Taguchi, K. Kino, M. Matsuo, S.J. Tucker, T. Komano, T. Amachi, K. Ueda, Non-equivalent cooperation between the two nucleotide-binding folds of P-glycoprotein, Biochim Biophys Acta 1373 (1998) 131-136.

S. TSURUOKA, K. ISHIBASHI, H. YAMAMOTO, M. WAKaUmi, M. SUZUKI, G.J. SCHWARTZ, M. Imal, A. FUJIMURA, Functional analysis of ABCA8, a new drug transporter, Biochem Biophys Res Commun. 298 (2002) 41-45.

O. Turriziani, J.D. Schuetz, F. Focher, C. Scagnolari, J. Sampath, M. Adachi, F. BAMBACIONI, E. RIVA, G. ANTONELLI, Impaired 2',3'-dideoxy-3'-thiacytidine accumulation in Tlymphoblastoid cells as a mechanism of acquired resistance independent of multidrug resistant protein 4 with a possible role for ATP-binding cassette C11, Biochem. J. 368 (2002) 325-332.

J.K. Tyzack, X. WANG, G.J. Belsham, C.G. Proud, ABC50 interacts with eukaryotic initiation factor 2 and associates with the ribosome in an ATP-dependent manner, J. Biol. Chem. 275 (2000) 34131-34139.

J. Vandesompele, K. De Preter, F. Pattyn, B. Poppe, N. van Roy, A. de Paepe, F. SPELEMAN, Accurate normalization of real-time quantitative RT-PCR data by geometric averaging of multiple internal control genes, Genome Biol 3(7) 2002 RESEARCH0034.

A. Venkateswaran, B.A. Laffitte, S.B. Joseph, P.A. MaK, D.C. Wilpitz, P.A. Edwards, P. TONTONOZ, Control of cellular cholesterol efflux by the nuclear oxysterol receptor LXR alpha, PNAS 97 (2000) 12097-12102.

B. Vulevic, Z. Chen, J.T. Boyd, W. Davis, E.S. Walsh, M.G. Belinsky, K.D. Tew, Cloning and characterization of human adenosine 5 '-triphosphate-binding cassette, sub-family $A$, transporter 2 (ABCA2), Cancer Res. 61 (2001) 3339-3347. 
J.E. WALKER, M. SARASTE, M.J. RUNSWICK, N.J. GAY, Distantly related sequences in the alpha- and beta-subunits of ATP synthase, myosin, kinases and other ATP-requiring enzymes and a common nucleotide binding fold, EMBO J. 1 (1982) 945-951.

N. Wang, D.L. Silver, P. Costet, A.R. TalL, Specific binding of ApoA-I, enhanced cholesterol efflux, and altered plasma membrane morphology in cells expressing $A B C 1, J$. Biol. Chem. 275 (2000) 33053-33058.

C.L. Wellington, Y.Z. Yang, S. Zhou, S.M. Clee, B. Tan, K. HiRano, K. Zwarts, A. KwoK, A Gelfer, M. Marcil, S. Newman, K. Roomp, R. Singaraja, J. Collins, L.H. Zhang, A.K. Groen, K. Hovingh, A. Brownlie, S. TAfuri, J. Genest, J.J. KAStelein, M.R. HAyden, Truncation mutations in ABCA1 suppress normal upregulation of full-length ABCA1 by 9-cisretinoic acid and 22-R-hydroxycholesterol, J. Lipid Res. 43 (2002) 1939-1949.

J. Weng, N.L. Mata, S.M. Azarian, R.T. Tzekov, D.G. BiRCh, G.H. Travis, Insights into the function of Rim protein in photoreceptors and etiology of Stargardt's disease from the phenotype in Abcr knockout mice, Cell 98 (1999) 13-23.

J.J. Wenzel, W.E. Kaminski, A. Piehler, S. Heimerl, T. Langmann, G. Schmitz, ABCA10, a novel cholesterol-regulated ABCA6-like ABC transporter, Biochem. Biophys. Res. Commun. 306 (2003) 1089-1098.

J. WiJnholds, C.A. Mol, L. van Deemter, M. DE HAAS, G.L. Sceffer, F. BaAs, J.H. BeiJnen, R.J. SchePer, S. HATSE, E. DE CleRcQ, Multidrug-resistance protein 5 is a multispecific organic anion transporter able to transport nucleotide analogs, PNAS 97 (2000) 7476-7481.

J. XIE, L.M. Adams, J. ZhaO, T.A. Gerken, P.B. DaVIS, J. MA, A short segment of the R domain of cystic fibrosis transmembrane conductance regulator contains channel stimulatory and inhibitory activities that are separable by sequence modification, J Biol Chem. 277 (2002) 23019-23027.

H. YabuUchi, H. Shimizu, S. Takayanagi, T. IShikawa, Multiple splicing variants of two new human ATP-binding cassette transporters, ABCC11 and ABCC12, Biochem. Biophys. Res. Commun. 288 (2001) 933-939.

H. YabuUchi, S. Takayanagi, K. Yoshinaga, N. Taniguchl, H. Aburatani, T. Ishikawa, $A B C C 13$, an unusual truncated $A B C$ transporter, is highly expressed in fetal human liver, Biochem Biophys. Res. Commun. 299 (2002) 410-417. 
G. Yamano, H. Funahashi, O. KaWANami, L.X. ZhaO, N. Ban, Y. UChIDA, T. MOROHOSHI, J. OGAWA, S. SHIODA, N. INAGAKI, ABCA3 is a lamellar body membrane protein in human lung alveolar type II cells, FEBS Lett. 508 (2001) 221-225.

C. ZIEMANN, A. BÜRKLE, G.F. KAHL, K.I. HIRSCH-ERNSt, Reactive oxygen species participate in mdr1b mRNA and P-glycoprotein overexpression in primary rat hepatocyte cultures, Carcinogenesis 20 (1999) 407-414. 


\section{Danksagungen}

Zum Gelingen dieser Arbeit haben viele hilfsbereite Freunde, Kollegen und Mitmenschen entscheidend beigetragen. Innen allen möchte ich hiermit herzlich danken, und ich bitte vorab um Verzeihung, falls ich in der Hektik jemanden vergessen sollte zu erwähnen.

Der gesamten Abteilung Toxikologie bin ich dankbar für die freundliche Aufnahme im Oktober 2000 sowie für die schnelle Einarbeitung und gute Zusammenarbeit. Ich habe mich von Anfang an bei den Toxikologen sehr wohlgefühlt. Mein besonderer Dank gilt dabei Anne Heder, Christina Ziemann und Hartmud Neurath für viele gute Diskussionen und Bewältigung der obligatorischen Frustphasen, ebenso Bernd Peter-Ernst (BPE) und Daniel Bauer für wertvolle PCR- und Klonierungstips, viele Sequenzierungen und Hilfestellungen im ersten Jahr dieser Arbeit. Ein lieber Dank gilt natürlich Sonja Blume u.a. für viele Northern Blots, Christoph Schmitz-Salue für Western Blots, zahlreiche Hepatozytenpräparationen (und vieles mehr), Gudrun Rüdell für ihre sorgältigen Protokolle, Anke Gregus für Maxipreps, Lösungen und für 1617 abgetippte Aminosäuren des ABCA6-Transporters!, Bärbel Förster für ihre Fähigkeit, den Laden zusammenzuhalten, ohne ein großes Aufsehen darüber zu verursachen und auch dem akademischen Nachwuchs Christian Lass und Ana Jakimenko für gute Gesellschaft und besonders Ana für Hilfe in der heißen Phase der letzten Monate.

Der Abteilung Klinische Pharmakologie von Herrn Professor Brockmöller danke ich für die Mitnutzung des Sequenzierers, des Taqmancyclers und für manchen Farbausdruck auf dem Deskjet 1220C. Meiner Freundin und Laborkollegin Cornelia Meineke bin ich sehr dankbar für die Idee und Konzeption der Versuche zur quantitativen Bestimmung der Splicevariante, für eine tolle Zusammenarbeit bei Zellkultur, Sequenzierungen, Klonierungen etc. sowie für viele Kaffee-Denk-Pausen im Labor und anderswo. Ein großer Dank gilt auch inrem Kollegen Mladen Tsvetkov für seine unschätzbare Hilfe bei den letzten Klonierungen und viele gute wissenschaftliche Ideen. Danke auch an Karoline Jobst und alle anderen Laborinsassen der klinischen Pharmakologie. Frau Uta Ferch (Abt. Humangenetik) danke ich für die Bereitstellung des 18S-Referenzplasmids. Vielen Dank auch an Frau Oesch und Frau Antoniou-Lipfert für die Bereitstellung der Sertolizellinie SER-W3.

Für die freundliche Aufnahme und zahlreiche Hilfestellungen möchte ich mich bei der Abteilung Pathologie, insbesondere bei Peter Middel, Steffi Zieschkau, Nicole Putzer, Anja Heintze, Swantje Wehn, Olga Walter und Anke Klages bedanken. Ohne Eure Hilfe hätte ich die schönen Bilder zur in situ Hybridisierung und zur subzellulären Lokalisation nicht in diese Arbeit aufnehmen können.

Unserem Systemadministrator Bernd Gümpel danke ich sehr für seine stete Hilfsbereitschaft bei allen Computerproblemen und die Vermeidung von Viruspannen beim Verfassen dieser Arbeit. Für das sorgfältige Korrekturlesen dieser Arbeit möchte ich mich bei Anne Heder, Cornelia Meineke, Vera Ritz, meiner Chefin Karen Hirsch-Ernst und bei meinem lieben Mann Sven herzlich bedanken.

Außerhalb des Instituts danke ich allen, die dafür sorgten, daß sich mein Leben in den vergangenen 3 3/4 Jahren nicht nur ums Labor drehte, unseren Freunden aus fern und nah und besonders natürlich meiner lieben Familie, Sven und unserer Tochter Tabea, die mir jeden Tag zeigt, welche Dinge im Leben wirklich wichtig sind. Der größte Dank geht an meine Eltern, auch wenn mein Vater die Abgabe dieser Arbeit nicht mehr miterleben kann, an meine Schwiegermutter Magdalena, unsere beiden Familien und vor allem an Sven, der mich mit seiner Liebe, Geduld und viel Zeit immer vorbehaltlos unterstützt hat. 


\section{CURRICUlum VitAE}

PERSÖNLICHE DATEN

\section{Frauke Petry, geb. Marquardt}

Geboren am 01.06.1975 in Dresden

Staatsangehörigkeit: Deutschland

Verheiratet mit Sven Petry, Theologe

Eine Tochter, Tabea, geboren am 05.01.2002

AUSBILDUNG

06/1995

$09 / 1995$ bis $06 / 1998$

06/1998

09/1998 bis $06 / 2000$

$06 / 2000$

$10 / 2000$ bis $03 / 2004$

$06 / 2004$

STIPENDIEN

$01 / 1996$ bis $06 / 2000$

$07 / 2001$ bis $03 / 2004$

BERUFSERFAHRUNG

1996

1997 und 1998

$10 / 2000$ bis $03 / 2002$

Seit $04 / 2004$
Abitur am Städtischen Gymnasium Bergkamen, Note: 1,1

Studium der Chemie an der University of Reading, Großbritannien

Abschluss: Bachelor of Science (Honours), First Class Degree

BACHELOR THESIS: Exploitation of chemical pre-disposition in synthesis: An Approach to Manzamenone K, Supervisor Dr. R.C. Whitehead

Studium der Chemie an der Georg-August-Universität Göttingen

Abschluss: Diplom-Chemikerin, Note: Sehr gut

Diplomarbeit bei Prof. Dr. A. de Meijere

Institut für Organische Chemie, Georg-August-Universität Göttingen

THEMA: Ein neuer Zugang zu funktionalisierten Carbobicyclen Intermolekulare Stille-Heck-Kreuzkupplungen mit nachfolgender $6 \pi$-Elektrocyclisierung

Promotion am Lehrstuhl Toxikologie im Institut für Pharmakologie und Toxikologie der Georg-August-Universität Göttingen

bei Prof. Dr. G.F. Kahl und PD Dr. K.I. Hirsch-Ernst

THEMA: Charakterisierung eines neuen ATP-binding cassette Transporters aus der ABCA-Subfamilie

Rigorosum und Abschluß der Promotion mit der Note: Magna cum laude

Promotionsförderung der Studienstiftung des Deutschen Volkes

Werkstudentin bei der Bayer AG in Leverkusen, Bereich Umweltschutz

Werkstudentin bei der Schering AG (Bergkamen), Bereich Verfahrensoptimierung

Wissenschaftliche Mitarbeiterin im Institut für Pharmakologie und Toxikologie

Wissenschaftliche Mitarbeiterin im Institut für Pharmakologie und Toxikologie

Göttingen, 03.09.2004 